Florida International University

FIU Digital Commons

$2-12-2020$

\title{
The Metabolic Ecology of Tropical Amphibians Across an Elevational Gradient in the Andes of Southeastern Peru
}

\author{
Michael R. Britton \\ Florida International University, mbrit037@fiu.edu
}

Follow this and additional works at: https://digitalcommons.fiu.edu/etd

Part of the Comparative and Evolutionary Physiology Commons, Evolution Commons, Integrative Biology Commons, and the Other Ecology and Evolutionary Biology Commons

\section{Recommended Citation}

Britton, Michael R., "The Metabolic Ecology of Tropical Amphibians Across an Elevational Gradient in the Andes of Southeastern Peru" (2020). FIU Electronic Theses and Dissertations. 4446.

https://digitalcommons.fiu.edu/etd/4446

This work is brought to you for free and open access by the University Graduate School at FIU Digital Commons. It has been accepted for inclusion in FIU Electronic Theses and Dissertations by an authorized administrator of FIU Digital Commons. For more information, please contact dcc@fiu.edu. 


\title{
FLORIDA INTERNATIONAL UNIVERSITY
}

Miami, Florida

THE METABOLIC ECOLOGY OF TROPICAL AMPHIBIANS ACROSS AN ELEVATIONAL GRADIENT IN THE ANDES OF SOUTHEASTERN PERU

A dissertation submitted in partial fulfillment of

\author{
the requirements for the degree of \\ DOCTOR OF PHILOSOPHY \\ in \\ BIOLOGY
}

by

Michael R. Britton 
To: Dean Michael R. Heithaus

College of Arts, Sciences and Education

This dissertation, written by Michael R. Britton, and entitled The Metabolic Ecology of Tropical Amphibians Across an Elevational Gradient in the Andes of Southeastern Peru, having been approved in respect to style and intellectual content, is referred to you for judgment.

We have read this dissertation and recommend that it be approved.

$\begin{array}{r}\hline \text { Alessandro M. Catenazzi } \\ \hline \text { Kenneth J. Feeley } \\ \hline \text { Joel T. Heinen } \\ \hline \text { Steven F. Oberbauer } \\ \hline \text { Maureen A. Donnelly, Major Professor }\end{array}$

Date of Defense: February 12, 2020

The dissertation of Michael R. Britton is approved.

Dean Michael R. Heithaus

College of Arts, Sciences and Education

Andrés G. Gil

Vice President for Research and Economic Development and Dean of the University Graduate School

Florida International University, 2020 
(C) Copyright 2020 by Michael R. Britton

All rights reserved. 


\section{DEDICATION}

This dissertation is dedicated to my parents, who endured and encouraged my curiosity while patiently answering my endless stream of questions. Until even they would yield, always with the suggestion of "research it."

Also, to libraries, where my questions invariably led. 


\section{ACKNOWLEDGMENTS}

I would first like to thank my advisor, Maureen Donnelly, for the endless stream of knowledge, wisdom, and encouragement throughout my dissertation. Mo provided me with intellectual freedom as well as constant and extensive feedback on my writing, research, and presentations, and in the process has developed my understanding and critical thinking as a scientist. Mo Donnelly has been an inspiration as an educator, a mentor, a leader, and a scientist for many years, and I am eternally grateful for everything she has done for me. Thank you, Mo.

My dissertation would not have been possible without the permission and assistance from a number of Peruvian organizations. The Asociación para la Conservación de la Cuenca Amazónica (ACCA) allowed me to work at three biological stations (Wayqecha, Villa Carmen, and Los Amigos) and helped me countless times with logistical difficulties, particularly at the beginning of my field work. The staff at the ACCA stations were wonderful and helped me to thrive and survive despite nocturnal and seldomly consistent activity periods. Perú Verde gave me permission to camp and work on their land and their camping platform was a blessing in one of the wettest regions in the tropical Andes. Magdalena Ruiz of La Reserva Ecológica Chontachaka gave me permission and assistance to work on their reserve and stay in Chaskawasi in Salvación. The Manu Learning Centre and CREES were invaluable in providing me a study site, a place to stay, and a brilliant atmosphere for science and conservation. The MLC was a haven for people passionate for science, conservation, education, and outreach, and I value my time there. 
A number of people helped me during my three years in Perú. Hillary Fenrich was an absolute treasure in the field and constantly helped me stay sane and laughing. A big thank you to Daniela Lopez for being a field assistant full of curiosity for biology and wisdom in everything else. Felipe Crispin Condori, Cristian Jancco Chillihuani, Gumercindo Crispin, Lee Fitzgerald, and Austin Fitzgerald were wonderful companions at over 5,000 meters asl in the Cordillera Vilcanota and made sure I survived. Robinson Palomino Paz, Carla Mere, Sandra Lucía Almeyda, Vanessa Luna, David Guevara, Luz Ruiz, Lida Ochoa, and Juvenal Huari Castilla were allies and sources of support at field stations.

I made a number of friends and colleagues along the way and I cannot thank them enough for the time and memories in the field: Roxy Cruz, Juriko Rupay, Will Helenbrook, Jess Suarez, Kristy Foster, Emily Middendorf, Bethany Watkins, Audrey Clavijo, Jemima Green, Lucy Millington, Julie Lamarque, Chris Katchis, Mark Thomas, Shauna and Jimi, Rachel Johnson, Zeidy Calendario, Dan Wolfe, Heather Norbert, Jimena Diaz, Rachel Mecissen, Edson Pacheco, and Jorge Caballero. My time in Peru would not have been the same without you all.

I thank my committee - Alessandro Catenazzi, Steve Oberbauer, Ken Feeley, and Joel Heinen - for all their guidance and comments throughout my dissertation. Steve helped me to understand, and build, a respirometry system that could be used off the grid in the tropics. Without his expertise and equipment, I would not have been able to measure metabolic rates in the field on over a hundred species across 5,000 meters of elevation. Ale and Ken provided important advice and expertise on field sites in the Manu region of southeastern Peru. Ale provided invaluable guidance on sampling 
amphibians at different elevations and identification of the species rich amphibian fauna in southeastern Peru. Ale's trips to the field were absolute whirlwinds of sampling, learning, identifying, and measuring that added vast numbers of individuals and species, elevational representation, and overall value to my dissertation. Thank you.

My labmates Michelle Thompson, Luke Linhoff, and Lilly Eluvathingal provided me with support, encouragement, and feedback (and laughs!) throughout my dissertation. My labmate and collaborator, Kelsey Reider, provided me support, feedback, adventure, and crepes at home and abroad, as well as a second home with Karina in Cusco. I would like to thank Alex Shepack for being a fantastic labmate and friend in the field and at FIU. Rudolf von May provided feedback in the field, guidance on species identification, and a detailed phylogeny for tropical amphibians, an almost unheard of resource for tropical researchers. Catherine Bravo was a great friend and colleague in Peru and at FIU. Thank you, all.

My friends and family have been wonderful throughout my dissertation. My parents took my long absences without phone and internet in stride and constantly encouraged and supported me. My siblings provided support when I needed it, updates on their lives when I felt alone in another hemisphere, and conversation whenever I needed it. Aunt Terri and Uncle Jim were hosts and friends for me during many visits to CNY and during a significant portion of data analysis and writing. They kept me fed, happy, and constantly reminded that curiosity and passion for science and nature are lifelong pursuits and transcend generations. I cannot thank MaryKate Romagnoli and Eric Meldrum enough for inviting me into their lives and home. Most of my writing was completed while in their care and I am grateful for the time we spent together. Eddie 
Watkins and Cat Cardelús have been sources of inspiration, support, feedback, and wisdom since my first year of undergrad. I appreciate all you have done and continue to do for me, in science and everyday life. I thank Tia Mackintosh for her friendship and support. To all of my friends and family, I thank you.

This dissertation would not have been possible without financial support from the following: FIU Dissertation Year Fellowship, FIU Doctoral Evidence Acquisition Fellowship, American Society of Ichthyologists and Herpetologists Gaige Award, FIU Tinker Field Research Grant, FIU Graduate and Professional Student Committee professional development award, CREES and the Manu Learning Centre, and La Reserva Ecológica Chontachaka. 


\begin{abstract}
OF THE DISSERTATION
THE METABOLIC ECOLOGY OF TROPICAL AMPHIBIANS ACROSS AN ELEVATIONAL GRADIENT IN THE ANDES OF SOUTHEASTERN PERU by
\end{abstract}

Michael R. Britton

Florida International University, 2020

Miami, Florida

\title{
Professor Maureen A. Donnelly, Major Professor
}

Metabolism is a fundamental biological process that determines the rate at which organisms process energy and materials, and determines the availability of resources for growth, maintenance, activity and reproduction. Metabolic rates scale across levels of organization from cells to whole organisms and affect population, community, and ecosystem processes. Anthropogenic climate change and other environmental changes are predicted to have major impacts on the energetics of organisms that will be mediated through metabolic physiology. Tropical amphibians may be among the most vulnerable to metabolic impacts of climate change as a result of being ectothermic, having high thermal sensitivity, and living at relatively high temperatures (close to upper thermal tolerances). However, most metabolic studies on amphibians have been conducted on temperate taxa, and metabolic studies on tropical amphibians continue to be underrepresented in the literature. In effect, many studies use metabolic scaling relationships derived predominantly from temperate taxa to characterize the metabolic physiology of amphibians as a group. A variety of physiological traits are known to vary 
across latitude in amphibians, yet few studies have examined how metabolic physiology of amphibians may vary across latitude.

I use field-based respirometry to examine the metabolic physiology of tropical amphibians along an elevational gradient on the eastern slope of the Andes in southeastern Peru. I describe variation in metabolic physiology of tropical amphibians and how it relates to patterns of phylogeny, ecology, and environment. I demonstrate that there are consistent diel rhythms in resting metabolic rates that lead to significant differences between day and night, and that the timing of circadian rhythms differs among families. I confirm that there are strong phylogenetic signals in the patterns of resting and active metabolic rates of tropical amphibians and illustrate that accounting for phylogenetic differences is important for analyses of interspecific comparisons of metabolic physiology. I discuss how variation in metabolic physiology may relate to ecological characteristics and how the combination of physiology and ecology may determine ecological strategies and vulnerability to potential metabolic impacts of climate change. Consideration of the variation in metabolism is essential to understand the integrative biology of tropical amphibians, to make accurate predictions of how climate change will affect metabolism, and to inform conservation and management decisions. 
TABLE OF CONTENTS

CHAPTER

PAGE

INTRODUCTION . .1

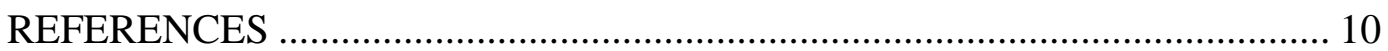

CHAPTER I: PATTERNS OF VARIATION IN THE METABOLIC RATES OF

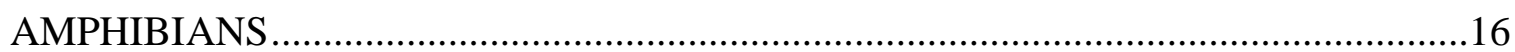

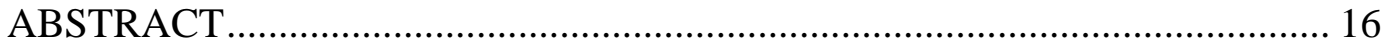

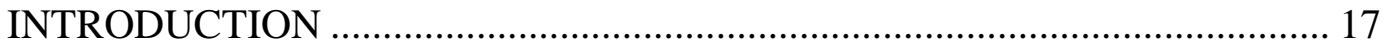

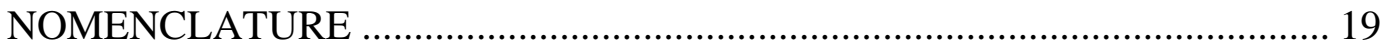

METABOLIC SCALING - MASS AND TEMPERATURE ............................ 22

TAXONOMIC VARIATION ...................................................................... 24

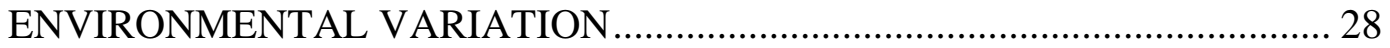

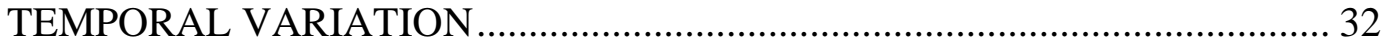

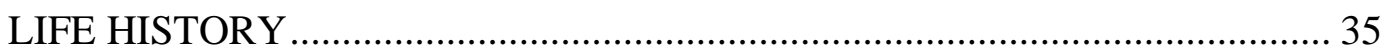

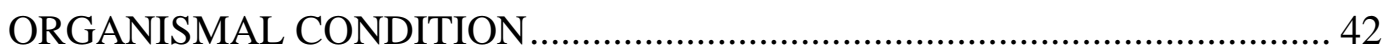

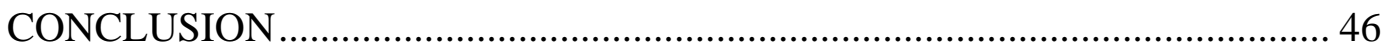

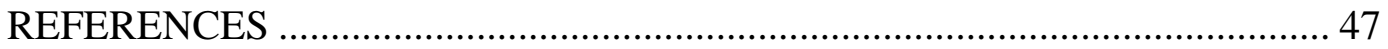

CHAPTER II: CIRCADIAN RHYTHMS IN RESTING METABOLIC RATE

AMONG TROPICAL LOWLAND AMPHIBIAN FAMILIES ....................................62

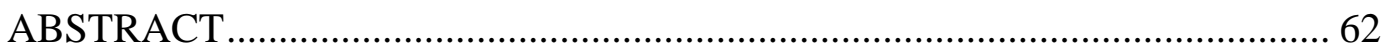

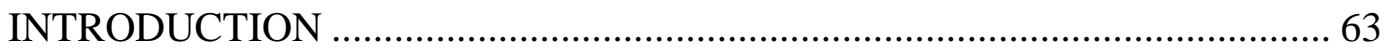

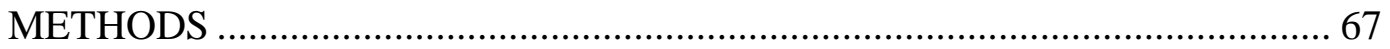

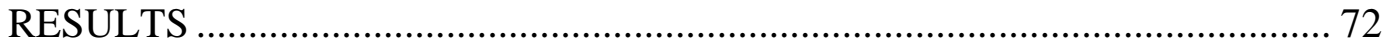

DISCUSSION .................................................................................... 74

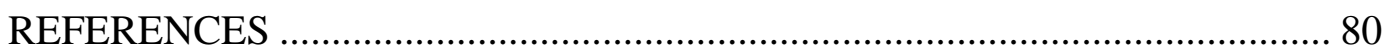

CHAPTER III. EVOLUTION AND VARIATION IN RESTING METABOLIC

RATE ACROSS ELEVATION IN TROPICAL AMPHIBIANS ..............................95

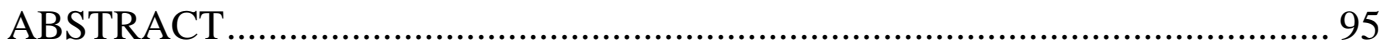

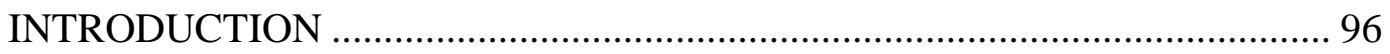

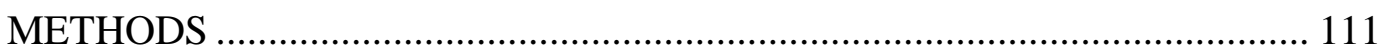

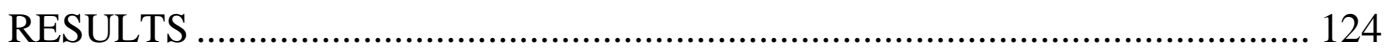

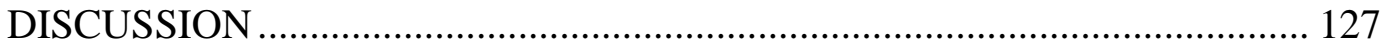

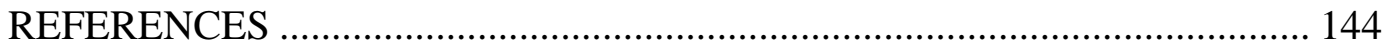

CHAPTER IV: VARIATION OF AEROBIC SCOPE IN TROPICAL

AMPHIBIANS: PATTERNS AND TESTS OF THE AEROBIC CAPACITY

MODEL

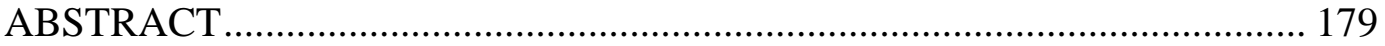

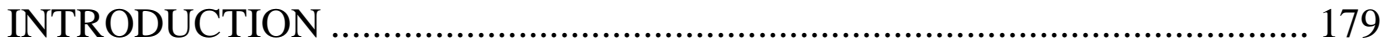

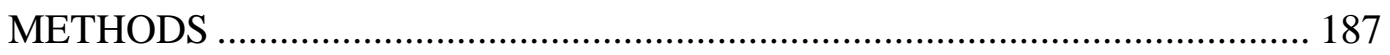

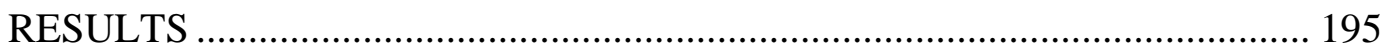




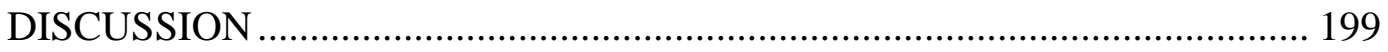

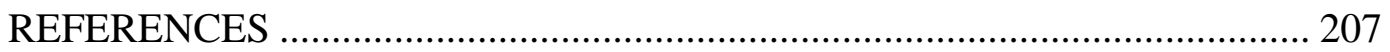

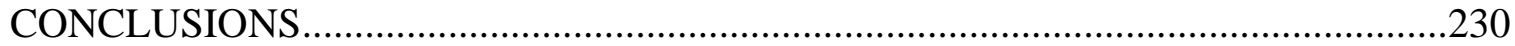

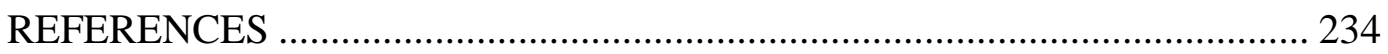

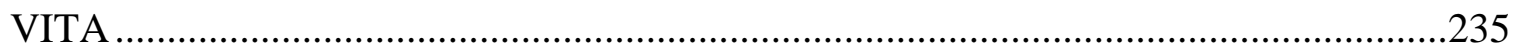




\section{LIST OF TABLES}

TABLE

PAGE

Table 2.1. Sample size and average mass (standard error) of species included in the study

Table 2.2. Summary of model parameters and fits for cosinor-based models of circadian rhythm of resting metabolic rate (RMR), corrected for mass and temperature, for each amphibian species

Table 2.3. Summary of model parameters and fits for cosinor-based models of circadian rhythm of resting metabolic rate (RMR), corrected for mass and temperature, for the compiled data of each amphibian family

Table 2.4. Results of comparisons of cosinor parameters of resting metabolic rate (RMR; mass and temperature-corrected) among families

Table 2.5. The results from the pairwise Wilcoxon rank sum test for the MESORs of RMR of each family

Table 2.6. Tests of assumptions for circular analysis of variance (ANOVA) of the acrophase of resting metabolic rate (RMR) for each family.

Table 3.1. Field sites and elevational ranges along the elevational gradient in southeastern Peru

Table 3.2. Models of evolution used to examine evolutionary patterns in resting metabolic rate of tropical amphibians.

Table 3.3. Results from repeated measures analysis of variance (ANOVA) between day and night

Table 3.4. The analysis of phylogenetic signal for the univariate and multivariate datasets of resting metabolic rate (RMR) for day and night

Table 3.5. Comparisons of model support by Akaike Information Criterion (AIC) for evolutionary models for day and night.

Table 3.6. Comparisons of model support by Akaike Information Criterion (AIC) of phylogenetic regressions of resting metabolic rate (RMR) against mass, temperature $(\mathrm{T})$ and elevation (ele)......

Table 3.7. Regression coefficients and significance for the most supported regression models and the ordinary least squares (OLS) regression of resting metabolic rate $(\mathrm{RMR})$ and mass and temperature. 
Table 3.8. The derived parameters of the additive regressions between resting metabolic rate (RMR) and mass and temperature

Table 3.9. Results from analysis of variance (ANOVA) of resting metabolic rate (RMR) among families of tropical anurans for both day and night....

Table 3.10. Results from analysis of covariance (ANCOVA) between logtransformed resting metabolic rate (RMR) and temperature among families of tropical anurans for both day and night

Table 3.11. Results from analysis of covariance (ANCOVA) between logtransformed resting metabolic rate (RMR) and temperature among elevational groups of tropical anurans for both day and night

Table 4.1. Summaries of model support for the regressions between the predictor variables of mass and temperature and the metabolic variables of resting metabolic rate (RMR), maximum metabolic rate (MMR), factorial aerobic scope (FAS), and net aerobic scope (NAS) for day and night

Table 4.2. Model fits for each metabolic variable against $\log$ (mass) and temperature for both day and night

Table 4.3. Phylogenetic signal as measured by Pagel's $\lambda$ and Blomberg's $K$ in the residuals of factorial aerobic scope (rFAS) and net aerobic scope (rNAS)

Table 4.4. Relative support by Akaike Information Criterion (AIC) and AIC weights (AICw) of evolutionary models applied to the residuals of factorial aerobic scope (rFAS) and net aerobic scope (rNAS)

Table 4.5. Model fits for linear regressions among the residuals of resting metabolic rate (RMR), maximum metabolic rate (MMR), factorial aerobic scope (FAS), and net aerobic scope (NAS) for day and night

Table 4.6. Results from the analysis of variance (ANOVA) of the residuals of factorial aerobic scope (rFAS) and net aerobic scope (rNAS) among tropical amphibian families for both day and night

Table 4.7. Results from the analysis of variance (ANOVA) of the residuals of factorial aerobic scope (rFAS) and net aerobic scope (rNAS) among elevational groups for both day and night 


\section{LIST OF FIGURES}

FIGURE

PAGE

Figure 2.1. Observed (dotted) and model fitted (solid) and standard deviation (shaded) of the cosinor-based circadian rhythms in resting metabolic rate (RMR) for each study species

Figure 2.2. Observed (dotted) and model fitted (solid) and standard deviation (shaded) of the cosinor-based circadian rhythms in resting metabolic rate (RMR) for each tropical amphibian family

Figure 3.1. Elevation map of eight study sites and protected areas in southeastern Peru

Figure 3.2. Phylogeny for 88 tropical amphibian species used in analyses of resting metabolic rate after von May et al. (2019)

Figure 3.3. Relationship between resting metabolic rate (RMR) and mass for both day (gray) and night (black).

Figure 3.4. Relationship between resting metabolic rate (RMR) and temperature for both day (gray) and night (black)....

Figure 3.5. Relationship between resting metabolic rate (RMR) and elevation for both day (gray) and night (black).

Figure 3.6. The temperature-corrected field resting metabolic rate (RMR) for day and night among families of anurans illustrating differences between wholeorganism RMR (A) and mass-specific RMR (B)

Figure 3.7. Resting metabolic rates (RMR) among families for both day and night after correction for mass and temperature

Figure 3.8. The comparison of $\mathrm{Q}_{10}$ among four families of tropical anurans for both day and night.

Figure 3.9. The $\mathrm{Q}_{10}$ among elevational groups of tropical anurans for both day and night

Figure 4.1. Relationship between mass and the metabolic variables resting metabolic rate (RMR), maximum metabolic rate (MMR), factorial aerobic scope (FAS), and net aerobic scope (NAS) for day and night

Figure 4.2. Relationship between temperature and the metabolic variables resting metabolic rate (RMR), maximum metabolic rate (MMR), factorial aerobic scope (FAS), and net aerobic scope (NAS) for day and night 
Figure 4.3. Phylogram illustrating how the residuals of factorial aerobic scope (rFAS) may have evolved across the phylogeny for day (A) and night (B)

Figure 4.4. Phylogram illustrating how the residuals of net aerobic scope (rNAS) may have evolved across the phylogeny

Figure 4.5. Relationship between the residuals of resting metabolic rate (rRMR) and A) maximal aerobic metabolic rate (rMMR), B) factorial aerobic scope (rFAS), and C) net aerobic scope (rNAS) for both day and night after correction for mass and temperature

Figure 4.6. Relationship between the residuals of maximum metabolic rate (rMMR) and A) factorial aerobic scope (rFAS) and B) net aerobic scope (rNAS) for both day and night

Figure 4.7. Relationship between the residuals of factorial aerobic scope (rFAS) and net aerobic scope (rNAS)

Figure 4.8. Boxplots showing the comparisons of the residuals of resting metabolic rate (rRMR), maximum metabolic rate (rMMR), factorial aerobic scope (rFAS) and net aerobic scope (rNAS) among tropical anuran families for both day and night.

Figure 4.9. Boxplots showing the comparisons of the residuals of resting metabolic rate (rRMR), maximum metabolic rate (rMMR), factorial aerobics scope (rFAS) and net aerobic scope (rNAS) among elevational groups for both day and night 


\section{INTRODUCTION}

Climate change is a pervasive threat to biological systems across the globe. A major question in biology today is how to predict and mitigate the effects of climate change on biodiversity. Climate change is already impacting many species (Parmesan 2006; Scheffers et al. 2016; Sheldon 2019; Walther et al. 2002), and the effects are expected to continue and worsen for many years to come (Reside et al. 2018; Sala et al. 2000; Thomas et al. 2004; Urban et al. 2016). A predictive framework for climate change will facilitate preventative mitigation actions, which are more efficient and effective than reactive ones (Mack et al. 2000; Pimental et al. 1995; Wilson et al. 2011). Tropical environments are predicted to experience high exposure to climate change relative to the low narrow climatic variability typical of tropical environments (Baettig et al. 2007; Janzen 1967; McCain 2009; Perez et al. 2016). Moreover, tropical organisms are expected to be sensitive to climate change impacts because of narrow climatic niches (Deutsch et al. 2008; Huey et al. 2012; Sunday et al. 2011, 2014; Tewksbury et al. 2008). As a group, amphibians may be especially vulnerable to the negative effects of climate change as a result of their dependence on environmental temperatures and hydric conditions (Blaustein et al. 2010; Carey \& Alexander 2003; Corn 2005; Foden et al. 2013). Thus, tropical amphibians are expected to be highly vulnerable to climate change impacts (Donnelly \& Crump 1998; Foden et al. 2013), although additional work is needed to address the predictions of theory (Perez et al. 2016).

The effects of climate change are expected to impact almost every aspect of amphibian biology. Individual amphibians will be impacted through effects on development, physiology, behavior, survival, and reproduction (Huey et al. 2012; Urban 
et al. 2016; Wong \& Candolin 2015). Many of the organismal impacts of climate change will scale up to affect population dynamics, potentially causing declines and extinctions (Blaustein et al. 2010; Deutsch et al. 2008; Donnelly \& Crump 1998; Mccaffery et al. 2012; Urban et al. 2016). Climate change will further impact community and ecosystem processes such as competition, predation, and food availability (Blaustein et al. 2010; Gilman et al. 2010). Understanding and predicting the future impacts of climate change is an important task for biology today to guide mitigation and conservation efforts (Li et al. 2012; Shoo et al. 2011). With accurate predictions of the effects of climate change, managers can pursue preventative actions against threats, which are known to be more effective and efficient than monitoring and reacting to perceived changes (although these will continue to be necessary; Mack et al. 2000; Pimental et al. 1995; Wilson et al. 2011).

\section{Vulnerability to climate change}

Vulnerability to climate change results from the combination of exposure, sensitivity, and potential for response (Foden et al. 2013; Moritz \& Agudo 2013; Williams et al. 2008). Exposure is defined as the climatic changes experienced by organisms relative to current climatic conditions. High exposure can result from large absolute changes in climatic conditions (as is expected at the poles and high elevations) or large changes relative to current climatic variability (as is expected in the lowland tropics; Baettig et al. 2007). Sensitivity is an attribute characterizing how biological processes of an individual or species, notably growth, survival, and reproduction, are expected to be impacted by changing climatic conditions (Foden et al. 2013; Williams et al. 2008). Organisms vary in their sensitivity to climate change, both intraspecifically and 
across the tree of life (Buckley et al. 2018, Foden et al. 2013; Pörtner \& Farrell 2008). There are many efforts to determine which species have high sensitivity to climatic changes (Foden et al. 2013; Urban et al. 2016; Williams et al. 2008) as well as to extrapolate predictions of sensitivity using data related to organismal traits (Huey et al. 2012; Pompe et al. 2014), population processes (Deutsch et al. 2008), and species distributions (Rinnan and Lawler 2019).

Potential responses to climate change broadly encompass mechanisms that may reduce exposure, sensitivity, or both (Foden et al. 2013; Moritz \& Agudo 2013). Exposure can be reduced by ectothermic organisms through behavioral thermoregulation using thermal variation across microhabitats (Huey et al. 2012; Sunday et al. 2014). Moreover, changes in geographic distribution (i.e., range shifts) may allow organisms to move their geographical areas to find or track suitable climatic conditions as the climate changes (Feeley et al. 2012, Miles 1994). For example, to escape rising temperatures, species may shift ranges to cool climates at high latitudes or high elevations (Feeley et al. 2012; Miles 1994; Seimon et al. 2007, 2017). Sensitivity may be reduced through changes in organismal traits within individuals and across generations (Moritz \& Agudo 2013). Plastic responses of individuals may occur throughout development (i.e., developmental plasticity) or within life stages (i.e., acclimation) in response to changing ambient conditions (Chevin et al. 2010; Feeley et al. 2012) and may be an important process for organisms to reduce sensitivity in response to changing climatic conditions. Adaptation consists of the genetic (and epigenetic), heritable changes that may occur within a species as a result of selection, including selection as a result of changing climatic conditions (Hoffmann \& Sgrò 2011; Williams et al. 2008). The variety of 
biological responses will be important to reduce exposure and sensitivity, and more work is necessary to determine the extent to which these processes may reduce vulnerability to climate change impacts (Moritz \& Agudo 2013; Urban et al. 2016; Williams et al. 2008). Lack of sufficient responses to reduce exposure and sensitivity to changing climatic conditions will lead to local and global extinctions (Moritz \& Agudo 2013).

\section{Tropical amphibians}

The tropics are major centers of biodiversity and are predicted to have high levels of both exposure and sensitivity to climate change (Deutsch et al. 2008; Foden et al. 2013). Many tropical organisms are predicted to have narrow climatic niches resulting from selective pressures for specialization in response to intense biotic interactions and low climatic variability (Deutsch et al. 2008; Janzen 1967; McCain 2009). Narrow climatic niches may be indicative of a high sensitivity to climatic changes. Exposure to climate change requires consideration of both future climatic conditions and their relationship to current climatic variability (Baettig et al. 2007). Thus, although the absolute rates of climate change in tropical areas are expected to be relatively low compared to the poles, the changes are large relative to the normal variation of tropical environments (Baettig et al. 2007; Foden et al. 2013; Li et al. 2018). The combination of high sensitivity and high exposure suggests that tropical organisms may be particularly vulnerable to climate change.

Amphibians as a group are demonstrably sensitive to a variety of changes in environmental conditions because of their permeable skin and ectothermic physiologies. As a result, the changes in both thermal and hydric conditions from climate change are 
expected to have large impacts on amphibians (Blaustein et al. 2010; Corn 2005).

Amphibian body temperatures are dependent on the conditions of microhabitats and the surrounding environment (Stevenson 1985). The environmental dependence of amphibian body temperatures is important as many amphibian functions are directly affected by temperature, including reproduction, behavior, and a variety of physiological processes (Feder \& Burggren 1992). Therefore, various aspects of amphibian biology are expected to be directly impacted by the changing temperatures resulting from climate change. Amphibians in the tropics may be additionally sensitive to changing temperatures because of narrow thermal niches (Deutsch et al. 2008; Huey et al. 2012; Tewksbury et al. 2008).

Amphibians are vulnerable to desiccation and sensitive to the hydric conditions of the environment because of highly permeable skin and complex life histories (Blaustein et al. 2010; Foden et al. 2013). Climate change will affect amphibians through changes in precipitation, humidity, cloud cover, and the presence and quality of a variety of aquatic resources and habitats (Blaustein et al. 2010; Corn 2005;). Many climatic changes will result in increased risks of water loss of amphibians by increasing the rates of desiccation and lengths of time exposed to desiccating conditions ( $\mathrm{Li}$ et al. 2012). Many of the changes in the hydric conditions of the environment will influence individual behaviors related to water conservation, microhabitat choice, and activity times (Bovo et al. 2018; Li et al. 2012). Amphibian water balance and body temperature are highly related, as higher temperatures result in faster desiccation rates (Blaustein et al. 2010; Tracy 1976) and evaporative water loss may allow amphibians to lower body temperatures in some environments (Huey et al. 2012; Stevenson 1985; Sunday et al. 2014). Thus, the changes 
in temperature, precipitation, and other hydric conditions expected from anthropogenic climate change will affect amphibians simultaneously and may have complex interactions and feedback loops (Blaustein et al. 2010).

In the tropics, there is a large diversity of reproductive modes in addition to the generalized, biphasic life cycle found in many temperate amphibian species (Crump 1974; 2015; Duellman 1978; Haddad and Prado 2005; Lutz 1947). For species with aquatic larvae and eggs, changes in availability and quality of aquatic habitats will have direct effects on successful reproduction. Moreover, embryonic and larval conditions may extend to impact processes and traits of metamorphic and adult life stages through latent effects (Blaustein et al. 2010; Pechenik 2006). The life histories of many tropical amphibians include terrestrial egg and larval stages which may be particularly vulnerable to the warming and drying conditions expected for many regions as a result of climate change (Baettig et al. 2007; Blaustein et al. 2010; Donnelly \& Crump 1998). The extensive diversity of life history in tropical amphibians makes generalizations difficult, and the relative sensitivity across the life cycle will likely vary among taxa and environments (Bovo et al. 2018).

Climate change may impact organisms through effects on energetic requirements and efficiencies of conversion. For ectothermic organisms, increased temperatures will increase the basic energetic costs of maintenance through changes in metabolic rates (Dillon et al. 2010). In the absence of increased prey availability and foraging, the result will be reduced energy availability for other processes such as growth, activity, and reproduction (Dillon et al. 2010). Metabolic rate is a measure of the energetic requirements of an organism and scales with a variety of processes from individuals to 
populations and ecosystems (Brown et al. 2004; Sibly et al. 2012). Thus, measurements

of metabolic rate can give insight into the relative energetic requirements of an organism as well as how metabolic requirements relate to a variety of other ecological processes. In my dissertation, I use measurements of metabolic rate to compare the energetic requirements of tropical amphibians across elevation to determine potential energetic impacts of climate change.

\section{Elevational gradients}

Elevational gradients present a suite of consistent and predictable changes in a variety of climatic factors and thus are useful for natural experiments (Becker et al. 2007; Sanders \& Rahbek 2012; Sundqvist et al. 2013). Across elevation, there are predictable changes in temperature, precipitation, humidity, cloud cover, and air pressure, as well as concurrent changes in vegetation structure. The variation in climatic variables across elevation have important effects on the conditions experienced in the variety of microhabitats used by amphibians.

I am most interested in the elevational changes in temperature and how thermal conditions relate to metabolic characteristics, and I focus on this relationship in my dissertation. Variation in metabolism across elevation and temperature provides insight into the thermal sensitivity of amphibian metabolism, the possible metabolic impacts of climate change, and the potential for metabolic responses (e.g., acclimation and/or adaptation) to climate change. At large spatial scales, average temperatures decrease and diurnal temperature ranges increase from low elevation to high elevation (Sundqvist et al. 2013). It is important to note that while temperature and elevation are strongly related at 
large spatial scales, elevation is an imperfect proxy for temperature at local scales. Heterogeneity of microhabitats at local scales can provide large variation in thermal conditions available for amphibians. For example, the daily temperature range of microhabitats under large boulders at high elevations is much lower than for other highelevation microhabitats (Shi et al. 2014; Shoo et al. 2010). Moreover, the temperature of microhabitats, in addition to effects from elevation, are further mediated by a range of variables including aspect, humidity, cloud cover, and vegetation. Cloud forests, for instance, are generally characterized by relatively low diurnal variation in temperature as a result of high cloud cover and high humidity (Rapp \& Silman 2012).

\section{Dissertation overview}

Herein, I describe and analyze patterns of metabolic physiology of a large diversity of amphibians across a tropical elevational gradient. The work was conducted on the eastern slopes of the tropical Andes in southeastern Peru, within and around the Manu Biosphere Reserve. My dissertation is an important contribution to biology in that it: (1) provides various measurements of the metabolic physiology for a large diversity of tropical amphibians, which have historically been understudied compared to species in northern temperate areas; and (2) includes measurements with a broad range of covariates (e.g., mass, temperature, and elevation) allowing for analysis of how these variables may be useful in prediction of metabolic physiology and potential impacts from climate change. In effect, my dissertation makes a large step to advance the understanding of amphibian physiology and will be valuable in meta-analyses and extrapolations for studies on evolution, physiology, macroecology, and climate change. 
In Chapter I, I conduct an integrative review of studies on resting metabolic rate (RMR) of amphibians while describing patterns and sources of variation. I relate patterns of variation in amphibian RMR to evolution, ecology, and environment and discuss areas for future research. I describe how variation in RMR will be important for predicting vulnerability to climate change impacts and potential for organismal responses. Chapter I additionally provides the background, definitions, and nomenclature used throughout the dissertation.

In Chapter II, I examine the circadian rhythm of RMR in a variety of lowland amphibian species. The average, amplitude, and timing of maxima and minima of RMR are compared across 11 species in six families of tropical amphibians and discussed in relation to ecological characteristics. Chapter II provides important information to infer the maintenance and energy budgets of amphibians across the diel cycle, providing insight into how singular metabolic measurements may relate to total daily energetic expenditure. Furthermore, I discuss important considerations for metabolic measurements and analyses for amphibians and how studies may be affected by time of day.

In Chapter III, I examine the evolution of RMR in a diverse assemblage of tropical anurans across the elevational gradient in southeastern Peru. I use phylogenetic comparative analyses to compare various models of evolution and how they provide insight to the evolutionary history of metabolic physiology of tropical amphibians. I use phylogenetic multiple regression to examine resting metabolic rate and how it relates to the predictive variables of mass, temperature, and elevation. I compare RMR and scaling relationships among taxonomic and elevational groups and relate differences to vulnerability to metabolic impacts from climate change. 
In Chapter IV, I compare RMRs and maximum metabolic rates (MMRs) for a subset of amphibian species. I examine how the relationship between RMR and MMR may have evolved across amphibians by combining these measurements into two calculations of aerobic scope: factorial aerobic scope (FAS), the ratio of MMR to RMR, and net aerobic scope (NAS), the difference between MMR and RMR. I examine variations within and correlations between RMR, MMR, and the two measures of aerobic scope (FAS and NAS) and determine that patterns are not consistent with predictions of the aerobic capacity model (Bennett \& Ruben 1979; Nespolo et al. 2017). I demonstrate that NAS seems to be driven predominantly by MMR, and thus is a measure of aerobic capacity in amphibians, while FAS is dependent on both RMR and MMR, and thus an appropriate measure of the relationship between RMR and MMR. I discuss how differences in FAS and NAS may relate to environment, ecology, and evolution.

I review and synthesize the findings of my dissertation in Chapter V. The importance of my studies of amphibian metabolism are discussed in how they contribute to overall understanding of amphibian energetics. I discuss how the various approaches to metabolic physiology I use throughout my dissertation may be complementary and provide an integral understanding of amphibian energetics across time and space. The metabolic variation among tropical amphibians is then discussed to explore the vulnerability of tropical amphibians to the metabolic impacts of climate change.

\section{REFERENCES}

Baettig MB, Wild M, Imboden DM. 2007. A climate change index: Where climate change may be most prominent in the 21 st century. Geophysical Research Letters. 34(1):L01705 
Becker A, Körner C, Brun JJ, Guisan A, Tappeiner U. 2007. Ecological and land use studies along elevational gradients. Mountain Research and Development. 27(1):58-65

Bennett AF, Ruben JA. 1979. Endothermy and activity in vertebrates. Science. 206:64954

Blaustein AR, Walls SC, Bancroft BA, Lawler JJ, Searle CL, Gervasi SS. 2010. Direct and indirect effects of climate change on amphibian populations. Diversity. 2(2):281-313

Bovo RP, Navas CA, Tejedo M, Valença SES, Gouveia SF. 2018. Ecophysiology of amphibians: Information for best mechanistic models. Diversity. 10(4):1-14

Brown JH, Gillooly JF, Allen AP, Savage VM, West GB. 2004. Toward a metabolic theory of ecology. Ecology. 85(7):1771-89

Buckley LB, Cannistra AF, John A. 2018. Leveraging organismal biology to forecast the effects of climate change. Integrative and Comparative Biology. 58(1):38-51

Carey C, Alexander MA. 2003. Climate change and amphibian declines: Is there a link? Diversity and Distributions. 9:111-21

Chevin LM, Lande R, Mace GM. 2010. Adaptation, plasticity, and extinction in a changing environment: Towards a predictive theory. PLoS Biology. 8(4):e1000357

Corn PS. 2005. Climate change and amphibians. Animal Biodiversity and Conservation. 28(1):59-67

Crump ML. 1974. Reproductive strategies in a tropical anuran community. University of Kansas Publications - Museum of Natural History. 61:1-68

Crump ML. 2015. Anuran reproductive modes: Evolving perspectives. Journal of Herpetology. 49(1):1-16

Deutsch CA, Tewksbury JJ, Huey RB, Sheldon KS, Ghalambor CK, et al. 2008. Impacts of climate warming on terrestrial ectotherms across latitude. Proceedings of the National Academy of Sciences of the United States of America. 105(18):6668-72

Dillon ME, Wang G, Huey RB. 2010. Global metabolic impacts of recent climate warming. Nature. 467:704-6

Donnelly MA, Crump ML. 1998. Potential effects of climate change on two Neotropical amphibian assemblages. Climatic Change. 39(2-3):541-561 
Duellman WE. 1978. The biology of an equatorial herpetofauna in Amazonian Ecuador. University of Kansas Publications - Museum of Natural History. 65:1-352

Feeley KJ, Rehm EM, Machovina B. 2012. The responses of tropical forest species to global climate change: Acclimate, adapt, migrate, or go extinct? Frontiers of Biogeography. 4(2):69-84

Foden WB, Butchart SHM, Stuart SN, Vié JC, Akçakaya HR, et al. 2013. Identifying the world's most climate change vulnerable species: A systematic trait-based assessment of all birds, amphibians and corals. PLoS ONE. 8(6):e65427

Gilman SE, Urban MC, Tewksbury JJ, Gilchrist GW, Holt RD. 2010. A framework for community interactions under climate change. Trends in Ecology \& Evolution. 25(6):325-31

Haddad CFBC, Prado CPA. 2005. Reproductive modes in frogs and their unexpected diversity in the Atlantic Forest of Brazil. BioScience. 55(3):207-17

Hoffmann AA, Sgrò CM. 2011. Climate change and evolutionary adaptation. Nature. 470(7335):479-85

Huey RB, Kearney MR, Krockenberger A, Holtum JAM, Jess M, Williams SE. 2012. Predicting organismal vulnerability to climate warming: Roles of behaviour, physiology and adaptation. Philosophical Transactions of the Royal Society of London B: Biological Sciences. 367(1596):1665-79

Janzen DH. 1967. Why mountain passes are higher in the tropics. American Naturalist. 101(919):233-49

Li D, Wu S, Liu L, Zhang Y, Li S. 2018. Vulnerability of the global terrestrial ecosystems to climate change. Global Change Biology. 24(9):4095-4106

Li Y, Cohen JM, Rohr JR. 2013. Review and synthesis of the effects of climate change on amphibians. Integrative Zoology. 8(2):145-61

Lutz B. 1947. Trends towards non-aquatic and direct development in frogs. Copeia. 1947:242-252.

Mack RN, Simberloff D, Lonsdale WM, Evans H, Clout M, Bazzaz FA. 2000. Biotic invasions: Causes, epidemiology, global consequences, and control. Ecological Applications. 10(3):689-710

Mccaffery R, Solonen A, Crone E. 2012. Frog population viability under present and future climate conditions: A Bayesian state-space approach. Journal of Animal Ecology. 81(5):978-85 
McCain CM. 2009. Vertebrate range sizes indicate that mountains may be "higher" in the tropics. Ecology Letters. 12(6):550-60

Miles DB. 1994. Population differentiation in locomotor performance and the potential response of a terrestrial organism to global environmental change. American Zoologist. 34(3):422-36

Moritz C, Agudo R. 2013. The future of species under climate change: Resilience or decline? Science. 341(6145):504-8

Nespolo RF, Solano-Iguaran JJ, Bozinovic F. 2017. Phylogenetic analysis supports the aerobic-capacity model for the evolution of endothermy. American Naturalist. 189(1):13-27

Parmesan C. 2006. Ecological and evolutionary responses to recent climate change. Annual Review of Ecology, Evolution, and Systematics. 37(1):637-69

Pechenik JA. 2006. Larval experience and latent effects - Metamorphosis is not a new beginning. Integrative and Comparative Biology. 46(3):323-33

Perez TM, Stroud JT, Feeley KJ. 2016. Thermal trouble in the tropics. Science. 351(6280):1392-93

Pimentel D, Harvey C, Resosudarmo P, Sinclair K, Kurz D, et al. 1995. Environmental and economic costs of soil erosion and conservation benefits. Science. 267(5201):1117-23

Pompe S, Hanspach J, Badeck FW, Klotz S, Bruelheide H, Kühn I. 2014. Using ecological and life-history characteristics for projecting species' responses to climate change. Frontiers of Biogeography. 6(3):119-31

Pörtner HO, Farrell AP. 2008. Physiology and Climate Change. Science. 322(5902):69092

Rapp JM, Silman MR. 2012. Diurnal, seasonal, and altitudinal trends in microclimate across a tropical montane cloud forest. Climate Research. 55(1):17-32

Reside AE, Butt N, Adams VM. 2018. Adapting systematic conservation planning for climate change. Biodiversity and Conservation. 27(1):1-29

Rinnan DS, Lawler J. 2019. Climate-niche factor analysis: a spatial approach to quantifying species vulnerability to climate change. Ecography. 42(9):1494-1503

Sala OE, Chapin FS, Armesto JJ, Berlow E, Bloomfield J, et al. 2000. Global biodiversity scenarios for the year 2100. Science. 287(5459):1770-74 
Sanders NJ, Rahbek C. 2012. The patterns and causes of elevational diversity gradients. Ecography. 35(1):1-3

Seimon TA, Seimon A, Daszak P, Halloy SRP, Schloegel LM, et al. 2007. Upward range extension of Andean anurans and chytridiomycosis to extreme elevations in response to tropical deglaciation. Global Change Biology. 13(1):288-99

Seimon TA, Seimon A, Yager K, Reider K, Delgado A, et al. 2017. Long-term monitoring of tropical alpine habitat change, Andean anurans, and chytrid fungus in the Cordillera Vilcanota, Peru: Results from a decade of study. Ecology and Evolution. 7(5):1527-40

Scheffers BR, De Meester L, Bridge TCL, Hoffmann AA, Pandolfi JM, et al. 2016. The broad footprint of climate change from genes to biomes to people. Science. 354(6313):aaf7671

Sheldon KS. 2019. Climate change in the tropics: Ecological and evolutionary responses at low latitudes. Annual Review of Ecology, Evolution, and Systematics. 50(1):303-33

Shi H, Paull D, Wen Z, Broome L. 2014. Thermal buffering effect of alpine boulder field microhabitats in Australia: Implications for habitat management and conservation. Biological Conservation. 180:278-87

Shoo LP, Storlie C, Williams YM, Williams SE. 2010. Potential for mountaintop boulder fields to buffer species against extreme heat stress under climate change. International Journal of Biometeorology. 54(4):475-78

Shoo LP, Olson DH, McMenamin SK, Murray KA, Van Sluys M, et al. 2011. Engineering a future for amphibians under climate change. Journal of Applied Ecology. 48(2):487-92

Sibly RM, Brown JH, Kodric-Brown A. 2012. Metabolic Ecology: A Scaling Approach. Chichester, West Sussex, UK: Wiley-Blackwell

Stevenson RD. 1985. The relative importance of behavioral and physiological adjustments controlling body temperature in terrestrial ectotherms. American Naturalist. 126(3):362-86

Sunday JM, Bates AE, Dulvy NK. 2011. Global analysis of thermal tolerance and latitude in ectotherms. Proceedings of the Royal Society B: Biological Sciences. 278(1713):1823-30 
Sunday JM, Bates AE, Kearney MR, Colwell RK, Dulvy NK, et al. 2014. Thermal-safety margins and the necessity of thermoregulatory behavior across latitude and elevation. Proceedings of the National Academy of Sciences of the United States of America. 111(15):5610-15

Sundqvist MK, Sanders NJ, Wardle DA. 2013. Community and ecosystem responses to elevational gradients: Processes, mechanisms, and insights for global change. Annual Review of Ecology, Evolution, and Systematics. 44(1):261-80

Tewksbury JJ, Huey RB, Deutsch CA. 2008. Putting the heat on tropical animals. Science. 320(5881):1296-97

Thomas CD, Cameron A, Green RE, Bakkenes M, Beaumont LJ, et al. 2004. Extinction risk from climate change. Nature. 427(6970):145-48

Tracy C. 1976. A model of the dynamic exchanges of water and energy between a terrestrial amphibian and its environment. Ecological Monographs. 46(3):293326

Urban MC, Bocedi G, Hendry AP, Mihoub JB, Pe'er G, et al. 2016. Improving the forecast for biodiversity under climate change. Science. 353(6304): aad8466

Walther GR. 2010. Community and ecosystem responses to recent climate change. Philosophical Transactions of the Royal Society of London B: Biological Sciences. 365(1549):2019-24

Walther GR, Post E, Convey P, Menzel A, Parmesan C, et al. 2002. Ecological responses to recent climate change. Nature. 416(6879):389-95

Williams SE, Moritz C, Shoo LP, Isaac JL, Hoffmann AA, Langham G. 2008. Towards an integrated framework for assessing the vulnerability of species to climate change. PLoS Biology. 6(12):2621-26

Wilson HB, Joseph LN, Moore AL, Possingham HP. 2011. When should we save the most endangered species? Ecology Letters. 14(9):886-90

Wong BBM, Candolin U. 2015. Behavioral responses to changing environments. Behavioral Ecology. 26(3):665-73 


\section{CHAPTER I: PATTERNS OF VARIATION IN THE METABOLIC RATES OF}

\section{AMPHIBIANS}

\section{ABSTRACT}

Amphibians are characterized by low-energy ecological strategies which are accompanied by relatively low metabolic rates. Many studies describe the metabolic physiology of amphibians using a single metabolic relationship which ignores substantial variation and diversity within the class Amphibia. Here, I synthesize the literature on amphibian metabolism and discuss biologically significant sources of variation in metabolic rates. Across Amphibia, there exists extensive variation in metabolic rates that is most apparent among the three orders and many families of amphibians but may exist at lower taxonomic levels as well. Many differences in amphibian metabolism are related to environment as is demonstrated by variation across latitude and elevation. Moreover, diel and seasonal environmental cycles are accompanied by metabolic changes in amphibians. Metabolic rates may differ among males and females, reproductive and nonreproductive individuals, and across life history stages, although the large reproductive diversity in amphibians obscures general patterns. Finally, organismal condition such as hydration state and time since last meal can exert strong influences on metabolic rate. Much of the variation found in amphibian metabolism has only been demonstrated in a few species, and often only in a single study. The lack of studies and measurements across a diversity of amphibians and environments precludes detailed examinations of the patterns of variation in amphibian metabolism. Nevertheless, the current knowledge of amphibian metabolism suggests that there is important variation that should be accounted 
for in studies and that the practice of categorizing all amphibians as a single group masks important biological variation in amphibian metabolism. Additional work is necessary to understand the complex drivers of variation in amphibian metabolism and to predict the metabolic impacts of climatic and other environmental changes.

\section{INTRODUCTION}

Amphibians have evolved biological strategies that maximize fitness while using relatively low amounts of energy (Pough 1980). The amphibian ecological strategy encompasses a suite of life history, behavioral, and physiological traits that together are described as a low-energy adaptive zone (Nespolo et al. 2017; Pough 1980) or slow paceof-life syndrome (Woodley 2017). Low metabolic expenditure may allow many amphibians to survive and thrive in environments characterized by periodic shortages of food, water, and/or oxygen (Nespolo et al. 2017; Pough 1980). Ectotherms such as amphibians have resting metabolic rates about 10 to 30 times lower than those for birds and mammals of similar mass and temperatures (Gatten et al. 1992; Gillooly et al. 2017; Pough 1980). Low-energy strategies are complemented by the small size of many amphibians and behavioral thermoregulation using ambient environmental temperatures (Wells 2007).

Unfortunately, current knowledge of amphibian metabolism is limited. Many of the large meta-analyses of metabolism often omit amphibians from analysis (e.g., Isaac \& Carbone 2010), although the reasons for doing so are unclear. Many studies that do include amphibians use a single relationship of mass and temperature to predict the metabolism of all amphibians (e.g., Dillon et al. 2010; Gillooly et al. 2001). The 
metabolic scaling relationship for amphibians perhaps most utilized comes from Gillooly et al. (2001), which is derived from metabolic data of limited taxonomic and geographic scope (11 anurans and 11 salamanders of primarily temperate species; Altman \& Dittmer 1974). Unfortunately, most studies of amphibian physiology and metabolism are limited in scope, either taxonomically or geographically, which severely limits our understanding of general patterns (Bovo et al. 2018; Winter et al. 2016). Most studies of amphibian metabolism have occurred on temperate species and regions in the northern hemisphere, a pattern that is common across the biological sciences (Brito 2008; Di Marco et al. 2017; Lawler et al. 2006; Martin et al. 2012; Schiesari et al. 2007; Winter et al. 2016). Amphibians are a diverse class of organisms, with extensive variation in size, morphology, physiology, behavior, life history, and habitat (Bovo et al. 2018; OchoaOchoa et al. 2019). Many studies have demonstrated that amphibian metabolism predictably varies with a number of ecological traits (Santos \& Cannatella 2011; Taigen \& Pough 1985; Taigen et al. 1982). Moreover, recurring combinations of behavior, morphology, and physiology have evolved independently across various clades of anurans, suggesting that there is evolutionary integration among various suites of traits (Pough et al. 1992). It can thus be expected that the variation in amphibian metabolism reflects the high ecological diversity of the group. While there have been systematic reviews and meta-analyses of amphibian metabolism that attempt to increase our understanding of patterns and variation (e.g., Feder \& Burggren 1992; Nespolo et al. 2017), they are limited by the breadth of published studies and the comparability of different measurements. 
Despite the high diversity of amphibians and large variety of environments in the tropics, metabolic studies of tropical amphibians have generally been limited to a few taxonomic groups and habitats. Many tropical studies focus on a few well-studied groups, such as the poison frogs (Pough \& Taigen 1990; Santos \& Cannatella 2011), or invasive species such as Rhinella marina (Overgaard et al. 2012; Seebacher \& Franklin 2011). While the few metabolic studies of tropical amphibians with broad taxonomic and environmental breadths (e.g., Gomes et al. 2004; Navas 1996) are important contributions for databases, reviews, and meta-analyses (Bovo et al. 2018), they are not enough to represent the vast diversity of amphibians in the tropics, both across phylogeny and environments.

Herein, I provide an overview of amphibian resting metabolism while focusing on patterns of variation. Patterns are necessarily inferred and extrapolated from examples as a result of the scarcity of studies of amphibian metabolism, particularly in relation to the broad diversity of amphibians. It is therefore difficult to determine the extent to which observed patterns of variation are applicable across amphibians. Additional work is necessary to make a predictive framework of amphibian metabolism, particularly for many of the understudied groups (i.e., everything that is not an adult male temperate amphibian).

\section{NOMENCLATURE}

There are various measures and terminologies associated with the study of metabolism, each with distinct biological meanings and implications for our understanding of physiology. Metabolism is the processing of energy and materials of an 
organism but can more specifically apply to a number of processes. In my review, metabolism will be used to refer to energy metabolism through aerobic pathways. Much of the vocabulary used for metabolism varies among fields (e.g., among studies of endotherms and ectotherms or aquatic and terrestrial taxa) and there have been many historical shifts in terminology as our understanding of metabolism has developed. Herein, I outline the nomenclature that I use throughout my dissertation.

The minimum energetic requirements for the normal functioning and basic maintenance of an ectothermic organism at rest is called the standard metabolic rate (SMR; Gatten et al. 1992), analogous to the basal metabolic rate (BMR) of endotherms (Norin \& Metcalfe 2019). There are several requirements for measurements to qualify as "true" measures of SMR. First, the organism must be in the inactive period of their diel cycles (e.g., daytime for nocturnal species). Second, organisms must not be in the process of digestion or assimilation, which results in elevated metabolic rates, a process known as specific dynamic action. The specific dynamic action of most amphibians is measured on the scale of days (Secor 2009). Further fasting can depress metabolic rate below what is considered to be "standard" metabolic rate (Gatten et al. 1992; Merkle \& Hanke 1988), similar to the depressed metabolic states during times of starvation, estivation, torpor, and hibernation (Pinder et al. 1992). Third, measures of standard metabolic rate assume that individuals are not growing and are not reproductive (e.g., producing eggs). As a result of the seasonal variation in metabolic rates, measurements must additionally occur outside of highly active seasons (e.g., spring reproductive season for many temperate amphibians). Finally, organisms, in addition to being at rest, must be unstressed, a difficult requirement for many measurement methodologies (Feder 1981). 
It is difficult to ensure the stringent requirements for SMR are met, even in controlled laboratory settings. Thus, many studies use resting metabolic rate (RMR) as an estimate of SMR (Gatten et al. 1992). The RMR of an organism represents the minimum energetic expenditure required for an organism at rest under normal conditions, with the recognition that not all conditions may qualify for as measurement of "true" SMR. Some authors have used RMR to refer to resting metabolic rates during active periods, while SMR is reserved for resting metabolic rates during inactive periods (Gatten et al. 1992). Unfortunately, there has been little consistency in the use and definition of RMR and SMR (Gatten et al. 1992; Wells 2007). It is thus appropriate to use the more inclusive term, RMR, as the measurement for all organisms at rest (Gatten et al. 1992; Wells 2007). In many cases, RMR provides a more biologically meaningful measurement than SMR in ecological contexts, as it may be rare that organisms ever satisfy all the requirements of SMR in natural environments (Wells 2007), and it may be unrealistic that organisms are unstressed during measurements (Feder 1981).

Various activities are accompanied by increases in metabolic rate to supply additional energy above basic maintenance requirements (Bennett 1978). The maximum metabolic rate (MMR) represents the maximum energetic expenditure that an organism is able to achieve, usually under high, often unsustainable, activity. The aerobic MMR is a measure of aerobic capacity of an organism, or the maximal use of oxygen for energetic purposes (Bennett 1978). The active metabolic rate (AMR) is a measure of metabolic rate under sustainable activity. In some organisms, particularly in fish, resting metabolic rates are necessarily accompanied by swimming behavior, and thus the "resting" metabolic rate itself is a baseline measure of AMR. The "resting" AMR in fish is often defined as 
the routine metabolic rate, resulting in a confusing overlap with the use of the acronym RMR, each with distinct biological meanings. Active or routine metabolic rates are difficult to compare among individuals, especially across studies, as there is a broad range of activity that exists between RMR and MMR. Thus, AMR is of limited use in a comparative capacity. In amphibians, comparisons of AMR are further restricted by the inability to control for speed or power output among various locomotory strategies (e.g., walking, hopping, jumping, climbing, slithering, and swimming).

Metabolic rates exist on a spectrum from SMR and RMR through various measures of AMR to the MMR of an organism (Bennett 1978). Baseline requirements for organismal function are best characterized through RMR, as the stringent requirements for SMR are difficult to achieve, measure, and are often biologically unrealistic (Gatten et al. 1992). The MMR relates the maximum aerobic capacity of an organism, while measures of AMR can examine the metabolic cost of various activities. The various measures of metabolism provide important and complementary information on the physiology and ecology of organism. Together, measurements of metabolic rates can be used to determine energy budgets and predict how the environment may affect organismal energetics.

\section{METABOLIC SCALING - MASS AND TEMPERATURE}

Metabolism provides the energy and materials necessary for the biological functions of life. The amount of energy and materials needed by an organism is directly proportional to the size of an organism. The allometric relationship between resting metabolic rate and mass most often takes the form of a power-law: 
where $R M R$ is the whole-organism resting metabolic rate, $M$ is the mass, $\alpha$ is the massscaling exponent, and $B_{0}$ is a normalization constant which varies among taxa. For amphibians, the mass-scaling exponent was calculated to be around 0.80 following a large meta-analysis by Gatten et al. (1992). The mass-scaling exponent was similar for both anurans and salamanders, but there was not enough data for a robust estimate of the mass-scaling exponent for caecilians (Gatten et al. 1992). The metabolic theory of ecology (MTE) proposes a universal mass-scaling exponent of 0.75 across vertebrates, which has been supported by some studies (Brown et al. 2004). However, there is debate over the universality of metabolic scaling (see Chapter III for discussion; Isaac \& Carbone 2010; White et al. 2006).

Temperature has a direct effect on the kinetics of biochemical reactions, including many of the reactions that govern metabolism. While there is contention as to how biochemical effects scale with multi-level processes such as metabolic rate (Clarke 2003, 2006; Marquet et al. 2004; van der Meer 2006), there is a well-known effect of temperature on metabolism. There is an exponential relationship between metabolic rate and temperature that is often modeled through the van't Hoff-Arrhenius equation:

$$
R M R \propto B_{0} e^{-E / k T}
$$

where $R M R$ is the whole-organism resting metabolic rate, $B_{0}$ is the empirical normalization constant (del Rio 2008), $k$ is the Boltzmann constant, $T$ is the temperature, 
and $E$ is an empirical constant most often defined as the average "activation energy" of the metabolic process. In Equation 1.2, thermal sensitivity is governed by the activation energy, $E$, which according to MTE should be around -0.65 (Brown et al. 2004). Other studies express thermal sensitivity through a $\mathrm{Q}_{10}$ value, which is the factor by which metabolism is expected to change over $10^{\circ} \mathrm{C}$ change in temperature. The extensive review by Gatten et al. (1992) found metabolic rate in amphibians to have a $Q_{10}$ value of around 2 (a doubling of metabolic rate for $10^{\circ} \mathrm{C}$ change in temperature). Moreover, Gatten et al. (1992) found that the mass and temperature scaling of resting metabolism is similar between adults and larvae.

However, many studies have found that thermal sensitivity varies among amphibian taxa (Whitford 1973) as well as across temperature (Brown \& Fitzpatrick 1981). In salamanders, Brown and Fitzpatrick (1981) found that $Q_{10}$ values range between 1.1 and 4.5, depending on the temperature range. Similarly, Fitzpatrick et al. (1972) found $\mathrm{Q}_{10}$ values vary between 1.15 and 3.63 depending on temperature. Whitford (1973) found that thermal sensitivity was much higher for tropical anurans and temperate amphibians (excluding lungless salamanders) compared to lungless and aquatic salamanders. Careau et al. (2014) demonstrated that intraspecific thermal sensitivity can also vary consistently among individuals, presenting the possibility for selection on individual variation.

\section{TAXONOMIC VARIATION}

The three orders of Amphibia are often observed to have consistent differences in metabolic rate. While the scaling in metabolic rate is similar for all three orders, the 
expected metabolic rates for each order (at the same mass and temperature) differ. In general, the anurans have the highest metabolic rate of all three orders, expected to be 1.5-2.5 times higher than a salamander of the same mass and temperature (Gatten et al. 1992). Metabolic rates for caecilians may be even lower than those of urodeles, especially in consideration of their fossorial and aquatic habits (Stiffler \& Talbot 2000; Wilkinson \& Nussbaum 1997). However, the relative lack of measurements of caecilian metabolism limits our understanding and ability to make generalizations for the entire order (Gatten et al. 1992).

Despite the often observed differences in RMR among orders, a recent phylogenetic meta-analysis failed to find separate optima in RMR (defined by evolutionary convergence) for the three orders (Nespolo et al. 2017). Instead, Nespolo et al. (2017) found that a single optimum best explains the distribution of RMR across 122 species of amphibians. However, the study by Nespolo et al. (2017) was limited by the availability of published results, including only four species of caecilians, and having a disproportionately large representation from temperate species. As the authors state, amphibian metabolism is likely tied to environmental conditions and subject to plastic changes, which were not accounted for in the meta-analysis (Nespolo et al. 2017).

There also appears to be consistent differences in resting metabolic rates at taxonomic levels below the ordinal level. The poison frogs of the family Dendrobatidae have been observed to have high metabolic rates compared to other families (Pough \& Taigen 1990; Santos \& Cannatella 2011). High metabolic rates in the poison frogs have been linked to active foraging, toxicity, and complex life histories (Taigen et al. 1982). However, even within Dendrobatidae, there appears to be variation in metabolic rates 
among species that may be intimately tied to a suite of ecological traits such as diet, toxicity, behavior, life history, and habitat (Santos \& Cannatella 2011; Taigen \& Pough 1983).

Similar to dendrobatids, toads in the family Bufonidae are active foragers, toxic, and have complex reproductive behaviors (Taigen et al. 1982; Carey 1979a). Taigen et al. (1982) found that while bufonids did not have high mass-specific RMR, bufonid MMR and dependence on aerobic metabolism for activity was particularly high. Although Taigen et al. (1982) discuss the allometric scaling exponent of RMR of their study (0.73), they only express mass-specific RMR instead of mass-corrected RMR. Thus, it is unclear if the bufonids in their study have high mass-corrected RMR, but the authors note that analysis of covariance indicates that differences in RMR among species persist independent of mass (i.e., mass-corrected RMRs vary significantly among species; Taigen et al. 1982). Carey (1979a) found montane bufonids had significantly higher RMRs than montane leptodactylids, and associated high aerobic capacity in bufonids with intense, prolonged reproductive activity.

However, metabolic rates may be further mediated by environmental factors. For example, in contrast to past studies on bufonids, Mokhatla et al. (2019) found that bufonids in southern Africa (Sclerophrys capensis) had much lower RMRs than other South African amphibians. They suggest that low RMR may allow S. capensis to preserve water for a terrestrial lifestyle (Mokhatla et al. 2019). The lack of studies on amphibian metabolism across taxonomic and geographic scales makes it difficult to determine if variation in metabolism is consistent within and among families, and how metabolic patterns may covary with ecological and environmental characteristics. 
Metabolic rate has also been demonstrated to show consistent intraspecific variation. Several studies have observed consistent (i.e., repeatable) differences among individuals in metabolism in amphibians (Careau et al. 2014; Gomes et al. 2004; Preest \& Pough 1985; Wells \& Taigen 1984). Moreover, the consistent variation of metabolism among individuals has been a proposed as an important aspect of differences in "personalities" within species and demonstrated in a variety of animals (Careau et al. 2008; Careau and Garland 2012; Holtmann et al. 2017; Roche et al. 2016). Metabolic differences in dendrobatid frogs have been shown to vary among populations that differ in diet and foraging (Taigen \& Pough 1985). Louppe et al. (2018) observed that in an invasive population of Xenopus laevis, individuals at the expanding range edge had lower RMR than individuals at the range center. Lower RMR at the expanding range edge may allow more energy to be invested into activities associated with dispersal (Louppe et al. 2018). Consistent individual differences in metabolic rate is an important prerequisite for the selection and adaptation of metabolic characteristics in response to changing climatic conditions (Careau et al. 2014; Gifford et al. 2014; Roche et al. 2016). However, not all studies of amphibians have found consistent differences among individuals in RMR (Gifford et al. 2014), suggesting that the individual variation necessary for selection may not be present in all species. Unfortunately, no studies have examined the heritability of evolvability of metabolic rate in amphibians. It is possible, as individual variation in metabolism has been demonstrated in invertebrates (Artacho et al. 2011; Einum et al. 2019; Mattila \& Hanski 2014), snakes (Garland \& Bennett 1990), birds (Bushuev et al. 2012; Mathot et al. 2013; Nilsson et al. 2009; Rønning et al. 2007), and mammals (Boratyński et al. 2013; Careau et al. 2011; Konarzewski et al. 2005; Nespolo et al. 2005; 
Sadowska et al. 2005; Wone et al. 2009; Zub et al. 2012). Further work should examine whether individual variation in metabolic characteristics in amphibians is heritable in a broad range of species and environments.

\section{ENVIRONMENTAL VARIATION}

\section{Latitude}

Unfortunately, there are few data available on the metabolic rates of tropical amphibians, making comparisons across latitude difficult. Latitudinal variation could occur both intraspecifically and interspecifically as a result of a variety of plastic and adaptive responses to both abiotic and biotic factors that change across latitude (Chown \& Gaston 1999). As is often characteristic of amphibians, there is large variation in patterns, with many findings being particular to individual species or studies.

Within species, variation across latitude could relate to plasticity in metabolic physiology during development, the effects of daily or seasonal acclimation to different temperatures, latitudinal variation in acclimation capacity, adaptation, or a variety of other factors (Chown \& Gaston 1999; Tsuji 1988). Dunlap (1972) found that, in Acris crepitans, metabolic rates at low temperature were higher for a high latitude population than those of a low latitude population, suggesting metabolic compensation at low temperatures may be important for high latitude populations. Tashian and Ray (1957), however, found no significant differences in metabolic rates between northern and southern populations of Anaxyrus (Bufo) boreas. Similarly, Chown and Gaston (1999) demonstrated that intraspecific latitudinal patterns of respiratory physiology in insects vary among studies and suggest that many clines are taxon-specific as a result of 
interactions between latitudinal ranges, abiotic conditions, organismal physiology, life history, and other ecological characteristics. The extensive diversity within Amphibia likely results in similar taxon-specific patterns across latitude, but lack of data precludes a more detailed examination.

Interspecific differences across latitude could similarly result from both plastic and adaptive responses but are further complicated by ecological and evolutionary differences. Some early studies found that tropical amphibians have lower metabolic rates than temperate amphibians (Hutchison et al. 1968; Whitford 1973). However, as pointed out by several authors, many early studies lacked statistical rigor and often compared organisms without adequately addressing differences in size, ecology, and evolutionary history (Gatten et al. 1992; Wells 2007). Some of the most studied tropical species, such as the poison frogs and the invasive cane toad (Rhinella marina), have been found to have particularly high metabolic rates. However, the analyses are confounded by differences in analytical techniques (e.g., mass-specific versus mass-corrected RMR) and latitudinal variation in ecological correlates of metabolic rates including toxicity, foraging mode, diet specialization, and life history (Pough \& Taigen 1990; Taigen et al. 1982).

Many tropical amphibians may have comparatively high thermal sensitivities of metabolism as a result of the high average temperatures and low seasonal variability of many tropical environments (Janzen 1967; McCain 2009). High thermal sensitivity in the tropics has been demonstrated for a variety of traits and ectotherms (Deutsch et al. 2008; Feder \& Lynch 1982; Huey et al. 2012; Sunday et al. 2011, 2014; Tewksbury et al. 2008). Novarro et al. (2018) found that increased temperatures caused lower latitude 
salamanders (Plethodon cinereus) to have higher elevated corticosterone, a hormone which leads to increased metabolic rates (Wack et al. 2012), compared to high latitude conspecifics. Moreover, low latitude salamanders had increased rates of ingestion in response to elevated temperatures compared to high latitude conspecifics (Novarro et al. 2018). Dunlap (1972), however, found that the thermal sensitivity of high and low latitude populations of Acris crepitans were identical $\left(\mathrm{Q}_{10}=2.8\right)$.

\section{Elevation}

Little work has examined differences in metabolism across elevation in amphibians, and patterns differ among taxa. While there are some studies that have examined metabolic characteristics of high-elevation species, few studies include lowelevation species for comparison. It is thus difficult to determine if there are consistent metabolic adaptations associated with elevation. Žagar et al. (2018) compared various metabolic measurements between high-elevation and low-elevation salamander species from the genus Salamandra. They found no significant differences in respiration rates between the two species but showed that the low-elevation species had higher thermal sensitivity of respiration rates than the high-elevation species (Žagar et al. 2018). Similarly, Gifford \& Kozak (2012) found similar resting metabolic rates (and scaling relationships with mass and temperature) between low-elevation and high elevation species in the genus Plethodon. However, when combined with other traits in a mechanistic energy budget model, they found that different processes may work in each species to maintain elevational range boundaries. While energetic constraints may determine the lower elevational range limit of high elevation salamanders, no such 
energetic limits are apparent in the upper range limit of the low elevation species (Gifford \& Kozak 2012). Thus, while metabolic characteristics may be important for determining species ranges and suitable habitat across elevation, the role of metabolism may differ among species as well as between upper and lower elevational range boundaries (Gifford \& Kozak 2012).

Perhaps the most detailed examination of metabolic physiology of amphibians across elevation has been conducted on tropical species. Navas (1996) found that high elevation species of Atelopus and Colostethus had higher resting metabolic rates than their low-elevation congeners. Moreover, high elevation species displayed evidence of metabolic compensation at low temperatures. Thus, high elevation amphibians may retain high metabolic capacity at low temperatures relative to low elevation species (Navas 1996). However, in the same study, there were no metabolic differences between high and low elevation congeners in the genera Eleutherodactylus and Hyla, regardless of temperature (Navas 1996). The taxon-specific patterns across elevation suggest that there may not be universal differences between high and low elevation species. Elevational patterns may instead depend on a variety of both organismal and environmental characteristics. Nevertheless, for all congeneric comparisons, capacity for active metabolism was maintained at low temperatures for high elevation species but not for low elevation species (Navas 1996). At temperatures above $10^{\circ} \mathrm{C}$, differences in active metabolism among elevational groups disappeared (Navas 1996). Thus, the selective pressures of high elevation environments may act more strongly on active metabolism than resting metabolism, particularly to maintain function at low temperatures. 


\section{TEMPORAL VARIATION}

\section{Daily}

Most amphibians that have been studied exhibit diel rhythms in RMR. The periods of high metabolic rates coincide with periods of activity, with nocturnal species exhibiting high metabolic rates at night and diurnal species exhibiting high metabolic rates during the day (Bucher et al. 1982; Dunlap 1969; Hutchison \& Kohl 1971; Miller \& Hutchison 1979; Taigen \& Pough 1983; Turney \& Hutchison 1974; Weathers \& Snyder 1977). Such diel rhythms have been demonstrated in both adults and larvae (Feder 1981). Whereas a "true" circadian rhythm must be endogenous in origin (i.e., maintained without external cues; Refinetti 2016), most amphibians to date have been found to have diel rhythms synced to environmental cues of light and temperature and are often assumed to be endogenous (Gatten et al. 1992). Moreover, outside of carefully controlled laboratory settings, in natural environments, circadian and noncircadian diel rhythms are indistinguishable. Thus, diel or circadian rhythms are important considerations for the energetics of amphibians (as well as other processes) regardless of endogenous or exogenous origin. Nevertheless, despite the long history demonstrating time of day as an important factor in metabolic rates, many studies have conducted measurements during a single time (often during the day) or not documented the time of day for measurements (Carey 1979b), which could affect findings and comparisons. In particular, daytime measurements (the active period for most humans) may introduce bias that leads to the conclusion that diurnal species have relatively high RMRs as compared to nocturnal species (see Chapter II for discussion). 


\section{Seasonal}

A variety of amphibians have been shown to have seasonal patterns in metabolic rate. During the breeding season, amphibians generally have high metabolic rates relative to other times of year (Dunlap 1973; Fromm \& Johnson 1955; Jameson et al. 1970). Much of the work on seasonal metabolism has been conducted on temperate amphibians, with spring and summer breeding seasons accompanied by high metabolic rates as compared to amphibians measured in fall and winter (Dunlap 1973). In the newts Taricha torosa, Harlow (1977) found that seasonal changes in habitat are accompanied by significant metabolic changes. Seasonal patterns in metabolic rate are present even when accounting for temperature (Dunlap 1969, 1973; Jameson et al. 1970), suggesting that there are physiological changes causing the seasonal differences in metabolic rates. Interestingly, some amphibians such as Hypsiboas prasinus actually have higher RMRs during the winter months (Kiss et al. 2009). However, H. prasinus inhabits a subtropical environment and is reproductively active throughout the year, and relatively high RMR during winter could be a form of metabolic compensation for reproductive activity (Kiss et al. 2009). Seasonal comparisons may be further complicated by seasonal dependence of thermal acclimation of metabolic rate, potentially obscuring the causes of seasonal differences in metabolism (Chang \& Hou 2005). Whitford and Hutchison (1965) found strong impacts of photoperiod on metabolic rates in Ambystoma maculatum, thereby providing a potential cue for seasonal onset of metabolic changes and associated behaviors.

In many environments, amphibians will enter into dormancy during dry seasons or cold winters. Dormant amphibians can have extremely low metabolic rates through 
two distinct processes: hibernation, where metabolic depression is achieved through lower body temperatures; or through estivation, where physiological changes results in significantly lower metabolic rates than would be achieved from changes in body temperature alone (Pinder et al. 1992). In amphibians, metabolic depression can occur in response to unfavorable thermal conditions as well as periodic changes in water availability (Carvalho et al. 2010; Pinder et al. 1992). Similar mechanisms that cause metabolic depression in daily cycles may be responsible for seasonal metabolic depression for estivation (Pinder et al. 1992). Withers (1993) observed that the magnitude of metabolic depression is similar for estivating frogs, salamanders, and fish. Metabolic depression to around $20-30 \%$ of normal resting values has been observed in bufonids (Seymour 1973; Whitford \& Meltzer 1976), a number of Australian Cyclorana and Neobatrachus species (Kayes et al. 2009; van Beurden 1980; Withers 1993), the African bullfrog Pyxicephalus adspersus (Loveridge \& Withers 1981), and salamanders (Etheridge 1990; Gehlbach et al. 1973). Similar levels of metabolic depression were observed for both juvenile and adult Spea (Scaphiopus) hammondi while burrowing (Seymour 1973; Whitford \& Meltzer 1976). Metabolic depression likely results from a combination of the effects of low temperature, starvation, mass loss, urea accumulation, decreased muscle tone, and other physiological mechanisms (Muir et al. 2010; Pinder et al. 1992; Storey \& Storey 1990; Tattersall \& Ultsch 2008). However, not all dormant amphibians undergo metabolic depression during estivation and hibernation, as evidenced by estivating Ceratophrys ornata and Rana muscosa (Bradford 1983; Groom et al. 2013). 


\section{LIFE HISTORY}

\section{$\operatorname{Sex}$}

Comparatively little work has been conducted on the metabolic rates of female amphibians. In part, this is a result of the definition of SMR, which historically has restricted many studies to males without the "complications" of the costs of female reproduction. Of course, this ignores an essential aspect of amphibian biology, especially considering the relative importance of females for population dynamics compared to males. Indeed, many population models perform relatively well while only using females to model population parameters (Leslie 1945, 1948; Otto \& Day 2007). Part of the problem also lies with the difficulty in determining female reproductive condition without the use of invasive techniques. Some studies have attempted to control for reproduction of females by measuring metabolic rates after eggs are laid (e.g., Taigen et al. 1985), but there is little information on the relative timing and overall changes of metabolic rate across the reproductive cycle. There are expected to be large energetic costs with the production and maintenance of eggs (Fitzpatrick 1973), which presumably would lead to increased metabolic rates. The use of ultrasound methodologies could prove useful to determine the reproductive status for females and account for the effects of egg production on metabolic rates (Gilman \& Wolf 2007; Lucas \& French 2012). Longphre and Gatten (1994) found no difference in the resting and active metabolic rate of males and females of cane toads (Rhinella (Bufo) marina). In Pseudacris (Hyla) crucifer, females had higher resting metabolic rates than males, but had lower metabolic rates during exercise. Males of $P$. crucifer also had larger muscle and greater muscle activity, which correlated with high metabolic capacity. In many species, males can 
undergo extensive male-male competition and combat for mates during reproduction. In Anaxyrus (Bufo) americanus, a species with prolonged combat between males, males had significantly higher metabolic rates than females (Pough 1983), which may be important to provide energy for costly combat behaviors. Similarly, Carey (1979a) suggested that high RMR and aerobic capacity in Anaxyrus (Bufo) boreas is related to prolonged and energetically costly male reproductive behaviors during the breeding season.

\section{Reproduction}

Reproduction is often energetically expensive for both male and female amphibians. In males, the energetic requirements of calling and male-male competition can be quite high (Taigen \& Wells 1985). In some species, calling is the most energetically expensive behavior for male amphibians, with calling males having higher metabolic rates than individuals undergoing exhaustive exercise (Taigen \& Wells 1985; Taigen et al. 1985). Furthermore, male-male competition can include defending territories, direct combat, and maintaining amplexus with mates while under assault from other males (Wells 2007). Many males have relatively high RMRs during the reproductive season, which may be related to energetic demands of reproductive activity (Fromm \& Johnson 1955; Taigen et al. 1985).

For female amphibians, egg production is expected to exert a large energetic cost (Fitzpatrick 1973). The energetic costs of reproduction for females includes both the production and maintenance of eggs. Many studies have found that gravid female amphibians have higher metabolic rates than both males and postgravid females (Finkler 2006; Finkler \& Cullum 2002; Finkler et al. 2003). While some studies have 
demonstrated that the relative differences in the metabolic rates between gravid females and males are temperature dependent (Fitzpatrick 1973), others have found the differences remain independent of temperature (Finkler 2006). Moreover, Finkler (2006) found that the resting metabolic rates of gravid females had a higher thermal sensitivity than males and postgravid females. Galloy and Denoël (2010) found that female palmate newts (Lissotriton helveticus) lay half as many eggs at high temperature $\left(22^{\circ} \mathrm{C}\right)$ as at low temperatures $\left(14^{\circ} \mathrm{C}\right)$, a finding consistent with high thermal sensitivity of female reproduction in amphibians. High metabolic rates and high thermal sensitivity may indicate that gravid female amphibians are particularly vulnerable to increased temperatures from climate change. The vulnerability of gravid females to increasing temperatures could result in immediate climate change impacts on the reproductive rates of amphibian species and be a mechanism for declines.

\section{Eggs}

Early embryonic amphibians within eggs start growth and differentiation depending mostly on anaerobic metabolic pathways (Burggren \& Just 1992). The aerobic capacity and dependence on aerobic metabolic pathways increases with embryonic development (Burggren \& Just 1992). A difficulty in measuring the metabolic rate of embryos lies in determination of mass. Amphibian embryos within eggs are surrounded with large amounts of unincorporated material and it can be difficult to determine how much of measured mass is caused by water content. Indeed, many amphibian eggs can remain relatively unchanged in terms of mass even when embryos have undergone considerable growth (Burggren \& Just 1992). Furthermore, due to the size and shape of 
egg masses, the metabolic rates of inner eggs may differ from those of outer eggs as a consequence of different oxygen environments (Pinder \& Friet 1994).

\section{Larvae}

There is extensive variation in the physiology and development of amphibian larvae as they emerge from eggs. In some amphibians, larvae emerge from the egg relatively early in development with poorly developed muscles and cardiovascular systems (Burggren \& Just 1992; Taigen \& Pough 1985). Others, such as in family

Craugastoridae, are direct developers and undergo extensive development (through metamorphosis) while still in the egg (Crump 2015). The larvae of many amphibian life histories fall between these two extremes, with length of duration of embryonic stages often related to the environment. Some amphibian larvae can choose to leave the egg in response to cues from potential predators, and thus can vary in size and developmental stage when they first leave the egg (Warkentin 2011). The combination of size and developmental stage of amphibian larvae likely determines resting metabolic rate, but little work has examined how metabolic rates change throughout larval development.

Moreover, developmental stage of amphibian larvae is often not correlated with body mass, which complicates comparisons among individuals. The larvae of $L$. catesbeiana can undergo large periods of development, including metamorphosis, without substantial changes in mass (Burggren \& Just 1992). Large studies or metaanalyses may be able to differentiate the separate influences of developmental stage and body size. However, few studies have measured the metabolic rates of amphibian larvae, and data have been collected for only a few species and conditions. Furthermore, 
comparisons among species are complicated by differences in development times, larval ecology, and physiology.

Part of the lack of studies on larval metabolism relates to the difficulty in conducting measurements. It is technically difficult to measure resting metabolic rate for aquatic amphibian larvae as they are often moving, defecate during measurements, and are highly sensitive to a variety of factors implicitly affected by experimental setup (e.g., handling stress, $p \mathrm{O}_{2}, p \mathrm{CO}_{2}, \mathrm{pH}$, temperature, and respirometer chamber volume; Feder 1981). Historically, many of these factors have often been ignored during measurements of larval metabolic rates (Feder 1981). As a result, the measured metabolic rates for many amphibian larvae probably overestimate minimum energetic requirements to varying degrees and are thus difficult to compare across studies (Feder 1981; Wells 2007). The extent to which RMR is overestimated may further depend on larval ecology and physiology, which vary extensively across amphibian life histories (e.g., size, behavior, trophic level, habitat, development time, growth rate).

Little work has examined how RMR changes with developmental stage of amphibian larvae, and few patterns are consistent among species. Some species have stage-dependent patterns of metabolic rate, while others seem to only be dependent on body size and growth (Burggren \& Just 1992). It is possible that the lack of common patterns is a result of the morphological, physiological, and ecological diversity of amphibian larvae, but there are not enough studies to infer any consistent explanations for observed patterns. Stage-specific variation of metabolic rate may result from energetically expensive processes related to differentiation (Burggren \& Just 1992). The largest increase in larval metabolic rates of Pseudis paradoxus coincided with the 
emergence of forelimbs, suggesting that this period of development is associated with high energetic costs (de Souza \& Kuribara 2006). A similar pattern was found for Xenopus laevis, where there were large increases in metabolic rate throughout development, with particularly high metabolic rates associated with metamorphosis (Hastings \& Burggren 1995). Pandian and Marian (1985) found that larval body size prior to metamorphosis had a large effect on the efficiency and metabolic costs of metamorphosis in Hoplobatrachus (Rana) tigrina. High metabolic rates during metamorphosis are not surprising given the extensive changes in morphology and physiology that accompany the transition from larval to adult life forms in amphibians (de Souza \& Kuribara 2006; Pandian \& Marian 1985).

Amphibian larvae display similar patterns of metabolic scaling patterns to adult amphibians. The mass-scaling exponent across pooled data for amphibian larvae varies considerably $(0.59-0.79)$ across different temperatures $\left(15-25^{\circ} \mathrm{C}\right.$; Gatten et al. 1992). The same dataset leads to a calculated $\mathrm{Q}_{10}$ value of 2.14, similar to calculated values for adults (Gatten et al. 1992). A recent study found a $\mathrm{Q}_{10}$ value of 1.72 for tadpoles of the treefrog Hyla chrysoscelis (Rowe \& Funck 2017). However, it is likely that thermal sensitivity of larvae vary among species and is related to habitat and environmental thermal variability (Rowe \& Funck 2017). Such variation may be important for predictions of climate change impacts, as it suggests that single relationships for pooled data may not be representative of individual species for which thermal sensitivity may vary widely. The intercepts of the regression of larval metabolic rates suggest that, for equal size and temperature, amphibian larvae have metabolic rates intermediate between adult salamanders and adult anurans (Gatten et al. 1992). 


\section{Juveniles}

Juvenile amphibians are expected to have relatively high metabolic rates to account for the energetic costs associated with growth (Peterson et al. 1999; Wieser 1994). Indeed, the diurnal basking behavior of some juvenile amphibians has been proposed to be a behavior to increase metabolic rate and growth (Taigen \& Pough 1985). However, as has been observed in larvae and adults, the metabolic rates of juveniles varies among taxa. In Pseudis paradoxus, juvenile metabolic rates decline sharply upon completion of metamorphosis, suggesting that the energetic demands of metamorphosis are higher than those for juvenile growth (de Souza \& Kuribara 2006). However, in Xenopus laevis, newly metamorphosed frogs had the highest mass-specific metabolic rates of any life stage (Hastings \& Burggren 1995). Some juveniles are diurnal, in contrast to nocturnal adults, which may confer advantages of increased metabolic and digestive rates associated with higher activity temperatures and lead to enhanced growth rates (Sanabria et al. 2015). Diurnal activity periods may further benefit juveniles by reducing predation from adult amphibians (Oishi et al. 2004; Pizzatto et al. 2008). Beck and Congdon (2000) demonstrated that metabolic rate, sprint speed, and endurance of juveiles are positively correlated to mass at metamorphosis and negatively correlated with age at metamorphosis in Anaxyrus (Bufo) terrestris. Thus, there may be a tradeoff between selective pressures for metabolic and locomotory performance of juveniles and the associated energetic costs of performance traits (Beck \& Congdon 2000). Moreover, the larval environment, as controlled by temperature and food levels, had significant impacts on metabolic rates of juveniles independent of mass and age at metamorphosis (Beck \& Congdon 2000). The selective balance between performance and efficiency, 
throughout the transition from larvae to juvenile stages, likely plays a role in the extensive variation of life history in amphibians and is likely mediated by environmental conditions.

Many studies have demonstrated that there are large changes in activity metabolism throughout growth of juveniles (Taigen \& Pough 1985). Newly metamorphosed juveniles of Anaxyrus (Bufo) americanus have low MMR and exhaust rapidly. During growth, the MMR and endurance of juveniles increase rapidly until size at dispersal, where MMR and endurance of juveniles is similar to those of adults (Taigen \& Pough 1981). However, not all amphibians show such large changes in aerobic capacity and is likely dependent on life history strategy (Pough \& Kamel 1984; Taigen \& Pough 1981, 1985). It is probable that the differences in growth and behavior of juveniles associated with different life history strategies have similar effects on RMR as has been demonstrated with MMR.

\section{ORGANISMAL CONDITION}

\section{Specific dynamic action}

Specific dynamic action (SDA) is the increase in metabolic rates associated with the energetic costs of feeding. It broadly includes the energetic expenses necessary for ingestion, digestion, absorption, and assimilation of meals (Secor 2009; Beaupre 2005). In amphibians, metabolic rates after feeding increase to a peak within the first 48 hours post-feeding, and then gradually decline to pre-feeding levels over several days (Secor 2009). Metabolic rates post-feeding typically increase 1.5 to 5 times that of resting metabolic rates (average of 28 species was $3.43 \pm 0.18$; Secor 2009). Comparisons among 
species and across studies can be difficult as the relative magnitude and duration of metabolic increases as a result of SDA vary with body mass, size of meals, meal energy, meal complexity, and body temperature (see Secor 2009 for a review).

Despite the comparative challenges outlined above, there are some general patterns in the variation in SDA of amphibians. Species that feed relatively infrequently, such as sit-and-wait predators, generally have relatively high metabolic increases from SDA (Secor 2001). Moreover, many sit-and-wait predators are associated with large meal sizes, a factor that increases both the magnitude and the duration of the SDA response. The highest increases in metabolic rates from SDA have been found directly after fasting for species that estivate through seasonal dry periods (Secor 2005). Thus, there may be seasonal patterns in SDA that relate to seasonal cycles of amphibian activity and reproduction. Given that SDA responses vary as a function of type of meal consumed, it is possible that there may be evolutionary integration between SDA responses and other ecological traits. For example, an interesting area of study could examine relative SDA responses for amphibians that have specialized diets between typical meals and other meal types. For dendrobatid frogs that specialize on ants and mites, there may differences in SDA between theses typical prey items and other prey types (even after accounting for mass and energy), which would further indicate dietary and digestive specialization. Some dendrobatids are known to shift their diet seasonally or in response to prey availability (Born et al. 2010; Donnelly 1991) and it is unknown whether dietary shifts are accompanied by associated changes in metabolic physiology and SDA. 


\section{Dehydration}

The hydration state of amphibians has extensive influence on behavior and various physiological processes (Anderson \& Andrade 2017; Cruz-Piedrahita et al. 2018; Jørgensen 1997). The effects of dehydration on metabolism vary among taxa and environments. Gatten (1987) demonstrated that dehydration had large effects on active metabolic rate in Rana pipiens and Anaxyrus (Bufo) americanus but produced no change on RMR. Similarly, Preest and Pough (2003) observed that the RMR of the toad Anaxyrus (Bufo) americanus decreased as a result of dehydration, but changes in RMR were small relative to changes in active metabolic rate. There was no impact of dehydration on RMR or active metabolic rates in the salamander Plethodon jordani (Stefanski et al. 1989). Other studies have found that amphibian RMR decreases significantly as a result of dehydration (Muir et al. 2007, Gil \& Katz 1996). Other studies have observed increases in metabolic rate as a result of dehydration (Senzano and Andrade 2018, Pough et al. 1983). Sherman and Stadlen (1986) found that RMR in both lunged and lungless salamanders increased as a result of dehydration and suggest that the metabolic increases were a result of systemic preparations for rehydration processes. However, as is a common problem in metabolic studies, their results may be sensitive to the approach to measurements and analysis (Stefanski et al. 1989).

The different metabolic responses to dehydration among amphibians could be related to environmental and ecological strategies. For example, there is significantly greater metabolic depression in response to dehydration in semiaquatic frogs as compared to terrestrial toads (Gatten 1987, Hillman 1987). Preest et al. (1992) suggest that the lack of metabolic response to dehydration in Dryophytes (Hyla) versicolor may be part of a 
suite of adaptations to inhabit xeric environments. Similarly, Gomez et al. (2006) found no metabolic impacts of dehydration for most hydration states in the arboreal Phyllomedusa hypochondrialis until the most extreme states of dehydration (after several days of desiccating conditions). Forster (2013) found that toads (Anaxyrus terrestris) had depressed metabolic rates as a result of dehydration, but this effect was only found at $20^{\circ}$ $\mathrm{C}$ and not at $30^{\circ} \mathrm{C}$, suggesting an interaction between temperature and hydration state. For amphibians that inhabit xeric environments or periodically desiccating conditions, there may be a selective advantage to maintain metabolic function during dehydration as has been proposed for locomotion (Gatten 1987; Prates et al. 2013). However, in a comparison of three anuran species in southern Africa, Mokhatla et al. (2019) found that only the terrestrial Sclerophrys capensis exhibited a relationship between hydration level and RMR, whereas the aquatic species showed no effect of dehydration on RMR.

The metabolic effects of dehydration are expected to be mediated by the interactions between organismal and environmental characteristics. The combination of regional and local climate and organismal habitat requirements likely determines daily and seasonal exposure to desiccating conditions. The intensity and duration of desiccating conditions are likely both important in determining metabolic responses to dehydration in amphibians. Metabolic adaptations to desiccation are likely further mediated by opportunities for rehydration across space and time (e.g., via rainfall, water bodies, and other hydric resources). The organisms most likely to maintain metabolic function during dehydration are those that experience frequent but unpredictable desiccating conditions of short duration with ample opportunity (either spatial or temporal) for rehydration or access to refugia. Predictable or cyclical desiccating conditions (e.g., daily desiccating 
conditions of arboreal habitats or seasonal dry periods) likely promote a variety of adaptations for avoidance and/or endurance of desiccating conditions (e.g., high cutaneous resistance and daily or seasonal estivation; Gomez et al. 2006; Jørgensen 1997; Navas et al. 2004). The relative importance of maintaining function during dehydration could further be mediated by temperature through the necessity for finding retreat sites. Amphibians that inhabit hot and dry environments may maintain function during hot and desiccating conditions in order to locate refugia necessary for survival. Additional work should expand the environmental and taxonomic representation of studies examining the metabolic impacts of dehydration to determine broad patterns and mediating factors. A predictive framework for the effects of dehydration on metabolism will be important to determine metabolic impacts of drying trends as a result of anthropogenic climate change (Baettig et al. 2007; Blaustein et al. 2010).

\section{CONCLUSION}

As I have demonstrated, there are many sources of variation in the metabolic ecology and physiology of amphibians. Taxonomic variation in RMR extends from the three orders of amphibians to lower taxonomic levels such as families and genera and has even been used to explain range boundaries between congeneric species. Consistent individual variation in metabolic characteristics has been observed in a number of amphibians, although further work is necessary to determine if such variation is widespread among species. There appears to be extensive effects of both latitude and elevation on the metabolic ecology of amphibians, but low sampling of high elevation and low latitude species precludes more detailed examinations. The temporal changes in 
RMR across diel and seasonal cycles suggests that amphibian metabolism is tied to the environment and integrated with activity and reproductive cycles. The connection between reproduction and metabolism is demonstrated further by the extensive differences in RMR between the sexes and across the life cycle. Finally, organismal condition, such as time since last meal and hydration state, has significant effects on the RMR of amphibians.

The patterns of variation suggest that amphibian metabolism is determined by a complex integration among evolutionary, environmental, and ecological characteristics and further mediated by organismal condition. The diversity of factors shown to influence amphibian metabolism suggests that universal models of metabolism applied to amphibians as a whole may obscure important sources and patterns of variation. Much of our understanding of amphibian metabolism is currently limited by the geographic and taxonomic biases of measurements and additional work is necessary to shift our understanding from circumstantial relationships to a predictive framework. A predictive framework for amphibian metabolism will have important applications for our understanding of amphibian ecology and evolution and will be valuable for models of amphibian energetics for conservation and management.

\section{REFERENCES}

Altman PL, Dittmer DS, eds. 1974. Biology Data Book, Vol. III. Bethesda, Maryland, USA: Federation of American Societies for Experimental Biology. 2nd ed.

Anderson RCO, Andrade D V. 2017. Trading heat and hops for water: Dehydration effects on locomotor performance, thermal limits, and thermoregulatory behavior of a terrestrial toad. Ecology and Evolution. 7(21):9066-75 
Artacho P, Figueroa CC, Cortes PA, Simon JC, Nespolo RF. 2011. Short-term consequences of reproductive mode variation on the genetic architecture of energy metabolism and life-history traits in the pea aphid. Journal of Insect Physiology. 57(7):986-94

Baettig MB, Wild M, Imboden DM. 2007. A climate change index: Where climate change may be most prominent in the 21 st century. Geophysical Research Letters. 34(1):L01705

Blaustein AR, Walls SC, Bancroft BA, Lawler JJ, Searle CL, Gervasi SS. 2010. Direct and indirect effects of climate change on amphibian populations. Diversity. 2(2):281-313

Beaupre SJ. 2005. Ratio representations of specific dynamic action (mass-specific SDA and SDA coefficient) do not standardize for body mass and meal size. Physiological and Biochemical Zoology. 78(1):126-31

Beck C, Congdon J. 2000. Effects of age and size at metamorphosis on performance and metabolic rates of southern toad, Bufo terrestris, metamorphs. Functional Ecology. 14:32-38

Bennett AF. 1978. Activity metabolism of the lower vertebrates. Annual Review of Physiology. 40:447-69

Born M, Bongers F, Poelman EH, Sterck FJ. 2010. Dry-season retreat and dietary shift of the dart-poison frog Dendrobates tinctorius (Anura: Dendrobatidae). Phyllomedusa. 9(1):37

Boratyński Z, Koskela E, Mappes T, Schroderus E. 2013. Quantitative genetics and fitness effects of basal metabolism. Evolutionary Ecology. 27(2):301-14

Bovo RP, Navas CA, Tejedo M, Valença SES, Gouveia SF. 2018. Ecophysiology of amphibians: Information for best mechanistic models. Diversity. 10(4):1-14

Bradford DF. 1983. Winterkill, oxygen relations, and energy metabolism of a submerged dormant amphibian, Rana muscosa. Ecology. 64(5):1171-83

Brito D. 2008. Amphibian conservation: Are we on the right track? Biological Conservation. 141(11):2912-17

Brown AV, Fitzpatrick LC. 1981. Thermal acclimation and metabolism in the graybellied salamander, Eurycea multiplicata griseogaster (Plethodontidae). Comparative Biochemistry and Physiology Part A: Physiology. 69(3):505-9

Brown JH, Gillooly JF, Allen AP, Savage VM, West GB. 2004. Toward a metabolic theory of ecology. Ecology. 85(7):1771-89 
Bucher TL, Ryan MJ, Bartholomew GA. 1982. Oxygen consumption during resting, calling, and nest building in the frog Physalaemus pustulosus. Physiological Zoology. 55(1):10-22

Burggren WW, Just JJ. 1992. Developmental changes in physiological systems. In Environmental Physiology of the Amphibians, eds. ME Feder, WW Burggren, pp. 467-530. Chicago, Illinois, USA: The University of Chicago Press

Bushuev A V., Husby A, Sternberg H, Grinkov VG. 2012. Quantitative genetics of basal metabolic rate and body mass in free-living pied flycatchers. Journal of Zoology. 288(4):245-51

Careau V, Garland T, Jr. 2012. Performance, personality, and energetics: Correlation, causation, and mechanism. Physiological and Biochemical Zoology. 85(6):543-71

Careau V, Gifford ME, Biro PA. 2014. Individual (co)variation in thermal reaction norms of standard and maximal metabolic rates in wild-caught slimy salamanders. Functional Ecology. 28(5):1175-86

Careau V, Thomas D, Humphries MM, Réale D. 2008. Energy metabolism and animal personality. Oikos. 117(5):641-53

Careau V, Thomas D, Pelletier F, Turki L, Landry F, et al. 2011. Genetic correlation between resting metabolic rate and exploratory behaviour in deer mice (Peromyscus maniculatus). Journal of Evolutionary Biology. 24(10):2153-63

Carey C. 1979a. Aerobic and anaerobic energy expenditure during rest and activity in montane Bufo b. boreas and Rana pipiens. Oecologia. 39(2):213-28

Carey C. 1979b. Effect of constant and fluctuating temperatures on resting and active oxygen consumption of toads, Bufo boreas. Oecologia. 39(2):201-12

Carvalho JE, Navas CA, Pereira IC. 2010. Energy and water in aestivating amphibians. In Aestivation: Molecular and Physiological Aspects, eds. CA Navas, JE Carvalho, pp. 141-69. Heidelberg, Germany: Springer.

Chang Y-M, Lucy Hou P-C. 2005. Thermal acclimation of metabolic rate may be seasonally dependent in the subtropical anuran Latouche's frog (Rana latouchii, Boulenger). Physiological and Biochemical Zoology. 78(6):947-55

Chown SL, Gaston KJ. 1999. Exploring links between physiology and ecology at macroscales: The role of respiratory metabolism in insects. Biological Reviews. 74(1):87-120

Clarke A. 2003. Costs and consequences of evolutionary temperature adaptation. Trends in Ecology \& Evolution. 18(11):573-81 
Clarke A. 2006. Temperature and the metabolic theory of ecology. Functional Ecology. 20(2):405-12

Crump ML. 2015. Anuran reproductive modes: Evolving perspectives. Journal of Herpetology. 49(1):1-16

Cruz-Piedrahita C, Navas CA, Crawford AJ. 2018. Life on the edge: A comparative study of ecophysiological adaptations of frogs to tropical semiarid environments.

Physiological and Biochemical Zoology. 91(1):740-56

de Souza SCR, Kuribara CM. 2006. Metabolic scaling associated with unusual size changes during larval development of the frog, Pseudis paradoxus. Journal of Experimental Biology. 209:1651-61

del Rio CM. 2008. Metabolic theory or metabolic models? Trends in Ecology \& Evolution. 23(5):256-60

Deutsch CA, Tewksbury JJ, Huey RB, Sheldon KS, Ghalambor CK, et al. 2008. Impacts of climate warming on terrestrial ectotherms across latitude. Proceedings of the National Academy of Sciences of the United States of America. 105(18):6668-72

Di Marco M, Chapman S, Althor G, Kearney S, Besancon C, et al. 2017. Changing trends and persisting biases in three decades of conservation science. Global Ecology and Conservation. 10:32-42

Dillon ME, Wang G, Huey RB. 2010. Global metabolic impacts of recent climate warming. Nature. 467:704-6

Donnelly MA. 1991. Feeding patterns of the strawberry poison frog, Dendrobates pumilio (Anura: Dendrobatidae). Copeia. 1991(3):723-30

Dunlap DG. 1969. Influence of temperature and duration of acclimation, time of day, sex and body weight on metabolic rates in the hylid frog, Acris crepitans.

Comparative Biochemistry And Physiology. 31(4):555-70

Dunlap DG. 1972. Latitudinal effects on metabolic rates in the cricket frog, Acris crepitans: Acutely measured rates in summer frogs. The Biological Bulletin. 143(2):332-43

Dunlap DG. 1973. Latitudinal effects on metabolic rates in the frog, Acris crepitans: Seasonal comparisons. The Biological Bulletin. 145(1):103-18

Einum S, Fossen EIF, Parry V, Pélabon C. 2019. Genetic variation in metabolic rate and correlations with other energy budget components and life history in Daphnia magna. Evolutionary Biology. 46(2):170-78 
Etheridge K. 1990. The energetics of estivating sirenid salamanders (Siren lacertina and Pseudobranchus striatus). Herpetologica. 46(4):407-14

Feder ME. 1981. Effect of body size, trophic state, time of day, and experimental stress on oxygen consumption of anuran larvae: An experimental assessment and evaluation of the literature. Comparative Biochemistry and Physiology Part A: Physiology. 70(4):497-508

Feder ME, Burggren WW, eds. 1992. Environmental Physiology of the Amphibians. Chicago, Illinois, USA: The University of Chicago Press

Feder ME, Lynch JF. 1982. Effects of latitude, season, elevation, and microhabitat on field body temperatures of neotropical and temperate zone salamanders. Ecology. 63(6): 1657

Finkler MS. 2006. Effects of temperature, sex, and gravidity on the metabolism of smallmouthed salamanders, Ambystoma texanum, during the reproductive season. Journal of Herpetology. 40(1):103-6

Finkler MS, Cullum KA. 2002. Sex-related differences in metabolic rate and energy reserves in spring-breeding small-mouthed salamanders (Ambystoma texanum). Copeia. 2002(3):824-29

Finkler MS, Sugalski MT, Claussen DL. 2003. Sex-related differences in metabolic rate and locomotor performance in breeding spotted salamanders (Ambystoma maculatum). Copeia. 2003(4):887-93

Fitzpatrick LC. 1973. Energy allocation in the allegheny mountain salamander, Desmognathus ochrophaeus. Ecological Monographs. 43(1):43-58

Fitzpatrick LC, Bristol JR, Stokes RM. 1972. Thermal acclimation and metabolic rates in the dusky salamander Desmognathus fuscus. Comparative Biochemistry and Physiology Part A: Physiology. 41(1):89-96

Forster CE. 2013. Dehydration in southern toads (Anaxyrus terrestris): Metabolic costs and effects of temperature selection. Scripps Senior Theses 161

Fromm P, Johnson R. 1955. The respiratory metabolism of frogs as related to season. Journal of Cellular and Comparative Physiology. 45(3):343-59

Galloy V, Denoël M. 2010. Detrimental effect of temperature increase on the fitness of an amphibian (Lissotriton helveticus). Acta Oecologica. 36(2):179-83

Garland T Jr, Bennett AF. 1990. Quantitative genetics of maximal oxygen consumption in a garter snake. American Journal of Physiology-Regulatory, Integrative and Comparative Physiology. 259(5):R986-92 
Gatten RE Jr. 1987. Activity metabolism of anuran amphibians: Tolerance to dehydration. Physiological Zoology. 60(5):576-85

Gatten RE Jr., Miller KJ, Full RJ. 1992. Energetics at rest and during locomotion. In Environmental Physiology of the Amphibians, eds. ME Feder, WW Burggren, pp. 314-74. Chicago, Illinois, USA: The University of Chicago Press

Gehlbach FR, Gordon R, Jordan JB. 1973. Aestivation of the salamander, Siren intermedia. American Midland Naturalist. 89(2):455

Gifford ME, Clay TA, Careau V. 2014. Individual (co)variation in standard metabolic rate, feeding rate, and exploratory behavior in wild-caught semiaquatic salamanders. Physiological and Biochemical Zoology. 87(3):384-96

Gifford ME, Kozak KH. 2012. Islands in the sky or squeezed at the top? Ecological causes of elevational range limits in montane salamanders. Ecography. 35(3):193-203

Gil N, Katz U. 1996. Oxygen consumption, heart rate and respiratory movements are maintained almost unchanged in toads (Bufo viridis) on soil without access to free water. Journal of Arid Environments. 33(2):237-45

Gillooly JF, Brown JH, West GB, Savage VM, Charnov EL. 2001. Effects of size and temperature on metabolic rate. Science. 293:2248-51

Gillooly JF, Gomez JP, Mavrodiev EV. 2017. A broad-scale comparison of aerobic activity levels in vertebrates: Endotherms versus ectotherms. Proceedings of the Royal Society B: Biological Sciences. 284(1849):20162328

Gilman CA, Wolf BO. 2007. Use of portable ultrasonography as a nondestructive method for estimating reproductive effort in lizards. Journal of Experimental Biology. 210(11):1859-67

Gomes FR, Chaui-Berlinck JG, Bicudo JEPW, Navas CA. 2004. Intraspecific relationships between resting and activity metabolism in anuran amphibians: Influence of ecology and behavior. Physiological and Biochemical Zoology. 77(2):197-208

Gomez NA, Acosta M, Zaidan F, III, Lillywhite HB. 2006. Wiping behavior, skin resistance, and the metabolic response to dehydration in the arboreal frog Phyllomedusa hypochondrialis. Physiological and Biochemical Zoology. 79(6):1058-68

Groom DJE, Kuchel L, Richards JG. 2013. Metabolic responses of the South American ornate horned frog (Ceratophrys ornata) to estivation. Comparative Biochemistry and Physiology Part B: Biochemistry and Molecular Biology. 164(1):2-9 
Harlow HJ. 1977. Seasonal oxygen metabolism and cutaneous osmoregulation in the California newt, Taricha torosa. Physiological Zoology. 50(3):231-36

Hastings D, Burggren WW. 1995. Developmental changes in oxygen consumption regulation in larvae of the South African clawed frog Xenopus laevis. Journal of Experimental Biology. 198:2465-75

Hillman SS. 1987. Dehydrational effects on cardiovascular and metabolic capacity in two amphibians. Physiological Zoology. 60(5):608-13

Holtmann B, Lagisz M, Nakagawa S. 2017. Metabolic rates, and not hormone levels, are a likely mediator of between-individual differences in behaviour: A metaanalysis. Functional Ecology. 31(3):685-96

Huey RB, Kearney MR, Krockenberger A, Holtum JAM, Jess M, Williams SE. 2012. Predicting organismal vulnerability to climate warming: Roles of behaviour, physiology and adaptation. Philosophical Transactions of the Royal Society of London B: Biological Sciences. 367(1596):1665-79

Hutchison VH, Kohl MA. 1971. The effect of photoperiod on daily rhythms of oxygen consumption in the tropical toad, Bufo marinus. Zeitschrift für Vergleichende Physiologie. 75(4):367-82

Hutchison VH, Whitford WG, Kohl MA. 1968. Relation of body size and surface area to gas exchange in anurans. Physiological Zoology. 41(1):65-85

Isaac NJB, Carbone C. 2010. Why are metabolic scaling exponents so controversial? Quantifying variance and testing hypotheses. Ecology Letters. 13(6):728-35

Jameson DL, Taylor W, Mountjoy J. 1970. Metabolic and morphological adaptation to heterogenous environments by the Pacific tree toad, Hyla regilla. Evolution. 24(1):75-89

Janzen DH. 1967. Why mountain passes are higher in the tropics. American Naturalist. 101(919):233-49

Jørgensen CB. 1997. 200 years of amphibian water economy: From Robert Towns to the present. Biological Reviews. 72(2):153-237

Kayes SM, Cramp RL, Franklin CE. 2009. Metabolic depression during aestivation in Cyclorana alboguttata. Comparative Biochemistry and Physiology Part A:

Molecular \& Integrative Physiology. 154(4):557-63 
Kiss ACI, Carvalho JE, Navas CA, Gomes FR. 2009. Seasonal metabolic changes in a year-round reproductively active subtropical tree-frog (Hypsiboas prasinus). Comparative Biochemistry and Physiology Part A: Molecular \& Integrative Physiology. 152(2):182-88

Konarzewski M, Ksiązek A, Łapo IB. 2005. Artificial selection on metabolic rates and related traits in rodents. Integrative and Comparative Biology. 45(3):416-25

Lawler JJ, Aukema JE, Grant JB, Halpern BS, Kareiva P, et al. 2006. Conservation science: A 20-year report card. Frontiers in Ecology and the Environment. 4(9):473-80

Leslie PH. 1945. On the use of matrices in certain population mathematics. Biometrika. 33(3):183-212

Leslie PH. 1948. Some further notes on the use of matrices in population mathematics. Biometrika. 35(3):213-45

Longphre M, Gatten RE Jr. 1994. Individual variability in sustained performance, aerobic metabolism, oxygen transport, and enzyme activity in toads (Bufo marinus). Copeia. 1994(4):887-96

Louppe V, Courant J, Videlier M, Herrel A. 2018. Differences in standard metabolic rate at the range edge versus the center of an expanding invasive population of Xenopus laevis in the West of France. Journal of Zoology. 305(3):163-72

Loveridge JP, Withers PC. 1981. Metabolism and water balance of active and cocooned African bullfrogs Pyxicephalus adspersus. Physiological Zoology. 54(2):203-14

Lucas LD, French SS. 2012. Stress-induced tradeoffs in a free-living lizard across a variable landscape: Consequences for individuals and populations. PLOS ONE. 7(11):e49895

Marquet PA, Labra FA, Maurer BA. 2004. Metabolic ecology: Linking individuals to ecosystems. Ecology. 85(7):1794-96

Martin LJ, Blossey B, Ellis E. 2012. Mapping where ecologists work: Biases in the global distribution of terrestrial ecological observations. Frontiers in Ecology and the Environment. 10(4):195-201

Mathot KJ, Martin K, Kempenaers B, Forstmeier W. 2013. Basal metabolic rate can evolve independently of morphological and behavioural traits. Heredity. 111(3):175-81

Mattila ALK, Hanski I. 2014. Heritability of flight and resting metabolic rates in the Glanville fritillary butterfly. Journal of Evolutionary Biology. 27(8):1733-43 
McCain CM. 2009. Vertebrate range sizes indicate that mountains may be "higher" in the tropics. Ecology Letters. 12(6):550-60

Merkle S, Hanke W. 1988. Long-term starvation in Xenopus laevis Daudin - I. Effects on general metabolism. Comparative Biochemistry and Physiology. 89(4):719-30

Miller K, Hutchison VH. 1979. Activity metabolism in the mudpuppy, Necturus maculosus. Physiological Zoology. 52(1):22-37

Mokhatla M, Measey J, Smit B. 2019. The role of ambient temperature and body mass on body temperature, standard metabolic rate and evaporative water loss in southern African anurans of different habitat specialisation. PeerJ. 7:e7885

Muir TJ, Costanzo JP, Lee RE. 2007. Osmotic and metabolic responses to dehydration and urea-loading in a dormant, terrestrially hibernating frog. Journal of Comparative Physiology B: Biochemical, Systemic, and Environmental Physiology. 177(8):917-926

Muir TJ, Costanzo JP, Lee RE. 2010. Evidence for urea-induced hypometabolism in isolated organs of dormant ectotherms. Journal of Experimental Zoology Part A: Ecological Genetics and Physiology. 313(1 A):28-34

Navas CA. 1996. Metabolic physiology, locomotor performance, and thermal niche breadth in Neotropical anurans. Physiological Zoology. 69(6):1481-1501

Navas CA, Antoniazzi MM, Jared C. 2004. A preliminary assessment of anuran physiological and morphological adaptation to the Caatinga, a Brazilian semi-arid environment. International Congress Series. 1275:298-305

Nespolo RF, Bustamante DM, Bacigalupe LD, Bozinovic F. 2005. Quantitative genetics of bioenergetics and growth-related traits in the wild mammal, Phyllotis darwini. Evolution. 59(8):1829-37

Nespolo RF, Figueroa J, Solano-Iguaran JJ. 2017. Studying the evolutionary significance of thermal adaptation in ectotherms: The diversification of amphibians' energetics. Journal of Thermal Biology. 68:5-13

Nilsson JÅ, Åkesson M, Nilsson JF. 2009. Heritability of resting metabolic rate in a wild population of blue tits. Journal of Evolutionary Biology. 22(9):1867-74

Norin T, Metcalfe NB. 2019. Ecological and evolutionary consequences of metabolic rate plasticity in response to environmental change. Philosophical Transactions of the Royal Society of London B: Biological Sciences. 374:20180180 
Novarro AJ, Gabor CR, Goff CB, Mezebish TD, Thompson LM, Grayson KL. 2018. Physiological responses to elevated temperature across the geographic range of a terrestrial salamander. Journal of Experimental Biology. 221(18):jeb178236

Ochoa-Ochoa LM, Mejía-Domínguez NR, Velasco JA, Marske KA, Rahbek C. 2019. Amphibian functional diversity is related to high annual precipitation and low precipitation seasonality in the New World. Global Ecology and Biogeography. 28(9):1219-29

Oishi T, Nagai K, Harada Y, Naruse M, Ohtani M, et al. 2004. Circadian rhythms in amphibians and reptiles: Ecological implications. Biological Rhythm Research. 35(1):105-20

Otto SP, Day T. 2007. A Biologist's Guide to Mathematical Modeling in Ecology and Evolution. Princeton, New Jersey, USA: University Press

Overgaard J, Andersen JL, Findsen A, Pedersen PBM, Hansen K, et al. 2012. Aerobic scope and cardiovascular oxygen transport is not compromised at high temperatures in the toad Rhinella marina. Journal of Experimental Biology. 215:3519-26

Pandian TJ, Marian MP. 1985. Time and energy costs of metamorphosis in the Indian bullfrog Rana tigrina. Copeia. 1985(3):653

Peterson CC, Walton BM, Bennett AF. 1999. Metabolic costs of growth in free-living garter snakes and the energy budgets of ectotherms. Functional Ecology. 13(4):500-507

Pinder AW, Friet SC. 1994. Oxygen transport in egg masses of the amphibians Rana sylvatica and Ambystoma maculatum: Convection, diffusion and oxygen production by algae. Journal of Experimental Biology. 197:17-30

Pinder AW, Storey KB, Ultsch GR. 1992. Estivation and hibernation. In Environmental Physiology of the Amphibians, eds. ME Feder, WW Burggren, pp. 150-274. Chicago, Illinois, USA: The University of Chicago Press

Pizzatto L, Child T, Shine R. 2008. Why be diurnal? Shifts in activity time enable young cane toads to evade cannibalistic conspecifics. Behavioral Ecology. 19(5):990-97

Pough FH. 1980. The advantages of ectothermy for tetrapods. American Naturalist. 115(1):92-112

Pough FH. 1983. Amphibians and reptiles as low-energy systems. In Behavioral Energetics: The Cost of Survival in Vertebrates, eds. WP Aspey, SI Lustick, pp. 141-88. Columbus, Ohio, USA: Ohio State University Press 
Pough FH, Kamel S. 1984. Post-metamorphic change in activity metabolism of anurans in relation to life history. Oecologia. 65(1):138-44

Pough FH, Magnusson WE, Ryan MJ, Wells KD, Taigen TL. 1992. Behavioral energetics. In Environmental Physiology of the Amphibians, eds. ME Feder, WW Burggren, pp. 395-436. Chicago, Illinois, USA: The University of Chicago Press

Pough FH, Taigen TL. 1990. Metabolic correlates of the foraging and social behaviour of dart-poison frogs. Animal Behaviour. 39(1):145-55

Pough FH, Taigen TL, Stewart MM, Brussard PF. 1983. Behavioral modification of evaporative water loss by a Puerto Rican frog. Ecology. 64(2):244-52

Prates I, Angilleta Jr. MJ, Wilson RS, Niehaus AC, Navas CA. 2013. Dehydration hardly slows hopping toads (Rhinella granulosa) from xeric and mesic environments. Physiological and Biochemical Zoology. 86(4):451-57

Preest MR, Brust DG, Wygoda ML. 1992. Cutaneous water loss and the effects of temperature and hydration state on aerobic metabolism of canyon treefrogs, Hyla arenicolor. Herpetologica. 48(2):210-19

Preest MR, Pough FH. 2003. Effects of body temperature and hydration state on organismal performance of toads, Bufo americanus. Physiological and Biochemical Zoology. 76(2):229-39

Refinetti R. 2016. Circadian Physiology. Boca Raton, Florida, USA: CRC Press. 3rd ed.

Roche DG, Careau V, Binning SA. 2016. Demystifying animal 'personality' (or not): Why individual variation matters to experimental biologists. Journal of Experimental Biology. 219(24):3832-43

Rønning B, Jensen H, Moe B, Bech C. 2007. Basal metabolic rate: Heritability and genetic correlations with morphological traits in the zebra finch. Journal of Evolutionary Biology. 20(5):1815-22

Rowe CL, Funck SA. 2017. Respiration rates of larval Cope's gray tree frogs (Hyla chrysoscelis) across a range in temperatures. Journal of Herpetology. 51(1):13033

Sadowska ET, Labocha MK, Baliga K, Stanisz A, Wróblewska AK, et al. 2005. Genetic correlations between basal and maximum metabolic rates in a wild rodent: Consequences for evolution of endothermy. Evolution. 59(3):672-81

Sanabria EA, Rodríguez CY, Vergara C, Ontivero E, Banchig M, et al. 2015. Thermal ecology of the post-metamorphic Andean toad (Rhinella spinulosa) at elevation in the Monte Desert, Argentina. Journal of Thermal Biology. 52:52-57 
Santos JC, Cannatella DC. 2011. Phenotypic integration emerges from aposematism and scale in poison frogs. Proceedings of the National Academy of Sciences of the United States of America. 108(15):6175-80

Schiesari L, Grillitsch B, Grillitsch H. 2007. Biogeographic biases in research and their consequences for linking amphibian declines to pollution. Conservation Biology. 21(2):465-71

Secor SM. 2001. Regulation of digestive performance: A proposed adaptive response. Comparative Biochemistry and Physiology Part A: Molecular \& Integrative Physiology. 128(3):565-77

Secor SM. 2005. Physiological responses to feeding, fasting and estivation for anurans. Journal of Experimental Biology. 208(13):2595-2609

Secor SM. 2009. Specific dynamic action: A review of the postprandial metabolic response. Journal of Comparative Physiology B: Biochemical, Systemic, and Environmental Physiology. 179(1):1-56

Seebacher F, Franklin CE. 2011. Physiology of invasion: Cane toads are constrained by thermal effects on physiological mechanisms that support locomotor performance. Journal of Experimental Biology. 214(Pt 9):1437-44

Senzano LM, Andrade DV. 2018. Temperature and dehydration effects on metabolism, water uptake and the partitioning between respiratory and cutaneous evaporative water loss in a terrestrial toad. Journal of Experimental Biology. 221(24):jeb188482

Seymour RS. 1973. Energy metabolism of dormant spadefoot toads (Scaphiopus). Copeia. 1973(3):435

Sherman E, Stadlen SG. 1986. The effect of dehydration on rehydration and metabolic rate in a lunged and a lungless salamander. Comparative Biochemistry and Physiology Part A: Physiology. 85(3):483-87

Stefanski M, Gatten REJ, Pough FH. 1989. Activity metabolism of salamanders: Tolerance to dehydration. Journal of Herpetology. 23(1):45

Stiffler DF, Talbot CR. 2000. Exchanges of oxygen, carbon dioxide, nitrogen and water in the caecilian Dermophis mexicanus. Journal of Comparative Physiology - B Biochemical, Systemic, and Environmental Physiology. 170(7):505-9

Storey KB, Storey JM. 1990. Metabolic rate depression and biochemical adaptation in anaerobiosis, hibernation and estivation. The Quarterly Review of Biology. 65(2):145-74 
Sunday JM, Bates AE, Dulvy NK. 2011. Global analysis of thermal tolerance and latitude in ectotherms. Proceedings of the Royal Society B: Biological Sciences. 278(1713):1823-30

Sunday JM, Bates AE, Kearney MR, Colwell RK, Dulvy NK, et al. 2014. Thermal-safety margins and the necessity of thermoregulatory behavior across latitude and elevation. Proceedings of the National Academy of Sciences of the United States of America. 111(15):5610-15

Taigen TL, Emerson SB, Pough FH. 1982. Ecological correlates of anuran exercise physiology. Oecologia. 52(1):49-56

Taigen TL, Pough FH. 1981. Activity metabolism of the toad (Bufo americanus): Ecological consequences of ontogenetic change. Journal of Comparative Physiology B: Biochemical, Systemic, and Environmental Physiology. 144(2):247-52

Taigen TL, Pough FH. 1983. Prey preference, foraging behavior, and metabolic characteristics of frogs. American Naturalist. 122(4):509-20

Taigen TL, Pough FH. 1985. Metabolic correlates of anuran behavior. Integrative and Comparative Biology. 25(4):987-97

Taigen TL, Wells KD. 1985. Energetics of vocalization by an anuran amphibian (Hyla versicolor). Journal of Comparative Physiology B. 155(2):163-70

Taigen TL, Wells KD, Marsh RL. 1985. The enzymatic basis of high metabolic rates in calling frogs. Physiological Zoology. 58(6):719-26

Tashian RE, Ray C. 1957. The relation of oxygen consumption to temperature in some tropical, temperate and boreal anuran amphibians. Zoologica: New York Zoological Society. 42(5):63-68

Tattersall GJ, Ultsch GR. 2008. Physiological ecology of aquatic overwintering in ranid frogs. Biological Reviews. 83(2):119-40

Tewksbury JJ, Huey RB, Deutsch CA. 2008. Putting the heat on tropical animals. Science. 320(5881):1296-97

Tsuji JS. 1988. Thermal acclimation of metabolism in Sceloporus lizards from different latitudes. Physiological Zoology. 61(3):241-53

Turney LD, Hutchison VH. 1974. Metabolic scope, oxygen debt and the diurnal oxygen consumption cycle of the leopard frog, Rana pipiens. Comparative Biochemistry and Physiology Part A: Physiology. 49(3):583-601 
van Beurden EK. 1980. Energy metabolism of dormant Australian water-holding frogs (Cyclorana platycephalus). Copeia. 1980(4):787

van der Meer J. 2006. Metabolic theories in ecology. Trends in Ecology \& Evolution. 21(3):136-40

Wack CL, DuRant SE, Hopkins WA, Lovern MB, Feldhoff RC, Woodley SK. 2012. Elevated plasma corticosterone increases metabolic rate in a terrestrial salamander. Comparative Biochemistry and Physiology Part A: Molecular \& Integrative Physiology. 161(2):153-58

Warkentin KM. 2011. Plasticity of hatching in amphibians: Evolution, trade-offs, cues and mechanisms. Integrative and Comparative Biology. 51:111-27

Weathers WW, Snyder GK. 1977. Relation of oxygen consumption to temperature and time of day in tropical anuran amphibians. Australian Journal of Zoology. 25(1):1-7

Wells KD. 2007. The Ecology and Behavior of Amphibians. Chicago, Illinois, USA: The University of Chicago Press

Wells KD, Taigen TL. 1984. Reproductive behavior and aerobic capacities of male American toads (Bufo americanus): Is behavior constrained by physiology? Herpetologica. 40(3):292-98

White CR, Phillips NF, Seymour RS. 2006. The scaling and temperature dependence of vertebrate metabolism. Biology Letters. 2(1):125-27

Whitford WG. 1973. The effects of temperature on respiration in the Amphibia. Integrative and Comparative Biology. 13(2):505-12

Whitford WG, Hutchison VH. 1965. Effect of photoperiod on pulmonary and cutaneous respiration in the spotted salamander, Ambystoma maculatum. Copeia. 1965(1):53

Whitford WG, Meltzer KH. 1976. Changes in $\mathrm{O}_{2}$ consumption, body water and lipid in burrowed desert juvenile anurans. Herpetologica. 32(1):23-25

Wieser W. 1994. Cost of growth in cells and organisms: General rules and comparative aspects. Biological Reviews. 69(1):1-33

Wilkinson M, Nussbaum RA. 1997. Comparative morphology and evolution of the lungless caecilian Atretochoana eiselti (Taylor) (Amphibia: Gymnophiona: Typhlonectidae). Biological Journal of the Linnean Society. 62(1):39-109

Winter M, Fiedler W, Hochachka WM, Koehncke A, Meiri S, De la Riva I. 2016. Patterns and biases in climate change research on amphibians and reptiles: A systematic review. Royal Society Open Science. 3(9):160158 
Withers PC. 1993. Metabolic depression during aestivation in the Australian frogs, Neobatrachus and Cyclorana. Australian Journal of Zoology. 41(5):467-73

Wone B, Sears MW, Labocha MK, Donovan ER, Hayes JP. 2009. Genetic variances and covariances of aerobic metabolic rates in laboratory mice. Proceedings of the Royal Society B: Biological Sciences. 276(1673):3695-3704

Woodley SK. 2017. Life in the slow lane: Stress responses in plethodontid salamanders. Herpetologica. 73(3):259-68

Žagar A, Carretero MA, Marguč D, Simčič T, Vrezec A. 2018. A metabolic syndrome in terrestrial ectotherms with different elevational and distribution patterns. Ecography. 41(10):1728-39

Zub K, Piertney S, Szafrańska PA, Konarzewski M. 2012. Environmental and genetic influences on body mass and resting metabolic rates (RMR) in a natural population of weasel Mustela nivalis. Molecular Ecology. 21(5):1283-93 


\title{
CHAPTER II: CIRCADIAN RHYTHMS IN RESTING METABOLIC RATE AMONG TROPICAL LOWLAND AMPHIBIAN FAMILIES
}

\begin{abstract}
Most organisms have circadian rhythms that synchronize a variety of organismal processes to each other as well as to external environmental factors such as light and temperature. Early work on amphibian metabolism demonstrated that time of day and photoperiod can have important effects on amphibian metabolism, yet little work has examined circadian rhythms of amphibian metabolism in a comparative framework and many studies do not report time of day of measurements. I measure resting metabolic rates of 11 species of amphibians in six families and two orders (including one salamander) every three hours for 24 hour periods. Comparisons among families indicate that there are important differences in average metabolic rates, amplitude of diel rhythms, and timing of metabolic maxima. The time of day at which the maxima in resting metabolic rates occurs coincides with activity times for every species measured. Moreover, there are differences in the timing of maxima among nocturnal species, suggesting temporal partitioning of activity times in agreement with other findings from diverse amphibian communities. The circadian differences among families have important implications for study design, as single measurement times for both diurnal and nocturnal species may introduce significant biases.
\end{abstract}




\section{INTRODUCTION}

Most organisms exhibit diel patterns in activity, behavior, and physiological processes which are synchronized with daily cycles in environmental variation (Edery 2000; Johnston 2014). Circadian rhythms have been found to be widespread across a diversity of organisms, from unicellular prokaryotes to multicellular plants, animals, and fungi (Yerushalmi \& Green 2009). The nearly ubiquitous nature of circadian rhythms and their relationships across environments suggests that there is adaptive significance in the synchronization between organismal processes and environmental variability (Yerushalmi \& Green 2009). Circadian rhythms characterize patterns of a number of processes including activity, behavior, reproduction, thermoregulation, metabolism, and sleep (Refinetti 2016). The timing of rhythms is often integrated across a variety of processes, suggesting that coordination in timing among organismal processes is important (Yerushalmi \& Green 2009). In natural settings, the circadian rhythms of organisms are often entrained to diel patterns in environmental cues, notably light and temperature, but can also be affected by resources and stressors (Buchanan 1992). Understanding the timing and patterns of diel rhythms is important to understand the temporal relationships between ecology and environment for a variety of organisms.

Circadian rhythms are defined as endogenous (i.e., internally-generated) cycles of approximately 24-hour periods which are often synchronized to diel cycles of environmental factors such as light and temperature (Refinetti 2016). In natural environments, rhythms are often assumed to be endogenous in origin (i.e., "true" circadian rhythms) and entrained by daily cycles in environmental cues (Refinetti 2016). The entrainment of diel rhythms to daily cycles results in most observed diel rhythms to 
have periods, or cycle lengths, of 24 hours (Refinetti 2016). To determine if observed diel patterns are truly endogenous in origin, organisms must be placed in laboratory settings without any variation in any environmental cues (e.g., light, temperature, and resources) for extensive periods of time and the duration or "robustness" of rhythms must be observed (Refinetti et al. 2007). Except for some exceptional habitats (e.g., deep caves or deep aquatic environments), the laboratory settings used to determine endogenous rhythms are unrealistic and not encountered by the vast majority of organisms. Thus, in most ecological settings, "true" circadian rhythms are often indistinguishable from those driven entirely by environmental cues. In my study, the observed diel patterns are assumed to be circadian rhythms.

Amphibians have long been used as model organisms for the study of circadian rhythms in laboratory settings. Amphibians, as well as their tissues and organs, have been instrumental in elucidating the biochemical mechanisms and environmental variables that mediate circadian rhythms. The internal 'clock' of amphibians is controlled by a variety of interacting genes, hormones, and proteins to regulate the timing of internal rhythms (see Cahill 2002 for a detailed review). The internal clock mechanisms, in turn, are entrained by environmental patterns of both light and temperature leading to synchronization between organismal rhythms and environmental cycles (Schneider 1971). Studies on amphibians in natural environments suggest that the diel rhythms may be further mediated by patterns in rainfall and humidity (Almeida-Gomes et al. 2007; Cui et al. 2011). For example, Navas (1996a) proposed that occasional diurnal activity of Eleutherodactylus bogotensis at high elevation is related to water availability. However, few studies explicitly link precipitation or humidity to daily rhythms and instead use 
these variables to predict general activity levels (Bider \& Morrison 1981; Buchanan 1992; Donnelly \& Guyer 1994; Graves 1999; Hatano et al. 2002; MacCulloch \& Bider 1975).

Comparatively little work has been conducted on the ecological aspects of circadian rhythms in amphibians. Most studies have examined how behavioral rhythms are related to reproduction and thermoregulation. During reproductive seasons, most male anurans call during distinct times of day. Diel patterns in calling can have single peaks during the 24 hour cycle (Runkle et al. 1994; Van Sluys et al. 2012), exhibit multiple peaks in calling times (most often bimodal; Almeida-Gomes et al. 2007; Cui et al. 2011; Van Sluys et al. 2012), or be relatively constant throughout long activity periods (Caldart et al. 2016; Hatano et al. 2002). Calling behavior can also vary consistently among individuals of the same species (Runkle et al. 1994; Shy 1985). Multiple diel peaks have been observed in a variety of behaviors in both anurans (Buchanan 1992; Hailman 1984) and salamanders (Griffiths 1985; Keen 1984; Nagai \& Oishi 1998). Thermoregulation, most often measured as thermal preference, also displays predictable diel patterns in amphibians (Hutchison \& Spriestersbach 1986; Navas 1996b). Most often, high temperatures are selected during active time periods, suggesting that there are different preferred temperatures for times of rest and times of activity. However, not all amphibians exhibit diel rhythms in thermoregulatory behavior (Casterlin \& Reynolds 1978, 1980; Mullens \& Hutchison 1992). Observed diel patterns of behavior are expected to be accompanied by metabolic cycles that facilitate energy availability during activity and conserve energy during times of rest. 
Unfortunately, little work has been conducted on the circadian rhythm of metabolism in amphibians. Circadian rhythms in metabolism are well-established in a variety of organisms including plants, invertebrates, reptiles, birds, and mammals (Refinetti 2016). Most amphibians which have been studied have displayed diel rhythms in resting metabolic rate (RMR), with high RMRs coinciding with activity times (Guimond \& Hutchison 1968; Hutchison \& Kohl 1971; Stern \& Mueller 1972; Turney \& Hutchison 1974). A lack of circadian rhythm in metabolism was found in the European blind cave salamander, which may be an adaptation to deep cave environments that often lack daily cycles of light, temperature, and resources (Hervant et al. 2000).

Circadian rhythms are expected to be adaptive in that they synchronize internal organismal processes with predictable changes in the external environment (Sharma 2003; Vaze \& Sharma 2013). Thus, differences in circadian rhythms, both seasonally and across taxa, are likely related to selective advantages for different diel rhythms (Vaze \& Sharma 2013). Several studies have observed that amphibian circadian rhythms can be relatively flexible within species both seasonally (Dolmen 2006; Dupont et al. 1979; Nagai \& Oishi 1998; Oishi et al. 2004) and ontogenetically (Dolmen 2006; Fitzgerald \& Bider 1974; Oishi et al. 2004; Pizzatto et al. 2008). Hervant et al. (2000) attributed differences in circadian rhythm between obligate and facultative cave-dwelling aquatic salamanders to ecological characteristics of their habitats. In caves, the lack of diel environmental cues and the low and discontinuous supply of resources selects for lowenergy adaptations. The lack of circadian rhythms in cave-dwelling organisms can be beneficial for maintaining low-energy states where resources may not follow predictable diel patterns (Hervant et al. 2000). The adaptive significance of the variety of circadian 
rhythms among taxa suggests that it is an important feature for understanding organismal biology and temporal coordination among various traits.

Herein, I characterize and compare the circadian rhythms of RMR of 11 species in six families of tropical amphibians. Circadian rhythms are fit to the data using cosinorbased rhythmometry and comparisons are made using three parameters of the cosinor models: MESOR, amplitude, and acrophase (Cornelissen 2014). The MESOR, or midline estimating statistic of rhythm, is the average RMR adjusted for circadian rhythm. The amplitude is a measure of the expected variability in circadian rhythm and half of the expected range in RMR across the diel cycle. The acrophase is a measure of the timing of peaks in circadian rhythm of RMR, in radians. The differences in the parameters of circadian rhythm are likely related to ecological differences among groups and have important implications in study design.

\section{METHODS}

\section{Study area and species}

The study was conducted at two locations in the foothills of the Andes of the Manu Biosphere Reserve in southeastern Peru. Villa Carmen Biological Station is located at 530 meters above sea level (m asl) and is composed of both secondary and primary rainforests. Manu Learning Centre is located at $460 \mathrm{~m}$ asl and is composed of secondary rainforests of various ages. Villa Carmen and Manu Learning Centre are 11.75 kilometers apart within the same river basin and have high species overlap (for map, see Chapter III, Figure 3.1). All species examined as part of my study can be found at both study locations. 
I sampled amphibians during visual encounter surveys (Crump \& Scott 1994) along trails and aquatic habitats. Amphibians were held for 18 to 24 hours before measurement to reduce handling stress, ensure hydration levels, reduce potential effects of past eating and activity, and to control thermal history before the measurement. Small amphibians were kept in plastic bags with plant material and sprayed with water to maintain hydration. Large amphibians were kept in perforated plastic containers to allow fresh air, with small amounts of water so animals could maintain hydration. All bags and containers were kept covered by cloth in shaded areas within covered, open-air facilities to reduce activity cues and maintain uniform thermal histories before measurements. All materials were washed and sterilized using $70 \%$ ethanol prior to reuse, a measure confirmed to be effective against most bacteria, fungi, and viruses, including Batrachochytrium dendrobatidis (Johnson et al. 2003; Phillott et al. 2010).

A total of 11 species from six families were selected for measurement of circadian rhythms of resting metabolic rate. Four to eight individuals were measured for each species, with most families represented by two species (Table 2.1). The six families included in my study are Bufonidae, Craugastoridae, Dendrobatidae, Hylidae, Leptodactylidae, and Plethodontidae and represent a broad range of size, morphology, physiology, behavior and life history. Furthermore, these families include many of the dominant species in amphibian assemblages throughout the Neotropics.

\section{Metabolic measurements}

I measured resting metabolic rates by monitoring changes in carbon dioxide $\left(\mathrm{CO}_{2}\right)$ using flow-through respirometry within a closed-loop system. Concentration of 
$\mathrm{CO}_{2}$ was measured using a Vaisala GMP 343 infrared gas analyzer (IRGA). Air was moved through the system using a diaphragm pump (LICOR 6262-04 reference pump) at a rate of 13.2 liters per hour. Air temperature and humidity were monitored using an Onset HOBO H08-004-02 Data Logger. As the humidity was generally high (97\% RH) and there were no rapid changes in temperature, air temperature was assumed to be a suitable measure of amphibian body temperature (Carey 1979a). A range of metabolic chambers were used to match amphibian size with the smallest chamber size available without restricting animal space or movement. The volume of metabolic chambers ranged from 200 to 1287 milliliters. Air pressure was measured using a Garmin 64s. The raw measurements of $\mathrm{CO}_{2}$ concentrations were converted to metabolic rates using the following equation modified from Lighton (2008):

$$
\dot{V}_{\mathrm{CO}_{2}}=\mathrm{FR} \times \mathrm{RT} \times \Delta \mathrm{CO}_{2}
$$

where $\dot{V}_{\mathrm{CO}_{2}}$ is the metabolic rate as measured by $\mathrm{CO}_{2}$ production $(\mathrm{mL} / \mathrm{hr}), F R$ is the flow rate of air through the system $(13,200 \mathrm{~mL} / \mathrm{hr}), R T$ is the response time of the entire system (hours), and $\triangle \mathrm{CO}_{2}$ is the change in $\mathrm{CO}_{2}$ concentration (fractional change per hour). Response time was calculated as the total volume of the system (all chambers and tubing) multiplied by the flow rate. All measurements were converted to standard temperature and pressure to facilitate comparisons among measurements and locations (Lighton 2008).

Amphibians were placed in chambers and monitored to ensure they were inactive for 20 minutes before the start of measurements. Cloth was used to cover the chambers to 
reduce visual stimulation of the animals, but still allowed observation of potential activity. Several metabolic chambers were used to allow multiple amphibians to come to rest and tubing connections were used to switch between metabolic chambers without moving the animals. Amphibian resting metabolic rate was measured for each individual every three hours, for ten-minute periods, for a total of eight measurements every 24 hours. The first measurement in the 24 hour time series occurred between 1800 and 0000 hours. Metabolic chambers were sterilized with $70 \%$ ethanol between measurements.

\section{Data analysis}

Measurements were binned by time using the following 3-hour divisions for measurements: 0000, 0300, 0600, 0900, 1200, 1500, 1800, and 2100 hours (h). The value of $0000 \mathrm{~h}$ refers to midnight. The value of each bin was taken as the midpoint of the time period for analysis (1.5 hours from each endpoint). Each measurement was corrected for both mass and temperature using phylogenetic generalized least squares (PGLS) regression. Observed RMR across the 24-hour period was examined for circadian rhythms at the species and family levels using cosinor-based rhythmometry. The period, or length of time, of the rhythm was assumed a priori to be 24 hours to allow fitting of the model to the data. The circadian rhythm was modeled as a cosinor function with three parameters: MESOR (midline estimating statistic of rhythm), a rhythm-adjusted mean of RMR for each group; amplitude, a measure of the magnitude of predictable change within a cycle, with two times the amplitude an estimate of expected diel range in RMR; and acrophase, a measure of the timing of overall high values of the diel cycle, in radians (Cornelissen 2014). The model can be written as: 


$$
R M R_{i}=M+A \cos \left(\theta_{i}+\phi\right)+e_{i}
$$

where $R M R_{i}$ is the expected resting metabolic rate of $i$ th measurement, corrected for mass and temperature, $M$ is the rhythm-adjusted mean (MESOR), $A$ is the amplitude, $\phi$ is the acrophase (radians), $e$ is the error term, and $\theta$ is equal to $2 \pi t_{i} / \tau$, where $\tau$ is the assumed period of 24 hours and $t_{i}$ is the time of the $i$ th measurement (hours). The modeled acrophase is converted from radians to the time of the maximum RMR $\left(T_{\phi}\right)$ using the equation:

$$
T_{\phi}=(-\tau / 2 \pi) / \phi
$$

where $\tau$ is the assumed period of 24 hours and $\phi$ is the acrophase (radians).

The parameters calculated from cosinor regression are only valid if the following assumptions are satisfied: (1) a reasonable fit between the model and the data, (2) a normal distribution of the residuals, (3) the variance is homogenous, (4) independence of residuals, and (5) the parameters are stationary through time. Model fits were calculated using an F-test, also known as a rhythm-detection test (Cornelissen 2014). Normality of residuals was examined using a Shapiro-Wilk test of normality (Royston 1995). Homogeneity of variance was tested using the Brown-Forsythe formulation of Levene's test for homogeneity of variances (Brown \& Forsythe 1974). Independence of residuals was tested using a runs test. Stationarity of cosinor parameters was assumed, as time series were not long enough to examine potential changes across days or seasons. The 
relatively low seasonal changes in both temperature and daylight in lowland tropical rainforests suggest that circadian rhythms are likely stable across the year for tropical lowland amphibians. The outlined assumptions are usually valid for "short and sparse time series" (Cornelissen 2014), and none of the assumptions were violated according to the tests outlined above. All analyses were conducted in R 3.6.1 (R Core Team 2019).

Comparisons among species within the same family were conducted to determine similarity within families. However, the results must be interpreted with caution as a result of poor model fits at the species level (see assumptions above). Further comparisons were restricted to the family level to increase sample sizes and is supported by the similarities among species within families (Table 2.2). The MESORs and amplitudes of families did not pass the test for normality using the Shapiro-Wilks test, so nonparametric Kruskal-Wallis tests were used to compare MESORs and amplitudes among families. Post-hoc comparisons among groups were conducted using a pairwise Wilcoxon rank sum test. The acrophases of families were compared using a circular ANOVA. The circular data for the acrophases passed both the assumptions of a von Mises distribution and uniformity of concentration parameters (Table 2.5). There are currently no post-hoc analyses formulated for circular ANOVA, and thus I conducted no pair-wise comparisons of acrophases. All analyses were conducted using the cosinor2 and circular packages in R 3.6.1 (R Core Team 2019).

\section{RESULTS}

The modeled circadian rhythms of species RMR agreed with predictions defined by activity periods (nocturnal vs. diurnal) without exception (Table 2.1). All nocturnal 
species were found to have maximum RMR between 2000 hours and 0300 hours. The two diurnal species (A. hahneli and A. macero) both have maxima between 0800 and 1200 hours. Interestingly, the maxima for most nocturnal species fall within the early evening (between 2000 and 0000 hours), while the only exceptions are both within the genus Pristimantis (P. ockendeni and P. reichlei with maxima of 0058 and 0236 hours, respectively). The comparisons of modeled circadian rhythm of RMR (estimated) to observed values show similar patterns in most species. Many nocturnal species display two distinct maxima of RMR throughout the evening, with acrophase calculations of the timing of maxima falling between the two peaks (Figure 2.1).

At the species level, the rhythm-detection tests for model fits generally result in non-significant fits with the exception of A. macero (Table 2.2). Marginally significant model-fits $(\alpha=0.1)$ were found in A. hahneli, P. vaillantii, and R. marina. Cosinor-based parameters were similar among species within families, supporting the combination of measurements within families. The rhythm-detection tests for families result in marginally significant fits of the cosinor functions $(\mathrm{p}<0.1)$ for all groups except for the salamanders of the family Plethodontidae (Table 2.3; Figure 2.2).

Data for the MESORs and the amplitudes within families did not pass tests of normality, and thus nonparametric tests were used for comparisons. The Kruskal-Wallis test demonstrates that there are significant differences in the MESORs, or rhythmadjusted mean RMRs, among families $\left(\chi^{2}=16.15, \mathrm{p}=0.006\right.$; Table 2.4). The pairwise Wilcoxon rank sum test finds that the significance is a result of differences between the anuran families and the salamander family Plethodontidae (Table 2.5 ), where 
salamanders have significantly lower MESOR of RMR than anurans (Table 2.3, Figure 2.2).

There was a large range of amplitudes (Table 2.3), with the highest amplitudes in the families Bufonidae and Dendrobatidae, and the lowest amplitude found in Plethodontidae. Differences in amplitude among families were not significant $\left(\chi^{2}=8.10\right.$, $\mathrm{p}=0.150 ;$ Table 2.4)

Most nocturnal families (Bufonidae, Hylidae, Leptodactylidae, and Plethodontidae) have circadian maxima of RMR between 2200 and 2300 hours (Table 2.3). The poison frogs in the family Dendrobatidae have a circadian maximum of RMR in the morning at 0942 hours. The litter frogs in the family Craugastoridae display a maximum RMR at 0149 hours. The circular ANOVA shows that there are significant differences in the acrophases among families (Table 2.4), although lack of a post-hoc test for circular ANOVA precludes analysis into which groups are statistically different from each other.

\section{DISCUSSION}

I demonstrate that tropical amphibians have marked circadian rhythms in RMR in southeastern Peru. Furthermore, I show that there are important, consistent differences in the parameters of circadian patterns among families. Patterns at the species and family levels have important implications for ecology and study design.

Within families, most species have similar parameters in circadian rhythm, although it is unclear what is driving similarities. Circadian rhythms could be similar for organisms that: (a) share a recent evolutionary history, or (b) share similar ecological 
characteristics. As evolutionary and ecological similarities are often correlated (closely related species are expected to be similar ecologically; Webb et al. 2002), it is difficult to distinguish how each factor contributes to observed patterns. In my study, the species within each family share various ecological traits, including activity times and habitat, and thus it is difficult to determine what drives similarities in circadian rhythms. The variability of circadian rhythms exhibited seasonally (Dolmen 2006; Dupont et al. 1979; Nagai \& Oishi 1998; Oishi et al. 2004), ontogenetically (Dolmen 2006; Fitzgerald \& Bider 1974; Oishi et al. 2004; Pizzatto et al. 2008), and among ecotypes (Hervant et al. 2000) suggests that there may be selective pressure for circadian rhythms to match ecological strategies. A potential approach to understand the evolutionary lability of circadian rhythms would be to select closely related species with contrasting ecological characteristics (such as in adaptive radiations) for further study.

The acrophase of circadian rhythm of RMR matched the activity period of each species analyzed, with diurnal and nocturnal species exhibiting daytime and nighttime maxima, respectively. There is a strong correlation between RMR and active metabolic rate, a relationship that has been proposed as a selective factor in the evolution of endothermy (Bennett \& Ruben 1979; Hayes \& Garland 1995; Nespolo et al. 2017). Thus, high RMR during active periods may correlate with high active metabolic rates and aerobic scope, which could be important for energetically intensive activities related to movement, foraging, calling, and reproduction (see Chapter IV for discussion).

Many amphibians from a variety of groups and habitats have been found to have bimodal patterns of activity (Almeida-Gomes et al. 2007; Buchanan 1992; Hailman 1984; Jaeger et al. 1976; Keen 1984; Van Sluys et al. 2012). Many nocturnal species in my 
study show evidence of bimodal peaks of RMR throughout the night (Figure 2.1), a pattern which is obscured at the family level (Figure 2.2). The small sample sizes within my study precludes a more detailed analysis of whether the circadian rhythms of RMR have multiple peaks. Additional work with large sample sizes and frequent sampling periods could explore the possibility of circadian rhythms in RMR having multiple peaks. The presence of multiple peaks in RMR would be expected to coincide with bimodal peaks of activity observed in many amphibians.

The RMRs of anurans were about two times higher than those of salamanders $(B$. altamazonica; Plethodontidae; Table 2.3), which agrees with many studies comparing RMR between anurans and salamanders (Gatten et al. 1992). The cosinor model of circadian rhythm in salamander had a relatively poor fit, although poor model fits may be a function of low sample size combined with the low amplitude of the observed circadian rhythm of RMR. The salamander B. altamazonica had the lowest amplitude of circadian rhythm in RMR out of all the species examined, which may be related to the low-energy adaptive zone characteristic of many salamanders (Hervant et al. 2000).

At the family level, the highest amplitudes were found in Bufonidae and Dendrobatidae. Many dendrobatids and bufonids are active foragers, highly toxic, and have complex reproductive behaviors (Carey 1979b; Donnelly 1991; Duellman 1992; Myers \& Daly 1983; Santos \& Cannatella 2011; Saporito et al. 2012), three characteristics which have been proposed as important correlates of high metabolic rates (Pough \& Taigen 1990; Taigen et al. 1982; Taigen \& Pough 1985). Several studies have suggested an association between toxicity and active metabolism and aerobic scope, often citing high values found in poison frogs (Santos \& Cannatella 2011). Alternative 
explanatory hypotheses for high metabolic rates include energetic requirements of various foraging behaviors (Pough \& Taigen 1990; Taigen \& Pough 1985; Taigen et al. 1982) and life history traits (Carey 1979b; Taigen et al. 1982). As many of these characteristics are highly correlated in amphibians (Santos \& Cannatella 2011), it is difficult to determine which factors may be proximate to high metabolic rates. The high amplitude of RMR in Bufonidae and Dendrobatidae may allow for high active metabolic rates (and thus increase energy availability) for active periods and behaviors (e.g., during foraging or reproduction) while conserving energy during periods of rest. The high active metabolic rates of Bufonidae and Dendrobatidae are likely associated with the high energetic demands of active foraging and may be part of the evolutionary integration found in a variety of actively foraging amphibians (e.g., high aerobic capacity, diet specialization, toxicity, and aposematism; Santos \& Cannatella 2011). In snakes and lizards, evolutionary integration has beeen observed in the coevolution of diet specialization (and diet-associated morphological traits; Bergmann et al. 2009; Meyers et al. 2006), foraging mode (Gasnier et al. 1994; Glaudas et al. 2019), and metabolic physiology (Andrews \& Pough 1985; Pough 1973). High metabolic rates during active periods are likely important for the evolution of active foraging and diet specialization across a broad range of taxa.

The circadian maxima of RMR in most nocturnal families (Bufonidae, Hylidae, Leptodactylidae, and Plethodontidae) occur between 2200 and 2300 hours (Table 2.3; Figure 2.2). The family Craugastoridae, however, exhibits a circadian maximum of RMR at a later time (0149 hours) than other nocturnal groups that could reflect a variety of potential factors. First, temporal partitioning could reduce predation pressure on the 
craugastorids. The frogs of family Craugastoridae are relatively small and later activity times could reduce predation pressure from some large species in the families Bufonidae, Leptodactylidae, and Hylidae. Similarly, the differences in activity times among life stages in amphibians has been proposed as a mechanism to decrease cannibalism between adults and juveniles and larvae (Oishi et al. 2004; Pizzatto et al. 2008). Second, many habitats are typically characterized by monotonic declines in temperature and increases in humidity throughout the night (Buchanan 1992). Thus, late activity times could reduce risk of desiccation, which could be important for the relatively small amphibians in the family Craugastoridae. Finally, many amphibians partition the acoustic landscape spatially, temporally, and through distinct calling characteristics (Wells 2007). Assuming the late time of maximal RMR in Craugastoridae coincides with reproductive behaviors, different activity times could facilitate temporal partitioning of calling among different species. Temporal partitioning of resources is expected in species rich communities and can help to promote coexistence between competitors as well as predators and prey (Kronfeld-Schor \& Dayan 2003). Each factor for differentiation of circadian rhythms need not operate individually, and any combination could select for distinct activity times in Craugastoridae as compared to other nocturnal amphibians.

Poison frogs of the family Dendrobatidae are diurnal and exhibit circadian maxima of RMR in the day (0934 hours; Table 2.3; Figure 2.2). While many studies have often demonstrated that poison frogs have elevated metabolic rates compared to other amphibians, my study found similar MESORs of RMR between dendrobatids and other anurans. Some methodological considerations may shed light into the discrepancy. First, my study only includes two dendrobatid species, which may have low RMRs relative to 
other poison frogs of the family Dendrobatidae. Several studies have found that there exists substantial variation in metabolic rates within the dendrobatid poison frogs (Santos \& Cannatella 2011; Taigen \& Pough 1983). Second, mass-scaling exponents are less than one for amphibians, meaning that mass-specific metabolic rates (metabolic rate divided by mass) are high for small amphibians. As a group, poison frogs are generally small, so the use of mass-specific metabolic rates in past studies would result in high values of RMR for poison frogs when compared to large amphibians, where I used mass-corrected RMR for comparisons. Third, there may be introduced biases if measurements are only recorded during the day (the active period of many humans). During the day, most poison frogs would be near their daily maximum RMR while nocturnal species would be near their minimum RMR as a result of different acrophases of circadian rhythms. It is difficult to ascertain the prevalence of a diurnal bias because, particularly in older studies, the time of measurements is often not reported (even when photoperiod is explicitly recorded). Finally, the relatively high RMRs often cited as a characteristic of Dendrobatidae could also be an artifact of comparisons between tropical and temperate species. Tropical amphibians are largely underrepresented in a variety of fields, and the general appeal of poison frogs may have promoted their overrepresentation in tropical studies of amphibians (pers. obs.). Thus, many taxonomic comparisons of metabolism in amphibians may be confounded by non-random sampling across latitude. Dendrobatidae is restricted to the Neotropics (Savage 1968), thus it is not possible to determine if poison frogs exhibit elevated metabolic rates in temperate latitudes. To determine if metabolic rates are relatively high for Dendrobatidae, further work should examine how the RMRs of dendrobatid frogs compare to other tropical species. 
The differences in the circadian rhythm of RMR among species and families have many important implications for study design. Metabolism is a fundamental process of ecology and is directly related to a variety of ecological characteristics of organisms (Brown et al. 2004; Sibly et al. 2012). Thus, patterns in metabolic rate could determine or affect the values, rhythms and patterns of a variety of other traits. Differences in circadian rhythms among species may confound interspecific comparisons that do not account for time of measurements and lead to erroneous conclusions. It is therefore important for ecological studies to consider the time of measurements to prevent potential biases in results. If studies only examine nocturnal and diurnal species, a potential solution would be to take measurements for both day and night and include time of measurement as a covariate or analyze each time period separately. However, many species are crepuscular, and my study finds that even nocturnal species may differ in times of maximal RMR (which is also possible for diurnal species). Moreover, some amphibians are known to shift activity periods seasonally or ontogenetically (Oishi et al. 2004; Pizzatto et al. 2008), and thus even within species there may be important variation to consider during study design and analysis. Additional work is needed to characterize the patterns of circadian rhythms across a broad diversity of amphibians, both in the laboratory and in the field, as well as how circadian rhythms may vary ontogenetically and seasonally.

\section{REFERENCES}

Almeida-Gomes M, Van Sluys M, Rocha CFD. 2007. Calling activity of Crossodactylus gaudichaudii (Anura: Hylodidae) in an Atlantic rainforest area at Ilha Grande, Rio de Janeiro, Brasil. Belgian Journal of Zoology. 137(2):203-7

Andrews RM, Pough FH. 1985. Metabolism of squamate reptiles: Allometric and ecological relationships. Physiological Zoology. 58(2):214-31 
Bennett AF, Ruben JA. 1979. Endothermy and activity in vertebrates. Science. 206:64954

Bergmann PJ, Meyers JJ, Irschick DJ. 2009. Directional evolution of stockiness coevolves with ecology and locomotion in lizards. Evolution. 63(1):215-27

Bider JR, Morrison KA. 1981. Changes in toad (Bufo americanus) responses to abiotic factors at the northern limit of their distribution. American Midland Naturalist. 106(2):293

Brown JH, Gillooly JF, Allen AP, Savage VM, West GB. 2004. Toward a metabolic theory of ecology. Ecology. 85(7):1771-89

Brown MB, Forsythe AB. 1974. Robust tests for the equality of variances. Journal of the American Statistical Association. 69(346):364-67

Buchanan BW. 1992. Bimodal nocturnal activity pattern of Hyla squirella. Journal of Herpetology. 26(4):521

Cahill GM. 2002. Circadian organization in fish and amphibians. In Biological Rhythms, pp. 120-28. Berlin, Heidelberg, Germany: Springer-Verlag

Caldart VM, Iop S, Lingnau R, Cechin SZ. 2016. Calling activity of a stream-breeding frog from the austral neotropics: Temporal patterns of activity and the role of environmental factors. Herpetologica. 72(2):90-97

Carey C. 1979a. Effect of constant and fluctuating temperatures on resting and active oxygen consumption of toads, Bufo boreas. Oecologia. 39(2):201-12

Carey C. 1979b. Aerobic and anaerobic energy expenditure during rest and activity in montane Bufo b. boreas and Rana pipiens. Oecologia. 39(2):213-28

Casterlin ME, Reynolds WW. 1978. Behavioural thermoregulation in Rana pipiens tadpoles. Journal of Thermal Biology. 3(3):143-45

Casterlin ME, Reynolds WW. 1980. Diel activity and thermoregulatory behavior of a fully aquatic frog: Xenopus laevis. Hydrobiologia. 75(2):189-91

Cordeiro GM, Paula GA, Botter DA. 1994. Improved likelihood ratio tests for dispersion models. International Statistical Review / Revue Internationale de Statistique. 62(2):257-74

Cornelissen G. 2014. Cosinor-based rhythmometry. Theoretical Biology and Medical Modelling. 11(1):16

Crump ML, Scott NJ Jr. 1994. Visual encounter surveys. In Measuring and Monitoring Biological Diversity: Standard Methods for Amphibians, eds. WR Heyer, MA 
Donnelly, RW McDiarmid, LC Hayek, MS Foster, pp. 84-92. Washington, DC: Smithsonian Institution Press

Cui J, Song X, Fang G, Xu F, Brauth SE, Tang Y. 2011. Circadian rhythm of calling behavior in the Emei music frog (Babina daunchina) is associated with habitat temperature and relative humidity. Asian Herpetological Research. 2(3):149-54

Dolmen D. 2006. Diel rhythms and microhabitat preference of the newts Triturus vulgaris and T. cristatus at the northern border of their distribution area. Journal of Herpetology. 17(1):23

Donnelly MA. 1991. Feeding patterns of the strawberry poison frog, Dendrobates pumilio (Anura: Dendrobatidae). Copeia. 1991(3):723-30

Donnelly MA, Guyer C. 1994. Patterns of reproduction and habitat use in an assemblage of Neotropical hylid frogs. Oecologia. 98(3-4):291-302

Duellman WE. 1992. Reproductive strategies of frogs. Scientific American. 267(1):80-87

Dupont W, Bourgeois P, Reinberg A, Vaillant R. 1979. Circannual and circadian rhythms in the concentration of corticosterone in the plasma of the edible frog (Rana esculenta L.). Journal of Endocrinology. 80(1):117-25

Edery I. 2000. Circadian rhythms in a nutshell. Physiological Genomics. 3(2):59-74

Fitzgerald GJ, Bider JR. 1974. Evidence of a relationship between age and activity in the toad Bufo americanus. Canadian Field-Naturalist. 88(September):499-501

Gasnier TR, Magnusson WE, Lima AP. 1994. Foraging activity and diet of four sympatric lizard species in a tropical rainforest. Journal of Herpetology. 28(2):187

Gatten RE Jr., Miller KJ, Full RJ. 1992. Energetics at rest and during locomotion. In Environmental Physiology of the Amphibians, eds. ME Feder, WW Burggren, pp. 314-74. Chicago, Illinois, USA: The University of Chicago Press

Glaudas X, Glennon KL, Martins M, Luiselli L, Fearn S, et al. 2019. Foraging mode, relative prey size and diet breadth: A phylogenetically explicit analysis of snake feeding ecology. Journal of Animal Ecology. 88(5):757-67

Graves BM. 1999. Diel activity patterns of the sympatric poison dart frogs, Dendrobates auratus and D. pumilio, in Costa Rica. Journal of Herpetology. 33(3):375

Griffiths RA. 1985. Diel profile of behaviour in the smooth newt, Triturus vulgaris (L.): An analysis of environmental cues and endogenous timing. Animal Behaviour. 33(2):573-82 
Guimond RW, Hutchison VH. 1968. The effect of temperature and photoperiod on gas exchange in the leopard frog, Rana pipiens. Comparative Biochemistry and Physiology. 27(1):177-95

Hailman JP. 1984. Bimodal nocturnal activity of the western toad (Bufo boreas) in relation to ambient illumination. Copeia. 1984(2):283

Hatano FH, Rocha CFD, Sluys M Van. 2002. Environmental factors affecting calling activity of a tropical diurnal frog (Hylodes phyllodes: Leptodactylidae). Journal of Herpetology. 36(2):314-18

Hayes JP, Garland T Jr. 1995. The evolution of endothermy: Testing the aerobic capacity model. Evolution. 49(5):836

Hervant F, Mathieu J, Durand JP. 2000. Metabolism and circadian rhythms of the European blind cave salamander Proteus anguinus and a facultative cave dweller, the Pyrenean newt (Euproctus asper). Canadian Journal of Zoology. 78:1427-32

Hutchison VH, Kohl MA. 1971. The effect of photoperiod on daily rhythms of oxygen consumption in the tropical toad, Bufo marinus. Zeitschrift für Vergleichende Physiologie. 75(4):367-82

Hutchison VH, Spriestersbach KK. 1986. Diel and seasonal cycles of activity and behavioral thermoregulation in the salamander Necturus maculosus. Copeia. 1986(3):612-18

Jaeger RG, Hailman JP, Jaeger LS. 1976. Bimodal diel activity of a Panamanian dendrobatid frog, Colostethus nubicola, in relation to light. Herpetologica. 32(1):77-81

Jammalamadaka SR, SenGupta A. 2001. Topics in Circular Statistics. Singapore: World Scientific

Johnson ML, Berger L, Philips L, Speare R. 2003. Fungicidal effects of chemical disinfectants, UV light, desiccation and heat on the amphibian chytrid Batrachochytrium dendrobatidis. Diseases of Aquatic Organisms. 57:255-60

Johnston JD. 2014. Physiological links between circadian rhythms, metabolism and nutrition. Experimental Physiology. 99(9):1133-37

Keen WH. 1984. Influence of moisture on the activity of a plethodontid salamander. Copeia. 1984(3):684

Kronfeld-Schor N, Dayan T. 2003. Partitioning of time as an ecological resource. Annual Review of Ecology, Evolution, and Systematics. 34(1):153-81 
Lighton JRB. 2008. Measuring Metabolic Rates: A Manual for Scientists. Oxford, UK: Oxford University Press

MacCulloch R, Bider, JR. 1975. Phenology, migrations, circadian rhythm and the effect of precipitation of the activity of Eurycea b. bislineata in Quebec. Herpetologica. 31(4):433-39

Mardia KV, Jupp PE. 2000. Directional Statistics. Chichester, West Sussex, UK: John Wiley \& Sons, Ltd

Meyers JJ, Herrel A, Nishikawa KC. 2006. Morphological correlates of ant eating in horned lizards (Phrynosoma). Biological Journal of the Linnean Society. 89(1):13-24

Mullens DP, Hutchison VH. 1992. Food-deprived thermoregulatory behaviour in tropical toads (Bufo marinus). Copeia. 17(1):63-67

Myers CW, Daly JW. 1983. Dart-poison frogs. Scientific American. 248(2):120-33

Nagai K, Oishi T. 1998. Behavioral rhythms of the Japanese newts, Cynops pyrrhogaster, under a semi-natural condition. International Journal of Biometeorology. 41(3):105-12

Navas CA. 1996a. The effect of temperature on the vocal activity of tropical anurans: A comparison of high and low-elevation species. Journal of Herpetology. 30(4):488-97

Navas CA. 1996b. Implications of microhabitat selection and patterns of activity on the thermal ecology of high elevation neotropical anurans. Oecologia. 108(4):617-26

Nespolo RF, Solano-Iguaran JJ, Bozinovic F. 2017. Phylogenetic analysis supports the aerobic-capacity model for the evolution of endothermy. American Naturalist. 189(1):13-27

Oishi T, Nagai K, Harada Y, Naruse M, Ohtani M, et al. 2004. Circadian rhythms in amphibians and reptiles: Ecological implications. Biological Rhythm Research. 35(1):105-20

Phillott AD, Speare R, Hines HB, Skerratt LF, Meyer E, et al. 2010. Minimising exposure of amphibians to pathogens during field studies. Diseases of Aquatic Organisms. 92(3):175-85

Pizzatto L, Child T, Shine R. 2008. Why be diurnal? Shifts in activity time enable young cane toads to evade cannibalistic conspecifics. Behavioral Ecology. 19(5):990-97

Pough FH. 1973. Lizard energetics and diet. Ecology. 54(4):837-44 
Pough FH, Taigen TL. 1990. Metabolic correlates of the foraging and social behaviour of dart-poison frogs. Animal Behaviour. 39(1):145-55

R Core Team. 2019. R: A language and environment for statistical computing. Vienna, Austria: R Foundation for Statistical Computing

Refinetti R. 2016. Circadian Physiology. Boca Raton, Florida, USA: CRC Press. 3rd ed.

Refinetti R, Cornélissen G, Halberg F. 2007. Procedures for numerical analysis of circadian rhythms. Biological Rhythm Research. 38(4):275-325

Royston P. 1995. Remark AS R94: A remark on algorithm AS 181: The W-test for normality. Applied Statistics. 44(4):547

Runkle LS, Wells KD, Robb CC, Lance SL. 1994. Individual, nightly, and seasonal variation in calling behavior of the gray tree frog, Hyla versicolor: Implications for energy expenditure. Behavioral Ecology. 5(3):318-25

Santos JC, Cannatella DC. 2011. Phenotypic integration emerges from aposematism and scale in poison frogs. Proceedings of the National Academy of Sciences of the United States of America. 108(15):6175-80

Saporito RA, Donnelly MA, Spande TF, Garraffo HM. 2012. A review of chemical ecology in poison frogs. Chemoecology. 22(3):159-68

Savage JM. 1968. The dendrobatid frogs of Central America. Copeia. 1968(4):745-76

Schneider H. 1971. Die steuerung des täglichen rufbeginns beim Laubfrosch, Hyla arborea arborea $(\mathrm{L}$.) (The control of the daily onset of calling activity in the tree frog, Hyla arborea arborea (L.)). Oecologia. 8(3):310-20

Sharma VK. 2003. Adaptive significance of circadian clocks. Chronobiology International. 20(6):901-19

Shy E. 1985. Individuality in the mating calls of the treefrog Hyla arborea savignyi. Amphibia-Reptilia. 6(4):343-53

Sibly RM, Brown JH, Kodric-Brown A. 2012. Metabolic Ecology: A Scaling Approach. Chichester, West Sussex, UK: Wiley-Blackwell

Stephens MA. 1970. Use of the Kolmogorov-Smirnov, Cramér-Von Mises and related statistics without extensive tables. Journal of the Royal Statistical Society: Series B. 32(1):115-22

Stern SL, Mueller CF. 1972. Diurnal variation in the oxygen consumption of Plethodon cinereus. American Midland Naturalist. 88(2):502 
Taigen TL, Emerson SB, Pough FH. 1982. Ecological correlates of anuran exercise physiology. Oecologia. 52(1):49-56

Taigen TL, Pough FH. 1983. Prey preference, foraging behavior, and metabolic characteristics of frogs. American Naturalist. 122(4):509-20

Taigen TL, Pough FH. 1985. Metabolic correlates of anuran behavior. Integrative and Comparative Biology. 25(4):987-97

Turney LD, Hutchison VH. 1974. Metabolic scope, oxygen debt and the diurnal oxygen consumption cycle of the leopard frog, Rana pipiens. Comparative Biochemistry and Physiology Part A: Physiology. 49(3):583-601

Van Sluys M, Marra RV, Boquimpani-Freitas L, Rocha CFD. 2012. Environmental factors affecting calling behavior of sympatric frog species at an Atlantic rain forest area, southeastern Brazil. Journal of Herpetology. 46(1):41-46

Vaze KM, Sharma VK. 2013. On the adaptive significance of circadian clocks for their owners. Chronobiology International. 30(4):413-33

Webb CO, Ackerly DD, McPeek MA, Donoghue MJ. 2002. Phylogenies and community ecology. Annual Review of Ecology and Systematics. 33:475-505

Wells KD. 2007. The Ecology and Behavior of Amphibians. Chicago, Illinois, USA: The University of Chicago Press

Yerushalmi S, Green RM. 2009. Evidence for the adaptive significance of circadian rhythms. Ecology Letters. 12(9):970-81 
Table 2.1. Sample size and average mass (standard error) of species included in the study. The family and activity times are listed for each species.

\begin{tabular}{|c|c|c|c|c|}
\hline Species & Family & Activity time & Sample size (n) & Average mass (g) \\
\hline Adenomera andreae & Leptodactylidae & Nocturnal & 8 & $1.27(0.09)$ \\
\hline Ameerega hahneli & Dendrobatidae & Diurnal & 5 & $0.58(0.02)$ \\
\hline Ameerega macero & Dendrobatidae & Diurnal & 5 & $1.85(0.06)$ \\
\hline Bolitoglossa altamazonica & Plethodontidae & Nocturnal & 5 & $0.99(0.05)$ \\
\hline Dendropsophus leucophyllatus & Hylidae & Nocturnal & 5 & $1.75(0.07)$ \\
\hline Hypsiboas geographicus & Hylidae & Nocturnal & 5 & $4.76(0.57)$ \\
\hline Leptodactylus rhodonotus & Leptodactylidae & Nocturnal & 4 & $31.80(4.32)$ \\
\hline Phyllomedusa vaillantii & Hylidae & Nocturnal & 4 & $3.56(0.37)$ \\
\hline Pristimantis ockendeni & Craugastoridae & Nocturnal & 4 & $0.40(0.02)$ \\
\hline Pristimantis reichlei & Craugastoridae & Nocturnal & 5 & $1.46(0.17)$ \\
\hline Rhinella marina & Bufonidae & Nocturnal & 5 & $57.09(5.14)$ \\
\hline
\end{tabular}


Table 2.2. Summary of model parameters and fits for cosinor-based models of circadian rhythm of resting metabolic rate (RMR), corrected for mass and temperature, for each amphibian species. The MESOR (midline estimating statistic of rhythm) is the rhythm-adjusted average RMR. The amplitude is a measure of the expected deviance of RMR from the MESOR as a result of circadian rhythm, and two times the amplitude is the expected circadian range in RMR. The acrophase, in radians, is a measure of the timing of peaks in circadian rhythm of RMR, and also has been converted to 24-hour format (Time of maximum). The results of a rhythm-detection test (Cornelissen 2014) include the $F$ statistic, degrees of freedom, and p-value.

\begin{tabular}{ccccccccccc}
\hline Species & Activity & MESOR & Amplitude & Acrophase & Time of maximum & F & df1 & df2 & p \\
\hline Adenomera andreae & nocturnal & 6.064 & 0.875 & -5.938 & $22: 41$ & 1.66 & 2 & 6 & 0.266 \\
Ameerega hahneli & diurnal & 5.900 & 0.643 & -2.924 & $11: 10$ & 10.35 & 2 & 3 & 0.045 & \\
Ameerega macero & diurnal & 4.712 & 1.410 & -2.317 & $08: 51$ & 32.62 & 2 & 3 & $0.009 * *$ \\
Bolitoglossa altamazonica & nocturnal & 2.644 & 0.277 & -5.805 & $22: 10$ & 2.08 & 2 & 3 & 0.271 \\
Dendropsophus leucophyllatus & nocturnal & 4.455 & 0.485 & -6.095 & $23: 17$ & 2.31 & 2 & 3 & 0.247 \\
Hypsiboas geographicus & nocturnal & 5.735 & 0.663 & -5.998 & $22: 55$ & 1.98 & 2 & 4 & 0.252 \\
Leptodactylus rhodonotus & nocturnal & 5.686 & 0.630 & -5.592 & $21: 22$ & 2.56 & 2 & 2 & 0.281 \\
Phyllomedusa vaillantii & nocturnal & 3.901 & 1.161 & -5.432 & $20: 45$ & 11.66 & 2 & 2 & 0.079 \\
Pristimantis ockendeni & nocturnal & 6.227 & 0.467 & -0.253 & $00: 58$ & 1.68 & 2 & 2 & 0.373 \\
Pristimantis reichlei & nocturnal & 5.396 & 0.332 & -0.681 & $02: 36$ & 1.16 & 2 & 4 & 0.400 \\
Rhinella marina & nocturnal & 5.640 & 1.091 & -5.998 & $22: 55$ & 5.20 & 2 & 3 & 0.106 \\
\hline
\end{tabular}

Levels of significance: $* \mathrm{p}<0.05 ; * * \mathrm{p}<0.01 ; * * * \mathrm{p}<0.001$. 
Table 2.3. Summary of model parameters and fits for cosinor-based models of circadian rhythm of resting metabolic rate (RMR), corrected for mass and temperature, for the compiled data of each amphibian family. The MESOR (midline estimating statistic of rhythm) is the rhythm-adjusted average RMR. The amplitude is a measure of the expected deviance of RMR from the MESOR as a result of circadian rhythm, and two times the amplitude is the expected circadian range in RMR. The acrophase, in radians, is a measure of the timing of peaks in circadian rhythm of RMR, and also has been converted to 24-hour format (Time of maximum). The results of a rhythm-detection test (Cornelissen 2014) include the $F$ statistic, degrees of freedom, and p-value.

\begin{tabular}{cccccccccc}
\hline Family & Activity & MESOR & Amplitude & Acrophase & Time of maximum & F & df1 & df2 & p \\
\hline Bufonidae & nocturnal & 5.640 & 1.091 & -5.998 & $22: 55$ & 5.202 & 2 & 3 & 0.106 \\
Craugastoridae & nocturnal & 5.728 & 0.377 & -0.474 & $01: 49$ & 2.782 & 2 & 8 & 0.121 \\
Dendrobatidae & diurnal & 5.306 & 0.986 & -2.504 & $09: 34$ & 14.362 & 2 & 8 & $0.002 * *$ \\
Hylidae & nocturnal & 4.819 & 0.704 & -5.783 & $22: 05$ & 8.895 & 2 & 13 & $0.004 * *$ \\
Leptodactylidae & nocturnal & 5.938 & 0.785 & -5.847 & $22: 20$ & 3.657 & 2 & 10 & 0.064 \\
Plethodontidae & nocturnal & 2.644 & 0.277 & -5.805 & $22: 10$ & 2.078 & 2 & 3 & 0.271 \\
\hline
\end{tabular}

Levels of significance: $* \mathrm{p}<0.05 ; * * \mathrm{p}<0.01 ; * * * \mathrm{p}<0.001$. 
Table 2.4. Results of comparisons of cosinor parameters of resting metabolic rate (RMR; mass and temperature-corrected) among families. MESOR is the rhythm-adjusted mean of RMR, amplitude is a measure of the daily variability of RMR as a result of circadian rhythm, and acrophase is a measure of the timing of the circadian maximum of RMR. The MESOR and amplitudes were compared using the non-parametric Kruskal-Wallis test. The acrophases were compared using a circular analysis of variance (ANOVA) using a likelihood ratio test with an approximate chi-squared distribution (Cordeiro et al. 1994).

\begin{tabular}{cccc}
\hline Parameter & Chi-squared & dF & p-value \\
\hline MESOR & 16.15 & 5 & $0.006^{* *}$ \\
Amplitude & 8.10 & 5 & 0.150 \\
Acrophase & 23.91 & 5 & $<0.001^{* * *}$ \\
\hline
\end{tabular}

Levels of significance: $* \mathrm{p}<0.05 ; * * \mathrm{p}<0.01 ; * * * \mathrm{p}<0.001$. 
Table 2.5. The results from the pairwise Wilcoxon rank sum test for the MESORs of RMR of each family. The only significant comparisons are between Plethodontidae and the other families.

\begin{tabular}{|c|c|c|c|c|c|}
\hline & Bufonidae & Craugastoridae & Dendrobatidae & Hylidae & Leptodactylidae \\
\hline Craugastoridae & 0.89 & & & & \\
\hline Dendrobatidae & 0.92 & 0.56 & & & \\
\hline Hylidae & 0.83 & 0.23 & 0.85 & & \\
\hline Leptodactylidae & 0.96 & 0.89 & 0.89 & 0.56 & \\
\hline Plethodontidae & $0.02 *$ & $0.00 * * *$ & $0.00 * * *$ & $0.00 * * *$ & $0.00 * * *$ \\
\hline
\end{tabular}


Table 2.6. Tests of assumptions for circular analysis of variance (ANOVA) of the acrophase of resting metabolic rate (RMR) for each family. The von Mises distribution is a continuous probability distribution analogous to the normal distribution formulated for circular data (Mardia and Jupp 2000). The Watson's goodness of fit test for the von Mises distribution (Stephens 1970; Jammalamadaka and SenGupta 2001) was used to demonstrate that the distribution of acrophase within each family was not significantly different from the assumed von Mises distribution for circular ANOVA. The test for homogeneity of concentration parameters (Mardia and Jupp 2000) was used to test the assumption of the same kappa $(\kappa)$ of the von Mises distribution among groups. All of the assumptions of the circular ANOVA were validated as a result of non-significant test results.

\begin{tabular}{ccc}
\hline \multicolumn{2}{c}{ Watson Test for goodness-of-fit tests for von Mises distribution } \\
Family & $\boldsymbol{W}^{2}$ & $\mathbf{p}$ \\
\hline Bufonidae & 0.0713 & $>0.10$ \\
Craugastoridae & 0.054 & $>0.10$ \\
Dendrobatidae & 0.0344 & $>0.10$ \\
Hylidae & 0.051 & $>0.10$ \\
Leptodactylidae & 0.0449 & $>0.10$ \\
Plethodontidae & 0.0389 & $>0.10$ \\
& & \\
Test for Homogeneity of Concentration Parameters & $\mathbf{p}$ \\
$\mathbf{d f}$ & $\chi^{2}$ & 0.2866 \\
5 & 6.206 &
\end{tabular}

Levels of significance: $* \mathrm{p}<0.05 ; * * \mathrm{p}<0.01 ; * * \mathrm{p}<0.001$. 

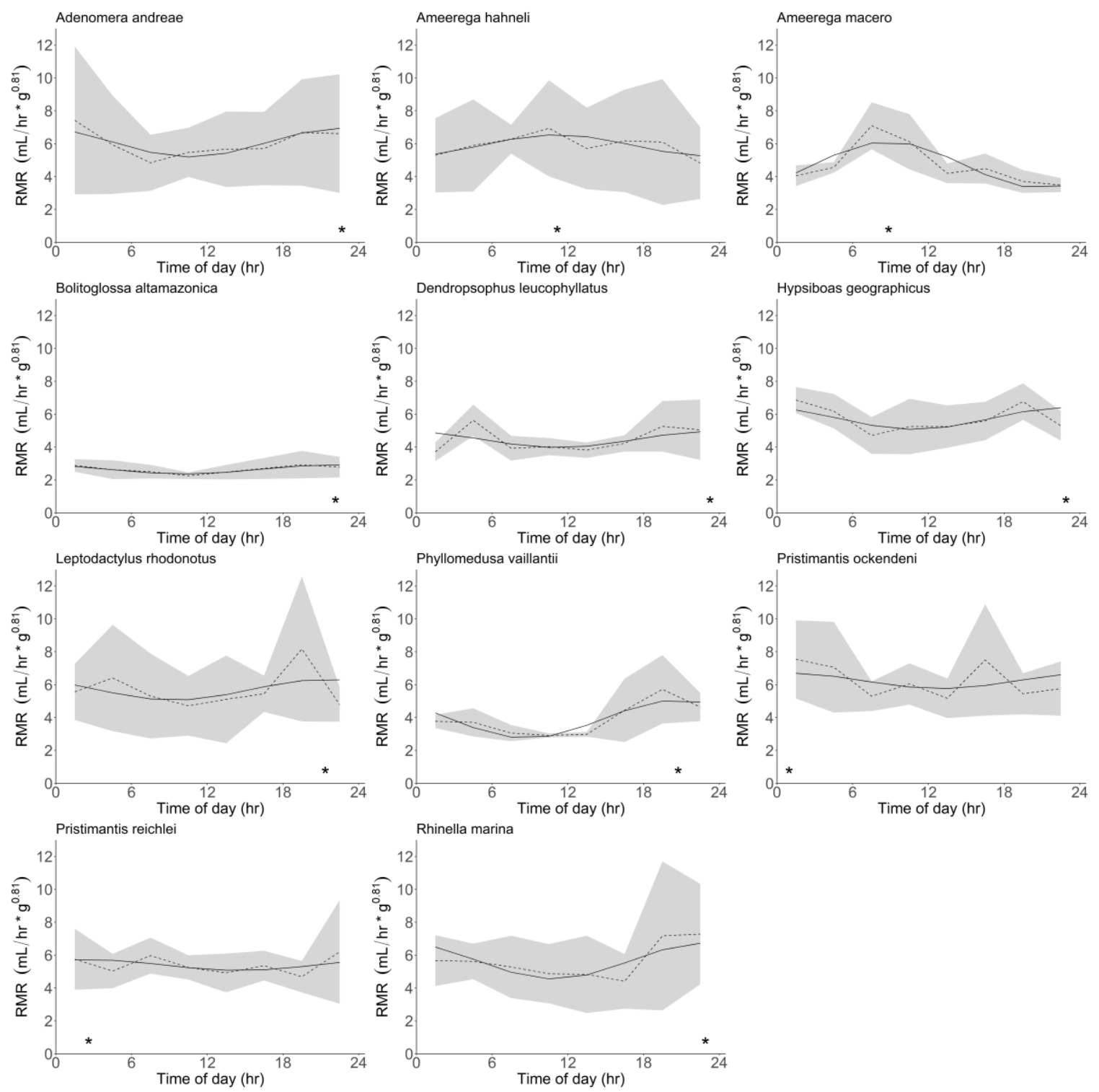

Figure 2.1. Observed (dotted) and model fitted (solid) and standard deviation (shaded) of the cosinor-based circadian rhythms in resting metabolic rate (RMR) for each study species. All RMRs were corrected for mass and temperature. The shaded area denotes a single standard deviation above and below observed values. The star (*) marks the time of the circadian maximum of RMR in each species. The parameters and tests for model fits for the cosinor models are summarized in Table 2.2. 

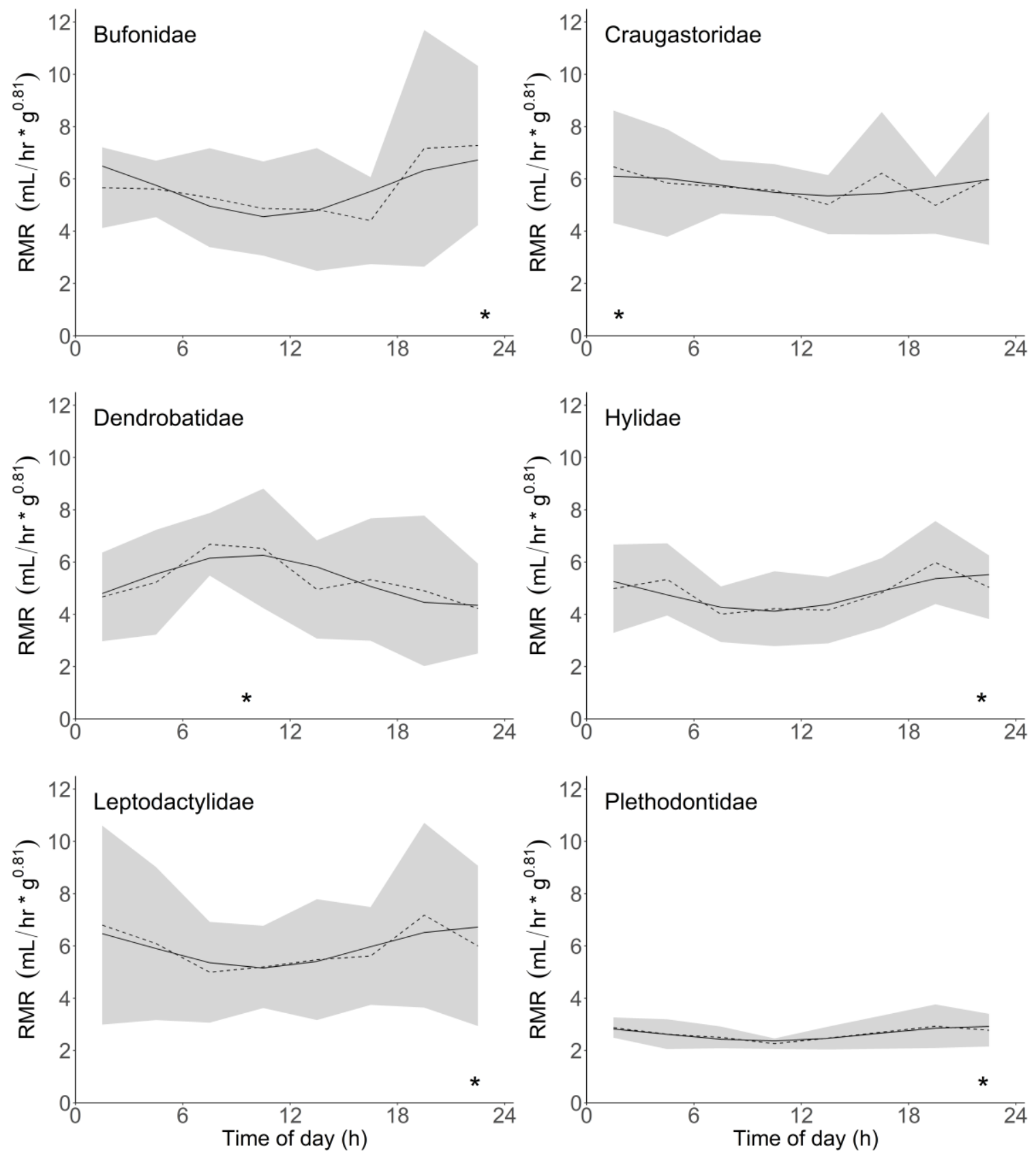

Figure 2.2. Observed (dotted) and model fitted (solid) and standard deviation (shaded) of the cosinor-based circadian rhythms in resting metabolic rate (RMR) for each tropical amphibian family. All RMRs were corrected for mass and temperature. The shaded area denotes a single standard deviation above and below observed values. The star $(*)$ marks the time of the circadian maximum of RMR in each family. The parameters and tests for model fits for the cosinor models for each family are summarized in Table 2.3. 


\title{
CHAPTER III. EVOLUTION AND VARIATION IN RESTING METABOLIC RATE ACROSS ELEVATION IN TROPICAL AMPHIBIANS
}

\begin{abstract}
Metabolism is a fundamental process of biology that is correlated with a variety of biological characteristics and processes. Metabolic rate is dependent on both mass and temperature, but there is confusion as to how metabolic relationships may apply across diverse taxa. In amphibians, many analyses often do not account for latitudinal, elevational, and phylogenetic variation in metabolic relationships which could have important implications for understanding vulnerability to climate change. I measured the resting metabolic rate of a large assemblage of tropical amphibians across a large elevational gradient to examine patterns of variation and to compare with previous studies. I used phylogenetic comparative methods to examine variation in mass-scaling exponents and thermal sensitivity of metabolism as well as to examine differences of mass and temperature-corrected resting metabolic rates among families and across elevation. I found that the thermal sensitivity of metabolism in tropical amphibians is considerably higher than has been found in other studies of predominantly temperate species. Furthermore, there appears to be an interaction between mass and temperature suggesting that small amphibians may be particularly vulnerable to metabolic impacts of increasing temperatures. There is important variation among families and across elevation in metabolic rate and thermal sensitivity which have important implications for predictions of metabolic impacts of climate change. My study suggests that using a single
\end{abstract}


metabolic relationship for all amphibians ignores important variation related to latitude, elevation, ecology, and evolutionary history.

\section{INTRODUCTION}

Metabolism is a fundamental process in biology that determines the rate at which organisms process energy and materials (Sibly et al. 2012). Metabolic characteristics broadly encompass basic energetic requirements, the capacity to increase metabolic production to meet demands, and how metabolic processes vary with organismal conditions (Bennett 1978). Metabolic traits are intimately tied to a variety of organismal processes that broadly encompass growth, maintenance, activity, and reproduction. Moreover, metabolic rates scale through various levels of biological organization from cellular processes to entire organisms to the processes of populations, communities and ecosystems (Sibly et al. 2012). A theoretical and mechanistic model of metabolism is necessary to be able to predict metabolic patterns and variation among organisms and across environments (Chown \& Gaston 1999) as well as to predict the potential metabolic impacts of anthropogenic climate change (Dillon et al. 2010). Such a model will provide a predictive framework to link the impact of stressors across scales from organisms to populations, communities and ecosystems. A suitable model will account for similarities as well as variation in metabolic characteristics across the tree of life.

Metabolism is a fundamental process of biology that is strongly related to a variety of processes across scales. Thus, metabolism represents both an intrinsic process of individuals and a possible mechanism to extrapolate predictions and measurements across scales (Brown et al. 2004; Sibly et al. 2012). At the scale of the individual, 
metabolic rate has been demonstrated to vary predictably with growth (Glazier 2015; Sears 2005; von Bertalanffy 1951; Zuo et al. 2012), foraging (Pough \& Taigen 1990; Taigen \& Pough 1983), stress (Francis et al. 2018; Woodley 2017), behavior (Biro \& Stamps 2010; Taigen \& Pough 1985), and reproductive cycles (Angilletta \& Sears 2000; Lardies \& Bozinovic 2006; Pettersen et al. 2016). At larger scales, metabolism scales with a variety of population traits (Bernhardt et al. 2018; Buckley et al. 2008; Hennemann 1983; Kurta \& Ferkin 1991; White \& Seymour 2004), community interactions (Bruno et al. 2015; Iles 2014; Lawton 1991), and ecosystem processes (Allen et al. 2005). Metabolic theory has also been related to the broader contexts of evolution (Enquist et al. 2007; Santos 2012), species distributions (Malishev et al. 2018), macroecological patterns (Enquist et al. 2015; Stegen et al. 2009; Tittensor \& Worm 2016), and conservation (Carey 2005; Fei et al. 2016). Additional research is required to understand the complex relationships between metabolism and other biological traits and processes (Glazier 2015; Shik et al. 2019), but these patterns will undoubtedly prove useful across a broad range of applications.

Metabolism has also been found to correlate with a variety of environmental conditions across spatial and temporal scales (Shik et al. 2019; Žagar et al. 2018). Metabolic rate increases exponentially with temperature and is often modeled using the van't Hoff-Arrhenius equation (see Equation 3.2 and discussion below). The thermal dependence of metabolic rate has direct effects on the energetics of ectothermic organisms, where body temperatures are determined by the interplay between environmental thermal conditions and individual behaviors (Stevenson 1985; Sinsch 1989; Tracy et al. 2010). In contrast, endotherm body temperatures are metabolically 
controlled within stable ranges, although the cost of metabolic heat production is dependent on organismal and environmental temperatures (Porter \& Kearney 2009). Metabolic characteristics also display macroecological patterns across latitude and elevation, which may be related to the predictable environmental changes across these gradients (Chown \& Gaston 1999).

The dependence of metabolism on a variety of climatic variables suggests that climate change will be associated with considerable metabolic impacts (Dillon et al. 2010). Climate change will encompass a large suite of changes in temperature, rainfall, seasonality, and extreme events (among many other effects). The body temperatures of amphibians and other ectotherms are intimately related to the surrounding thermal environment (Clusella-Trullas et al. 2011; Sunday et al. 2014). Thus, many ectothermic organisms, including amphibians, are predicted to be particularly vulnerable to the thermal impacts of climate change (Buckley et al. 2012; Deutsch et al. 2008; Huey et al. 2009). The effects of broad climatic changes will in turn be mediated through mechanisms of physiology and behavior (Hofmann \& Todgham 2010; Huey et al. 2012). Many biological processes of ectotherms, including metabolism, are expected to be directly impacted by changing temperatures resulting from climate change (Buckley et al. 2012; Dillon et al. 2010).

Amphibians in the tropics may be especially sensitive to the metabolic impacts of climate change. There is a growing literature that demonstrates that tropical ectotherms may be among the most vulnerable groups to climate change impacts (Clusella-Trullas et al. 2011; Deutsch et al. 2008; Foden et al. 2013; Huey et al. 2009). Many tropical ectotherms, particularly in the lowlands, currently live at temperatures close to their 
upper lethal limits (Sunday et al. 2014; von May et al. 2017). Therefore, small increases in temperature could have disproportionately large impacts on tropical lowland ectotherms. Indeed, many studies have demonstrated that tropical ectotherms have higher thermal sensitivities and narrower thermal ranges than similar species in temperate environments (Deutsch et al. 2008; Huey et al. 2012; Sunday et al. 2011, 2014;

Tewksbury et al. 2008). Moreover, the expected increases in metabolic rates of tropical biota will be higher than they will be for temperate and polar regions (Dillon et al. 2010). Accurate predictions of metabolic impacts of climate change will require understanding of the evolutionary, ecological, and environmental causes of variation in metabolic rate.

The prediction of metabolic impacts of climate change necessitates a mechanistic and theoretical understanding of metabolism across organisms and scales. A suitable metabolic framework will account for the similarities among organisms, such as in metabolic scaling parameters, as well as the important sources of variation, such as ecology, environment, and evolutionary history. There exists a large literature on metabolic theory and how it may relate to a variety of traits and conditions of both organisms and environment. Some theories have focused on similarities among metabolic characteristics of organisms, such as the metabolic scaling in mass and temperature, and have even gone as far as to suggest that some relationships are universal (Brown et al. 2004; Gillooly et al. 2001). Other studies, however, have demonstrated that there are important differences in metabolism among taxa, both in metabolic rates (e.g., between ectotherms and endotherms) as well as in metabolic scaling parameters (Agutter \& Wheatley 2004; Isaac \& Carbone 2010). Many metabolic characteristics are correlated with ecological characteristics and environmental conditions, suggesting the possibility of 
a predictive framework that integrates the diversity of organisms and habitats with metabolic characteristics and energetics. It is fundamental to understand how metabolism relates to environmental conditions and organismal characteristics to create a theoretical and mechanistic understanding of metabolism. With such an understanding of metabolism across phylogeny and environments, we can empirically predict the metabolic impacts of climate change and inform conservation and mitigation actions across scales from individuals to populations, communities, and ecosystems.

\section{Metabolic theory}

Metabolism is a process that is highly dependent on a variety of organismal traits and conditions. Many metabolic theories have been proposed to account for the vast variation observed in metabolic rates (see Agutter \& Wheatley 2004 for review). Mass and temperature are among the most studied and discussed covariates related to metabolic rates. Large organisms have high demands for energy and resources, and thus have high metabolic rates to meet those needs. Metabolic rates also increase with temperature as a result of the thermodynamic effect of temperature on the rate of biochemical reactions (Clarke \& Fraser 2004). Some theories incorporate other factors to account for perceived variation in metabolism such as cell and genome size, organismal body organization, and environmental variation. A major goal of metabolic theory is to explain and predict broad patterns of metabolism across taxa and environments (e.g., latitude and elevation), with applicability across taxa while simultaneously describing variation. Theoretical and mechanistic models of metabolism will be important for integrating understanding of 
ecology, physiology, and evolution as well as for prediction of the impacts of anthropogenic climate change.

An important debate in the study of metabolism centers on how metabolic relationships apply across organisms. The metabolic theory of ecology (MTE) asserts that the mass scaling and thermal sensitivity of metabolism is universal across the tree of life (Brown et al. 2004). While many organisms do exhibit similar relationships of metabolism to factors such as mass and temperature (Brown et al. 2004; Gillooly et al. 2001), there is extensive variation of scaling parameters both within and among different phylogenetic groups and across studies (Agutter \& Wheatley 2004; Isaac \& Carbone 2010). Even among theories that propose universal metabolic scaling relationships, many disagree on the responsible mechanisms and parameter values (Kearney \& White 2012). The large variation inherent across different organisms and studies of metabolism, as well as the breadth of analytical techniques, have provided conflicting evidence for universality.

Several recent analyses have demonstrated how support for universal metabolic scaling may depend upon analytical techniques. The a priori assumption of universal scaling can lead to large statistical groupings of organisms that obscure important and biologically relevant variation in metabolic scaling parameters (Isaac \& Carbone 2010; White et al. 2006). As such, some metabolic theories may be useful statistical generalizations that apply to large interspecific datasets (Clarke 2004). However, more applicable metabolic theories should aim to explain both the similarities and sources of variation in metabolism of organisms. Such an integrative understanding of metabolism 
would be valuable for understanding macroecological patterns and predicting potential impacts of environmental change.

\section{Body size}

The relationship between body size and metabolic rate has been a hot topic for debate both historically (Kleiber 1932) and recently (Agutter \& Wheatley 2004; Isaac \& Carbone 2010). Body size is directly related to the resource and energy requirements of an organism, and thus metabolic rates are positively correlated with body size. Body size is most often expressed by the proxies of mass or surface area (either external or various internal approximations), and the choice of proxy most often relates to the explanatory mechanism that relates body size to metabolism. The allometric relationship between RMR and mass is most often expressed as a power law of the form:

$$
R M R \propto B_{0} M^{\alpha}
$$

where $R M R$ is the whole-organism metabolic rate, $B_{0}$ is the empirical normalization constant (del Rio 2008), $M$ is the mass, and $\alpha$ is the mass-scaling exponent. According to Equation 3.1, whole-organism RMR is expected to increase with mass but the relationship is modified by the mass-scaling exponent, $\alpha$. When $\alpha$ is less than one, the metabolic rate per gram declines with increasing body size. Kleiber (1932) first proposed the mass-scaling exponent of 0.75 for the basal metabolic rate of endotherms. Since then, the value of 0.75 has been proposed as the universal mass-scaling exponent of metabolism across the tree of life (Brown et al. 2004; Gillooly et al. 2001). 
However, there exists a wide variation in the mass-scaling exponents across different taxa and scales (Agutter \& Wheatley 2004; Isaac \& Carbone 2010). Several studies have found curvature in metabolic scaling of body mass, suggesting differences in scaling relationships among taxa (Ehnes et al. 2011; Kolokotrones et al. 2010; Uyeda et al. 2017). Other studies have found that average mass-scaling exponents of large groupings of organisms conforms to the assumed universal constant of 0.75 . However, large groupings and focus on averages obscures important variation among taxa (Agutter \& Wheatley 2004; Isaac \& Carbone 2010). Isaac \& Carbone (2010) found that allometric scaling exhibited large variation among orders of animals. While the average allometric scaling exponent of the entire dataset (all orders combined) was found to converge to 0.75, half of the orders were expected to have mass-scaling exponents outside of the range $0.68-0.82$, suggesting that there is substantial biological variation in mass-scaling exponents. The significance of biological variation in mass-scaling exponents requires further investigation.

\section{Temperature}

Most biochemical reactions, including metabolic rates, increase exponentially with temperature (Brown et al. 2004; Clarke 2006; Gillooly et al. 2001). Temperature affects the kinetics, or energy of molecular motion, of biochemical reactions and thus impacts both the rates of collisions between molecules as well as the proportion of molecules with sufficient kinetic energy (activation energy) to trigger a reaction (Brown et al. 2004; Clarke 2004). Most metabolic theories model the temperature effect on biological processes using the van't Hoff-Arrhenius equation: 


$$
R M R \propto B_{0} e^{-E / k T}
$$

where $R M R$ is the whole-organism resting metabolic rate, $B_{0}$ is the empirical normalization constant (del Rio 2008), $k$ is the Boltzmann constant, $T$ is the temperature, and $E$ is an empirical constant most often defined as the average "activation energy" of the metabolic process. However, the empirical constant $E$ integrates processes across various levels of biological organization and thus is not a true activation energy in the biochemical sense (Clarke 2006; Lighton 2008). Although the van't Hoff-Arrhenius equation has been used to examine the temperature dependence of biological processes in a diversity of studies, some scientists have criticized its use as a mechanistic relationship, instead pointing out that it is a valuable statistical generalization (Clarke 2003, 2006; Marquet et al. 2004; van der Meer 2006). The assumption in using the van't HoffArrhenius equation is that the thermal effects on the kinetics of biochemical reactions apply to cellular processes and scale consistently through cellular to whole-organism levels of biological metabolism (Clarke 2006). Thus, some suggest that the thermal dependence of metabolism and other multilevel biological processes should be determined empirically until there is a thorough theoretical and mechanistic understanding of the relationship between temperature and metabolic rate (Clarke 2004; Clarke \& Fraser 2004).

While many agree on the exponential relationship between temperature and metabolism, there is substantial variation in the magnitude of the thermal dependence of metabolic rate. Quantification of the thermal dependence, or thermal sensitivity, of metabolic rate is most often expressed via the activation energy, $E$, or transformed into 
$\mathrm{Q}_{10}$ values, the factor by which a rate changes per 10 degree change in temperature. The size of $E$ or $\mathrm{Q}_{10}$ dictates the thermal sensitivity of metabolic rate and can vary substantially among taxa and individuals (Clarke 2004).

The use of a single value of $E$ or $\mathrm{Q}_{10}$ for metabolic rate across large ranges of temperature assumes that thermal sensitivity is constant across temperature. However, many studies have demonstrated that there can be substantial variation in thermal sensitivity of metabolic rate even within the biologically relevant range of temperatures (Brown \& Fitzpatrick 1981). In salamanders, Brown and Fitzpatrick (1981) found that $\mathrm{Q}_{10}$ values of metabolism range between 1.1 and 4.5, depending on the temperature range. Fitzpatrick et al. (1972) found a similar pattern in another species of salamander, with $\mathrm{Q}_{10}$ values of metabolism varying between 1.15 and 3.63 depending on temperature. Thermal reaction norms relate the temperature dependence of a process across ranges of temperatures, and thus avoid the assumption of constant thermal sensitivity (Shik et al. 2019). Extensive variation in thermal reaction norms have demonstrated the potential for complex relationships between metabolism and temperature (Angilletta et al. 2003; Careau et al. 2014).

Many studies have found that the thermal sensitivity of metabolic rate, and a suite of other biological characteristics, depends on the thermal heterogeneity of the environment. Thus, thermal sensitivity is expected to vary across environments in relation to tradeoffs imposed by thermal conditions (Angilletta et al. 2003). The lowland tropics are often characterized by low daily and seasonal thermal variation (Fetcher et al. 1985; Rapp \& Silman 2012). Temperate and polar latitudes are characterized by marked seasonal variation in temperature. High elevation sites are characterized by high diel 
variation in temperature, even in the tropics. However, the effects of thermal heterogeneity across elevation on metabolic rate in amphibians are varied (Navas 1996). The effects of thermal heterogeneity are likely taxon-specific and may further depend on other variables such as the thermal landscape, water availability, or other factors (Chown \& Gaston 1999). Careau et al. (2014) demonstrated that thermal reaction norms can vary intraspecifically among individuals. Individual variation in the shape and level of thermal sensitivity may be important for adaptive selection in response to changing thermal conditions.

\section{Evolution of metabolism}

The extensive variation in metabolism and the metabolic relationships to a suite of organismal and environmental characteristics suggests that metabolism is adaptive and integrated with ecological strategies. As such, metabolic traits should evolve in response to a variety of organismal and environmental characteristics (Uyeda et al. 2017).

Most studies have found that modern distributions of metabolic rates across phylogenies are best characterized by evolutionary processes that incorporate stabilizing selection as described by Ornstein-Uhlenbeck (OU) models (Nespolo et al. 2017a, b; Uyeda et al. 2017). Ornstein-Uhlenbeck models characterize evolution through Brownian motion with a stabilizing parameter pulling species traits towards an "optimum" value (Beaulieu et al. 2012; Butler \& King 2004). The stabilizing selection represented by OU models suggests that while there is important variation in metabolic characteristics, the metabolic traits of organisms may be constrained and/or under stabilizing selection. However, many studies have demonstrated that the optimal metabolic characteristics may 
have shifted through time or among different clades (Uyeda et al. 2017). Stabilizing selection as suggested by OU models has been found in studies of vertebrates (Uyeda et al. 2017), including amphibians (Nespolo et al. 2017a). Stabilizing selection in the evolution of metabolism may have given rise to the similarities in metabolic scaling of mass and temperature among taxa.

The comparative analysis of metabolic rates depends on the incorporation of phylogenetic history, and omission of the phylogeny from analyses can lead to erroneous conclusions (Capellini et al. 2010; Garland et al. 2005; Martins \& Garland 1991). Several studies have found curvature in the metabolic scaling of mass and temperature (Ehnes et al. 2011; Kolokotrones et al. 2010; Uyeda et al. 2017). Often, the presence of the curvature in metabolic scaling is related to the diversity of organisms included in the analysis. Uyeda et al. (2017) found that the curvature in allometric scaling of mammals was related to large variation in body size. Ehnes et al. (2011) found curvature in the ordinary least squares regression of metabolic rate against mass in insects, but this curvature disappeared when using phylogenetic regression. They suggest the variation in metabolic scaling was related to the extensive morphological, ecological, and physiological diversity of insects (Ehnes et al. 2011). Thus, organismal diversity is likely reflected in variation in metabolic scaling parameters, and thus explicit consideration and inclusion of phylogenetic history (as well as other sources of variation in metabolic parameters) should be made in analyses of metabolic rates, particularly in comparative studies of diverse groups of organisms. 


\section{Metabolic impacts of climate change}

The metabolic impacts of climate change will affect a broad range of organisms and likely cascade through a variety of processes and scales. Increasing temperatures will lead to exponential increases in the metabolic rate of organisms. Ectotherms such as amphibians will experience the metabolic increases directly, as their body temperatures are highly dependent on the environment. The metabolic impacts of climate change will be mediated by thermoregulation, hydric condition, and energetic efficiency, potentially instigating ecological cascades and feedback loops (both positive and negative). Moreover, the thermal changes from climate change will not occur in isolation and will interact with a variety of abiotic and biotic changes.

Vulnerability to the impacts of climate change will be determined by the combinations of exposure, sensitivity, and the potential for response (Foden et al. 2013; Pacifici et al. 2015). Exposure is defined by the climatic changes experienced by organisms relative to current environmental variation. High exposure is expected from the high absolute changes in temperature predicted for high elevations and high latitudes. The absolute rates of climate change in lowland tropical environments are expected to be relatively low compared to the poles. However, the predicted climatic changes in the lowland tropics are large relative to the typical climatic variation of tropical environments (Baettig et al. 2007; Pacifici et al. 2015).

Sensitivity is broadly defined by the magnitude of effects for an organism as a result of climate change (Foden et al. 2013). High sensitivity could be caused by a large impacts of climate change on life history, behavior, and physiology. Tropical ectotherms are predicted to have high thermal sensitivity as a result of narrow thermal tolerances and 
small thermal-safety margins (i.e., current temperatures relatively close to thermal maxima; Deutsch et al. 2008; Huey et al. 2012; Sunday et al. 2011, 2014; Tewksbury et al. 2008).

Potential for response to climate change encompasses processes that may allow organisms to reduce exposure, sensitivity, or both (Huey et al. 2012; Moritz \& Agudo 2013; Urban et al. 2016). Potential responses include compensatory mechanisms, range shifts, plasticity, acclimation, and adaptation (Feeley et al. 2012; Huey et al. 2012). Compensation to changing climatic conditions can be achieved through physiological and behavioral changes that mediate organismal temperatures (Huey et al. 2012), range shifts to relatively cool environments (e.g., high latitudes and elevations), and plastic and adaptive changes in thermal reaction norms (Shik et al. 2019; Feeley et al. 2012; Seimon et al. 2017). The variation in metabolic rates and metabolic scaling relationships across taxa will translate into differences in sensitivity to metabolic impacts of climate change. Moreover, patterns of variation within species and across elevation are likely indicative of potential mechanisms for metabolic changes in response to climate change. There are likely to be considerable differences among taxa in vulnerability to the metabolic impacts of climate change, but additional work is necessary to understand how variation in metabolic physiology will translate to differences in metabolic impacts of climate change. Such an understanding will be important to guide conservation and management actions.

The metabolic costs expected from climate change will have important implications on the energy budgets and allocation patterns of organisms (Dillon et al. 2010). In the absence of compensatory mechanisms, increased metabolic rates will increase the energy consumed for basic maintenance and may reduce the energy available 
for allocation to other processes such as growth, activity, and reproduction. Increased metabolic rates may thus lead to decreases in growth rate, body size, foraging, reproductive output, and survival rates. Indeed, decreasing body size has been proposed to be a "universal" effect of climate change, and has been demonstrated in a variety of organisms (Gardner et al. 2011; Prokosch et al. 2019), including amphibians (Caruso et al. 2014; Narins \& Meenderink 2014; Reading 2007). High temperatures have been shown to decrease the reproductive output of newts (Galloy \& Denoël 2010), an effect that may result from changes in metabolic expenditure. Many effects on individuals will scale up to affect population dynamics, community interactions, and ecosystem processes. However, a large meta-analysis of temperature effects on body size found that the relative impacts are organism specific and mediated by a variety of factors outside of simple metabolic impacts such as life history and behavior (Gardner et al. 2011). For example, some ectotherms may benefit from increased temperature by expanding activity periods and foraging time and potentially increasing total resource pools (Yuan et al. 2018). However, most studies predict that lowland tropical ectotherms, already living near their thermal limits, are unlikely to benefit from increases in temperature compared to temperate and polar taxa or those living at high elevations (Huey et al. 2012).

\section{Objective}

To understand the ecological and evolutionary patterns of variation in metabolic rate in tropical amphibians, I measured the resting metabolic rate (RMR) of a diverse assemblage of amphibians in the field across elevation in southeastern Peru. The measurements include wide ranges of mass, temperature, and elevation allowing a 
detailed examination of how various factors may influence RMR in tropical amphibians. The phylogenetic breadth of species $(\mathrm{n}=113)$ sampled across the gradient allows consideration of the role of evolutionary history during the analysis of the above factors and RMR. Moreover, the ecological diversity facilitates examination of factors that may contribute to vulnerability to metabolic impacts of climate change. My study is a valuable contribution in understanding the determinants and variation of metabolic rate for a large diversity of amphibians in the understudied tropics.

\section{METHODS}

\section{Study sites}

The present investigation was conducted across an elevational gradient on the eastern slopes of the Andes in southeastern Peru within the Manu Biosphere Reserve, with additional sites located in the Los Amigos Concession, and the Cordillera Vilcanota (hereafter Manu, Los Amigos, and Vilcanota, respectively). The gradient extends between 224 meters above sea level (m asl) in Los Amigos in the upper Amazon, through the Kosñipata Valley within Manu, to $5196 \mathrm{~m}$ asl in the Vilcanota. Measurements on frogs were conducted at eight sites across the elevational gradient (Table 3.1; Figure 3.1). The steep elevational change on the eastern slopes of the Andes allowed most of the elevational gradient to be sampled from the eight study sites (elevational increases of 4000-5000 m over horizontal distances of only 50-80 km; Killeen et al. 2007).

Forest type varies predictably with elevation, resulting in distinctive habitat characteristics within elevational bands. Lowland rainforest is characterized by high canopies and large trees and occurs below $500 \mathrm{~m}$ asl (Presley et al. 2012). Montane rain 
forests have relatively low canopies ( 35 m) and extend between 500 and $1400 \mathrm{~m}$ asl. Cloud forests are extremely wet montane forests characterized by dense coverings of moss and epiphytes on trees and shrubs and typically occur between 1400 and $2800 \mathrm{~m}$ asl. The local characteristics of cloud forests depend on surrounding geography and can be vary considerably in elevational range, moisture, and epiphyte density (Presley et al. 2012). The highest elevation forests are called elfin forest, and often occur between 2800 and $3200 \mathrm{~m}$ (Presley et al. 2012). Many areas within the buffer zone of Manu are characterized by recovering secondary forests, which generally have small trees, low canopies, and dense understory vegetation as compared to primary forests (Guariguata \& Ostertag 2008). Above elfin forests, high elevation grasslands known as puna persist with elevational limits varying with local geography (2000 - 4400 m; Lugo et al. 2008). Above grasslands are the subalpine and alpine zones, which are characterized by rocky substrates and limited growth of cushion plants, mosses, lichens, and scattered vascular plants (Ellenberg 1979).

\section{Climate}

The Manu region is located near the "elbow" of the Andes, which leads to distinctive climatic conditions with important variation seasonally and across elevation (Killeen et al. 2007). Seasons across the gradient can be divided into wet (November through March), dry (May through July), and austral spring (September through October) seasons, with transitional periods that vary year to year (Rapp \& Silman 2012). The seasons exhibit marked variation in climatic conditions such as temperature, rainfall, humidity, and cloud dynamics. Moreover, the timing and magnitude of seasonal changes 
vary across elevation (Rapp \& Silman 2012). The Manu and Los Amigos areas are classified together as a superhumid zone by Killeen et al. (2007) because of high amounts of precipitation relative to other areas in the tropical Andes (mean annual rainfall $=4,304$ $\mathrm{mm})$.

In the lowlands, forests are relatively warm year-round, both during the day and night. Average annual temperature at Los Amigos is around $24^{\circ} \mathrm{C}$. The wet season is slightly warmer than the dry season, but monthly averages of temperature are usually between $21-26^{\circ} \mathrm{C}$. Rainfall at Los Amigos is highly seasonal, with most rain occurring within the wet season, and annually is typically around 2700-3000 mm (Pitman 2010; von May et al. 2009). Humidity in the area is relatively high, averaging over $80 \%$ in the research clearing of Los Amigos Biological Station, and expected to be consistently higher within the forest (Pitman 2010). Cold air incursions known as friajes can lead to substantial decreases in temperature, even in the lowlands. Observed temperatures can decrease as much as $20^{\circ} \mathrm{C}$, to temperatures as low as $5^{\circ} \mathrm{C}$ at night, and are accompanied by decreases in humidity (Doan 2004; Garreaud 1999).

Within the Kosñipata Valley, there is considerable variation in climatic conditions across elevation. In the understory, mean annual temperatures during the day range from $18.1^{\circ} \mathrm{C}$ at $1500 \mathrm{~m}$ asl to $7.3^{\circ} \mathrm{C}$ at $3600 \mathrm{~m}$ asl. For the same elevational range, night mean annual temperatures range from $16.8^{\circ} \mathrm{C}$ to $5.7^{\circ} \mathrm{C}$. Temperatures are higher in the wet season than in the dry season, and seasonal differences in temperature are greater at low elevations than high elevations (Rapp \& Silman 2012). Rainfall is highest during the wet season, typically peaking in January and February, and lowest in June and July of the dry season (Rapp \& Silman 2012). The highest rainfall in the Kosñipata Valley occurs at 890 
$\mathrm{m}$ asl with over $5000 \mathrm{~mm}$ per year. Above $890 \mathrm{~m}$ asl, rainfall declines monotonically with elevation to less than $1000 \mathrm{~mm}$ per year at $4130 \mathrm{~m}$ asl (Rapp \& Silman 2012). Diurnal temperature range is similar across intermediate elevations between 1000 and $3500 \mathrm{~m}$ asl (Rapp \& Silman 2012). Relative humidity is high for much of the year across elevation and is above $95 \%$ for the majority of the wet season (Rapp \& Silman 2012).

The Vilcanota region above $4000 \mathrm{~m}$ asl is characterized by an alpine climate. Average monthly temperatures vary from about $12^{\circ} \mathrm{C}$ in the wet season to $22^{\circ} \mathrm{C}$ in the dry season (Nemergut et al. 2007). The low pressure and high radiation of high elevations lead to large ranges in diurnal temperature, often more than $20^{\circ} \mathrm{C}$ range across the daily cycle. Moreover, solar radiation can cause particularly high soil surface temperatures, leading to diurnal temperature ranges of exposed surfaces to be as high as $30^{\circ} \mathrm{C}$ at 5000 m asl (Nemergut al. 2007; Schmidt et al. 2009). The Vilcanota receives an average annual precipitation of $702 \mathrm{~mm}$ with distinct wet (October to April) and dry (May to September) seasons (Seimon et al. 2017). The combination of low temperatures, low air density, and high radiation leads to relatively dry conditions within the Vilcanota through much of the year. Suitable habitats for amphibians are either found in and around aquatic habitats from glacier runoff, or under rocks and boulders relatively protected from direct radiation and the drying conditions of the air.

\section{Amphibian surveys}

The tropical Andes are a hotspot of biodiversity and endemism and are home to over $17 \%$ of global amphibian species richness (Jenkins et al. 2013; Myers et al. 2000). Within the Manu Biosphere Reserve, an inventory published in 2013 lists 155 species 
(Catenazzi et al. 2013), and many species continue to be described each year from the region. The combination of favorable climatic conditions, large area, and large elevational range makes Manu National Park the most biodiverse protected area in the world for herpetofauna (Catenazzi et al. 2013). Amphibians across the gradient have been heavily impacted by the fungus Batrachochytrium dendrobatidis $(B d)$, causing the disappearance of many species, particularly at mid to high elevations (Catenazzi et al. 2011, 2014).

I sampled amphibians during visual encounter surveys (Crump \& Scott 1994) across a variety of habitats (aquatic and terrestrial) and along trails and roads. Below the tree line, surveys were conducted by visually inspecting vegetation and leaf litter. Above the tree line, in the puna grasslands, surveys were conducted by searching within moss, dense grasses, and under rocks. In the alpine zone of the Vilcanota, all amphibians were found under rocks, likely because these habitats are moist and thermally buffered (Shoo et al. 2010). Below the tree line, surveys were conducted primarily at night, but amphibians encountered during the day were also collected for physiological measurements. Above the tree line, surveys were conducted during the day.

Amphibians were held for 12 to 24 hours before measurements were taken to reduce the effects of handling stress, maintain hydration levels, reduce potential effects of past activity, and to control thermal history prior to the measurement. Small amphibians were kept in sealed plastic bags with plants from the capture location and sprayed with water to maintain humidity and hydration. Medium to large amphibians were kept in perforated plastic containers to allow fresh air, with small amounts of water so animals could maintain hydration. Amphibians were kept for a total of 48 hours, at which time 
they were released at the capture location. Bags and containers were washed and sterilized using $70 \%$ ethanol prior to reuse, a measure demonstrated to be effective against most bacteria, fungi, and viruses, including Bd (Johnson et al. 2003; Phillott et al. 2010).

\section{Metabolic rates}

Metabolic rates were measured as changes in the concentration of carbon dioxide $\left(\mathrm{CO}_{2}\right)$ using flow-through respirometry within a closed-loop system. A Vaisala GMP 343 infrared gas analyzer (IRGA) was used to measured changes in $\mathrm{CO}_{2}$ concentration over time. Air was pumped through the system at a rate of 13.2 liters per hour using a diaphragm pump (LICOR 6262-04 reference pump). Metabolic chambers ranged in volume from 200 to 1287 milliliters. Amphibians were measured using the smallest volume metabolic chamber available without restriction of animal movement. Temperature and humidity within the system were monitored using a HOBO data logger (Onset HOBO H08-004-02 Data Logger). The air temperature was assumed to be the same as amphibian body temperature as the humidity in chambers remained high (average 93\%) and there were no rapid changes in temperature during measurements (Carey 1979). Air pressure was measured using a Garmin 64s, but because of equipment malfunctions during some periods, some data were extrapolated from weather stations and previous measurements.

Amphibians were placed within chambers, and determined to be unmoving, for 20 minutes before the start of measurements. Most amphibians were within chambers for more than 30 minutes prior to measurement. Metabolic chambers were covered with 
cloth to reduce visual stimulation of the animals, but still allowed monitoring for activity. Amphibian respiration was measured for a minimum of ten minutes, often longer for small amphibians and cold temperatures. Multiple chambers were used to facilitate the resting period of multiple amphibians during measurements, and separate tubing was used to switch measurements between chambers without repositioning and potentially causing amphibians to move. Metabolic chambers were sterilized using 70\% ethanol between measurements. Measurements were recorded during the night between 2200 and $0600 \mathrm{~h}$ and during the day between 1100 and $1800 \mathrm{~h}$.

Resting metabolic rates were taken as the taken to be the minimum $\Delta \mathrm{CO}_{2}$ of a moving 180 second window applied across the entire measurement period. Longer periods of the moving window were used for individuals with low metabolic rates (raw $\Delta \mathrm{CO}_{2}$ values less than $0.02 \mathrm{~s}^{-1}$ ) to account for low signal-to-noise ratios (small amphibians and cold temperatures. Raw changes in $\mathrm{CO}_{2}$ concentrations were converted to metabolic rates using the following equation modified from Lighton (2008):

$$
\dot{V}_{\mathrm{CO}_{2}}=\mathrm{FR} \times \mathrm{RT} \times \Delta \mathrm{CO}_{2}
$$

where $\dot{V}_{\mathrm{CO}_{2}}$ is the metabolic rate as measured by $\mathrm{CO}_{2}$ production $(\mathrm{mL} / \mathrm{hr}), F R$ is the flow rate of air through the system $(13,200 \mathrm{~mL} / \mathrm{hr}), R T$ is the response time of the system (hours), and $\triangle C O_{2}$ is the change in $\mathrm{CO}_{2}$ concentration (fractional change per hour). Response time was calculated as the flow rate multiplied by the total volume of the system. All measurements were converted to standard temperature and pressure for comparisons (Lighton 2008). 


\section{Day and night comparisons}

As a method to examine whether metabolic rates should be analyzed separately for day and night, I used repeated measures analysis of variance (ANOVA) to examine differences between RMRs of day and night. To make the measurements comparable, I ran separate ordinary least squares (OLS) regressions (non-phylogenetic) for both day and night using an additive model of $\log (\mathrm{RMR})$ against $\log ($ mass) and temperature. Using the results from the regressions for day and night, I corrected all measurements of RMR using the power law with mass (Equation 3.1) and the exponential relationship with temperature (to $20^{\circ} \mathrm{C}$; Equation 3.2). The corrected values were compiled for all measurements and a repeated measure ANOVA was conducted using individual ID to denote subject and day and night as factors. All analysis was conducted using the package nlme in R 3.6.1 (R Core Team 2019). Further analyses were run separately for day and night measurements given the significant differences of RMR between day and night.

\section{Evolutionary analyses}

Phylogenetic relationships among taxa were obtained using the tree of von May et al. (2019) and trimmed to include only the anurans contained within this study. The tree was constructed to determine the phylogenetic relationships among the amphibian species in southeastern Peru, and thus represents the most comprehensive phylogeny for the present study. The phylogeny of Pyron and Wiens (2011) has often been used in phylogenetic analyses for amphibians, but only 58 species in my study are represented in their phylogeny. The phylogeny constructed by von May et al. (2019) uses higher order 
constraints (family and above) following Pyron and Wiens (2011) and includes 88 of my 114 study species. The phylogeny was trimmed and matched to the data using the ape package in R 3.6.1 (R Core Team 2019).

\section{Phylogenetic signal}

I analyzed the univariate and multivariate phylogenetic signal separately for both day and night using Pagel's $\lambda$ and Blomberg's $K$. The multivariate datasets included RMR, mass, temperature and elevation. The univariate dataset only included the RMR corrected for both mass and temperature following the OLS regression discussed above. Pagel's $\lambda$ estimates the phylogenetic signal using data from within lineages and along branches under the assumption of a Brownian motion model of evolution (Diniz-Filho et al. 2012). Brownian motion assumes that evolution along a phylogeny occurs along each branch as a random walk from each past node with trait variance relative to branch lengths (Blomberg et al. 2003). Brownian motion further assumes that the rate of evolution is constant through time and across the phylogeny (Freckleton \& Harvey 2006). Brownian motion may be appropriate for modeling random genetic drift or selection in response to randomly fluctuating environmental conditions (Díaz-Uriarte \& Garland 1996). The values for Pagel's $\lambda$ range from zero (no phylogenetic signal) to one (strong phylogenetic signal under assumptions of Brownian motion). Blomberg's $K$ estimates evolutionary change occurring at the nodes and, unlike many indices for phylogenetic signal, does not assume and depend on Brownian motion as an evolutionary model (Adams 2014; Blomberg et al. 2003). Values of Blomberg's $K$ close to zero indicate an absence of phylogenetic signal within the data (Rainford et al. 2016). As Blomberg's $K$ 
approaches one, it indicates increasing phylogenetic signal, with the value of one being expected under evolutionary scenarios determined by Brownian motion (Diniz-Filho et al. 2012; Rainford et al. 2016). Values above one indicate strong phylogenetic signal and that closely related species are more similar than would be expected under Brownian motion. Values between zero and one indicate the presence of a phylogenetic signal, but with less similarity between closely related species than would be expected under Brownian motion. The two measures of phylogenetic signal (Pagel's $\lambda$ and Blomberg's $K)$ are complimentary in that they have different assumptions of evolutionary mode and calculate phylogenetic signal using different criteria. All analyses were implemented using the Rphylopars, ape, and phytools packages in R 3.6.1 (R Core Team 2019).

\section{Evolutionary models}

Various models of evolution were fit to the tree and data to examine the pattern of evolution of metabolic rate in the study species (Table 3.2). Different models represent varying assumptions of the influence of the tree, the independence of traits, and the relationships between traits both intraspecifically and across the phylogeny. The White Noise or Star model represents the scenario where phylogeny has no effect on the expected values of traits and can be used as a null model assuming no influence of phylogeny (Rainford et al. 2016). The Brownian Motion (BM) model represents the expected trait values if evolution occurred neutrally via a random walk (Felsenstein 1985). The Lambda model calculates a single Pagel's $\lambda$ for the traits and back-transforms the branch lengths of the phylogeny to match the tree to the patterns of traits to match expectations under Brownian Motion (Rainford et al. 2016). Thus, the Lambda 
transformation can model evolutionary scenarios that happen between completely random $(\lambda=0 ;$ star phylogeny) and $\mathrm{BM}(\lambda=1)$. There are three Ornstein-Uhlenbeck (OU) models of evolution considered in the analysis that model various scenarios for selection towards an optimum value (Beaulieu et al. 2012; Butler \& King 2004). The first OU model calculates a single alpha term representing the strength of stabilizing selection that is applied to each trait evolving across the tree. The second OU model (mvOU1) calculates a distinct alpha value for each individual trait, with no influence between traits. The final model (mvOU2) calculates individual alpha values for each trait and also accounts for intraspecific correlations between traits and its influence on the strength of stabilizing selection (Goolsby et al. 2017).

Previous studies have demonstrated that likelihood multivariate phylogenetic comparative methods (e.g., MVMorph, Rphylopars) have desirable statistical characteristics (rotation invariant and robust to trait covariation) and perform well under relatively low levels of trait dimensionality compared to number of species (Adams \& Collyer 2018). Many comparative methods are restricted to analyses of single values for each species represented in the phylogeny, thereby restricting the ability to explicitly incorporate intraspecific variation. I used the package Rphylopars as a way to incorporate intraspecific variation in traits (mass, temperature, elevation and RMR) into the analyses. The intraspecific variation in these traits may be particularly important for many of the study species that are characterized by large elevational ranges and high variation in mass and/or temperature. Data were analyzed in R 3.6.1 using the package Rphylopars (Goolsby et al. 2017; R Core Team 2019). 


\section{Phylogenetic regression}

Phylogenetic regressions were fit to the data using the most supported evolutionary model for both day and night datasets (mvOU1). Regressions considered the additive and interactive regressions of RMR against each individual and combination of mass, temperature, and elevation. Regressions were run separately for day and night. The regressions were run using raw data of RMR and mass as well as the log-transformed values of RMR and mass, as the predicted relationships between metabolic rate and mass and temperature are expected to be characterized as power laws and exponential relationships, respectively. Fitting regressions using both the raw and log-transformed data allows an explicit examination of the assumed relationships between RMR, mass, and temperature. The package Rphylopars was used for phylogenetic regression to incorporate both intraspecific and interspecific variation among variables (Goolsby et al. 2017). All analyses were conducted in R 3.6.1 (R Core Team 2019).

The additive phylogenetic regression of $\log (\mathrm{RMR})$ against both $\log (\mathrm{mass})$ and temperature was used to allow explicit comparisons with other studies using the same model equation. The MTE model does not include an interaction between mass and temperature, and often does not consider phylogenetic relatedness within groups (amphibians are often compiled as a single group). Thus, the additive model provides both the mass-scaling exponent and temperature sensitivity (as $E$ or $\mathrm{Q}_{10}$ ) across the entire group of amphibians while accounting for phylogeny. The mass-scaling exponent is equal to the coefficient of $\log$ (mass) while the coefficient with temperature is transformed to $E$ and $\mathrm{Q}_{10}$ values. The influence of phylogeny on the value of scaling parameters was explicitly examined by comparing two additive regressions. The Star model was used to 
examine potential scaling parameters under the assumption of universal scaling and without incorporating phylogenetic relationships (and is equivalent to ordinary least squares (OLS) regression). The mvOU1 model was used to examine how scaling parameters change in the regression with the incorporation of phylogenetic relationships and a multivariate Ornstein-Uhlenbeck model of evolution. Apart from the evolutionary models, the two regressions are identical.

\section{Comparisons}

Comparisons of RMR required measurements to be corrected for both mass and temperature to remove the influences of these variables from analyses. The mass and temperature coefficients from the additive model of $\log (\mathrm{RMR})$ against $\log (\mathrm{mass})$ and temperature were used to correct all measurements of field RMR. A one-way ANOVA with measurements grouped by family (following Frost et al. 2006) was used to examine differences in RMR among tropical anuran families. Another one-way ANOVA was used with measurements grouped by elevation to examine differences in RMR across elevation. I examined the influence of elevation by splitting species and measurements into three elevational groups: low elevation (<600 m asl), mid elevation $(600-2,000 \mathrm{~m}$ asl), and high elevation (> 2,000 $\mathrm{m}$ asl). Separate analyses were conducted for day and night.

Variation in thermal sensitivity was examined by comparing regressions of logtransformed RMR and temperature among families and elevational groups. Only the families Bufonidae, Craugastoridae, Hylidae, and Leptodactylidae were included in this analysis as they have high numbers of measurements from a variety of species across 
elevation. Separate regressions were run on each of the three elevational groups. Regressions were run separately for day and night and converted to $\mathrm{Q}_{10}$ values for comparison. Analysis of covariance (ANCOVA) was used to examine whether the slopes of the regressions differed among families and elevational groups.

\section{RESULTS}

I measured RMR for a total of 1073 individuals of 113 species. The metabolic data were combined with the phylogeny for a total of 88 species representing 984 individuals included in the analysis (Figure 3.2). The repeated-measures analysis of variance (ANOVA) only used individuals that had measurements for both day and night $(\mathrm{n}=881)$. There were significant differences for the RMR between day and night (Table 3.3). Thus, the dataset was further broken down to RMR measurements collected during the day $\left(\mathrm{n}_{\mathrm{obs}}=910, \mathrm{n}_{\mathrm{spp}}=88\right)$ and night $\left(\mathrm{n}_{\mathrm{obs}}=956, \mathrm{n}_{\mathrm{spp}}=88\right)$. There are clear relationships between RMR with mass (Figure 3.3), temperature (Figure 3.4), and elevation (Figure 3.5).

\section{Phylogenetic signal}

The two measures of phylogenetic signal in tropical anurans were robust to different configurations of the data, both in univariate and multivariate forms (Table 3.3). Both Pagel's $\lambda$ and Blomberg's $K$ were significantly different than zero for all configurations of the variables, suggesting that there is a strong phylogenetic signal within tropical amphibian RMR and related traits. Pagel's $\lambda$ was found to be close to one $(\lambda>0.9)$ for all times and datasets, consistent with assumptions of Brownian Motion 
(Table 3.4). The measures of Blomberg's $K$ were close to the expected value under Brownian Motion $(K=1)$ for the multivariate data sets but were less than one for the univariate datasets (Table 3.4). Therefore, there is a strong phylogenetic signal in the data, demonstrated by both Pagel's $\lambda$ and Blomberg's $K$.

\section{Evolutionary models}

The mvOU1 evolutionary model was among the most supported models in the analyses of day and night RMR by Akaike Information Criterion (AIC; Table 3.5). For night, the mvOU1 model was the most supported model of evolution by AIC. The daytime dataset had mvOU1 as the fourth most supported model by AIC, but relatively close to the top three models of evolution. To facilitate comparison among the datasets, the mvOU1 model was selected for further analyses.

\section{Phylogenetic regression}

Phylogenetic regression of RMR against mass, temperature, and elevation was conducted on each of the day and night datasets (Table 3.6). All models considering logtransformed variables of RMR and mass, regardless of formula, were more supported than the phylogenetic regressions using untransformed data. The log-transformed data model RMR and mass and temperature as power law and exponential functions, respectively. The models that included both mass and temperature were selected for further analyses as they were consistently among the best fit models for day and night (Table 3.6). The best fit models for both day and night include an interaction term that is rarely considered in metabolic scaling theories (Table 3.6). Thus, the additive model was 
also included in further analyses, as it facilitates comparison of the effects of mass and temperature on metabolic rate with other studies, which often neglect interactions (e.g., Brown et al. 2004; Gilloly et al. 2001). Model parameters differed between day and night and were highly dependent on regression methods (OLS vs. PGLS) and the inclusion of interaction terms (Table 3.7). Even within the additive models, the mass scaling exponents and the two measures of thermal sensitivity $\left(E\right.$ and $\left.\mathrm{Q}_{10}\right)$ vary considerably between OLS and PGLS regressions (Table 3.7; Table 3.8). The interaction terms between mass and temperature in the in the best fit models were negative for both day and night (Table 3.7).

\section{Comparisons}

The whole-organism measurements show the highest RMRs for families with the largest body size (e.g., Bufonidae, Ceratophryidae, and Leptodactylidae; Figure 3.6A). In contrast, the mass-specific RMRs bias the highest measurements to the families with the smallest body sizes (e.g., Aromobatidae, Centrolenidae, Craugastoridae, and Dendrobatidae; Figure 3.6B). Relative differences among families are much greater in the whole-organism measurements as a result of the orders of magnitude differences in body size among families.

The mass-corrected RMR uses the empirically determined mass-scaling exponent to correct RMR separately for both day and night (Figure 3.7). The distribution of RMR is much more similar among families for mass-corrected RMR than for either whole-

organism or mass-specific RMR. The differences in mass-corrected RMR are significant among families during the day but not at night (Table 3.9). The largest deviation among 
families is for the family Ceratophryidae, which has much lower mass-corrected RMRs than those observed in other families. The biases from body size evident in Figure 3.6 are no longer apparent in the mass-corrected RMRs in Figure 3.7, and differences instead are likely related to physiological and ecological patterns (see Discussion).

The patterns between day and night within each family are consistent across all measurements of RMR (Figure 3.7). Most families have higher RMR at night than during the day. The only exceptions are for the diurnal poison frogs in the families Aromobatidae (higher RMR during the day than at night) and Dendrobatidae (similar RMR for day and night).

There are significant differences in thermal sensitivity $\left(\mathrm{Q}_{10}\right)$ among the four families of anurans for both day and night (Figure 3.8, Table 3.10). The highest $\mathrm{Q}_{10}$ values are found in Craugastoridae and Bufonidae. The lowest $\mathrm{Q}_{10}$ value is found in Hylidae. The $\mathrm{Q}_{10}$ value for the family Leptodactylidae is intermediate. Families differ in whether $\mathrm{Q}_{10}$ is higher at night (Bufonidae and Craugastoridae) or during the day (Hylidae and Leptodactylidae).

The $\mathrm{Q}_{10}$ values are also significantly different among elevational groups for both day and night (Figure 3.9; Table 3.11). The high elevation amphibians have the highest $\mathrm{Q}_{10}$ values for both day and night are for high elevation amphibians. The lowest $\mathrm{Q}_{10}$ values are for low elevation amphibians, and the mid-elevation group is intermediate.

\section{DISCUSSION}

I demonstrate that there is important variation in the RMR of tropical amphibians across phylogeny and elevation. Phylogenetic comparative methods show that 
evolutionary history is an important consideration in analyses of amphibian metabolism. The incorporation of phylogenetic relatedness into regressions resulted in considerably different metabolic scaling parameters compared to nonphylogenetic methods. Furthermore, my study suggests that there may be an interaction between mass and temperature on metabolic rates, which may be important in determining vulnerability to climate change. Comparisons among groups (using family and elevation) suggest that single metabolic scaling relationships may not be sufficient to describe the diversity of metabolic physiology of amphibians. Ongoing anthropogenic climate change will have substantial metabolic impacts on organisms across the globe. The challenge for biologists is to understand the magnitude, direction, and rate of climate change impacts on organisms across scales to inform potential mitigation and conservation actions to preserve biodiversity (Helmuth et al. 2005). The extensive variation in the metabolic ecology of tropical amphibians suggests that there may be important differences in vulnerability to metabolic impacts of climate change.

\section{Evolution}

The phylogenetic pattern of field RMR in tropical anurans suggests that there is a significant phylogenetic signal that must be accounted for in analyses (Table 3.4). Both Blomberg's $K$ and Pagel's $\lambda$ were significantly different than zero, regardless of which dataset was used (univariate and multivariate), stressing the importance of accounting for phylogenetic history in analyses of RMR. Multivariate phylogenetic analysis of evolution supports the mvOU1 model, a multivariate Ornstein-Uhlenbeck (OU) model of evolution (Table 3.5) that incorporates selective pressures within the traits (mass, temperature, 
elevation, and RMR). The mvOU1 model allows for a distinct optimum value for each of the variables and also accounts for differences in the selective pressures for each trait (Table 3.2; Goolsby et al. 2017). Ornstein-Uhlenbeck models incorporate selection around an optimum, suggesting that RMR may be constrained or selected for in tropical amphibians (Butler \& King 2004; Hansen 1997).

The multiple regression of RMR against mass and temperature was highly dependent upon the incorporation of phylogeny, supporting other studies in demonstrating the importance of evolutionary history for analyses of metabolism (Ehnes et al. 2011; Uyeda et al. 2017). The mass-scaling exponent of amphibian RMR using ordinary least squares (OLS) regression was overestimated and underestimated for day and night, respectively, as compared to the phylogenetic regression using the mvOU1 evolutionary model (Table 3.7). The thermal sensitivity, however, was underestimated for both day and night when using OLS compared to phylogenetic regression (Table 3.8). The changes in coefficient estimates using regression with and without phylogenetic consideration suggests that evolution may act upon the metabolic characteristics of day and night in distinct ways that vary across the phylogeny. Moreover, the coefficients found from OLS regression are relatively similar to the proposed value of universal scaling in metabolism (Brown et al. 2004), similarities which disappear when phylogeny is incorporated into the analysis. My study thus adds to the literature that demonstrates important phylogenetic signal in metabolic rates across taxa, and that support for universal metabolic scaling relationships may be an artifact of large groupings that obscure variation (Agutter \& Wheatley 2004; Ehnes et al. 2011; Isaac \& Carbone 2010). It is therefore inappropriate to combine amphibians into a single group for metabolic 
studies and doing so may lead to oversimplification and erroneous conclusions. While it does appear that metabolism is constrained and selected for in tropical amphibians, there appears to be important variation across the phylogeny and between day and night that will be important in modeling organismal vulnerability to the metabolic impacts of climate change.

\section{Metabolic scaling}

Both mass and temperature are included among the most supported regressions of RMR for both day and night. However, the most-supported model for night includes elevation instead of temperature, and an interaction between mass and elevation. Elevation correlates strongly with temperature, especially at night, as nighttime lapse rates in temperature across elevation are higher at night than during the day in the Kosñipata Valley (Rapp \& Silman 2012). Elevation may provide a stronger correlation to RMR than temperature at night because it may incorporate both the thermal dependence of RMR as well as any potential influence of elevation on metabolic scaling, such as metabolic compensation at low temperatures (Chown \& Gaston 1999; Navas 1997). Various relationships between elevation and tropical amphibian metabolism were demonstrated by Navas (1996), with complex relationships of various metabolic characteristics among species and across temperature. The interaction terms of the best fit models make it difficult to compare the metabolic scaling of my results to other studies, that often analyze mass and temperature separately. Thus, I use the additive phylogenetic regressions of mass and temperature below to make comparisons with other studies. 
The mass-scaling exponents of metabolism in tropical amphibians from the additive regression models are well-within the ranges found across various taxa (Isaac \& Carbone 2010). Interestingly, the OLS regression of amphibian metabolism, without an interaction with temperature (following MTE; Brown et al. 2004; Sibly et al. 2012), yields mass-scaling exponents similar to the assumed value of 0.75 for both day and night (0.717 and 0.743 , respectively). However, incorporation of phylogeny into the analysis yields distinct mass-scaling exponents for day and night RMR (0.601 and 0.799, respectively). The discrepancies arising from different analyses highlight how different statistical approaches can lead to different conclusions regarding the universal scaling of metabolism. Combining diverse taxa and data sets for macroecological analyses may obscure important biological variation in favor of "universal" averages with little biological meaning (Agutter \& Wheatley 2004; Bokma 2004). My results suggest that mass-scaling exponents of tropical amphibians not only differ from commonly proposed universal values but also differ between day and night.

The thermal sensitivity of metabolism, as measured through the activation energy $(E)$ or $\mathrm{Q}_{10}$ value (Table 3.8), is higher in the assemblage of tropical amphibians I studied than has been previously reported for other adult amphibians. The proposed universal value of $E$ by MTE is $0.65 \mathrm{eV} / \mathrm{K}$ (Brown et al. 2004; Sibly et al. 2012), whereas the PGLS regression in my study found $E$ of tropical amphibians to be 1.085 and 0.959 for day and night, respectively. The same regressions yield $\mathrm{Q}_{10}$ values of 4.221 and 3.743 for day and night, respectively. According to Dillon et al. (2010), climate change is expected to have high metabolic impacts on ectotherms in the tropics as a result of high temperatures and the exponential relationship with metabolism. However, the study by 
Dillon et al. (2010) assumes a universal temperature sensitivity of metabolic rate across taxa and across regions (using large phylogenetic groupings such as amphibians or reptiles). For amphibians, particularly, the analysis by Dillon et al. (2010) applies a relatively low thermal sensitivity $(E=0.5 \mathrm{eV} / \mathrm{K})$, calculated from an analysis of only 22 amphibians of primarily northern temperate regions (Altman \& Dittmer 1974; Gillooly et al. 2001). My results suggest that the thermal sensitivity of metabolism of tropical amphibians may be considerably higher than suggested by previous studies of temperate taxa. Therefore, tropical amphibians may be subject to the compound effects of high thermal sensitivity and high tropical temperatures that may lead to alarming metabolic impacts from climate change.

The best fit regression of tropical amphibian RMR includes an interaction between mass and temperature. The interaction coefficient is negative, which suggests that the temperature sensitivity of amphibians is highest in amphibians with small body size. The interaction term has several important implications. First, it suggests that small amphibians, the vast majority of tropical amphibian diversity, will be more sensitive to metabolic impacts of climate change than large amphibians. The vulnerability of small species may be important to understand and predict the relative vulnerability of different species and to coordinate conservation efforts. Second, if this relationship holds within species and individuals across growth trajectories, it suggests that juveniles and subadults will be more sensitive to metabolic impacts of climate change than full grown adults. Juveniles and subadults have been found to be more sensitive than adults to a range of other impacts such as desiccation, pollution, disease, and land-use change (Biek et al. 2002; Cushman 2006; Gray et al. 2009; Petrovan \& Schmidt 2019; Rittenhouse et al. 
2008; Rothermel \& Semlitsch 2002). The high thermal sensitivity of juvenile and subadult life stages may lead to synergistic interactions among various stressors that affect amphibians (Linder et al. 2003; Rohr \& Palmer 2013). It will be important for conservation and mitigation planning to consider which species and life-stages will be most affected by stressors resulting from anthropogenic climate change to guide conservation decisions. Most amphibians have small adult stages, and all amphibians are relatively small as larvae and juveniles. The metabolic impacts of climate change are likely to be widespread across amphibians, and the effects may be most prominent in small species and life stages.

The regressions for RMR demonstrate that there are important differences in the mass-scaling exponent and the temperature sensitivity between day and night. The coefficients show that field RMR is more strongly dependent on both mass and temperature at night than during the day. However, this effect may be mediated by the interaction term, which has a higher coefficient (stronger effect) at night than during the day. Without the consideration of interaction terms, both the mass and temperature effects are stronger during the day than at night. The measurements of RMR during the day and night both reflect resting metabolic rate, yet there are circadian rhythms in metabolic rate that may be impacting the observed relationships (see Chapter II for discussion). During the active period, the metabolic system may be "primed" for activity and could include a suite of physiological changes, including elevated RMR and changes in the mass and temperature scaling of metabolic rates. Furthermore, the environmental differences between day and night include a range of potentially important variables, such as temperature, sunlight, and risk of desiccation. The results of my analysis suggest 
that selective pressures on metabolism may be different for day and night in tropical amphibians. Differences between the scaling parameters between day and night may relate to different selective pressures for metabolic characteristics during active and resting periods.

\section{How to express RMR?}

There are extensive differences in the patterns of RMR when expressed as wholeorganism rates and mass-specific rates (Figure 3.6). Whole-organism RMRs are highest in families with relatively large-bodied species such as Bufonidae, Ceratophryidae, and Leptodactylidae (Figure 3.6A). In contrast, the highest mass-specific RMRs are for the small-bodied families such as Aromobatidae and Dendrobatidae (Figure 3.6B). The discrepancies between whole-organism RMR and mass-specific RMR are caused by the mass-scaling exponent $(\alpha)$. When $\alpha$ is less than one, the metabolic cost per gram decreases as organisms increase in size (while whole-organism metabolic rates increase). All else being equal, the smallest amphibians are expected to have the highest massspecific RMRs and the lowest whole-organism RMRs. Both whole-organism RMR and mass-specific RMR, while commonly used in the literature, will introduce biases as a function of body size into interspecific comparisons of metabolic rates.

For interspecific comparisons, metabolic rates should be expressed as masscorrected metabolic rates, corrected using the empirically-determined mass-scaling exponent. Some studies express mass-corrected rates using empirically determined scaling relationships. Other studies correct metabolic rates using the assumed universal mass-scaling exponent of 0.75 . However, many studies have found that mass-scaling 
exponents can be considerably different from 0.75 (Agutter \& Tuszynski 2011; Isaac \& Carbone 2010), and thus scaling exponents should be empirically determined for each study. In the absence of suitable data, the value of 0.75 is an appropriate option as a null model, as most studies have shown that averages across large groups of organisms converge close to 0.75 (Isaac \& Carbone 2010). However, if mass-scaling exponents are different than those assumed under MTE, using 0.75 could introduce bias as a function of body size.

It is important to note that there are applications for which it would be suitable to use mass-specific or whole-organism metabolic rates. For example, in modeling the energetic impacts of climate change, each measure has important contributions. Wholeorganism metabolic rates are useful for modeling and understanding impacts on total energetic requirements of an organism and its consequences for energy budgets and foraging requirements). Mass-specific metabolic rates are useful in calculating conversion efficiencies and connecting food webs and energetics across scales. However, the use of mass-specific or whole-organism metabolic rates in a comparative context will introduce significant biases.

\section{Comparisons among groups}

Among families, there are significant differences in the mass and temperaturecorrected RMR for day but not for night (Table 3.9; Figure 3.7). The lack of significance at night possibly results from increased variation in RMR during the night as compared to the day. High variance would be expected during the activity periods of amphibians, when there may be variation in physiological conditions associated with activity. 
Most families have higher RMRs at night than during the day. Most amphibians are nocturnal, and elevated metabolic rates during times of activity may facilitate energy availability for important activities such as foraging, reproduction, and predator avoidance. The only exceptions are for poison frogs in the families Aromobatidae (higher RMR during the day) and Dendrobatidae (similar RMR for day and night). Poison frogs are diurnal (Saporito et al. 2012), and thus metabolic rates would be expected to be relatively high during the day to coincide with activity times. While some poison frogs have often been found to have relatively high resting and active metabolic rates (e.g., Santos \& Cannatella 2011; Pough \& Taigen 1990), my study finds that the comparisons may be dependent on time of day. During the day, the diurnal families Aromobatidae and Dendrobatidae exhibit high RMR relative to other nocturnal groups, a pattern which is not observed at night. Other studies have also found metabolic rates of poison frogs to be higher during the day than at night (Taigen \& Pough 1983). However, many analyses do not report time of day of metabolic measurements and it is unclear how meta-analyses incorporate time of measurements into comparative analyses. It is possible that the relatively high metabolic rates of poison frogs found in some studies are an artefact of comparing daytime measurements of diurnal and nocturnal species combined with using mass-specific metabolic rates instead of mass-corrected metabolic rates.

Ceratophryidae has the lowest metabolic rate of all the families for both day and night. The single species in Ceratophryidae in my study, Ceratophrys cornuta, is a classic sit-and-wait predator (Duellman \& Lizana 1994). The extremely low metabolic rate may be adaptive in that low maintenance costs facilitate the sit-and-wait ecological strategy, allowing them to be energetically efficient while waiting for potential prey items. 
Relatively low metabolic rates for sit-and-wait predators have been found in other ectotherms such as snakes (Dupoué et al. 2017) and lizards (Andrews \& Pough 1985). It is relevant to note that, despite having the lowest mass and temperature corrected RMRs, Ceratophryidae has among the highest whole-organism metabolic rates as a result of large body size. Thus, whole-organism metabolic costs of increasing temperatures are likely to be high in species in the family Ceratophryidae.

While the mass and temperature-corrected metabolic rates among families exhibit notable patterns, it is important to note that corrected values were calculated using the same mass and temperature scaling parameters for each family. Using a single relationship for all groups may obscure important differences by forcing the regression through a common relationship. Indeed, calculations of the thermal sensitivity among four families (Figure 3.8) illustrate that there is considerable variation among families as well as between day and night. Correcting metabolic rates for mass and temperature using individual scaling relationships for each family may reveal distinct patterns that are obscured by using a single regression.

There also appears to be variation in thermal sensitivity among elevational groups (Figure 3.9). The $\mathrm{Q}_{10}$ value for the low elevation amphibians is less than one, suggesting that metabolic rate decreases with increasing temperature. While this is theoretically possible (Gangloff et al. 2016), the low $\mathrm{Q}_{10}$ value is likely an artefact of low thermal variability of lowland measurements, so that the relationship is driven more by individual variation in RMR rather than actual thermal effects. For mid and high elevations, the observed $\mathrm{Q}_{10}$ values have more relevance as there is sufficient thermal variation to calculate temperature sensitivity of RMR. It appears that the thermal sensitivity is higher 
for high elevation amphibians than for mid-elevation amphibians. High elevations are also predicted to have relatively high absolute increases in temperature (high exposure) as compared to the lowlands. High elevation amphibians may thus be highly vulnerable to metabolic impacts of climate change as a result of high exposure and the high thermal sensitivity of metabolism. More work is necessary to determine the extent to which organisms may be able to reduce exposure and/or sensitivity through responses including behavioral and physiological compensatory mechanisms, plasticity and acclimation, and adaptation (Huey et al. 2012; Moritz \& Agudo 2013; Urban et al. 2016).

\section{Climate change}

Elevated metabolic costs of maintenance may be a universal impact of rising temperatures across taxa and environments (Dillon et al. 2010; Moffett et al. 2018). In the absence of compensatory mechanisms, increased maintenance costs of individuals will decrease the energy available for allocation to other processes. As a result, the metabolic impacts of climate change may lead to decreased growth and adult body size (Gardner et al. 2011; Reading 2007; Zuo et al. 2012), reductions in reproductive allocation (Galloy \& Denoël 2010; Gibbons \& McCarthy 1986; Reading 1986), and low rates of survival (Reading 2007). Many impacts, particularly those affecting reproduction and survival, will cascade across scales to impact populations, communities, and ecosystems (Gilman et al. 2010; Hendry \& Green 2017; Post \& Palkovacs 2009; Vitousek 2012; Walther 2010).

Vulnerability to climate change will result from the combination of exposure, sensitivity, and potential for response. Tropical ectotherms may face both high exposure 
and high sensitivity to climatic changes as a result of low climatic variability typical of many tropical environments (Foden et al. 2013). My results suggest that tropical amphibians may have substantially higher thermal sensitivity in metabolism than found by past analyses (on the basis of a few, primarily temperate, amphibian species; Altman \& Dittmer 1974; Dillon et al. 2010; Gillooly et al. 2001). Thus, tropical ectotherms may be more highly impacted by climate change than suggested by previous studies. Moreover, the differences in thermal sensitivity among families and elevational groups (Figure 3.8; Figure 3.9) suggest that vulnerability may be further influenced by environmental conditions evolutionary history.

The potential for response to climate change broadly includes compensation (behavioral and physiological), plasticity and acclimation, and adaptation. Compensatory mechanisms to deal with increased maintenance costs could include reduced activity, increased foraging, reduced reproductive allocation, and complex changes in physiology and behavior (Huey et al. 2012). Compensation will likely depend on the interface between ecology, habitat, and behavior, and be further mediated by physiological characteristics. For example, as active foragers, the poison frogs of Aromobatidae and Dendrobatidae may be able to shift foraging times to increase energy intake and account for the potential increased energetic costs of resting metabolic rate as a result of climate change. The potential for mitigation through increased foraging assumes that prey abundance and availability will be similar or higher than current levels under ongoing climate change. Indirect impacts of climate change through species interactions will likely be important for species persistence (Gilman et al. 2010; Walther 2010), but few studies have examined how trophic interactions in amphibians will be impacted by 
climate change (Blaustein et al. 2010). Regardless of prey availability, sit-and-wait predators, such as $C$. cornuta (Ceratophryidae), will not be able to actively manipulate prey encounter rates, and thus may not be able to compensate for increased maintenance costs with increased prey captures. Sit-and-wait predators will thus be sensitive to changes in prey availability and encounter rates as a result of climate change.

The potential for plasticity and acclimation of metabolic traits to climatic changes has rarely been examined and merits further study. Physiological changes within individuals can occur both during development (plasticity) and within single life stages (acclimation). Latent effects from embryonic, larval, and juvenile environments are known to persist to adult life stages in amphibians, though it has rarely been studied in relations to metabolic rate. Beck and Congdon (2000) demonstrated that temperature and resource levels of larval environments can have significant effects on the size and age of metamorphosis as well as the metabolic rates of metamorphs. It is likely that plastic responses in development as a result of environmental conditions may be important in determining amphibian physiological characteristics across life stages in response to climate change. However, plastic responses to environmental conditions are not always beneficial, and more work is necessary to determine the potential effects that result from developmental plasticity and changing climatic conditions. The direction and magnitude of plastic responses will likely vary among taxa with diverse life histories and habitats. Acclimation potential of metabolic rates in amphibians differs among taxa and shows a strong latitudinal trend (Feder 1982). In a review of the literature, Feder (1982) found that acclimation was evident in all 22 temperate amphibian species that had been studied at that time. However, most tropical and subtropical amphibians display limited 
or no capacity for acclimation of metabolic rates to changing temperatures (Feder 1978; 1982). Even extended acclimation periods (27 days) had no discernable effect on oxygen consumption in Rhinella (Bufo) marina (Feder 1982). Chang and Hou (2005) found evidence for acclimation of metabolic rates in a subtropical frog but found that acclimation potential varied seasonally. Further research needs to address the large knowledge gap to determine if amphibians will be able to acclimate metabolic rates to changing climatic conditions.

Little is known about the genetic and epigenetic potential for adaptation of metabolism in amphibians. There are several studies that demonstrate consistent (i.e., repeatable) individual variation in metabolic rates in amphibians (Careau et al. 2014; Gomes et al. 2004), which is an important prerequisite for adaptation. However, no studies to date have examined the heritability or evolvability of metabolic characteristics in amphibians, so potential for selection is unknown. Heritability and evolvability of metabolic traits have been demonstrated in a variety of other taxa (e.g., Boratyński et al. 2013; Einum et al. 2019; Garland \& Bennett 1990; Mattila \& Hanski 2014; Wone et al. 2009). However, heritably varies considerably among studies and even among populations within the same species (Mathot et al. 2013). Thus, the potential for adaptation is likely taxon-specific and dependent on a variety of traits at the species and population levels.

In the absence of compensatory, acclimatory, and adaptive responses of metabolic characteristics to increasing temperatures, the metabolic impacts from climate change will lead to decreased adult body size in amphibians. Indeed, decreased size has been proposed to be one of the universal impacts of climate change. However, meta-analyses 
demonstrate that, as a result of the complex integration between body size and many ecological characteristics, there seem to be no universal patterns between climate change and body size (Gardner et al. 2011; Ohlberger 2013). Even within amphibians, the relationship between temperature and body size is complex (Sheridan et al. 2018). Nevertheless, some studies have found strong evidence for a link between climate change and declining amphibian body size (Caruso et al. 2014; Reading 2007). The effects of changing temperatures may be further complicated by the various scales and potentially conflicting selective pressures of temperature (e.g., mean vs. extremes; Gardner et al. 2011; Helmuth et al. 2005) and interactions with other climatic variables (Sheridan et al. 2018).

Nevertheless, rising temperatures will impact amphibians through both the metabolic costs of maintenance and the relationship between growth and differentiation (Zuo et al. 2012). Increased maintenance costs across life stages may decrease available energy for allocation to growth and thus decrease growth rates, causing relatively small body size across life stages. The metabolic impacts on growth rates may be compounded by acceleration of differentiation by increased temperatures (Zuo et al. 2012). In effect, rising temperatures may lower the ratio between rates of growth and differentiation and lead to faster development rates that lead to decreased sizes of various life stages from tadpoles through adults. Thus, the impacts of climate change may be compounded in amphibians through the combined effects of temperature on metabolism, growth, and development.

Body size has many important implications in amphibians. With highly permeable skin, amphibians are vulnerable to desiccation. Small body sizes will increase the surface 
area-to-volume ratio of amphibians and thus increase rates of desiccation and vulnerability to its effects (Newman \& Dunham 1994). High risk of desiccation, and desiccation avoidance behaviors, could have cascading impacts on behavior, habitat use, and reproductive activity. Reproduction itself is also highly dependent on body size in amphibians (Gibbons \& McCarthy 1986; Reading 1986). Large-bodied females tend to produce more eggs than smaller females (Gibbons \& McCarthy 1986; Reading 1986). Furthermore, male reproductive success is related to body size through effects on calling characteristics and female preference (Marquez 1993; Ryan 1990, 1991; Wilbur et al. 1978), duration and number of reproductive activities (Marquez 1993; Ryan 1991), direct male-to-male competition and mate choice (Berven 1981; Ryan 1990, 1991; Wells 1977), and offspring characteristics (Ryan 1991). Changes in amphibian body size will also likely affect trophic interactions, with decreasing sizes reducing the potential diet breadth of amphibians and increasing potential predators (Toft 1981; Wells 2007).

\section{Conclusions}

My study of tropical anurans has several important conclusions. First, it suggests that the high ecological diversity of amphibians belies a high physiological diversity in metabolism. Thus, the use of taxonomically and geographically restricted studies of amphibian physiology to extrapolate to amphibians as an entire group may obscure biologically significant variation. Second, tropical amphibian metabolism may have higher thermal sensitivity than has been typically found for other amphibians in past studies. Several studies that have demonstrated the high vulnerability of tropical amphibians may have underestimated potential impacts by using relatively low thermal 
sensitivity than what I have demonstrated in my study. Finally, small amphibians may be particularly vulnerable to metabolic impacts of climate change, which has extensive implications for the majority of amphibian biodiversity and relative vulnerability across life stages. The increased metabolic costs of maintenance are likely to have extensive impacts on growth, survival, and reproduction, with important implications for the conservation of tropical amphibians in the face of ongoing anthropogenic climate change.

\section{REFERENCES}

Adams DC. 2014. A generalized K statistic for estimating phylogenetic signal from shape and other high-dimensional multivariate data. Systematic Biology. 63(5):685-97

Adams DC, Collyer ML. 2018. Multivariate phylogenetic comparative methods: Evaluations, comparisons, and recommendations. Systematic Biology. 67(1):1431

Agutter PS, Tuszynski JA. 2011. Analytic theories of allometric scaling. Journal of Experimental Biology. 214(7):1055-62

Agutter PS, Wheatley DN. 2004. Metabolic scaling: Consensus or controversy? Theoretical Biology and Medical Modelling. 1:13

Allen AP, Gillooly JF, Brown JH. 2005. Linking the global carbon cycle to individual metabolism. Functional Ecology. 19(2):202-13

Altman PL, Dittmer DS, eds. 1974. Biology Data Book, Vol. III. Bethesda, Maryland, USA: Federation of American Societies for Experimental Biology. 2nd ed.

Andrews RM, Pough FH. 1985. Metabolism of squamate reptiles: Allometric and ecological relationships. Physiological Zoology. 58(2):214-31

Angilletta MJ Jr, Sears MW. 2000. The metabolic cost of reproduction in an oviparous lizard. Functional Ecology. 14(1):39-45

Angilletta MJ Jr, Wilson RS, Navas CA, James RS. 2003. Tradeoffs and the evolution of thermal reaction norms. Trends in Ecology \& Evolution. 18(5):234-40

Baettig MB, Wild M, Imboden DM. 2007. A climate change index: Where climate change may be most prominent in the 21st century. Geophysical Research Letters. 34(1):L01705 
Beck C, Congdon J. 2000. Effects of age and size at metamorphosis on performance and metabolic rates of southern toad, Bufo terrestris, metamorphs. Functional Ecology. 14:32-38

Beaulieu JM, Jhwueng DC, Boettiger C, O'Meara BC. 2012. Modeling stabilizing selection: Expanding the Ornstein-Uhlenbeck model of adaptive evolution. Evolution. 66(8):2369-83

Bennett AF. 1978. Activity metabolism of the lower vertebrates. Annual Review of Physiology. 40:447-69

Bernhardt JR, Sunday JM, O'Connor MI. 2018. Metabolic theory and the temperaturesize rule explain the temperature dependence of population carrying capacity. American Naturalist. 192(6):687-97

Berven KA. 1981. Mate choice in the wood frog, Rana sylvatica. Evolution. 35(4):707

Biek R, Funk WC, Maxell BA, Mills LS. 2002. What is missing in amphibian decline research: Insights from ecological sensitivity analysis. Conservation Biology. 16(3):728-34

Biro PA, Stamps JA. 2010. Do consistent individual differences in metabolic rate promote consistent individual differences in behavior? Trends in Ecology \& Evolution. 25(11):653-59

Blaustein AR, Walls SC, Bancroft BA, Lawler JJ, Searle CL, Gervasi SS. 2010. Direct and indirect effects of climate change on amphibian populations. Diversity. 2(2):281-313

Blomberg SP, Garland T Jr., Ives AR. 2003. Testing for phylogenetic signal in comparative data: Behavioral traits are more labile. Evolution. 57(4):717

Bokma F. 2004. Evidence against universal metabolic allometry. Functional Ecology. 18(2):184-87

Boratyński Z, Koskela E, Mappes T, Schroderus E. 2013. Quantitative genetics and fitness effects of basal metabolism. Evolutionary Ecology. 27(2):301-14

Brown AV, Fitzpatrick LC. 1981. Thermal acclimation and metabolism in the graybellied salamander, Eurycea multiplicata griseogaster (Plethodontidae). Comparative Biochemistry and Physiology Part A: Physiology. 69(3):505-9

Brown JH, Gillooly JF, Allen AP, Savage VM, West GB. 2004. Toward a metabolic theory of ecology. Ecology. 85(7):1771-89

Bruno JF, Carr LA, O'Connor MI. 2015. Exploring the role of temperature in the ocean through metabolic scaling. Ecology. 96(12):3126-40 
Buckley LB, Hurlbert AH, Jetz W. 2012. Broad-scale ecological implications of ectothermy and endothermy in changing environments. Global Ecology and Biogeography. 21(9):873-85

Buckley LB, Rodda GH, Jetz W. 2008. Thermal and energetic constraints on ectotherm abundance: A global test using lizards. Ecology. 89(1):48-55

Butler MA, King AA. 2004. Phylogenetic comparative analysis: A modeling approach for adaptive evolution. American Naturalist. 164(6):683-95

Capellini I, Venditti C, Barton RA. 2010. Phylogeny and metabolic scaling in mammals. Ecology. 91(9):2783-2793

Careau V, Gifford ME, Biro PA. 2014. Individual (co)variation in thermal reaction norms of standard and maximal metabolic rates in wild-caught slimy salamanders. Functional Ecology. 28(5):1175-86

Carey C. 1979. Effect of constant and fluctuating temperatures on resting and active oxygen consumption of toads, Bufo boreas. Oecologia. 39(2):201-12

Carey C. 2005. How physiological methods and concepts can be useful in conservation biology. Integrative and Comparative Biology. 45(1):4-11

Caruso NM, Sears MW, Adams DC, Lips KR. 2014. Widespread rapid reductions in body size of adult salamanders in response to climate change. Global Change Biology. 20(6):1751-59

Catenazzi A, Lehr E, May R. 2013. The amphibians and reptiles of Manu National Park and its buffer zone, Amazon basin and eastern slopes of the Andes, Peru. Biota Neotropica. 13(4):269-83

Catenazzi A, Lehr E, Rodriguez LO, Vredenburg VT. 2011. Batrachochytrium dendrobatidis and the collapse of anuran species richness and abundance in the upper Manu National Park, Southeastern Peru. Conservation Biology. 25(2):38291

Catenazzi A, Lehr E, Vredenburg VT. 2014. Thermal physiology, disease, and amphibian declines on the eastern slopes of the Andes. Conservation Biology. 28(2):509-17

Chang YM, Hou PCL. 2005. Thermal acclimation of metabolic rate may be seasonally dependent in the subtropical anuran Latouche's frog (Rana latouchii, Boulenger). Physiological and Biochemical Zoology. 78(6):947-55

Chown SL, Gaston KJ. 1999. Exploring links between physiology and ecology at macroscales: The role of respiratory metabolism in insects. Biological Reviews. 74(1):87-120 
Clarke A. 2003. Costs and consequences of evolutionary temperature adaptation. Trends in Ecology \& Evolution. 18(11):573-81

Clarke A. 2004. Is there a universal temperature dependence of metabolism? Functional Ecology. 18(2):252-56

Clarke A. 2006. Temperature and the metabolic theory of ecology. Functional Ecology. 20(2):405-12

Clarke A, Fraser KPP. 2004. Why does metabolism scale with temperature? Functional Ecology. 18(2):243-51

Clusella-Trullas S, Blackburn TM, Chown SL. 2011. Climatic predictors of temperature performance curve parameters in ectotherms imply complex responses to climate change. American Naturalist. 177(6):738-51

Crump ML, Scott NJ Jr. 1994. Visual encounter surveys. In Measuring and Monitoring Biological Diversity: Standard Methods for Amphibians, eds. WR Heyer, MA Donnelly, RW McDiarmid, LC Hayek, MS Foster, pp. 84-92. Washington, DC: Smithsonian Institution Press

Cushman SA. 2006. Effects of habitat loss and fragmentation on amphibians: A review and prospectus. Biological Conservation. 128(2):231-40

del Rio CM. 2008. Metabolic theory or metabolic models? Trends in Ecology \& Evolution. 23(5):256-60

Deutsch CA, Tewksbury JJ, Huey RB, Sheldon KS, Ghalambor CK, et al. 2008. Impacts of climate warming on terrestrial ectotherms across latitude. Proceedings of the National Academy of Sciences of the United States of America. 105(18):6668-72

Díaz-Uriarte R, Garland T Jr. 1996. Testing hypotheses of correlated evolution using phylogenetically independent contrasts: Sensitivity to deviations from Brownian motion. Systematic Biology. 45(1):27-47

Dillon ME, Wang G, Huey RB. 2010. Global metabolic impacts of recent climate warming. Nature. 467:704-6

Diniz-Filho JAF, Santos T, Rangel TF, Bini LM. 2012. A comparison of metrics for estimating phylogenetic signal under alternative evolutionary models. Genetics and Molecular Biology. 35(3):673-79

Doan TM. 2004. Extreme weather events and the vertical microhabitat of rain forest anurans. Journal of Herpetology. 38(3):422-25

Duellman WE, Lizana M. 1994. Biology of a sit-and-wait predator, the leptodactylid frog Ceratophrys cornuta. Herpetologica. 50(1):51-64 
Dupoué A, Brischoux F, Lourdais O. 2017. Climate and foraging mode explain interspecific variation in snake metabolic rates. Proceedings of the Royal Society B: Biological Sciences. 284(1867):20172108

Ehnes RB, Rall BC, Brose U. 2011. Phylogenetic grouping, curvature and metabolic scaling in terrestrial invertebrates. Ecology Letters. 14(10):993-1000

Einum S, Fossen EIF, Parry V, Pélabon C. 2019. Genetic variation in metabolic rate and correlations with other energy budget components and life history in Daphnia magna. Evolutionary Biology. 46(2):1

Ellenberg H. 1979. Man's influence on tropical mountain ecosystems in South America: The second Tansley lecture. Journal of Ecology. 67(2):401-16

Enquist BJ, Norberg J, Bonser SP, Violle C, Webb CT, et al. 2015. Scaling from traits to ecosystems: Developing a general trait driver theory via integrating trait-based and metabolic scaling theories. In Advances in Ecological Research, Vol. 52, pp. 249-318. Waltham, Maryland, USA: Academic Press

Enquist BJ, Tiffney BH, Niklas KJ. 2007. Metabolic scaling and the evolutionary dynamics of plant size, form, and diversity: Toward a synthesis of ecology, evolution, and paleontology. International Journal of Plant Sciences. 168(5):72949

Feder ME. 1978. Environmental variability and thermal acclimation in neotropical and temperate zone salamanders. Physiological Zoology. 51(1):7-16

Feder ME. 1982. Environmental variability and thermal acclimation of metabolism in tropical anurans. Journal of Thermal Biology. 7(1):23-28

Feeley KJ, Rehm EM, Machovina B. 2012. The responses of tropical forest species to global climate change: Acclimate, adapt, migrate, or go extinct? Frontiers of Biogeography. 4(2):69-84

Fei Y, Hou R, Spotila JR, Paladino FV, Qi D, Zhang Z. 2016. Metabolic rates of giant pandas inform conservation strategies. Scientific Reports. 6:1-11

Fetcher N, Oberbauer SF, Strain BR. 1985. Vegetation effects on microclimate in lowland tropical forest in Costa Rica. International Journal of Biometeorology. 29(2):145-55

Felsenstein J. 1985. Phylogenies and the comparative method. American Naturalist. 125(1):1-15 
Fitzpatrick LC, Bristol JR, Stokes RM. 1972. Thermal acclimation and metabolic rates in the dusky salamander Desmognathus fuscus. Comparative Biochemistry and Physiology Part A: Physiology. 41(1):89-96

Foden WB, Butchart SHM, Stuart SN, Vié JC, Akçakaya HR, et al. 2013. Identifying the world's most climate change vulnerable species: A systematic trait-based assessment of all birds, amphibians and corals. PLoS ONE. 8(6):e65427

Francis CD, Donald JW, Fuxjager MJ, Goymann W, Hau M, et al. 2018. Metabolic scaling of stress hormones in vertebrates. Integrative and Comparative Biology. 58(4):729-38

Freckleton RP, Harvey PH. 2006. Detecting non-Brownian trait evolution in adaptive radiations. PLoS Biology. 4(11):2104-11

Frost DR, Grant T, Faivovich J, Bain RH, Haas A, et al. 2006. The amphibian tree of life. Bulletin of the American Museum of Natural History. 297(297):1-291

Galloy V, Denoël M. 2010. Detrimental effect of temperature increase on the fitness of an amphibian (Lissotriton helveticus). Acta Oecologica. 36(2):179-83

Gangloff EJ, Holden KG, Telemeco RS, Baumgard LH, Bronikowski AM. 2016. Hormonal and metabolic responses to upper temperature extremes in divergent life-history ecotypes of a garter snake. Journal of Experimental Biology. 219(18):2944-54

Gardner JL, Peters A, Kearney MR, Joseph L, Heinsohn R. 2011. Declining body size: A third universal response to warming? Trends in Ecology \& Evolution. 26(6):28591

Garland T Jr, Bennett AF. 1990. Quantitative genetics of maximal oxygen consumption in a garter snake. American Journal of Physiology-Regulatory, Integrative and Comparative Physiology. 259(5):R986-92

Garland T Jr., Bennett AF, Rezende EL. 2005. Phylogenetic approaches in comparative physiology. Journal of Experimental Biology. 208(16):3015-35

Garreaud RD. 1999. Cold air incursions over subtropical and tropical South America: A numerical case study. Monthly Weather Review. 127(12):2823-53

Gibbons MM, McCarthy TK. 1986. The reproductive output of frogs Rana temporaria (L.) with particular reference to body size and age. Journal of Zoology. 209(4):579-93

Gillooly JF, Brown JH, West GB, Savage VM, Charnov EL. 2001. Effects of size and temperature on metabolic rate. Science. 293:2248-51 
Gilman SE, Urban MC, Tewksbury JJ, Gilchrist GW, Holt RD. 2010. A framework for community interactions under climate change. Trends in Ecology \& Evolution. 25(6):325-31

Glazier DS. 2015. Is metabolic rate a universal "pacemaker” for biological processes? Biological Reviews. 90(2):377-407

Gomes FR, Chaui-Berlinck JG, Bicudo JEPW, Navas CA. 2004. Intraspecific relationships between resting and activity metabolism in anuran amphibians: Influence of ecology and behavior. Physiological and Biochemical Zoology. 77(2):197-208

Goolsby EW, Bruggeman J, Ané C. 2017. Rphylopars: Fast multivariate phylogenetic comparative methods for missing data and within-species variation. Methods in Ecology and Evolution. 8(1):22-27

Gray MJ, Miller DL, Hoverman JT. 2009. Ecology and pathology of amphibian ranaviruses. Diseases of Aquatic Organisms. 87(3):243-66

Guariguata MR, Ostertag R. 2008. Neotropical secondary forest succession: Changes in structural and functional characteristics. Forest Ecology and Management. 38(1):255-65

Hansen TF. 1997. Stabilizing selection and the comparative analysis of adaptation. Evolution. 51(5):1341

Helmuth B, Kingsolver JG, Carrington E. 2005. Biophysics, physiological ecology, and climate change: Does mechanism matter? Annual Review of Physiology. 67:177201

Hendry AP, Green DM. 2017. Eco-evolutionary dynamics in cold blood. Copeia. 105(3):441-50

Hennemann WW. 1983. Relationship among body mass, metabolic rate and the intrinsic rate of natural increase in mammals. Oecologia. 56(1):104-8

Hofmann GE, Todgham AE. 2010. Living in the now: Physiological mechanisms to tolerate a rapidly changing environment. Annual Review of Physiology. 72(1):127-45

Huey RB, Deutsch CA, Tewksbury JJ, Vitt LJ, Hertz PE, et al. 2009. Why tropical forest lizards are vulnerable to climate warming. Proceedings of the Royal Society B: Biological Sciences. 276(1664):1939-48

Huey RB, Kearney MR, Krockenberger A, Holtum JAM, Jess M, Williams SE. 2012. Predicting organismal vulnerability to climate warming: Roles of behaviour, 
physiology and adaptation. Philosophical Transactions of the Royal Society of London B: Biological Sciences. 367(1596):1665-79

Jenkins CN, Pimm SL, Joppa LN. 2013. Global patterns of terrestrial vertebrate diversity and conservation. Proceedings of the National Academy of Sciences of the United States of America. 110(28):E2603-10

Iles AC. 2014. Toward predicting community-level effects of climate: Relative temperature scaling of metabolic and ingestion rates. Ecology. 95(9):2657-68

Isaac NJB, Carbone C. 2010. Why are metabolic scaling exponents so controversial? Quantifying variance and testing hypotheses. Ecology Letters. 13(6):728-35

Johnson ML, Berger L, Philips L, Speare R. 2003. Fungicidal effects of chemical disinfectants, UV light, desiccation and heat on the amphibian chytrid Batrachochytrium dendrobatidis. Diseases of Aquatic Organisms. 57:255-60

Kearney MR, White CR. 2012. Testing metabolic theories. American Naturalist. 180(5):546-65

Killeen TJ, Douglas M, Consiglio T, Jørgensen PM, Mejia J. 2007. Dry spots and wet spots in the Andean hotspot. Journal of Biogeography. 34(8):1357-73

Kleiber M. 1932. Body size and metabolism. Hilgardia. 6(11):315-53

Kolokotrones T, Savage V, Deeds EJ, Fontana W. 2010. Curvature in metabolic scaling. Nature. 464:753-56

Kurta A, Ferkin M. 1991. The correlation between demography and metabolic rate: A test using the beach vole (Microtus breweri) and the meadow vole (Microtus pennsylvanicus). Oecologia. 87(1):102-5

Lardies MA, Bozinovic F. 2006. Geographic covariation between metabolic rate and lifehistory traits. Evolutionary Ecology Research. 8(3):455-70

Lawton JH. 1991. From physiology to population dynamics and communities. Functional Ecology. 5(2):155

Lighton JRB. 2008. Measuring Metabolic Rates: A Manual for Scientists. Oxford, UK: Oxford University Press

Linder GL, Krest S, Sparling D, Little EE, eds. 2003. Multiple Stressor Effects in Relation to Declining Amphibian Populations. West Conshohocken, Pennsylvania, USA: American Society for Testing and Materials International 
Lugo MA, Ferrero M, Menoyo E, Estévez MC, Siñeriz F, Anton A. 2008. Arbuscular mycorrhizal fungi and rhizospheric bacteria diversity along an altitudinal gradient in South American puna grassland. Microbial Ecology. 55(4):705-13

Malishev M, Bull CM, Kearney MR. 2018. An individual-based model of ectotherm movement integrating metabolic and microclimatic constraints. Methods in Ecology and Evolution. 9(3):472-89

Marquet PA, Labra FA, Maurer BA. 2004. Metabolic ecology: Linking individuals to ecosystems. Ecology. 85(7):1794-96

Márquez R. 1993. Male reproductive success in two midwife toads, Alytes obstetricans and A. cisternasii. Behavioral Ecology and Sociobiology. 32(4):283-91

Martins EP, Garland T Jr. 1991. Phylogenetic analyses of the correlated evolution of continuous characters: A simulation study. Evolution. 45(3):534

Mathot KJ, Martin K, Kempenaers B, Forstmeier W. 2013. Basal metabolic rate can evolve independently of morphological and behavioural traits. Heredity. 111(3):175-81

Mattila ALK, Hanski I. 2014. Heritability of flight and resting metabolic rates in the Glanville fritillary butterfly. Journal of Evolutionary Biology. 27(8):1733-43

Moffett ER, Fryxell DC, Palkovacs EP, Kinnison MT, Simon KS. 2018. Local adaptation reduces the metabolic cost of environmental warming. Ecology. 99(10):1-9

Moritz C, Agudo R. 2013. The future of species under climate change: Resilience or decline? Science. 341(6145):504-8

Myers N, Mittermeier RA, Mittermeier CG, da Fonseca GAB, Kent J. 2000. Biodiversity hotspots for conservation priorities. Nature. 403:853-58

Narins PM, Meenderink SWF. 2014. Climate change and frog calls: Long-term correlations along a tropical altitudinal gradient. Proceedings of the Royal Society B: Biological Sciences. 281(1783): 20140401

Navas CA. 1996. Metabolic physiology, locomotor performance, and thermal niche breadth in neotropical anurans. Physiological Zoology. 69(6):1481-1501

Navas CA. 1997. Thermal extremes at high elevations in the Andes: Physiological ecology of frogs. Journal of Thermal Biology. 22(6):467-77

Nemergut DR, Anderson SP, Cleveland CC, Martin AP, Miller AE, et al. 2007. Microbial community succession in an unvegetated, recently deglaciated soil. Microbial Ecology. 53(1):110-22 
Nespolo RF, Figueroa J, Solano-Iguaran JJ. 2017a. Studying the evolutionary significance of thermal adaptation in ectotherms: The diversification of amphibians' energetics. Journal of Thermal Biology. 68:5-13

Nespolo RF, Solano-Iguaran JJ, Bozinovic F. 2017b. Phylogenetic analysis supports the aerobic-capacity model for the evolution of endothermy. American Naturalist. 189(1):13-27

Newman RA, Dunham AE. 1994. Size at metamorphosis and water loss in a desert anuran (Scaphiopus couchii). Copeia. 1994(2):372-81

Ohlberger J. 2013. Climate warming and ectotherm body size - from individual physiology to community ecology. Functional Ecology. 27(4):991-1001

Ortega JV, Whitworth A, Burdekin O. 2013. Osteocephalus mimeticus (Melin, 1941) (Amphibia: Anura: Hylidae): New locality, range extension and notes on distribution. Check List. 9(5):1126

Pacifici M, Foden WB, Visconti P, Watson JEM, Butchart SHM, et al. 2015. Assessing species vulnerability to climate change. Nature Climate Change. 5(3):215-24

Palin O, Eggleton P, Malhi Y. 2011. Termite diversity along an Amazon-Andes elevation gradient, Peru. Biotropica. 43(1):100-107

Petrovan SO, Schmidt BR. 2019. Neglected juveniles; a call for integrating all amphibian life stages in assessments of mitigation success (and how to do it). Biological Conservation. 236(November 2018):252-60

Pettersen AK, White CR, Marshall DJ. 2016. Metabolic rate covaries with fitness and the pace of the life history in the field. Proceedings of the Royal Society B: Biological Sciences. 283(1831):20160323

Phillott AD, Speare R, Hines HB, Skerratt LF, Meyer E, et al. 2010. Minimising exposure of amphibians to pathogens during field studies. Diseases of Aquatic Organisms. 92(3):175-85

Pitman NCA. 2010. An overview of the Los Amigos watershed, Madre de Dios, southeastern Peru. Draft report for Amazon Conservation Association. (February): $1-87$

Poremba RJ, Perry LB, Seimon A, Martin DT, Tupayachi A. 2015. Meteorological characteristics of heavy snowfall events in the Cordillera Vilcanota, Peru. 72nd Eastern Snow Conference, pp. 167-80

Porter WP, Kearney M. 2009. Size, shape, and the thermal niche of endotherms. Proceedings of the National Academy of Sciences. 106:19666-72 
Post DM, Palkovacs EP. 2009. Eco-evolutionary feedbacks in community and ecosystem ecology: Interactions between the ecological theatre and the evolutionary play. Philosophical Transactions of the Royal Society B: Biological Sciences. 364(1523):1629-40

Pough FH, Taigen TL. 1990. Metabolic correlates of the foraging and social behaviour of dart-poison frogs. Animal Behaviour. 39(1):145-55

Presley SJ, Cisneros LM, Patterson BD, Willig MR. 2012. Vertebrate metacommunity structure along an extensive elevational gradient in the tropics: A comparison of bats, rodents and birds. Global Ecology and Biogeography. 21(10):968-76

Prokosch J, Bernitz Z, Bernitz H, Erni B, Altwegg R. 2019. Are animals shrinking due to climate change? Temperature-mediated selection on body mass in mountain wagtails. Oecologia. 189(3):841-49

Pyron RA, Wiens JJ. 2011. A large-scale phylogeny of Amphibia including over 2800 species, and a revised classification of extant frogs, salamanders, and caecilians. Molecular Phylogenetics and Evolution. 61(2):543-83

R Core Team. 2019. R: A language and environment for statistical computing. Vienna, Austria: R Foundation for Statistical Computing

Rainford JL, Hofreiter M, Mayhew PJ. 2016. Phylogenetic analyses suggest that diversification and body size evolution are independent in. BMC Evolutionary Biology. 16(1):1-17

Rapp JM, Silman MR. 2012. Diurnal, seasonal, and altitudinal trends in microclimate across a tropical montane cloud forest. Climate Research. 55(1):17-32

Reading CJ. 1986. Egg production in the common toad, Bufo bufo. Journal of Zoology. 208(1):99-107

Reading CJ. 2007. Linking global warming to amphibian declines through its effects on female body condition and survivorship. Oecologia. 151(1):125-31

Rittenhouse TAG, Harper EB, Rehard LR, Semlitsch RD. 2008. The role of microhabitats in the desiccation and survival of anurans in recently harvested oak-hickory forest. Copeia. 2008(4):807-14

Rohr JR, Palmer BD. 2013. Climate change, multiple stressors, and the decline of ectotherms. Conservation Biology. 27(4):741-51

Rothermel BB, Semlitsch RD. 2002. An experimental investigation of landscape resistance of forest versus old-field habitats to emigrating juvenile amphibians. Conservation Biology. 16(5):1324-32 
Ryan MJ. 1990. Signals, species, and sexual selection. American Scientist. 78(1):46-52

Ryan MJ. 1991. Sexual selection and communication in frogs. Trends in Ecology \& Evolution. 6(11):351-55

Santos JC. 2012. Fast molecular evolution associated with high active metabolic rates in poison frogs. Molecular Biology and Evolution. 29(8):2001-18

Santos JC, Cannatella DC. 2011. Phenotypic integration emerges from aposematism and scale in poison frogs. Proceedings of the National Academy of Sciences of the United States of America. 108(15):6175-80

Saporito RA, Donnelly MA, Spande TF, Garraffo HM. 2012. A review of chemical ecology in poison frogs. Chemoecology. 22(3):159-68

Schmidt SK, Nemergut DR, Miller AE, Freeman KR, King AJ, Seimon A. 2009. Microbial activity and diversity during extreme freeze-thaw cycles in periglacial soils, 5400 m elevation, Cordillera Vilcanota, Perú. Extremophiles. 13(5):807-16

Sears MW. 2005. Resting metabolic expenditure as a potential source of variation in growth rates of the sagebrush lizard. Comparative Biochemistry and Physiology Part A: Molecular \& Integrative Physiology. 140(2):171-77

Seimon TA, Seimon A, Daszak P, Halloy SRP, Schloegel LM, et al. 2007. Upward range extension of Andean anurans and chytridiomycosis to extreme elevations in response to tropical deglaciation. Global Change Biology. 13(1):288-99

Seimon TA, Seimon A, Yager K, Reider K, Delgado A, et al. 2017. Long-term monitoring of tropical alpine habitat change, Andean anurans, and chytrid fungus in the Cordillera Vilcanota, Peru: Results from a decade of study. Ecology and Evolution. 7(5):1527-40

Sheridan JA, Caruso NM, Apodaca JJ, Rissler LJ. 2018. Shifts in frog size and phenology: Testing predictions of climate change on a widespread anuran using data from prior to rapid climate warming. Ecology and Evolution. 8(2):1316-27

Shik JZ, Arnan X, Oms CS, Cerdá X, Boulay R. 2019. Evidence for locally adaptive metabolic rates among ant populations along an elevational gradient. Journal of Animal Ecology. 88(8):1240-49

Shoo LP, Storlie C, Williams YM, Williams SE. 2010. Potential for mountaintop boulder fields to buffer species against extreme heat stress under climate change. International Journal of Biometeorology. 54(4):475-78

Sibly RM, Brown JH, Kodric-Brown A. 2012. Metabolic Ecology: A Scaling Approach. Chichester, West Sussex, UK: Wiley-Blackwell 
Sinsch U. 1989. Behavioural thermoregulation of the Andean toad (Bufo spinulosus) at high altitudes. Oecologia. 80:32-38

Stegen JC, Enquist BJ, Ferriere R. 2009. Advancing the metabolic theory of biodiversity. Ecology Letters. 12(10):1001-15

Stevenson RD. 1985. The relative importance of behavioral and physiological adjustments controlling body temperature in terrestrial ectotherms. American Naturalist. 126(3):362-86

Sunday JM, Bates AE, Dulvy NK. 2011. Global analysis of thermal tolerance and latitude in ectotherms. Proceedings of the Royal Society B: Biological Sciences. 278(1713):1823-30

Sunday JM, Bates AE, Kearney MR, Colwell RK, Dulvy NK, et al. 2014. Thermal-safety margins and the necessity of thermoregulatory behavior across latitude and elevation. Proceedings of the National Academy of Sciences of the United States of America. 111(15):5610-15

Taigen TL, Pough FH. 1983. Prey preference, foraging behavior, and metabolic characteristics of frogs. American Naturalist. 122(4):509-20

Taigen TL, Pough FH. 1985. Metabolic correlates of anuran behavior. Integrative and Comparative Biology. 25(4):987-97

Tewksbury JJ, Huey RB, Deutsch CA. 2008. Putting the heat on tropical animals. Science. 320(5881):1296-97

Tittensor DP, Worm B. 2016. A neutral-metabolic theory of latitudinal biodiversity. Global Ecology and Biogeography. 25(6):630-41

Toft CA. 1981. Feeding ecology of panamanian litter anurans: Patterns in diet and foraging mode. Journal of Herpetology. 15(2):139-44

Tracy CR, Christian KA, Tracy CR. 2010. Not just small, wet, and cold: Effects of body size and skin resistance on thermoregulation and arboreality of frogs. Ecology. 91(5):1477-84

Urban MC, Bocedi G, Hendry AP, Mihoub JB, Pe'er G, et al. 2016. Improving the forecast for biodiversity under climate change. Science. 353(6304): aad8466

Uyeda JC, Pennell MW, Miller ET, Maia R, McClain CR, et al. 2017. The evolution of energetic scaling across the vertebrate tree of life. American Naturalist. 190(2):185-99

van der Meer J. 2006. Metabolic theories in ecology. Trends in Ecology \& Evolution. 21(3):136-40 
Vitousek PM. 2012. Beyond global warming. Ecology. 75(7):1861-76

von Bertalanffy L. 1951. Metabolic types and growth types. American Naturalist. 85(821):111-17

von May R, Catenazzi A, Corl A, Santa-Cruz R, Carnaval AC, Moritz C. 2017. Divergence of thermal physiological traits in terrestrial breeding frogs along a tropical elevational gradient. Ecology and Evolution. 7(9):3257-67

von May R, Catenazzi A, Santa-Cruz R, Gutierrez AS, Moritz C, Rabosky DL. 2019. Thermal physiological traits in tropical lowland amphibians: Vulnerability to climate warming and cooling. PLoS ONE. 14(8):e0219759

von May R, Medina-Müller M, Donnelly MA, Summers K. 2009. Breeding-site selection by the poison frog Ranitomeya biolat in Amazonian bamboo forests: An experimental approach. Canadian Journal of Zoology. 87(5):453-64

Walther GR. 2010. Community and ecosystem responses to recent climate change. Philosophical Transactions of the Royal Society of London B: Biological Sciences. 365(1549):2019-24

Wells KD. 1977. Territoriality and male mating success in the green frog (Rana clamitans). Ecology. 58(4):750-62

Wells KD. 2007. The Ecology and Behavior of Amphibians. Chicago, Illinois, USA: The University of Chicago Press

White CR, Phillips NF, Seymour RS. 2006. The scaling and temperature dependence of vertebrate metabolism. Biology Letters. 2(1):125-27

White CR, Seymour RS. 2004. Does basal metabolic rate contain a useful signal? Mammalian BMR allometry and correlations with a selection of physiological, ecological, and life-history variables. Physiological and Biochemical Zoology. 77(6):929-41

Wilbur HM, Rubenstein DI, Fairchild L. 1978. Sexual selection in toads: The roles of female choice and male body size. Evolution. 32(2):264

Wone B, Sears MW, Labocha MK, Donovan ER, Hayes JP. 2009. Genetic variances and covariances of aerobic metabolic rates in laboratory mice. Proceedings of the Royal Society B: Biological Sciences. 276(1673):3695-3704

Woodley SK. 2017. Life in the slow lane: Stress responses in plethodontid salamanders. Herpetologica. 73(3):259-68 
Yuan FL, Freedman AH, Chirio L, LeBreton M, Bonebrake TC. 2018. Ecophysiological variation across a forest-ecotone gradient produces divergent climate change vulnerability within species. Ecography. 41(10):1627-37

Žagar A, Carretero MA, Marguč D, Simčič T, Vrezec A. 2018. A metabolic syndrome in terrestrial ectotherms with different elevational and distribution patterns.

Ecography. 41(10):1728-39

Zuo W, Moses ME, West GB, Hou C, Brown JH. 2012. A general model for effects of temperature on ectotherm ontogenetic growth and development. Proceedings of the Royal Society B: Biological Sciences. 279(1734):1840-46 
Table 3.1. Field sites and elevational ranges along the elevational gradient in southeastern Peru.

\begin{tabular}{|c|c|c|c|c|}
\hline Location & $\begin{array}{c}\text { Managing } \\
\text { organization }\end{array}$ & $\begin{array}{c}\text { Elevational } \\
\text { range }\end{array}$ & $\begin{array}{c}\text { Station } \\
\text { elevations }\end{array}$ & References \\
\hline CICRA & ACCA & $224-297 \mathrm{~m}$ & $268 \mathrm{~m}$ & Pitman 2010 \\
\hline $\begin{array}{c}\text { Manu Learning } \\
\text { Centre }\end{array}$ & CREES & $450-550 \mathrm{~m}$ & $460 \mathrm{~m}$ & Ortega et al. 2013 \\
\hline Villa Carmen & $\mathrm{ACCA}$ & $500-750 \mathrm{~m}$ & $530 \mathrm{~m}$ & von May et al. 2017 \\
\hline $\begin{array}{c}\text { Reserva } \\
\text { Ecológica } \\
\text { Chontachaka }\end{array}$ & & $800-1200 \mathrm{~m}$ & $915 \mathrm{~m}$ & \\
\hline San Pedro & Perú Verde & $1100-1800 \mathrm{~m}$ & $1400 \mathrm{~m}$ & von May et al. 2017 \\
\hline Wayqecha & ACCA & $1800-3700 \mathrm{~m}$ & $3025 \mathrm{~m}$ & Palin et al. 2011 \\
\hline $\begin{array}{l}\text { Cordillera } \\
\text { Vilcanota }\end{array}$ & & $4000-5400 \mathrm{~m}$ & $\begin{array}{l}4800 \mathrm{~m} \\
5240 \mathrm{~m}\end{array}$ & $\begin{array}{l}\text { Poremba et al. 2015; } \\
\text { Seimon et al. 2007, } \\
2017\end{array}$ \\
\hline
\end{tabular}


Table 3.2. Models of evolution used to examine evolutionary patterns in resting metabolic rate of tropical amphibians.

\begin{tabular}{|c|c|c|}
\hline Model & Parameters & Description \\
\hline $\begin{array}{l}\text { Brownian } \\
\text { Motion }\end{array}$ & None & $\begin{array}{l}\text { Multivariate implementation of a random walk along the } \\
\text { phylogeny. Evolution across the tree is represented by an } \\
\text { initial mean trait value and a standard deviation representing } \\
\text { rate of random walk across the tree. }\end{array}$ \\
\hline $\begin{array}{c}\text { White Noise } \\
\text { / Star }\end{array}$ & Single & $\begin{array}{l}\text { Also known as a star phylogeny, it is a model represented } \\
\text { completely random trait values with no influence of } \\
\text { phylogeny. It assumes a lambda of zero which transforms all } \\
\text { branch lengths to zero and thus is a representation of trait } \\
\text { values with no influence of phylogeny. }\end{array}$ \\
\hline Lambda & Single & $\begin{array}{c}\text { A transformation of the tree branch lengths to represent the } \\
\text { phylogeny based on trait values under the assumptions of a } \\
\text { Brownian Motion model of evolution. The single value of } \\
\text { lambda is determined based on all traits and applied across the } \\
\text { phylogeny. }\end{array}$ \\
\hline Early Burst & Single & $\begin{array}{l}\text { A mode of evolution where the rapid evolutionary change } \\
\text { occurs during the early branches and slows down during later } \\
\text { branches, described as a rate of change in evolutionary } \\
\text { diversification across the tree. A single rate is applied to all } \\
\text { traits across the tree. }\end{array}$ \\
\hline $\begin{array}{l}\text { Ornstein- } \\
\text { Uhlenbeck }\end{array}$ & Single & $\begin{array}{l}\text { A modification of the Brownian Motion model of evolution } \\
\text { that includes an alpha term that represents the strength of } \\
\text { stabilizing selection towards an "optimal" value (the ancestral } \\
\text { reconstructed mean for a single optima). For this model, a } \\
\text { single alpha value is fitted for all traits. }\end{array}$ \\
\hline mvOU1 & $\begin{array}{l}\text { Diagonal alpha } \\
\text { matrix }\end{array}$ & $\begin{array}{l}\text { A multivariate implementation of the Ornstein-Uhlenbeck } \\
\text { model that considers distinct alpha values for each individual } \\
\text { trait. This is represented by an alpha matrix with distinct alpha } \\
\text { values for each trait, but no correlation between traits } \\
\text { affecting the strength of adaptation. }\end{array}$ \\
\hline mvOU2 & $\begin{array}{l}\text { Full alpha } \\
\text { matrix }\end{array}$ & $\begin{array}{l}\text { A multivariate implementation of the Ornstein-Uhlenbeck } \\
\text { model that considers distinct alpha values for each individual } \\
\text { trait and possible coevolution between traits. This is } \\
\text { represented by a full alpha matrix with distinct alpha values } \\
\text { for each trait and further accounts for the strength of } \\
\text { intraspecific correlation between traits and its effect on the } \\
\text { alpha parameter. }\end{array}$ \\
\hline
\end{tabular}


Table 3.3. Results from repeated measures analysis of variance (ANOVA) between day and night. Significant results indicate that measurements are significantly different between day and night while accounting for the repeated measures of individuals.

\begin{tabular}{ccccccc}
\hline Level & term & df & SS & MS & F & p \\
\hline ID:Time & time & 1 & 911.044 & 911.044 & 1085.519 & $<0.001 * * *$ \\
ID & Residuals & 87 & 368.127 & 4.231 & NA & NA \\
ID:Time & Residuals & 87 & 73.017 & 0.839 & NA & NA \\
\hline
\end{tabular}

Levels of significance: $* \mathrm{p}<0.05$; ** $\mathrm{p}<0.01$; *** $\mathrm{p}<0.001$. 
Table 3.4. The analysis of phylogenetic signal for the univariate and multivariate datasets of resting metabolic rate (RMR) for day and night. The variables included are mass, elevation, RMRd, Td, RMRn, and Tn. The univariate measures of phylogenetic signal for day and night (RMRd and RMRn, respectively) are the univariate constructions of Blomberg's $K$ and Pagel's $\lambda$. The phylogenetic signal of the other four datasets are calculated using the multivariate constructions of $K$ and $\lambda$. The total dataset uses the entire dataset with missing values, the complete dataset has all observations with any missing data removed, the day and night measurements only include the complete measurements of day and night measurements.

\begin{tabular}{cccccc}
\hline Time & Dataset & $\boldsymbol{K}$ & P-value & $\lambda$ & $\mathbf{p}$ \\
\hline \multirow{2}{*}{ Day } & Univariate & 0.583 & 0.001 & 0.957 & $<0.001 * * *$ \\
& Multivariate & 0.818 & $<0.001$ & 0.945 & $<0.001 * * *$ \\
\hline \multirow{2}{*}{ Night } & Univariate & 0.660 & 0.002 & 1.009 & $<0.001 * * *$ \\
& Multivariate & 0.814 & $<0.001$ & 0.974 & $<0.001 * * *$ \\
\hline
\end{tabular}

Levels of significance: $* \mathrm{p}<0.05 ; * * \mathrm{p}<0.01 ; * * * \mathrm{p}<0.001$. 
Table 3.5. Comparisons of model support by Akaike Information Criterion (AIC) for evolutionary models for day and night. The most supported evolutionary model for night is the mvOU1 model, a multivariate Ornstein-Uhlenbeck model assuming that adaptation (alpha) acts only on individual traits, and not on the relationship between traits. There were multiple supported models in for the daytime dataset, and the mvOU1 model was the fourth most supported model. Further analyses were run on mvOU1 models to facilitate comparisons between measurements during the day and night.

\begin{tabular}{cccccc}
\hline & \multicolumn{3}{c}{ Day } & \multicolumn{2}{c}{ Night } \\
Model & $\mathbf{d F}$ & $\mathbf{l n L}$ & AIC & $\mathbf{l n L}$ & AIC \\
\hline Brownian Motion & 20 & -16380.5 & $\mathbf{3 2 8 0 1 . 0 7}$ & -17459.2 & 34958.43 \\
White Noise & 20 & -16407.5 & 32854.91 & -17495.9 & 35031.9 \\
Lambda & 21 & -16377.6 & $\mathbf{3 2 7 9 7 . 2 9}$ & -17457.7 & 34957.41 \\
Early Burst & 21 & -16380.5 & $\mathbf{3 2 8 0 3 . 0 7}$ & -17459.2 & 34960.43 \\
Ornstein-Uhlenbeck & 21 & -16367.6 & 32777.23 & -17453.8 & 34949.6 \\
mvOU1 & $\mathbf{2 4}$ & $\mathbf{- 1 6 3 8 3 . 6}$ & $\mathbf{3 2 8 1 5 . 1 7}$ & $\mathbf{- 1 7 4 4 5 . 3}$ & $\mathbf{3 4 9 3 8 . 5 4}$ \\
mvOU2 & 30 & -16362.5 & 32784.97 & -17506.8 & 35073.68 \\
\hline
\end{tabular}


Table 3.6. Comparisons of model support by Akaike Information Criterion (AIC) of phylogenetic regressions of resting metabolic rate (RMR) against mass, temperature (T) and elevation (ele). The regressions were performed using generalized least squares regression using the mvOU1 model for both day and night. The AIC values demonstrate that the log-transformed RMR and log-transformed mass (natural logarithms) result in better fits than untransformed regressions. The most supported model across both day and night includes both mass and temperature with an interaction between them. The best supported models by AIC for day and night are in bold.

\begin{tabular}{|c|c|c|c|c|c|}
\hline \multirow[b]{2}{*}{ Model } & \multirow[b]{2}{*}{ df } & \multicolumn{2}{|c|}{ Day } & \multicolumn{2}{|c|}{ Night } \\
\hline & & $\ln \mathbf{L}$ & AIC & $\ln \mathbf{L}$ & AIC \\
\hline $\mathrm{RMR} \sim$ mass & 3 & -546.84 & 1099.68 & -478.62 & 963.23 \\
\hline $\mathrm{RMR} \sim \mathrm{T}$ & 3 & -633.80 & 1273.60 & -643.12 & 1292.25 \\
\hline $\mathrm{RMR} \sim$ ele & 3 & -641.13 & 1288.27 & -643.40 & 1292.79 \\
\hline $\mathrm{RMR} \sim$ mass $+\mathrm{T}$ & 4 & -540.22 & 1088.44 & -454.93 & 917.86 \\
\hline $\mathrm{RMR} \sim$ mass + ele & 4 & -542.41 & 1092.82 & -844.79 & 1697.58 \\
\hline $\mathrm{RMR} \sim \mathrm{T}+$ ele & 4 & -635.02 & 1278.04 & -642.92 & 1293.83 \\
\hline RMR $\sim$ mass $+\mathrm{T}+$ ele & 5 & -544.67 & 1099.33 & -510.02 & 1030.04 \\
\hline $\mathrm{RMR} \sim \operatorname{mass} * \mathrm{~T}$ & 5 & -517.52 & 1045.04 & -449.88 & 909.75 \\
\hline $\mathrm{RMR} \sim$ mass $*$ ele & 5 & -592.67 & 1195.34 & -520.06 & 1050.13 \\
\hline $\mathrm{RMR} \sim \mathrm{T} *$ ele & 5 & -634.75 & 1279.51 & -690.89 & 1391.79 \\
\hline $\mathrm{RMR} \sim \operatorname{mass} * \mathrm{~T} *$ ele & 9 & -1037.13 & 2092.26 & -359.65 & 737.29 \\
\hline $\log (\mathrm{RMR}) \sim \log ($ mass $)$ & 3 & -202.14 & 410.28 & -256.70 & 519.40 \\
\hline $\log (\mathrm{RMR}) \sim \mathrm{T}$ & 3 & -236.27 & 478.55 & -250.30 & 506.59 \\
\hline $\log (\mathrm{RMR}) \sim$ ele & 3 & -421.85 & 849.70 & -274.32 & 554.64 \\
\hline $\log (\mathrm{RMR}) \sim \log ($ mass $)+\mathrm{T}$ & 4 & -148.23 & 304.47 & -141.27 & 290.53 \\
\hline $\log ($ RMR $) \sim \log ($ mass $)+$ ele & 4 & -187.41 & 382.82 & -131.14 & 270.28 \\
\hline $\log (\mathrm{RMR}) \sim \mathrm{T}+$ ele & 4 & -240.88 & 489.76 & -293.25 & 594.50 \\
\hline $\log (\mathrm{RMR}) \sim \log ($ mass $)+\mathrm{T}+$ ele & 5 & -471.65 & 953.31 & -177.25 & 364.49 \\
\hline $\log (\mathrm{RMR}) \sim \log ($ mass $) * \mathrm{~T}$ & 5 & -104.99 & 219.98 & -124.15 & 258.30 \\
\hline $\log (\mathrm{RMR}) \sim \log ($ mass $) *$ ele & 5 & -163.87 & 337.75 & -90.75 & 191.50 \\
\hline $\log (\mathrm{RMR}) \sim \mathrm{T} *$ ele & 5 & -225.23 & 460.47 & -286.58 & 583.16 \\
\hline $\log (\mathrm{RMR}) \sim \log ($ mass $) * \mathrm{~T} *$ ele & 9 & -128.48 & 274.96 & -170.67 & 359.33 \\
\hline
\end{tabular}


Table 3.7. Regression coefficients and significance for the most supported regression models and the ordinary least squares (OLS) regression of resting metabolic rate (RMR) and mass and temperature. The phylogenetic generalized least squares (PGLS) regressions use the mvOU1 model and include the most supported model with an interaction term, as well as the additive regression model for comparison with the results of other studies. The OLS model uses the same regression technique and a phylogenetic transformation using Pagel's $\lambda=0$, which creates a star phylogeny with no evolutionary relationships.

\begin{tabular}{|c|c|c|c|c|c|c|}
\hline \multirow[b]{2}{*}{ Model } & \multirow[b]{2}{*}{ Regression } & \multirow[b]{2}{*}{ Term } & \multicolumn{2}{|c|}{ Day } & \multicolumn{2}{|c|}{ Night } \\
\hline & & & Coefficients & $\mathbf{p}$ & Coefficients & $\mathbf{p}$ \\
\hline \multirow{3}{*}{$\log (R M R) \sim \log ($ mass $)+T$} & \multirow{3}{*}{ OLS } & (Intercept) & -0.502 & - & -0.092 & - \\
\hline & & $\log$ (mass) & 0.717 & $<0.001 * * *$ & 0.743 & $<0.001 * * *$ \\
\hline & & $\mathrm{T}$ & 0.128 & $<0.001 * * *$ & 0.128 & $<0.001 * * *$ \\
\hline \multirow{3}{*}{$\log (R M R) \sim \log ($ mass $)+T$} & \multirow{3}{*}{ PGLS } & (Intercept) & -0.922 & - & -0.303 & - \\
\hline & & $\log ($ mass $)$ & 0.601 & $<0.001 * * *$ & 0.799 & $<0.001 * * *$ \\
\hline & & $\mathrm{T}$ & 0.144 & $<0.001 * * *$ & 0.132 & $<0.001 * * *$ \\
\hline \multirow{4}{*}{$\log (R M R) \sim \log ($ mass $) * T$} & \multirow{4}{*}{ PGLS } & (Intercept) & -0.643 & - & -0.529 & - \\
\hline & & $\log ($ mass $)$ & 1.510 & $<0.001 * * *$ & 2.229 & $<0.001 * * *$ \\
\hline & & $\mathrm{T}$ & 0.131 & $<0.001 * * *$ & 0.147 & $<0.001 * * *$ \\
\hline & & $\log ($ mass $) * \mathrm{~T}$ & -0.030 & $<0.001 * * *$ & -0.066 & $<0.001 * * *$ \\
\hline
\end{tabular}

Levels of significance: $* \mathrm{p}<0.05 ; * * \mathrm{p}<0.01 ; * * * \mathrm{p}<0.001$. 
Table 3.8. The derived parameters of the additive regressions between resting metabolic rate (RMR) and mass and temperature. The phylogenetic generalized least squares (PGLS) regression uses the multivariate Ornstein-Uhlenbeck (mvOU1) model, while the ordinary least squares regression (OLS) uses the white noise model (a transformed "star" phylogeny representing no evolutionary relationships). The mass-scaling exponents are the coefficients from the regressions in Table 3.5. The activation energy, $E$, was determined by using the same regressions from Table 3.5 with the temperature transformed into $1 / \mathrm{kT}$. The $\mathrm{Q}_{10}$ values were calculated using the equation $Q_{10}=e^{10 C_{T}}$ where $C_{T}$ is the temperature coefficient from the regressions in Table 3.5.

\begin{tabular}{c|cc|cc}
\hline & \multicolumn{2}{|c|}{ OLS } & \multicolumn{2}{c}{ PGLS } \\
Metabolic parameter & Day & Night & Day & Night \\
\hline Mass-scaling exponent & 0.601 & 0.743 & 0.717 & 0.799 \\
$E$ (activation energy) & 1.085 & 0.934 & 0.965 & 0.959 \\
$\mathrm{Q}_{10}$ & 4.221 & 3.608 & 3.581 & 3.743 \\
\hline
\end{tabular}


Table 3.9. Results from analysis of variance (ANOVA) of resting metabolic rate (RMR) among families of tropical anurans for both day and night.

\begin{tabular}{ccccccc}
\hline Time & Term & dF & SS & MS & F & p \\
\hline \multirow{2}{*}{ Day } & Family & 9 & 1073.71 & 119.30 & 5.012 & $<0.001 * * *$ \\
& Residuals & 872 & 20757.45 & 23.80 & & \\
\hline \multirow{2}{*}{ Night } & Family & 9 & 783.12 & 87.01 & 1.349 & 0.207 \\
& Residuals & 872 & 56240.32 & 64.50 & & \\
\hline Levels of significance: $* \mathrm{p}<0.05 ; * * \mathrm{p}<0.01 ; * * * \mathrm{p}<0.001$. & &
\end{tabular}


Table 3.10. Results from analysis of covariance (ANCOVA) between log-transformed resting metabolic rate (RMR) and temperature among families of tropical anurans for both day and night. The families tested include Craugastoridae, Bufonidae, Hylidae, and Leptodactylidae. The interaction term (Temperature:Family) indicates the slopes between metabolic rates and temperature are significantly different among families.

\begin{tabular}{ccccccc}
\hline Time & Term & dF & SS & MS & F & p \\
\hline \multirow{4}{*}{ Day } & Temperature & 1 & 261.46 & 261.46 & 300.27 & $<0.001 * * *$ \\
& Family & 3 & 113.20 & 37.73 & 43.33 & $<0.001 * * *$ \\
& Temperature:Family & 3 & 10.54 & 3.51 & 4.03 & $0.007 * *$ \\
& Residuals & 814 & 708.79 & 0.87 & & \\
\multirow{2}{*}{ Night } & Temperature & 1 & 605.99 & 605.99 & 626.72 & $<0.001 * * *$ \\
& Family & 3 & 104.16 & 34.72 & 35.91 & $<0.001 * * *$ \\
& Temperature:Family & 3 & 20.73 & 6.91 & 7.15 & $<0.001 * * *$ \\
& Residuals & 860 & 831.55 & 0.97 & & \\
\hline
\end{tabular}

Levels of significance: $* \mathrm{p}<0.05 ; * * \mathrm{p}<0.01 ; * * * \mathrm{p}<0.001$. 
Table 3.11. Results from analysis of covariance (ANCOVA) between log-transformed resting metabolic rate (RMR) and temperature among elevational groups of tropical anurans for both day and night. The elevational groups were classified as high elevation (> 2,000 $\mathrm{m}$ asl), mid elevation $(600-2,000 \mathrm{~m}$ asl), and low elevation (<600 $\mathrm{m}$ asl). The interaction term (Temperature:Elevation) indicates the slopes between metabolic rates and temperature are significantly different among the three elevational groups.

\begin{tabular}{lcccccc}
\hline Time & Term & dF & SS & MS & F & p \\
\hline \multirow{4}{*}{ Day } & Temperature & 1 & 272.66 & 272.66 & 292.18 & $<0.001^{* * *}$ \\
& Elevation & 2 & 63.41 & 31.71 & 33.98 & $<0.001^{* * *}$ \\
& Temperature:Elevation & 2 & 5.70 & 2.85 & 3.06 & $0.048^{*}$ \\
& Residuals & 869 & 810.96 & 0.93 & & \\
\hline \multirow{4}{*}{ Night } & Temperature & 1 & 658.93 & 658.93 & 637.49 & $<0.001^{* * *}$ \\
& Elevation & 2 & 36.63 & 18.31 & 17.72 & $<0.001^{* * *}$ \\
& Temperature:Elevation & 2 & 13.81 & 6.91 & 6.68 & $0.001^{* *}$ \\
\hline Levels of significance: $* \mathrm{p}<0.05 ; * * \mathrm{p}<0.01 ; * * * \mathrm{p}<0.001$. & &
\end{tabular}




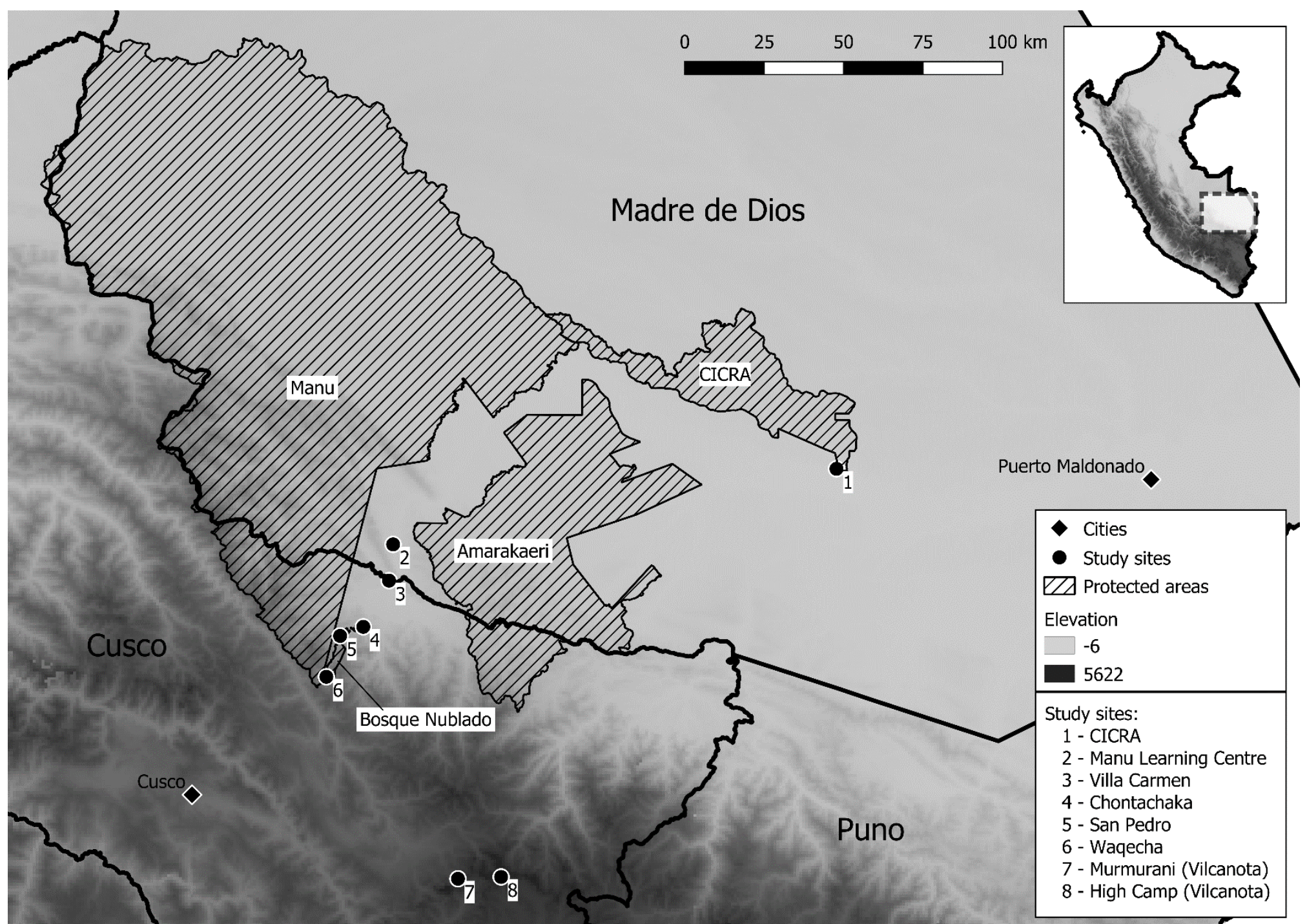

Figure 3.1. Elevation map of eight study sites and protected areas in southeastern Peru. 


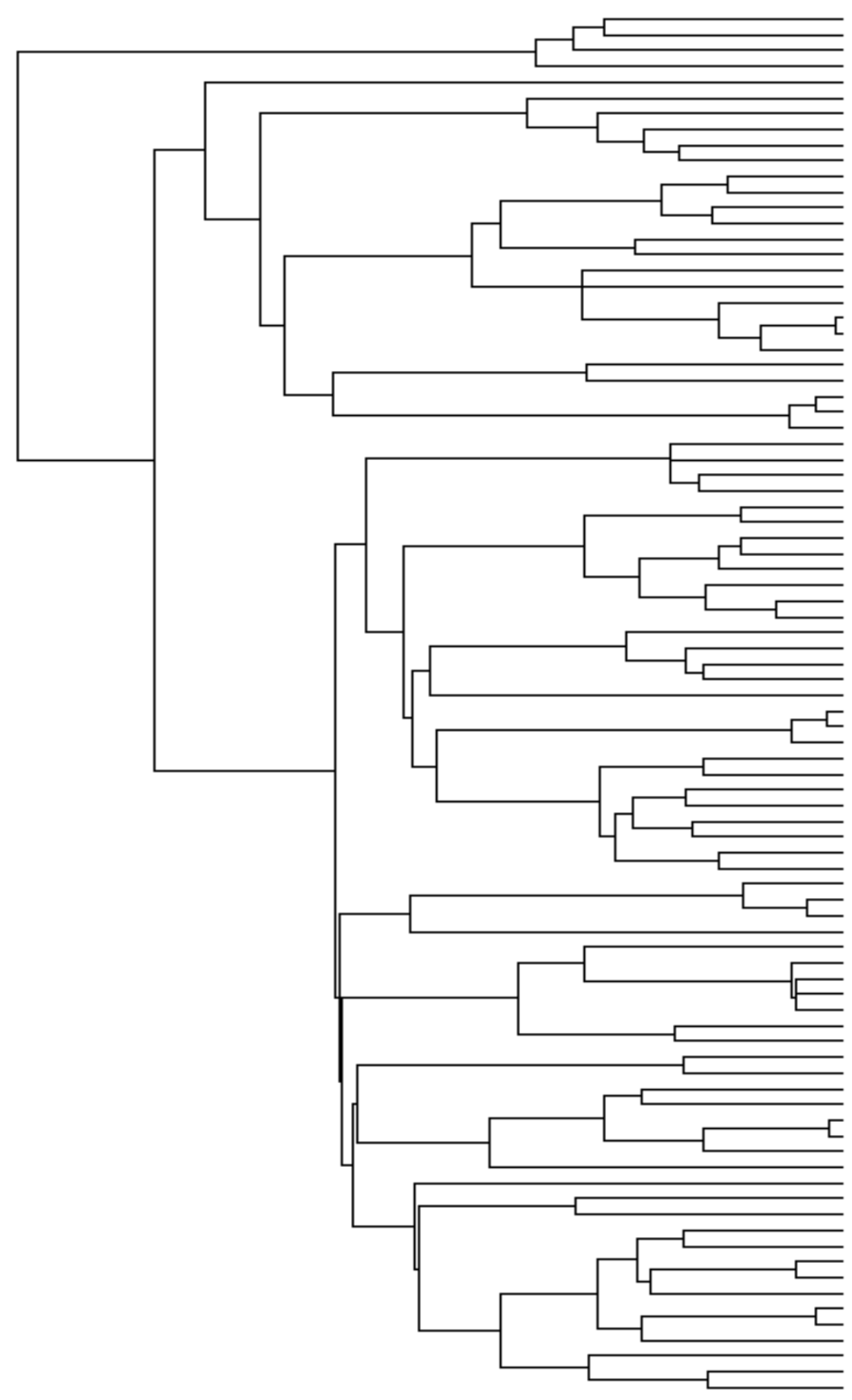

Mamptophryne bollviana

Ctenophryne geay!

Chlasmociels roy)

Strabomantis sulcatus

Oreobates gencare

Oreohates cruralls

oreobates granulosus

Oreobates amarakaer:

Pristimantis relchlel

Pristimantis danae

Pristimantis totae

Pristimantis tenestratus.

Pristimants buccinator

Pristimants ockenoen

Pristimantis ilnoae

Pristimants carvalhol

Pristlmants platyoactylus

Pristimantis altamazonicus

Pristimant's altamazonicus

Noblella pygmaga

Bryophryne hansesuer

Bryouhrune conhltes

Phyilomedusa pallata

Phyllomedusa tomoatern

Phillomedusa camba

Phyllomeousa vallant

Hyps lboas punctatus.

Hypsiboas cinerascens

cypsobas lancliormis

Hyps boas calcaratus

Hypsiboas qladatar

H) psiboas oeographicus

yps boas boans

chax garbel

chax chinultons

scarthyla golnorum

Osteocephalus casteuri

Ostocenhalus mimeticus

Denaroos sonus parvicen

Denaropsophus koechlinl

Denaropsophus rhoolopeplus

Denaropsophus leall

Denaropsophus marmaratus

Denaropsophus minutus

Denaropsophus leucophyllatus

Gastrotheca excubltor

Gastrotheca testuolnea

Gastrotheca nebulanastes

Ceratophrys cornuta

Ranitomeya slirensits

Ameerega macero

Ameerega shlhuemoy

Ameerega trivittata

Ameerega hahnell

Allobass thluneatus

Fval nobatrachlum berger!

Fhinella margarittera

Rhinella many

Rhinella marina

Rhinella veraouensts

Amazophrynella javlerbustamantes

Pleuroosma marmaratum

Engystomops freberg

Boalarhina perez!

Leptodactylus inoodonotus

Leptodactylus moodmystax

Leptooactyus pentadactylus

eptooactylus knuosent

Leptodactylus oldymus

eptooactylus pefersII

Lepodololos

Lepooactylus bollvianus

A conomera hylaed

A

Figure 3.2. Phylogeny for 88 tropical amphibian species used in analyses of resting metabolic rate after von May et al. (2019). All 88 species are included in the analyses for both day and night. 


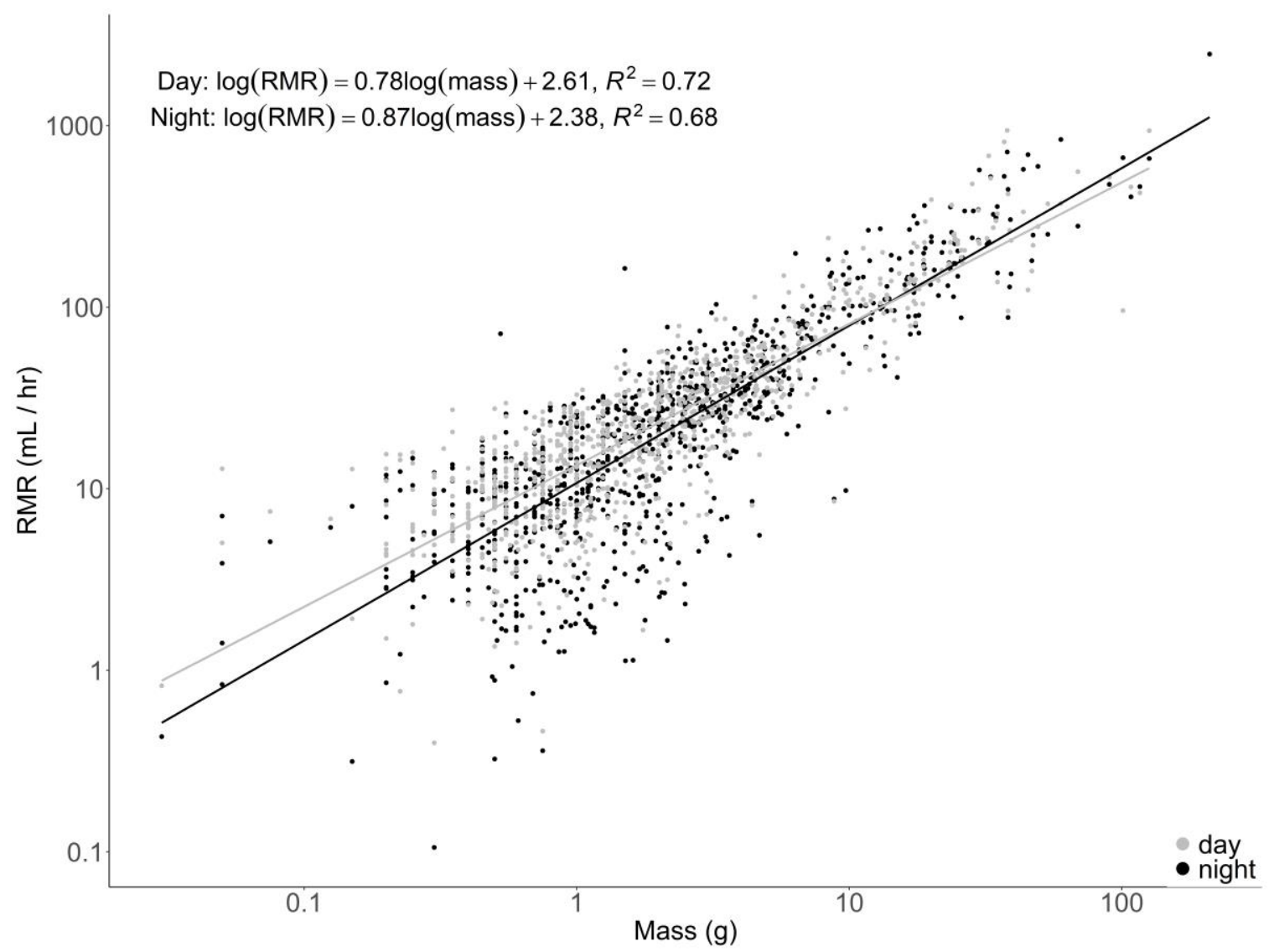

Figure 3.3. Relationship between resting metabolic rate (RMR) and mass for both day (gray) and night (black). The regression lines depict the ordinary least squares regression separately for day (gray) and night (black). 


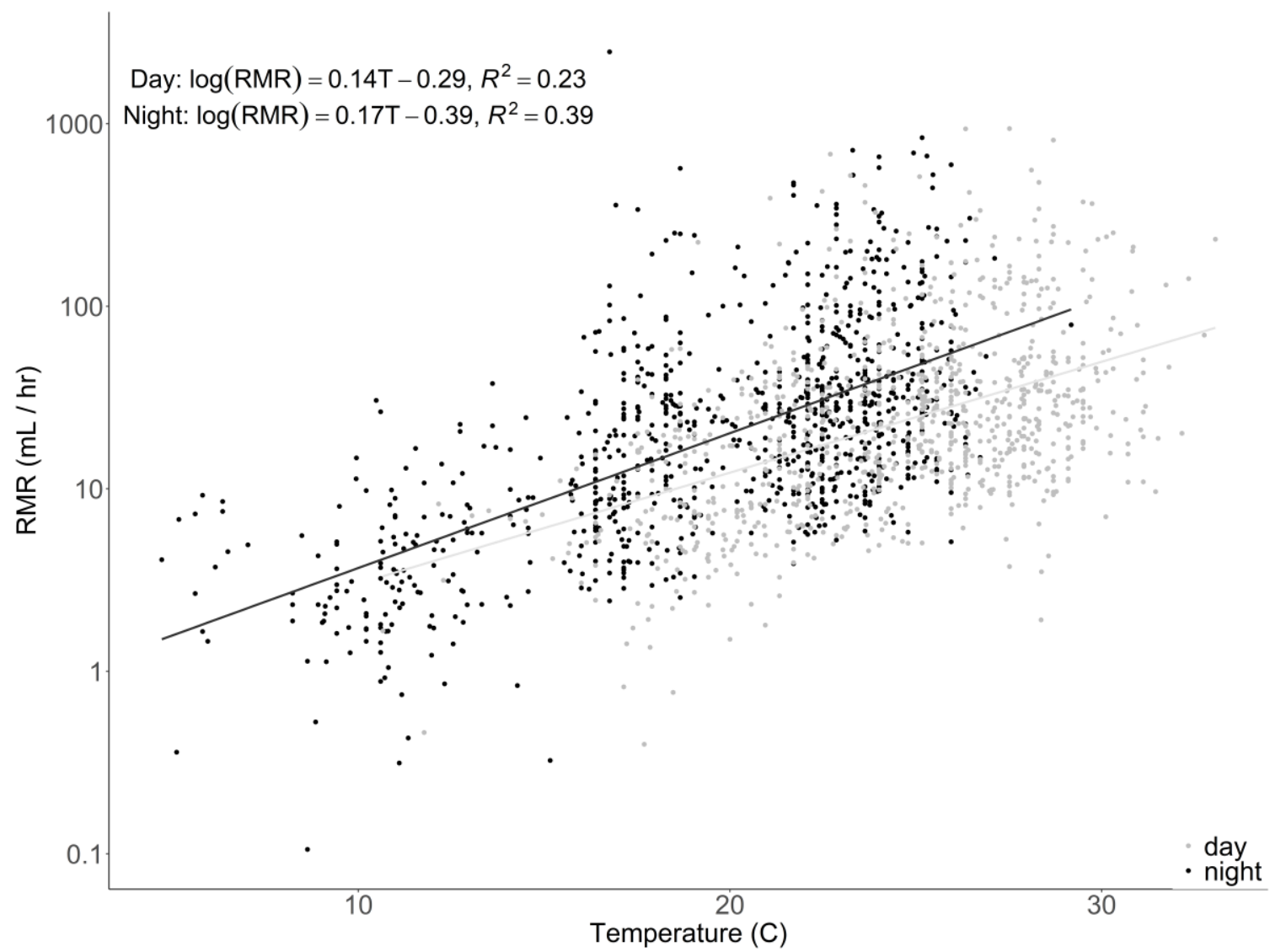

Figure 3.4. Relationship between resting metabolic rate (RMR) and temperature for both day (gray) and night (black). The regression lines depict the ordinary least squares regression separately for day (gray) and night (black). 


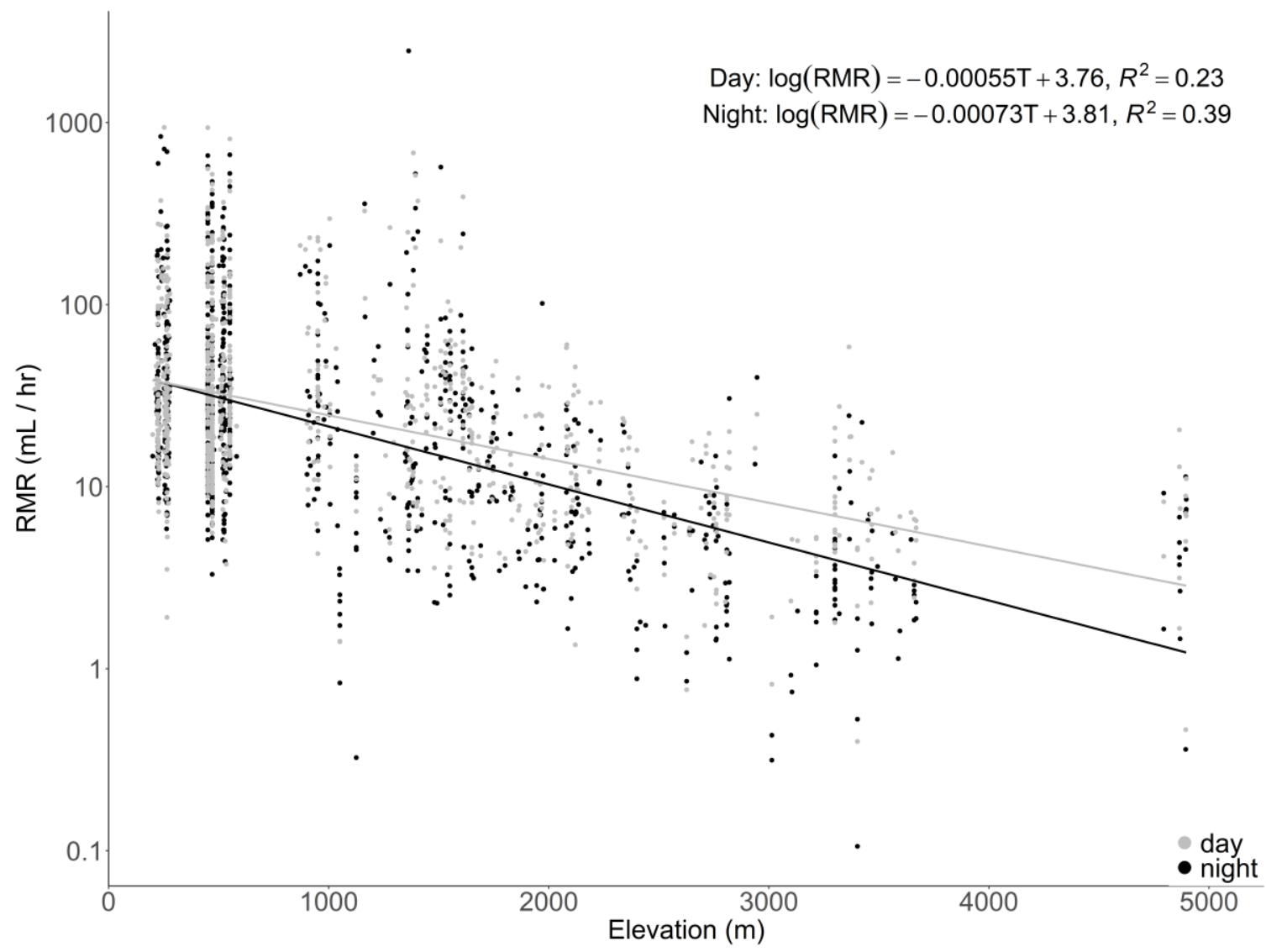

Figure 3.5. Relationship between resting metabolic rate (RMR) and elevation for both day (gray) and night (black). The regression lines depict the ordinary least squares regression separately for day (gray) and night (black). 

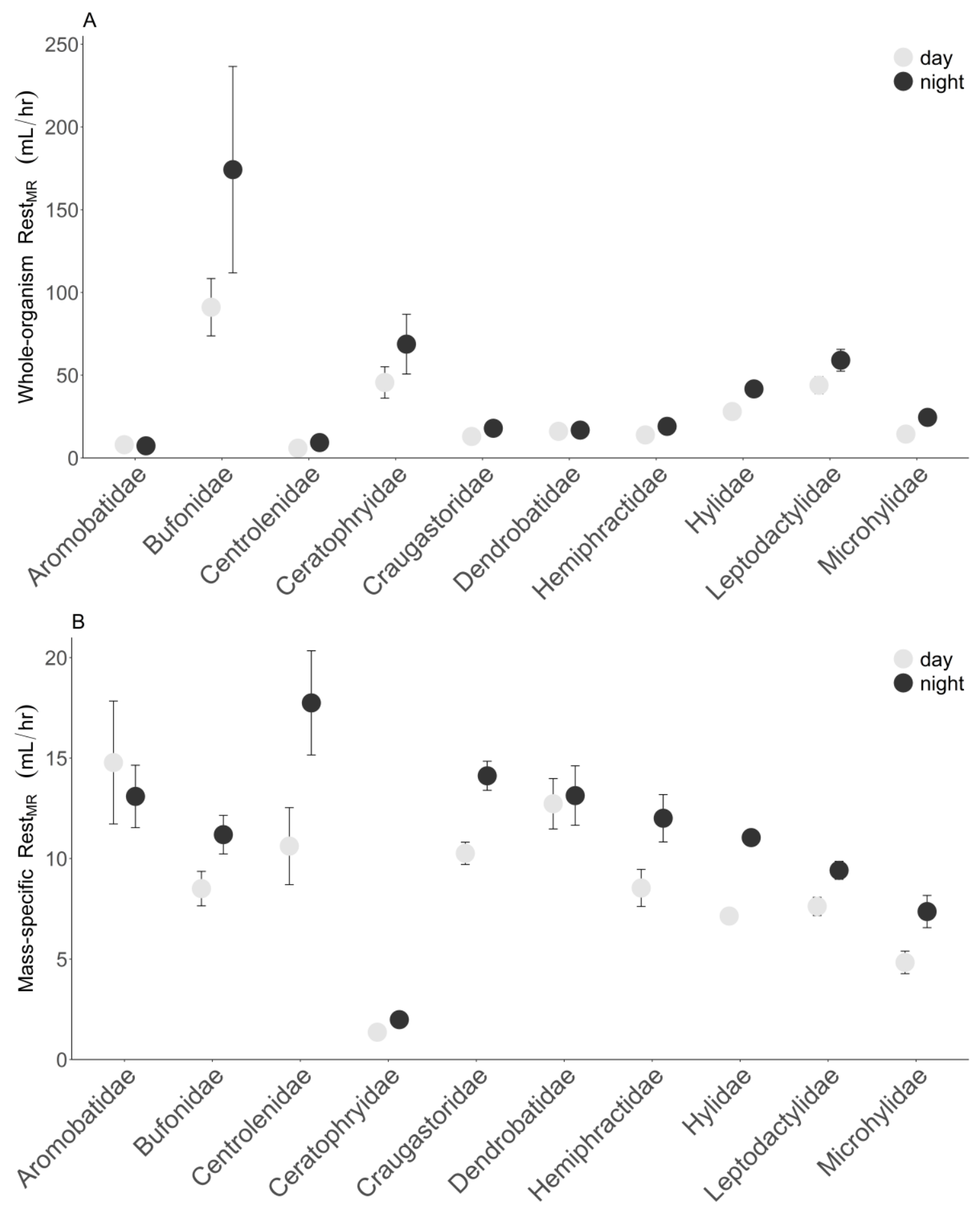

Figure 3.6. The temperature-corrected field resting metabolic rate (RMR) for day and night among families of anurans illustrating differences between whole-organism RMR (A) and mass-specific RMR (B). The RMR is corrected for temperature using the $\mathrm{Q}_{10}$ values from the phylogenetic generalized least squares (PGLS) regression summarized in Table 3.8. Standard error is denoted by the error bars. Mass-specific RMR was calculated by dividing the temperature-corrected RMRs by mass (grams). 


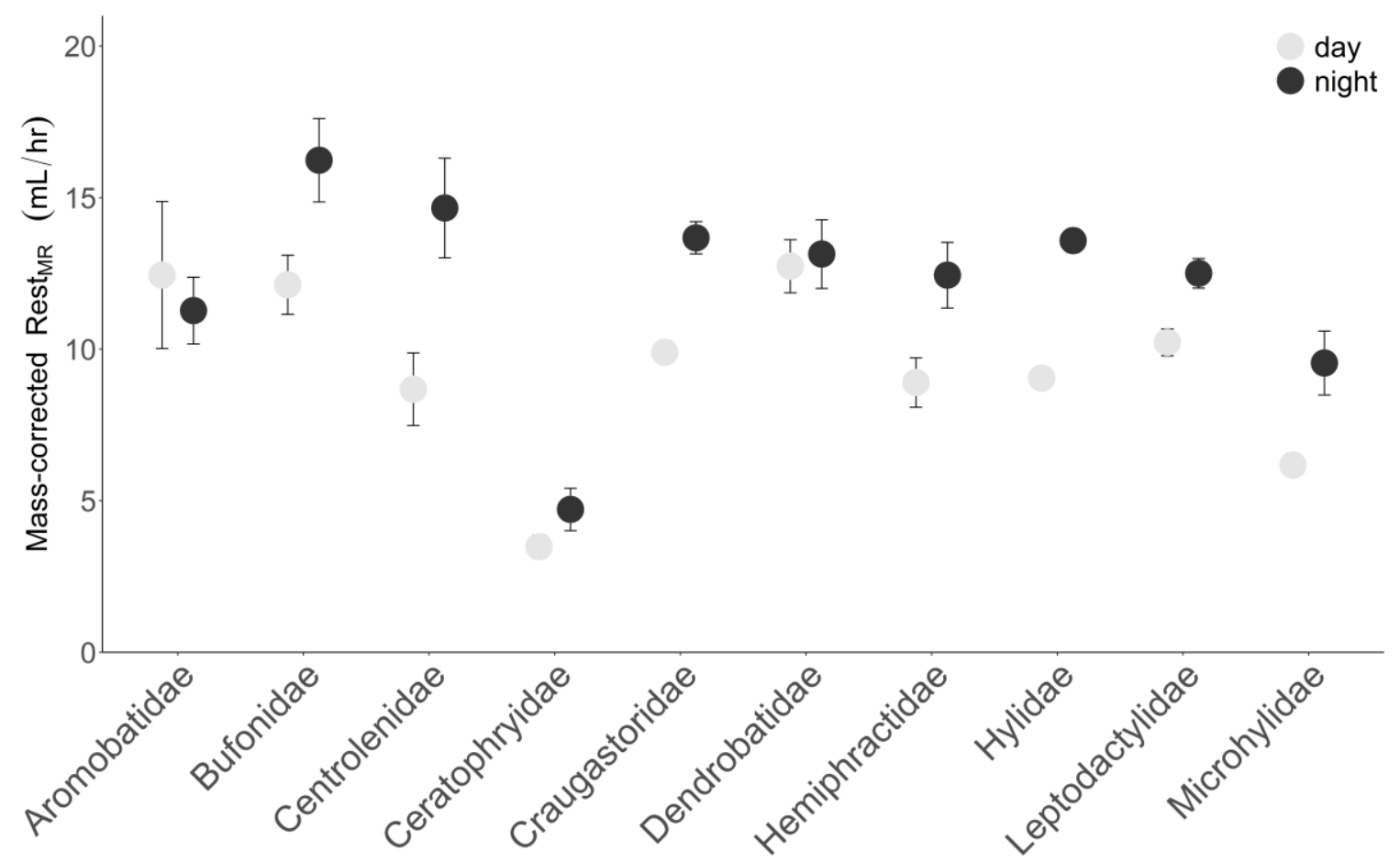

Figure 3.7. Resting metabolic rates (RMR) among families for both day and night after correction for mass and temperature. Correction for mass and temperature used the ordinary least squares additive model of $\log (\mathrm{RMR})$ against $\log$ (mass) and temperature to $20^{\circ} \mathrm{C}$. Error bars depict standard error. 


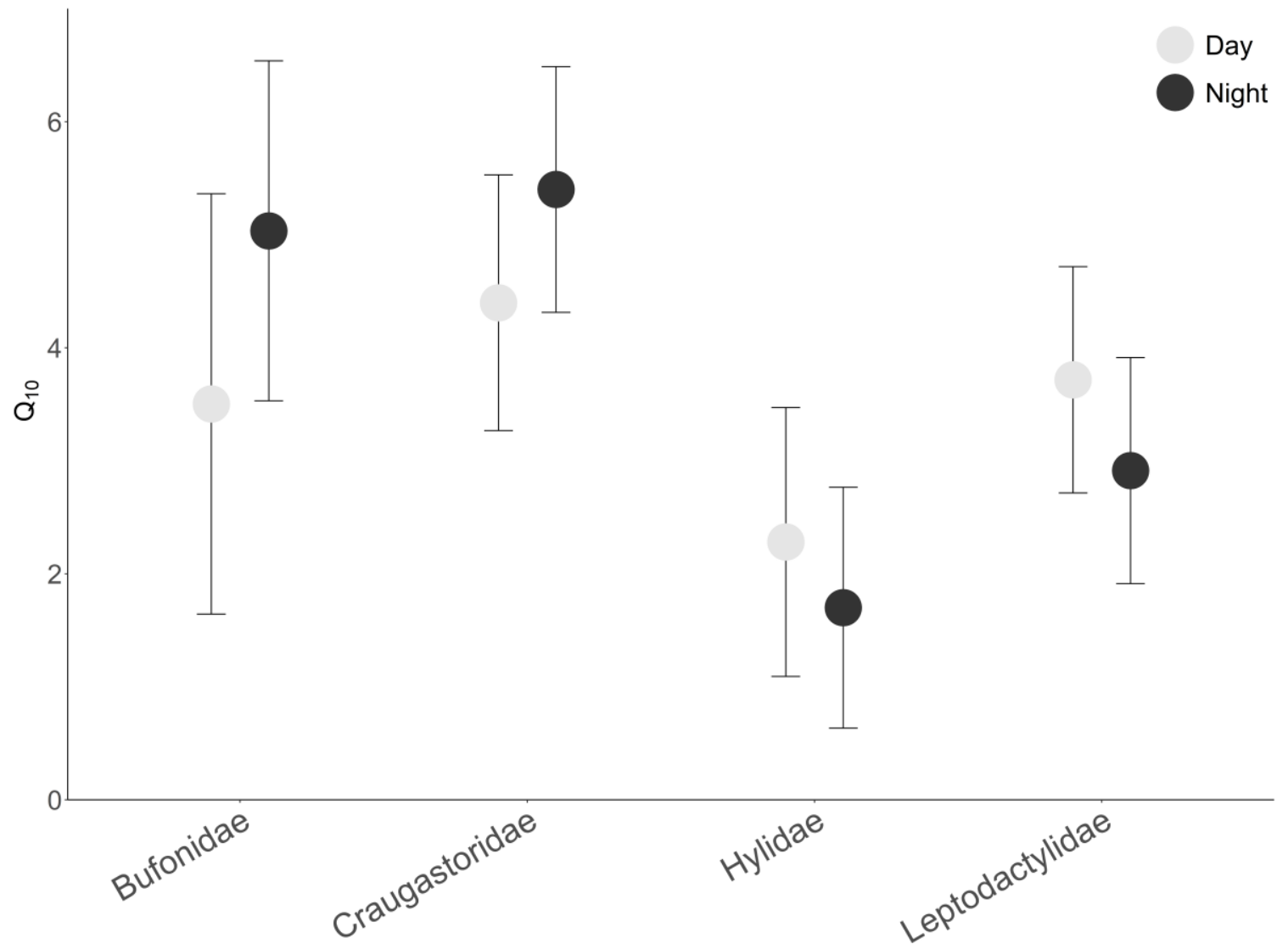

Figure 3.8. The comparison of $\mathrm{Q}_{10}$ among four families of tropical anurans for both day and night. The families Bufonidae, Craugastoridae, Hylidae, and Leptodactylidae were selected as they have high sample sizes, high numbers of species measured, and representation across large elevational ranges. Error bars represent standard error. Differences are significant for both day and night as shown by analysis of covariance (ANCOVA; Table 3.10). 


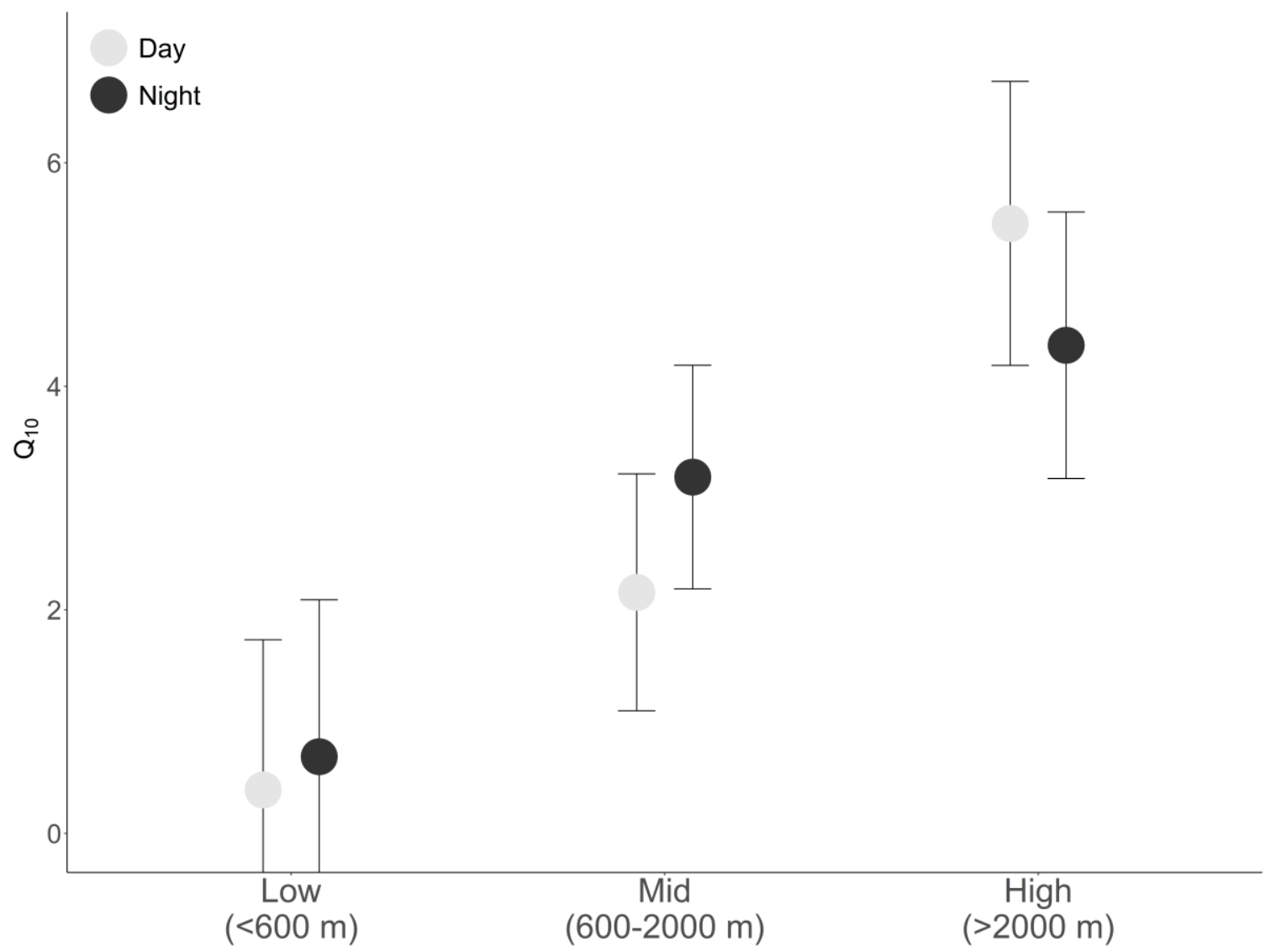

Figure 3.9. The $\mathrm{Q}_{10}$ among elevational groups of tropical anurans for both day and night. The elevational groups were classified as high elevation $(>2,000 \mathrm{~m}$ asl), mid elevation $(600-2,000 \mathrm{~m}$ asl), and low elevation (<600 $\mathrm{m}$ asl). Standard error is depicted by the error bars. Differences are significant for both day and night as shown by analysis of covariance (ANCOVA; Table 3.11). 


\title{
CHAPTER IV: VARIATION OF AEROBIC SCOPE IN TROPICAL AMPHIBIANS: PATTERNS AND TESTS OF THE AEROBIC CAPACITY MODEL
}

\author{
ABSTRACT \\ The aerobic capacity (AC) model posits that resting metabolic rate and maximum \\ metabolic rate are highly correlated as a result of systemic limitations. The AC model has \\ been proposed to explain the low interspecific variation in factorial aerobic scope (FAS) \\ among a diversity of taxa, the high interspecific variation of net aerobic scope (NAS), \\ and as an important factor in the evolution of endothermy. I examine the patterns of \\ aerobic scope (both FAS and NAS) of tropical amphibians and explicitly test the AC \\ model. I demonstrate that there is extensive variation in both FAS and NAS in tropical \\ amphibians that does not support the predictions of the AC model. Moreover, the \\ variation in FAS and NAS is related to phylogeny, environment, and time of day and \\ could have important ecological implications. The litter frogs in the family \\ Craugastoridae are found to have particularly low FAS and NAS that might be related to \\ selective pressures associated with direct development. My study demonstrates that both \\ FAS and NAS contain important and complementary biological information and each \\ may be useful in understanding amphibian physiology in relation to ecology and \\ evolution.
}

\section{INTRODUCTION}

Metabolism is a process that is intimately related to a variety of characteristics related to physiology, ecology, and evolution. As metabolism determines the energetic 
budgets of organisms, both fundamental requirements and availability for various activities and functions, it is important to understand metabolic physiology of organisms as an integral part of their biology. Moreover, particularly for ectotherms such as amphibians, metabolism is intimately tied to environmental conditions. Thus, we need to understand metabolic physiology if we hope to predict the energetic impacts of anthropogenic climate change.

Aerobic scope describes the relationship between the minimum energetic requirements and the maximum energetic capacity of an organism (Clark et al. 2013). The minimum metabolic requirements of an organism are often estimated through measurements of resting metabolic rate (RMR; Gatten et al. 1992). The minimum energetic requirement, or standard metabolic rate, is defined when organisms are at rest, inactive, not digesting or processing food, not growing, nonreproductive, and unstressed. In practice, especially in field settings, it is difficult to ensure all the stringent requirements are met, which is why RMR is an estimate of the true minimal or standard metabolic rates (see Chapter I for discussion). The maximum aerobic capacity of an organism can be measured by examining the metabolic rate during forced, strenuous exercise and is termed maximum metabolic rate (Walsberg 1986). Aerobic scope explicitly quantifies the relationship between RMR and MMR for comparisons across a variety of scales. Patterns of aerobic scope have been instrumental to understanding the relationships between energetics and fitness and evolution (Auer et al. 2015a, b; Behrens et al. 2017; Killen et al. 2012, 2014; Miller \& Hutchison 1980).

High aerobic scope is often correlated with increased performance measures such as locomotion (Garland \& Albuquerque 2017), feeding capacity (Auer et al. 2015a), and 
growth rates (Auer et al. 2015b). While such correlations with aerobic scope have been demonstrated in a variety of organisms, some studies have found that relationships with aerobic scope are context dependent (Auer et al. 2015a; Norin \& Clark 2017). Aerobic scope determines the capacity for a variety of physical activities and can cause intraspecific behavioral differences (Biro et al. 2018), including those involved in interactions such as aggression and dominance (Killen et al. 2014). Low aerobic scopes may act as a limitation on behavior and the ability to respond to various stressors and challenges (Biro et al. 2018; Killen et al. 2007). Aerobic scope has also been related to differences in physiological traits and conditions. In fish, air-breathing was shown to be used to maintain aerobic scope in hypoxic aquatic conditions, which otherwise cause large decreases in aerobic scope (McKenzie et al. 2012). In mammals, aerobic scope was found to vary with the use of carbohydrate or lipid metabolism during exercise (Schippers et al. 2014).

There are two methods to calculate aerobic scope that differ in their biological interpretations. The factorial aerobic scope (FAS) is calculated as the ratio between MMR and RMR and provides a relative measure of the energetic capacity of an organism with respect to resting energetic needs. The absolute or net aerobic scope (NAS) is calculated as the difference between MMR and RMR and represents the absolute capacity for increased energy usage above resting levels. Thus, NAS is an absolute measure of the potential energy availability for behaviors and processes above routine levels (Nespolo et al. 2017a). Interestingly, the choice of using FAS or NAS is often seemingly chosen at random, with little justification (Clark et al. 2013), although there are trends to use FAS in ectothermic studies and NAS for endotherms (Nespolo et al. 2017a). Interestingly, the 
choice to calculate aerobic scope as FAS or NAS can lead to profoundly different conclusions and thus limit or bias interpretations and understanding (Clark et al. 2013).

According to the aerobic capacity (AC) model (Bennett \& Ruben 1979), the ratio between minimum and maximum oxygen consumption (FAS) is proposed to be restricted by systemic limitations of oxygen delivery or utilization (Bennett 1978). Thus, selective pressures for increases in MMR are necessarily accompanied by proportional increases in RMR. In the AC model, the selective advantage of high active metabolic rates allows increased ability to forage, reproduce, and deal with stressors such as disease and predators. Indeed, many studies have found that FAS is constrained across vertebrates (Nespolo et al. 2017a) and within large clades such as teleost fish (Killen et al. 2016). In contrast, NAS has been demonstrated to have relatively high variation among organisms (e.g., Killen et al. 2016; Nespolo et al. 2017a) and has thus been proposed to be more informative of physiological differences and more useful in comparative studies than FAS (Clark et al. 2013). As the two calculations of aerobic scope have distinct biological interpretations, each may provide different insights into physiology, ecology, and energetics.

While some studies have found FAS to be relatively similar across vertebrates (e.g., Nespolo et al. 2017a), other studies have observed consistent differences among groups. Careau (2013) demonstrated that rodent species from cold environments that undergo torpor have relatively high FAS and proposed that high FAS is an adaptation to minimize energy use during torpor while increasing thermogenic capacity. Hinds et al. (1993) demonstrated that FAS varies systematically among endotherms but that patterns may depend of how FAS is measured. Many studies have used the thermal variation of 
aerobic scope, both FAS and NAS, to determine the thermal optima of organisms (Clark et al. 2013; Farrell 2016; Rummer et al. 2014). However, other studies have found that aerobic scope may change dynamically in response to acclimation temperature, suggesting flexibility in aerobic scope and plastic responses to environmental conditions (Norin et al. 2014). Moreover, Wone (2015) demonstrated that basal and maximal metabolic rates can be selected for independently in laboratory mice. The independent selection of RMR and MMR suggests a potential mechanism for differences in selective pressures between FAS and NAS and gives weight to the distinct biological interpretations of each measure of aerobic scope.

Herein, I compare RMR, MMR, FAS, and NAS of tropical amphibians across an elevational gradient in southeastern Peru. The objectives of my study are two-fold: first, to test the predictions of the AC model for tropical amphibians; and second, to explore possible explanatory variables for variation in the two measures of aerobic scope, FAS and NAS. The AC model and variation in aerobic scope have been tested and examined across vertebrates (Nespolo et al. 2017a) as well as in some clades (Dutenhoffer \& Swanson 1996; Gçbczyński \& Konarzewski 2009; Gomes et al. 2004; Sadowska et al. 2005). However, many studies necessarily rely on metanalysis to make comparisons across many taxa (Nespolo et al. 2017a) or restrict analyses to single species (Gomes et al. 2004). My study uses a consistent methodology applied to a large diversity of organisms with repeated measurements for both day and night. To my knowledge, this is the first time the AC model and variation in aerobic scope are explicitly examined in tropical amphibians using phylogenetic comparative methods. 
Three predictions of the AC model are explicitly tested in my study. First, there should be correlated evolution between RMR and MMR. Second, the variation in FAS should be relatively small and uncorrelated with explanatory variables, such as mass, temperature, elevation, or phylogeny. Variation in FAS should be small because, under the AC model, FAS is self-correcting relative to RMR. Thus, mass-scaling and thermal sensitivity of RMR should be reflected in proportional changes in MMR and mass and temperature should thus have no effect on FAS. Third, FAS should evolve according to an Ornstein-Uhlenbeck model of evolution with a single optimum reflecting the relative invariance in FAS.

The explanatory variables for RMR, MMR, FAS, and NAS include mass, temperature, elevation, and phylogeny. It is well-known that RMR and MMR vary as a function of mass and temperature, although there is disagreement over the parameters of mass and temperature relationships. Furthermore, while extensive work has focused on the metabolic scaling of RMR, there is considerably less work on MMR and other metabolic rates (but see Bishop 1999; Glazier 2008, 2009). As most metabolic studies in amphibians have focused on temperate taxa, my study represents a novel examination of metabolic scaling of MMR with mass and temperature in tropical amphibians. Differences in the mass-scaling and thermal sensitivity of RMR and MMR would be reflected in the scaling of FAS and NAS and have important implications for organismal function during changing environmental conditions.

Variation in aerobic scope, after accounting for mass and temperature, may relate to a variety of factors. Phylogenetic differences in aerobic scope could relate to different selective pressures on physiological traits among clades. However, it is difficult to 
determine whether phylogenetic differences are directly related to physiology itself, or through coadaptation related to other ecological characteristics (which are often expected to be more similar within clades than among clades; Losos 2008; Webb et al. 2002). For example, FAS and NAS could correlate with ecological characteristics such as habitat, diet, or life history, which would be expected to be more similar within families than among families. However, the conclusions drawn from comparisons among groups, and even among individuals, can vary as a result of the metric of aerobic scope used (FAS or NAS; Clark et al. 2013). Thus, it is appropriate to include both FAS and NAS in studies of aerobic scope (Clark et al. 2013).

However, the interpretations of FAS and NAS, particularly in comparative studies, are not always clear. FAS is often assumed to be determined by systemic limitations of physiological systems and to be relatively constant across vertebrates (Bennet 1978; Killen 2016). Thus, variation in FAS among clades may reflect systemic physiological traits that differ among groups, such as differences in cardiorespiratory characteristics (Bennet 1978). In theory, NAS has been proposed as a measure of the total capacity for oxygen consuming processes above maintenance levels (i.e., RMR; Clark et al. 2013; Killen et al. 2016). Thus, NAS sets the energetic limits for activity, reproduction, digestion and assimilation, and coping with stressors and disease (Killen et al. 2016). However, analyses often choose a single metric of aerobic scope without justification, and sometimes there can be different or even opposing conclusions depending on which metric of aerobic scope is used (Clark et al. 2013). Few studies have explicitly examined both FAS and NAS, but current evidence supports different 
biological interpretations of each metric (Clark et al. 2013; Killen et al. 2016; Nespolo et al. 2017a).

Additional insight into amphibian metabolic physiology can be achieved by examining the correlation between FAS and NAS. High correlation between FAS and NAS may suggest that: (a) the two metrics of aerobic scope are redundant and provide similar information on the metabolic physiology of amphibians, or (b) the maximal aerobic capacity of amphibians are correlated with systemic differences in metabolic physiology (Bennett 1978). Low correlation between FAS and NAS may provide evidence that the two metrics have distinct biological meanings as they relate to amphibian physiology. Differences in how each metric of aerobic scope relates to environmental variables, ecological traits, and evolutionary history may further provide insight into how FAS and NAS may be interpreted and related to amphibian biology as a whole.

Elevational gradients are often accompanied by consistent, predictable changes in a variety of abiotic and biotic factors (Becker et al. 2007; Sanders \& Rahbek 2012; Sundqvist et al. 2013). Abiotic changes in temperature, precipitation, humidity, oxygen availability, and air pressure often result in similar adaptations across distantly related taxa (i.e., convergent evolution in response to similar biological challenges). The abiotic gradients across elevation are often accompanied by predictable changes in biotic variables such as those related to forest type and leaf litter. Many studies have found metabolic traits that correlate with elevation, suggesting that there may be different metabolic characteristics that are selected for as a function of elevation (Chown \& Gaston 1999; Gomes et al. 2004; Navas 1996; Sears 2005). Differences in FAS and NAS across 
elevation could provide insight into some of the aerobic strategies employed in tropical amphibians across elevation.

Finally, it is possible that aerobic scope varies during the diel cycle. In Chapter II, I demonstrated marked circadian rhythms in the RMRs of tropical amphibians where activity times are accompanied by increased RMR. According to the aerobic capacity model, high RMR should be accompanied by proportionally high MMR. Thus, FAS should remain relatively unchanged between day and night while increases in aerobic capacity are reflected by changes in NAS. If FAS is consistent across both day and night, it is likely that systemic limitations on FAS are unchanged between active and resting states. However, if there are differences in FAS between day and night, it means that there are systemic changes across the diel cycle that affect the limitation of FAS. For example, if limitation occurs as a result of oxygen supply, changes in cardiorespiratory functioning during times of activity (e.g., increased respiration rates, increased blood flow, or increased dissolved oxygen in blood) could affect the factors limiting FAS and cause differences between day and night. Differences in aerobic scope between day and night would also have important implications for study design. Finally, differences in the patterns between FAS and NAS could provide evidence for the physiological changes that accompany shifts between resting and active states.

\section{METHODS}

\section{Study sites and species}

I conducted my study at three sites across an elevational gradient within the Manu Biosphere Reserve on the eastern slopes of the Andes in southeastern Peru. The gradient 
extends between 460 meters above sea level (m asl) in lowland rainforest to $3669 \mathrm{~m}$ asl above the tree line. The three study sites are the Manu Learning Centre at $460 \mathrm{~m}$ asl, the Gallito de Las Rocas lodge at $1450 \mathrm{~m}$ asl, and the Wayqecha Biological Station at 3025 $\mathrm{m}$ asl (for map, see Chapter III, Figure 3.1). The rapid elevational change on the eastern slopes of the Andes (Killeen et al. 2007) allowed access to large portions of the gradient from the three study sites.

I sampled amphibians during visual encounter surveys (Crump \& Scott 1994) along trails and roads and across a variety of habitats (aquatic and terrestrial). Within forests below the tree line, surveys were conducted primarily at night by inspecting vegetation and leaf litter. Amphibians encountered during the day were also collected for physiological measurements. In the puna grasslands above the tree line, surveys were conducted during the day by searching within mosses, dense grasses, and under rocks. Amphibians were kept for 12 to 24 hours before measurements were taken to reduce handling stress, ensure hydration levels, and reduce potential effects of thermal history, digestion, and activity. Small amphibians were held in sealed plastic bags with small amounts of water and plants to maintain humidity. Large amphibians were kept in perforated plastic containers to allow air flow and were sprayed with water to maintain humidity and hydration levels. Amphibians were kept for a maximum of 48 hours and then released at the location of capture. All materials used in housing were washed and sterilized using $70 \%$ ethanol prior to reuse, a process proved to be effective against most bacteria, fungi, and viruses, including Batrachochytrium dendrobatidis (Johnson et al. 2003; Phillott et al. 2010). A total of 54 species of anurans were sampled for 
measurements of resting and maximum metabolic rates. Most species were found only at a single study site, and no species were found at all three.

\section{Metabolic rates}

Metabolic rates were measured using flow-through respirometry within a closed system consisting of four interconnected structures: an infrared gas analyzer (IRGA), an air pump, a datalogger chamber to monitor temperature and humidity, and a metabolic chamber. A Vaisala GMP 343 IRGA was used to measured changes in $\mathrm{CO}_{2}$ concentration over time. Air was moved through the closed loop at a rate of 13.2 liters per hour using a diaphragm pump (LICOR 6262-04 reference pump). A variety of metabolic chambers were used that ranged in volume from 200 to 1287 milliliters. Efforts were made to match amphibians to the smallest volume chamber available without restricting the space for the animal (a method that reduces movement of animals and increases signal-to-noise ratio; pers. obs.). Temperature and humidity within the system were constantly monitored and recorded by a $\mathrm{HOBO}$ data logger (Onset HOBO H08-004-02) placed in a $200 \mathrm{~mL}$ chamber. As amphibians were maintained in thermally stable environments and relative humidity was consistently high (average 96\% RH), air temperature was assumed to be a suitable measurement for amphibian body temperature given their ectothermic nature (Carey 1979). Air pressure was measured separately for each day and night of measurements using a Garmin 64s, but some pressures were extrapolated from weather stations and previous measurements because of system malfunctions. Raw changes in $\mathrm{CO}_{2}$ concentrations were converted to metabolic rates using the following equation modified from Lighton (2008): 


$$
\dot{V}_{\mathrm{CO}_{2}}=\mathrm{FR} \times \mathrm{RT} \times \mathrm{SCO}_{2}
$$

where $\dot{V}_{\mathrm{CO}_{2}}$ is the rate of the metabolic rate as measured by $\mathrm{CO}_{2}$ production $(\mathrm{mL} / \mathrm{hr}), F R$ is the flow rate of air through the system $(13,200 \mathrm{~mL} / \mathrm{hr}), R T$ is the response time of the system (hours), and $\triangle \mathrm{CO}_{2}$ is the change in $\mathrm{CO}_{2}$ concentration (fractional change per hour). Response time was calculated as the total volume of the system (mL) divided by the flow rate $(\mathrm{mL} / \mathrm{hr})$. All measurements were converted to standard temperature and pressure using standard equations (Lighton 2008).

Amphibians were placed within chambers and observed to be at rest for at least 20 minutes before measurements were started. Most amphibians were in chambers and unmoving for more than 30 minutes prior to measurement. Metabolic chambers were covered with dark cloth to reduce visual stimuli during measurements while still allowing for the monitoring of animal activity. Multiple chambers were used to facilitate the resting period of multiple amphibians during measurements, and separate tubing was used to shift the respirometry system among chambers without repositioning and potentially causing amphibians to move. Measurements were recorded during the night between 2200 and $0600 \mathrm{~h}$ and during the day between 1100 and $1800 \mathrm{~h}$. Metabolic chambers were sterilized using 70\% ethanol between measurements (Johnson et al. 2003; Phillott et al. 2010).

Resting metabolic rates were measured for inactive amphibians for at least ten minutes (sometimes longer, particularly for small amphibians and cold temperatures). Amphibians were then forced to undergo strenuous activity by turning the container upside down, which flipped the amphibian onto their dorsum. Amphibians were 
constantly flipped onto their dorsal side, allowing time for righting response to their upright position. Such a procedure has been demonstrated to be suitable to measure of MMR and to be a consistent measurement among various amphibians of different habitats and modes of locomotion (Overgaard et al. 2012; Walsberg 1986; Withers et al. 1988). The value of RMR was taken to be the minimum $\dot{V}_{\mathrm{CO}_{2}}$ of a moving window of 180 seconds across the entire measurement period. The value of MMR was taken to be the maximum $\dot{V}_{\mathrm{CO}_{2}}$ of a moving window of 60 seconds across the measurement period. The duration of the moving window was extended for individuals with extremely low metabolic rates (raw $\Delta \mathrm{CO}_{2}$ values less than $0.02 \mathrm{~s}^{-1}$ ) to account for low signal-to-noise ratios (i.e., small amphibians and cold temperatures).

Aerobic scope was calculated in two ways: first, factorial aerobic scope (FAS) was calculated as the ratio of MMR divided by RMR; second, absolute or net aerobic scope (NAS) was calculated as the difference between MMR and RMR. The various metabolic variables (RMR, MMR, FAS, and NAS) were log-transformed (natural logarithm) prior to analysis (Bishop 1999; Killen et al. 2016; Nespolo et al. 2017a). All analyses were conducted separately for day and night to account for metabolic differences between active and resting periods (see Chapters II and III for discussion).

\section{Mass and temperature}

Linear regression was used to examine the relationships between the metabolic variables (RMR, MMR, FAS, and NAS) and mass and temperature. Mass is related to RMR via a power-law relationship where the mass-scaling exponent is determined by the linear slope between log-transformed mass and log-transformed RMR. Few studies have 
examined the relationships between mass and MMR, FAS, and NAS, so both logtransformed and raw mass were used as potential predictor variables. Mass and temperature were regressed against the metabolic variables singly and combined in an additive regression model. The most consistently supported regression for the metabolic variables included log-transformed mass and temperature and was used to correct the metabolic variables for comparisons. Unless otherwise stated, all further analyses were conducted using the residuals of RMR, MMR, FAS, and NAS (herein rRMR, rMMR, rFAS, and rNAS, respectively) from the additive regression models of log-transformed mass and temperature. All analyses were conducted in R 3.6.1 (R Core Team 2019).

\section{Evolutionary analyses}

A phylogeny for amphibians of southeastern Peru was obtained from von May et al. (2019) and provides the most comprehensive phylogeny for the study species. The tree constructed by von May et al. (2019) uses higher order constraints (family and above) following Pyron and Wiens (2011) and includes 50 of my 54 study species. The phylogeny was trimmed and matched to the data using the ape package in $\mathrm{R}$ 3.6.1 ( $\mathrm{R}$ Core Team 2019).

I analyzed the phylogenetic signal in the residuals of the metabolic variables using Pagel's $\lambda$ and Blomberg's $K$. Both indices provide robust estimations of phylogenetic signal but use different methods of calculation (Münkemüller et al. 2012). Pagel's $\lambda$ estimates evolutionary rates using data from within lineages and along branches and assumes a Brownian motion (BM) mode of evolution. Pagel's $\lambda$ is generally bound between zero (no phylogenetic signal) to one (strong phylogenetic signal under 
assumptions of Brownian motion), although there are some instances where the value can fall slightly above one (Münkemüller et al. 2012). Blomberg's $K$ estimates evolutionary change occurring at the nodes and does not depend on BM as an evolutionary model (Adams 2014; Blomberg et al. 2003). A value of Blomberg's $K$ of zero indicates a lack of phylogenetic signal within the data (Rainford et al. 2016). Values significantly different than zero indicate phylogenetic signal within the data, and a value of one is the expected value of Blomberg's $K$ under the assumptions of BM (Rainford et al. 2016). Values above one indicate species within clades are more similar than would be expected under Brownian Motion, and values less than one indicate less similarity among species within clades than would be expected under BM. Analyses were conducted using the phytools packages in R 3.6.1 (R Core Team 2019; Revell 2012).

Various evolutionary models were fit to the tree and data to examine the pattern of evolution of metabolic rate in the study species (see Chapter III for a summary of each model). Models vary in their assumptions about the process of evolution and the influence of phylogeny. The Brownian Motion (BM) evolutionary model assumes a random walk of trait values across the lengths of branches of the tree. The Star model transforms the tree to a single polytomy with all branch lengths equal and is equivalent to assumptions of no phylogenetic relationships. The Lambda model calculates Pagel's $\lambda$ for the distribution of traits and transforms the branches of the tree to match the expectations under assumptions of BM. The Ornstein-Uhlenbeck (OU) model incorporates a parameter that models stabilizing selective pressure (alpha) into a model of BM across the tree. 
The package Rphylopars was used to fit the evolutionary models to the residual datasets of aerobic scope (rFAS and rNAS). The evolution of RMR is examined and discussed in Chapter III. I did not examine the evolution of rMMR to avoid redundancy with rNAS, as there is high correlation between the two variables (see below). Several studies have shown that likelihood phylogenetic comparative methods, such as those used by Rphylopars, have advantageous statistical characteristics (rotation invariant and robust to trait covariation) and perform well with relatively high numbers of species (Adams \& Collyer 2018). Data were analyzed in R 3.6.1 using the package Rphylopars (Goolsby et al. 2017; R Core Team 2019).

Phylograms were created to visualize how the residuals of RMR, MMR, FAS, and NAS are distributed across the phylogeny. The average residual values of the metabolic variables were compiled for each species and used to construct ancestral states across the phylogeny along with $95 \%$ confidence intervals. The phylograms were created using the package phytools in R 3.6.1 (R Core Team 2019; Revell 2012).

\section{Correlations among metabolic variables}

To test the correlative predictions of the $\mathrm{AC}$ model and the metabolic drivers of aerobic scope, I used phylogenetic generalized least squares (PGLS) regression. The regressions assumed a Brownian motion model of evolution as supported by the model comparisons described above. The PGLS regression between rMMR and rRMR was used to test the hypothesis of correlated evolution between rMMR and rRMR as would be consistent with the AC model. The two measures of aerobic scope (rFAS and rNAS) were regressed against the metabolic measurements (rRMR and rMMR) to examine the 
extent to which each metabolic variable drives patterns of aerobic scope. Finally, the PGLS regression between rFAS and rNAS is used to test whether each aerobic scope provide similar insight to each other (high positive correlation). A lack of correlation between rFAS and rNAS may indicate that each calculation of aerobic scope may provide different biological interpretations.

\section{Comparisons among groups}

To examine patterns in aerobic scope among groups, I used phylogenetic analyses of variance (ANOVA) on the residuals of FAS and NAS after correction for mass and temperature (rFAS and rNAS). I used phylogenetic ANOVA separately for day and night with family as a factor to test if there are taxonomic differences in rFAS and rNAS. I examined the influence of elevation by separating measurements into three groups: low elevation (< $600 \mathrm{~m}$ asl), mid elevation $(600-2,000 \mathrm{~m}$ asl), and high elevation $(>2,000 \mathrm{~m}$ asl). I used phylogenetic ANOVA, separately for day and night, to determine if rFAS and rNAS differ among elevational groups.

\section{RESULTS}

\section{Mass and temperature}

Model comparisons among the various metabolic variables show that the additive model that includes temperature and log-transformed mass to be the most consistently supported model by Akaike information criterion (AIC) values (Table 4.1). The additive model was the most supported model for RMR, MMR, and NAS for both day and night datasets. For FAS, other models were the most supported for both day and night, but the 
AIC values were similar among the various models (Table 4.1). For consistency in correction for mass and temperature, the same additive model using temperature and logtransformed mass was selected for each metabolic variable.

The coefficients of temperature and log-transformed mass for RMR, MMR, FAS, and NAS are summarized in Table 4.2. The coefficient between log-transformed mass and RMR (the mass-scaling exponent) was $0.79 \pm 0.03$ and $0.73 \pm 0.02$ for day and night, respectively, relatively close to the value proposed by the metabolic theory of ecology (MTE) of 0.75 (Brown et al. 2004). The mass-scaling exponent was higher for MMR than RMR at $0.84 \pm 0.02$ and $0.89 \pm 0.02$ for day and night, respectively. The massscaling exponent of FAS is the difference of mass-scaling exponents between RMR and MMR, and thus relatively small as a result of similar mass-scaling exponents of RMR and MMR $(0.05 \pm 0.03$ and $0.16 \pm 0.03$, day and night $)$. The mass-scaling exponent for NAS was $0.84 \pm 0.03$ and $0.92 \pm 0.03$ for day and night, respectively.

The effects of temperature are similar for RMR, MMR, and NAS, with increasing temperatures increasing each metabolic variable. The effects of temperature are higher at night $(0.13-0.14)$ than during the day $(0.11)$ for each metabolic measurement, suggesting that thermal sensitivity is higher at night than during the day. Similar to the effect of mass, the influence of temperature was quite small in FAS, and only distinguishable from zero at night $(0.00 \pm 0.01$ and $-0.01 \pm 0.01$ for day and night, respectively)

\section{Evolutionary analysis}

The measures of phylogenetic signal are similar for both rFAS and rNAS and for both day and night (Table 4.3). The values of Pagel's $\lambda$ are significant $(\lambda=1.01, \mathrm{p}<0.01)$ 
for each time and dataset. Values of Blomberg's $K$ are above 1.5 for each time and dataset, suggesting that values of rFAS and rNAS are more similar within clades than would be expected from Brownian motion.

There is support for multiple evolutionary models by AIC for each time period for both measures of aerobic scope (Table 4.4). The most supported model for rFAS was the Brownian motion model of evolution for both day and night. For rNAS, the model that incorporates the lambda transformation was the most supported evolutionary model for day and night. However, there was support for the same three models across each time and measure of aerobic scope: Brownian motion model, the lambda model, and the Ornstein-Uhlenbeck model. The AIC weights (AICw) demonstrate the relative support for each of the three models of evolution for each time period and dataset (Table 4.4). The star model, representing the absence of phylogeny in the distribution of residual aerobic scopes, was not supported in any of the datasets or time periods, confirming the results from the analysis of phylogenetic signal in indicating that the incorporation of the phylogeny is important for analyses of aerobic scope.

\section{Correlations between metabolic variables}

Phylogenetic regression demonstrates that there is significant correlation $(\mathrm{p}<$ 0.001) between rRMR and rMMR for both day and night (Table 4.5; Figure 4.5A). The coefficients were positive for both day and night $(0.42 \pm 0.05$ and $0.46 \pm 0.06$, respectively). However, the correlation between rRMR and rMMR has relatively low explanatory power for both day (adj. $\left.\mathrm{R}^{2}=0.184\right)$ and night $\left(\operatorname{adj} . \mathrm{R}^{2}=0.187\right)$. 
The phylogenetic regressions between the rFAS and the two measures of metabolic rates differed between day and night (Table 4.5). As expected, for both time periods, the relationship between rFAS and rRMR (the denominator) was negative while the relationship with rMMR (the numerator) was positive. At night, both correlations of rFAS were significant $(\mathrm{p}<0.001)$, yet neither of the relationships were significant during the day.

The correlations show that rNAS has a significant relationship with rMMR both day and night $(\mathrm{p}<0.001)$ and that this relationship has extremely high explanatory power (adj. $\mathrm{R}^{2}>0.95$; Table 4.5). In contrast, the relationship between rNAS and rRMR has low explanatory power (adj. $\left.R^{2}<0.07\right)$ and was only significant during the day. The relationships of rNAS were positive for both rRMR and rMMR, but the coefficient is higher for rMMR (coefficient > 1.1) than for rRMR (coefficient < 0.32). Altogether, the results suggest that MMR may have a greater influence on the value of NAS than RMR.

The phylogenetic regression between rFAS and rNAS finds that there is a significant, positive correlation between rFAS and rNAS ( $\mathrm{p}<0.01$; Table 4.5). Moreover, the adj. $\mathrm{R}^{2}$ value between rFAS and rNAS was relatively high for both day and night (0.43 and 0.51 , respectively). However, the unexplained variation in the correlation between rFAS and rNAS may be important in understanding the distinct biological interpretations of FAS and NAS.

\section{Comparisons}

There were highly significant differences among families in the residuals of all the metabolic variables (rRMR, rMMR, rFAS, and rNAS), both day and night (Table 
4.6). Post-hoc analysis shows that the significant differences among families are often a result of one or two families being significantly different than the others (Figure 4.9). Craugastoridae, Dendrobatidae, and Hylidae are often the families that are significantly different from the others. In Dendrobatidae, there seems to be a trend for large differences from other families in one time period (night or day), but not both.

The metabolic variables are significantly different among the three elevational groups, but they seem to be dependent on time of day. The differences in rFAS among elevational groups are significant for both day and night (Table 4.7), although the pattern among elevations differs (Figure 4.10). At night, the mid-elevation species have significantly lower rFAS than both high and low elevation species, which do not differ from each other. During the day however, low elevation species have a significantly higher rFAS than high elevation species, with mid-elevation species intermediate. For rNAS, differences were significant only during the day, where low elevation species had higher rNAS than high elevation species and mid-elevation species were intermediate.

\section{DISCUSSION}

Aerobic scope within tropical amphibians is highly dependent on organismal traits, environmental characteristics, and evolutionary history. Many of the patterns of metabolic characteristics in the tropical amphibians in my study do not conform to the predictions of the aerobic capacity (AC) model (Nespolo \& Roff 2014). I demonstrate that the two measures of aerobic scope, FAS and NAS, have a high phylogenetic signal for both day and night, highlighting the importance of incorporating evolutionary history into analyses of physiology. Moreover, the results of phylogenetic analyses find 
consistent patterns in the evolution of aerobic scope, regardless of method of calculation. The patterns display differences between day and night, suggesting that circadian effects on physiological characteristics are important for determining aerobic scope. There are also important differences in aerobic scope among families and across elevation, suggesting that there may be important evolutionary, ecological, and environmental correlates of aerobic scope. My study has important implications for understanding the evolution of aerobic scope and what may drive variation in aerobic scope in tropical amphibians.

The mass-scaling exponents for RMR for day and night were similar to the proposed value of 0.75 from MTE (Brown et al. 2004). The fractal transport explanatory mechanisms for the MTE (West et al. 1997) suggest that the mass-scaling exponent of 0.75 should also apply to maximum metabolic rates (Bishop 1999). However, my results suggest that mass-scaling exponents for MMR in tropical amphibians are higher than proposed by MTE, as has been found in a number of other studies of MMR (Bishop 1999, Glazier 2008, 2009). The differences in mass-scaling exponents between MMR and RMR is reflected in the positive mass-scaling exponents of FAS. The positive massscaling exponent of FAS (0.12 and 0.06 for day and night, respectively) suggests that there is predictable variation in FAS dependent on organismal characteristics, as has been found in other studies (Bishop 1999), and contrasts with the prediction of invariable FAS of the AC model (Nespolo \& Roff 2014). The mass-scaling exponent of NAS is similar to that of MMR, which is not surprising given the high correlation between these two measurements. 
The thermal sensitivities are similar for RMR and MMR for both day and night. However, the temperature coefficient is higher at night than during the day, suggesting that the metabolic characteristics during the active periods of amphibians (predominantly nocturnal) may have a higher thermal sensitivity than metabolic characteristics during resting periods. There are two important consequences of high thermal sensitivity during active times. First, the potential for microhabitat buffering of increased temperatures is likely to be greatest in sheltered microhabitats used primarily during resting periods (Kearney et al. 2009; Scheffers et al. 2014). During activities such as reproduction and foraging, amphibians will leave potentially buffered microhabitats and thus be exposed to ambient conditions while also the most sensitive to the metabolic impacts of high temperatures. While diurnal species may be able to mitigate climate change impacts by shifting activity patterns (Levy et al. 2019), nocturnal amphibians will not be able to shift activity times to cooler periods. Second, high thermal sensitivity during active periods may have direct consequences on behaviors such as foraging and reproduction. Thus, high thermal sensitivity during active periods may have cascading effects on other aspects of organismal biology apart from metabolism.

The similar thermal sensitivities of RMR and MMR are reflected in the lack of thermal dependence in FAS (Figure 4.2). In contrast, the NAS of amphibians has high thermal sensitivity similar to MMR. The high correlation between NAS and MMR, and lack of correlation between NAS and RMR, suggest that NAS is primarily determined by MMR. It is therefore not surprising that NAS has a similar thermal sensitivity as MMR as changes in NAS would be predominantly determined by changes in MMR. In comparative studies, particularly those examining the influence of temperature, NAS may 
be a more useful metric of aerobic scope than FAS as a result of the high thermal sensitivity of NAS and the lack of thermal variation in FAS (Clark et al. 2013).

Phylogenetic signal in both rFAS and rNAS demonstrates the importance of incorporating phylogeny in analyses of aerobic scope. The values of Blomberg's $K$ suggest that aerobic scope is more similar within clades than would be expected if FAS and NAS evolved according to a Brownian motion model of evolution. Such a distribution of trait values could result from high phylogenetic conservatism throughout the tree (Kozak \& Wiens 2010; Losos 2008) or distinct ecological strategies of different clades that are correlated with different metabolic characteristics. Unfortunately, it is difficult to infer adaptation from phylogenetic methods, as it is difficult to distinguish between observed patterns are a result of shared evolutionary history or similar ecological traits among organisms within clades (and thus also correlated across the phylogeny; Losos 2008; Rezende \& Diniz-Filho 2012).

Interestingly, although the phylogenetic signals in aerobic scope indicate more similarity than would be expected from Brownian motion, the most supported evolutionary models by AIC follow Brownian motion (with or without the lambda transformation for rFAS and rNAS, respectively). However, the AIC weights show that there is mixed support for each of the BM, lambda, and OU models. The mixed support is consistent across each time period (day and night) and measure of aerobic scope (rFAS and rNAS). The mixed support for multiple models may reflect the high similarity within clades (Blomberg's $K$ above expectations for Brownian motion; Table 4.3) but the penalty of the additional parameters necessary for OU models compared to the Brownian motion model (Table 4.4). Large datasets may have the statistical power to detect and 
support OU models of evolution in aerobic scope as has been found in other studies (Nespolo \& Roff 2014; Nespolo et al. 2017a, b).

My results generally disagree with the predictions of the AC model (Nespolo \& Roff 2014; Bennett \& Ruben 1979). First, the AC model predicts a high correlation between resting and active metabolic rates, which would result in low variation in FAS. While there is a significant correlation between rRMR and rMMR, there remains high variation in rFAS among taxa. Moreover, the variation in rFAS has correlations with organismal and environmental variables that would be unexpected under the AC model. The differences in the mass-scaling exponents of RMR and MMR produce a significant mass-scaling exponent of FAS, although the relationship between FAS and mass may be explained by equations other than a power-law and may vary among life stages and species with different life histories (Killen et al. 2007). Additional work could explicitly examine how FAS varies with mass and if the traditional allometric equations are appropriate for a variable incorporating a ratio of allometric traits (RMR and MMR). Second, the AC model predicts high correlation between rNAS and both rRMR and rMMR. However, while there is a high correlation between rNAS and rMMR (adj. $\mathrm{R}^{2}$ > 0.95 for both day and night; Table 4.5, Figure 4.6B), the correlation between rNAS and rRMR is relatively weak (adj. $R^{2}<0.07$ for both day and night; Table 4.5, Figure 4.5C). Thus, rNAS appears to be almost entirely dependent on rMMR. The relationship between rRMR and rMMR and the variation in rFAS diverge from predictions of the AC model. Moreover, rNAS seems to be almost entirely dependent on rMMR, suggesting that it may be a similar measure of aerobic capacity as rMMR. 
Variation in rFAS, according to the AC model, should be random and not follow any consistent taxonomic patterns. However, the residuals of FAS are also found to have significant differences among families, with notably low rFAS found throughout the family Craugastoridae (Figure 4.3). The litter frogs in Craugastoridae have consistently low rFAS, as well rNAS, compared to other families both day and night (Figure 4.8). The low aerobic scope (both rFAS and rNAS) of Craugastoridae is the most striking feature of the phenograms of rFAS and rNAS, both day and night (Figure 4.3; Figure 4.4). The low aerobic scope in Craugastoridae could reflect ancestral changes that preceded the radiation of the group or could be associated with ecological characteristics.

The frogs in the family Craugastoridae lay terrestrial eggs with direct development to juvenile froglets (Duellman \& Lehr 2009). The direct-developing life history of Craugastoridae could be associated with coevolved traits and selective pressures that result in the observed low aerobic scope. In my study, the family Craugastoridae is represented across the entire elevational gradient, and includes both fossorial and semi-arboreal species, thus the observed pattern is unlikely to be a result of habitat or elevation. Other ecological characteristics of Craugastoridae, such as size and diet, are shared with other families and are thus unlikely predictors of low aerobic scope. Direct development has evolved several times in amphibians and transitions to terrestrial direct development has been preceded by various reproductive modes (Crump 2015; Gomez-Metre et al. 2012). Nevertheless, direct development is often accompanied by a suite of morphological, physiological, and behavioral characteristics and is more likely to be found in relatively warm and wet environments (Crump 2015; Gomez-Metre et al. 2012). My study suggests that direct development may also be associated with metabolic 
characteristics such as low aerobic scope (FAS and NAS). Additional work could examine if low aerobic scope is characteristic for other anurans, salamanders, and caecilians that undergo direct development.

The family Dendrobatidae displays interesting patterns for rFAS between day and night (Figure 4.8C). At night, dendrobatids have relatively similar values of rFAS compared to other families. However, during the day, rFAS is the lowest among the families. The contrasting patterns of rFAS between day and night seems to be driven primarily by differences in rRMR, which for Dendrobatidae is high during the day and low at night (Figure 4.8A). The diel changes in rRMR likely result from the differences in circadian rhythm of RMR among families that were demonstrated in Chapter II. However, for the differences in rRMR to directly impact rFAS, the changes in rRMR must not be accompanied by proportional changes in rMMR. Thus, the high diurnal RMR in dendrobatids does not seem to correspond to high MMR as has been proposed as an evolutionary explanation for high RMR in poison frogs (Santos \& Cannatella 2011). High RMR without accompanying MMR also contradicts predictions of the AC model (Nespolo \& Roff 2014). It is possible that high RMR may confer advantages separate from aerobic capacity, such as an increasing the efficiency and rate of transitions between RMR and active metabolic rates (and MMR) or reducing dependence on anaerobic pathways (Bennet \& Licht 1973, 1974; Ejbye-Ernst et al. 2016).

The rFAS varies significantly across elevation for both day and night, although the pattern among elevations differs between time periods. At night, both low and high elevation species have significantly higher rFAS than mid-elevation species. During the day, however, there is a gradient, with low elevation species having significantly higher 
rFAS than high elevation species, and mid-elevation species are intermediate between the two extremes. The same significant pattern of decrease from low to high elevation species is found for rNAS during the day. However, differences in rNAS among elevational groups are not significant at night. The differences in aerobic scope across elevation are difficult to interpret, especially given the differences in pattern between day and night. Navas (1996) found that high elevation species maintain similar aerobic scope over large temperature ranges, while low elevation species lose aerobic scope at low temperatures. In my study, however, I used environmental temperatures that did not approach the extremes (both high and low) used in other studies, which may reduce the ability to detect differences among environments.

Overall, in contrast to the predictions of the AC model, there appears to be extensive variation in the aerobic scope of tropical amphibians. The differences in aerobic scope between day and night suggest that there are circadian influences on the relationship between resting and maximal metabolic rates that could be related to physiological changes occurring between active and resting periods. Moreover, there are important phylogenetic patterns in both FAS and NAS that could reflect systemic limitations in physiology or adaptation for similar ecological strategies, but it is difficult to determine what drives patterns among families. The high correlation between NAS and MMR suggests that NAS may be almost entirely determined by aerobic capacity, likely owing to the low RMR relative to MMR typical of amphibians. The patterns of aerobic scope across elevation suggests the environment has a strong effect on the selection of metabolic physiology. Within amphibians, it appears that there is decoupled evolution 
between RMR and MMR, which suggests that there may be distinct selective pressures

between the two metabolic rates that lead to differences in aerobic scope.

\section{REFERENCES}

Adams DC. 2014. A generalized K statistic for estimating phylogenetic signal from shape and other high-dimensional multivariate data. Systematic Biology. 63(5):685-97

Adams DC, Collyer ML. 2018. Multivariate phylogenetic comparative methods: Evaluations, comparisons, and recommendations. Systematic Biology. 67(1):1431

Auer SK, Salin K, Anderson GJ, Metcalfe NB. 2015a. Aerobic scope explains individual variation in feeding capacity. Biology Letters. 11(11):10-12

Auer SK, Salin K, Rudolf AM, Anderson GJ, Metcalfe NB. 2015b. The optimal combination of standard metabolic rate and aerobic scope for somatic growth depends on food availability. Functional Ecology. 29(4):479-86

Becker A, Körner C, Brun JJ, Guisan A, Tappeiner U. 2007. Ecological and land use studies along elevational gradients. Mountain Research and Development. 27(1):58-65

Behrens JW, Van Deurs M, Christensen EAF. 2017. Evaluating dispersal potential of an invasive fish by the use of aerobic scope and osmoregulation capacity. PLoS ONE. 12(4):1-19

Bennett AF. 1978. Activity metabolism of the lower vertebrates. Annual Review of Physiology. 40:447-69

Bennett AF, Licht P. 1973. Relative contributions of anaerobic and aerobic energy production during activity in Amphibia. Journal of Comparative Physiology. 87(4):351-60

Bennett AF, Licht P. 1974. Anaerobic metabolism during activity in amphibians. Comparative Biochemistry and Physiology Part A: Physiology. 48(2):319-27

Bennett AF, Ruben JA. 1979. Endothermy and activity in vertebrates. Science. 206:64954

Biro PA, Ujvari B, Post JR, Thomas F, Garland T Jr., Beckmann C. 2018. Metabolic scope as a proximate constraint on individual behavioral variation: Effects on personality, plasticity, and predictability. American Naturalist. 192(2):142-54 
Bishop CM. 1999. The maximum oxygen consumption and aerobic scope of birds and mammals: Getting to the heart of the matter. Proceedings of the Royal Society of London B. 266(May):2275-81

Blomberg SP, Garland T Jr., Ives AR. 2003. Testing for phylogenetic signal in comparative data: Behavioral traits are more labile. Evolution. 57(4):717

Brown JH, Gillooly JF, Allen AP, Savage VM, West GB. 2004. Toward a metabolic theory of ecology. Ecology. 85(7):1771-89

Careau V. 2013. Basal metabolic rate, maximum thermogenic capacity and aerobic scope in rodents: Interaction between environmental temperature and torpor use. Biology Letters. 9(2):20121104

Carey C. 1979. Effect of constant and fluctuating temperatures on resting and active oxygen consumption of toads, Bufo boreas. Oecologia. 39(2):201-12

Chown SL, Gaston KJ. 1999. Exploring links between physiology and ecology at macroscales: The role of respiratory metabolism in insects. Biological Reviews. 74(1):87-120

Clark TD, Sandblom E, Jutfelt F. 2013. Aerobic scope measurements of fishes in an era of climate change: Respirometry, relevance and recommendations. Journal of Experimental Biology. 216(15):2771-82

Crump ML. 2015. Anuran reproductive modes: Evolving perspectives. Journal of Herpetology. 49(1):1-16

Crump ML, Scott NJ Jr. 1994. Visual encounter surveys. In Measuring and Monitoring Biological Diversity: Standard Methods for Amphibians, eds. WR Heyer, MA Donnelly, RW McDiarmid, LC Hayek, MS Foster, pp. 84-92. Washington, DC: Smithsonian Institution Press

Dutenhoffer MS, Swanson DL. 1996. Relationship of basal to summit metabolic rate in passerine birds and the aerobic capacity model for the evolution of endothermy. Physiological Zoology. 69(5):1232-54

Duellman WE, Lehr E. 2009. Terrestrial-Breeding Frogs (Strabomantidae) in Peru. Münster, Germany: Natur und Tier-Verlag

Ejbye-Ernst R, Michaelsen TY, Tirsgaard B, Wilson JM, Jensen LF, et al. 2016. Partitioning the metabolic scope: The importance of anaerobic metabolism and implications for the oxygen- and capacity-limited thermal tolerance (OCLTT) hypothesis. Conservation Physiology. 4(1):1-13

Farrell AP. 2016. Pragmatic perspective on aerobic scope: Peaking, plummeting, pejus and apportioning. Journal of Fish Biology. 88(1):322-43 
Garland T Jr., Albuquerque RL. 2017. Locomotion, energetics, performance, and behavior: A mammalian perspective on lizards, and vice versa. Integrative and Comparative Biology. 57(2):252-66

Gatten RE Jr., Miller KJ, Full RJ. 1992. Energetics at rest and during locomotion. In Environmental Physiology of the Amphibians, eds. ME Feder, WW Burggren, pp. 314-74. Chicago, Illinois, USA: The University of Chicago Press

Gçbczyński AK, Konarzewski M. 2009. Metabolic correlates of selection on aerobic capacity in laboratory mice: A test of the model for the evolution of endothermy. Journal of Experimental Biology. 212(17):2872-78

Glazier DS. 2008. Effects of metabolic level on the body size scaling of metabolic rate in birds and mammals. Proceedings of the Royal Society B: Biological Sciences. 275(1641):1405-10

Glazier DS. 2009. Activity affects intraspecific body-size scaling of metabolic rate in ectothermic animals. Journal of Comparative Physiology B: Biochemical, Systemic, and Environmental Physiology. 179(7):821-28

Gomes FR, Chaui-Berlinck JG, Bicudo JEPW, Navas CA. 2004. Intraspecific relationships between resting and activity metabolism in anuran amphibians: Influence of ecology and behavior. Physiological and Biochemical Zoology. 77(2):197-208

Gomez-Mestre I, Pyron RA, Wiens JJ. 2012. Phylogenetic analyses reveal unexpected patterns in the evolution of reproductive modes in frogs. Evolution. 66(12):36873700

Goolsby EW, Bruggeman J, Ané C. 2017. Rphylopars: Fast multivariate phylogenetic comparative methods for missing data and within-species variation. Methods in Ecology and Evolution. 8(1):22-27

Hinds DS, Baudinette RV, MacMillen RE, Halpern EA. 1993. Maximum metabolism and the aerobic factorial scope of endotherms. Journal of Experimental Biology. $182: 41-56$

Johnson ML, Berger L, Philips L, Speare R. 2003. Fungicidal effects of chemical disinfectants, UV light, desiccation and heat on the amphibian chytrid Batrachochytrium dendrobatidis. Diseases of Aquatic Organisms. 57:255-60

Kearney M, Shine R, Porter WP. 2009. The potential for behavioral thermoregulation to buffer "cold-blooded" animals against climate warming. Proceedings of the National Academy of Sciences of the United States of America. 106(10):3835-40

Killeen TJ, Douglas M, Consiglio T, Jørgensen PM, Mejia J. 2007. Dry spots and wet spots in the Andean hotspot. Journal of Biogeography. 34(8):1357-73 
Killen SS, Costa I, Brown JA, Gamperl AK. 2007. Little left in the tank: Metabolic scaling in marine teleosts and its implications for aerobic scope. Proceedings of the Royal Society B: Biological Sciences. 274:431-38

Killen SS, Glazier DS, Rezende EL, Clark TD, Atkinson D, et al. 2016. Ecological influences and morphological correlates of resting and maximal metabolic rates across teleost fish species. American Naturalist. 187(5):592-606

Killen SS, Marras S, Steffensen JF, Mckenzie DJ. 2012. Aerobic capacity influences the spatial position of individuals within fish schools. Proceedings of the Royal Society B: Biological Sciences. 279:357-64

Killen SS, Mitchell MD, Rummer JL, Chivers DP, Ferrari MCO, et al. 2014. Aerobic scope predicts dominance during early life in a tropical damselfish. Functional Ecology. 28(6):1367-76

Kozak KH, Wiens JJ. 2010. Niche conservatism drives elevational diversity patterns in appalachian salamanders. American Naturalist. 176(1):40-54

Levy O, Dayan T, Porter WP, Kronfeld-Schor N. 2019. Time and ecological resilience: Can diurnal animals compensate for climate change by shifting to nocturnal activity? Ecological Monographs. 89(1):1-22

Lighton JRB. 2008. Measuring Metabolic Rates: A Manual for Scientists. Oxford, UK: Oxford University Press

Losos JB. 2008. Phylogenetic niche conservatism, phylogenetic signal and the relationship between phylogenetic relatedness and ecological similarity among species. Ecology Letters. 11(10):995-1003

McKenzie DJ, Steffensen JF, Taylor EW, Abe AS. 2012. The contribution of air breathing to aerobic scope and exercise performance in the banded knifefish Gymnotus carapo L. Journal of Experimental Biology. 215(8):1323-30

Miller K, Hutchison VH. 1980. Aerobic and anaerobic scope for activity in the giant toad, Bufo marinus. Physiological Zoology. 53(2):170-75

Münkemüller T, Lavergne S, Bzeznik B, Dray S, Jombart T, et al. 2012. How to measure and test phylogenetic signal. Methods in Ecology and Evolution. 3(4):743-56

Navas CA. 1996. Metabolic physiology, locomotor performance, and thermal niche breadth in neotropical anurans. Physiological Zoology. 69(6):1481-1501

Nespolo RF, Figueroa J, Solano-Iguaran JJ. 2017b. Studying the evolutionary significance of thermal adaptation in ectotherms: The diversification of amphibians' energetics. Journal of Thermal Biology. 68:5-13 
Nespolo RF, Roff DA. 2014. Testing the aerobic model for the evolution of endothermy: Implications of using present correlations to infer past evolution. American Naturalist. 183(1):74-83

Nespolo RF, Solano-Iguaran JJ, Bozinovic F. 2017a. Phylogenetic analysis supports the aerobic-capacity model for the evolution of endothermy. American Naturalist. 189(1):13-27

Norin T, Clark TD. 2017. Fish face a trade-off between 'eating big' for growth efficiency and 'eating small' to retain aerobic capacity. Biology Letters. 13(9):20170298

Norin T, Malte H, Clark TD. 2014. Aerobic scope does not predict the performance of a tropical eurythermal fish at elevated temperatures. Journal of Experimental Biology. 217(2):244-51

Overgaard J, Andersen JL, Findsen A, Pedersen PBM, Hansen K, et al. 2012. Aerobic scope and cardiovascular oxygen transport is not compromised at high temperatures in the toad Rhinella marina. Journal of Experimental Biology. 215:3519-26

Phillott AD, Speare R, Hines HB, Skerratt LF, Meyer E, et al. 2010. Minimising exposure of amphibians to pathogens during field studies. Diseases of Aquatic Organisms. 92(3):175-85

Pyron RA, Wiens JJ. 2011. A large-scale phylogeny of Amphibia including over 2800 species, and a revised classification of extant frogs, salamanders, and caecilians. Molecular Phylogenetics and Evolution. 61(2):543-83

R Core Team. 2019. R: A language and environment for statistical computing. Vienna, Austria: R Foundation for Statistical Computing

Rainford JL, Hofreiter M, Mayhew PJ. 2016. Phylogenetic analyses suggest that diversification and body size evolution are independent in insects. $B M C$ Evolutionary Biology. 16(1):1-17

Revell LJ. 2012. phytools: An R package for phylogenetic comparative biology (and other things). Methods in Ecology and Evolution. 3(2):217-23

Rezende EL, Diniz-Filho JAF. 2012. Phylogenetic analyses: Comparing species to infer adaptations and physiological mechanisms. Comprehensive Physiology. 2(1):63974

Rummer JL, Couturier CS, Stecyk JAW, Gardiner NM, Kinch JP, et al. 2014. Life on the edge: Thermal optima for aerobic scope of equatorial reef fishes are close to current day temperatures. Global Change Biology. 20(4):1055-66 
Sadowska ET, Labocha MK, Baliga K, Stanisz A, Wróblewska AK, et al. 2005. Genetic correlations between basal and maximum metabolic rates in a wild rodent: Consequences for evolution of endothermy. Evolution. 59(3):672

Sanders NJ, Rahbek C. 2012. The patterns and causes of elevational diversity gradients. Ecography. 35(1):1-3

Santos JC, Cannatella DC. 2011. Phenotypic integration emerges from aposematism and scale in poison frogs. Proceedings of the National Academy of Sciences of the United States of America. 108(15):6175-80

Scheffers BR, Edwards DP, Diesmos A, Williams SE, Evans TA. 2014. Microhabitats reduce animal's exposure to climate extremes. Global Change Biology. 20(2):495-503

Schippers MP, LeMoine CMR, McClelland GB. 2014. Patterns of fuel use during locomotion in mammals revisited: The importance of aerobic scope. Journal of Experimental Biology. 217(18):3193-96

Sears MW. 2005. Resting metabolic expenditure as a potential source of variation in growth rates of the sagebrush lizard. Comparative Biochemistry and Physiology Part A: Molecular \& Integrative Physiology. 140(2):171-77

Sundqvist MK, Sanders NJ, Wardle DA. 2013. Community and ecosystem responses to elevational gradients: Processes, mechanisms, and insights for global change. Annual Review of Ecology, Evolution, and Systematics. 44(1):261-80

von May R, Catenazzi A, Santa-Cruz R, Gutierrez AS, Moritz C, Rabosky DL. 2019. Thermal physiological traits in tropical lowland amphibians: Vulnerability to climate warming and cooling. PLoS ONE. 14(8):e0219759

Walsberg GE. 1986. Comparison of two techniques for estimating the maximum aerobic capacity of amphibians. Herpetologica. 42(3):389-94

Webb CO, Ackerly DD, McPeek MA, Donoghue MJ. 2002. Phylogenies and community ecology. Annual Review of Ecology and Systematics. 33:475-505

West GB, Brown JH, Enquist BJ. 1997. General model for the origin of allometric scaling laws in biology. Science. 276(April):122-126

Withers PC, Hillman SS, Simmons LA, Zygmunt AC. 1988. Cardiovascular adjustments to enforced activity in the anuran amphibian, Bufo marinus. Comparative Biochemistry and Physiology Part A: Physiology. 89(1):45-49

Wone BWM, Madsen P, Donovan ER, Labocha MK, Sears MW, et al. 2015. A strong response to selection on mass-independent maximal metabolic rate without a correlated response in basal metabolic rate. Heredity. 114(4):419-27 
Table 4.1. Summaries of model support for the regressions between the predictor variables of mass and temperature and the metabolic variables of resting metabolic rate (RMR), maximum metabolic rate (MMR), factorial aerobic scope (FAS), and net aerobic scope (NAS) for day and night. The most supported model by Akaike Information Criterion (AIC) is in bold for each time and dataset. Levels of significance: $* \mathrm{p}<0.05 ; * * \mathrm{p}<0.01 ; * * * \mathrm{p}<0.001$.

\begin{tabular}{|c|c|c|c|c|c|c|c|c|}
\hline Time & Model & Adj. $R^{2}$ & $\mathbf{T}$ & $\mathbf{p}$ & $\mathbf{d F}$ & dF (res) & logLik & AIC \\
\hline \multirow{20}{*}{ Day } & $\log \mathrm{RMR} \sim$ mass & 0.46 & 231.49 & $<0.01 * *$ & 2 & 273 & -298.50 & 603.00 \\
\hline & $\log \mathrm{RMR} \sim \operatorname{logmass}$ & 0.69 & 598.37 & $<0.01 * *$ & 2 & 273 & -223.35 & 452.70 \\
\hline & $\log \mathrm{RMR} \sim$ temp & 0.23 & 85.12 & $<0.01 * *$ & 2 & 273 & -345.62 & 697.23 \\
\hline & $\log \mathrm{RMR} \sim$ mass + temp & 0.61 & 214.12 & $<0.01 * *$ & 3 & 272 & -252.91 & 513.82 \\
\hline & $\log R M R \sim \operatorname{logmass}+$ temp & 0.84 & 700.14 & $<0.01 * *$ & 3 & 272 & -133.21 & 274.43 \\
\hline & $\log M M R \sim$ mass & 0.53 & 307.07 & $<0.01 * *$ & 2 & 273 & -317.43 & 640.86 \\
\hline & $\log \mathrm{MMR} \sim \log$ mass & 0.75 & 818.35 & $<0.01 * *$ & 2 & 273 & -230.52 & 467.05 \\
\hline & $\log M M R \sim$ temp & 0.19 & 63.64 & $<0.01 * *$ & 2 & 273 & -392.24 & 790.49 \\
\hline & $\log M M R \sim$ mass + temp & 0.64 & 239.87 & $<0.01 * *$ & 3 & 272 & -281.28 & 570.56 \\
\hline & $\log M M R \sim \operatorname{logmass}+$ temp & 0.86 & 828.40 & $<0.01 * *$ & 3 & 272 & -151.72 & 311.43 \\
\hline & $\log \mathrm{FAS} \sim \operatorname{mass}$ & 0.11 & 34.10 & $<0.01 * *$ & 2 & 273 & -162.17 & 330.34 \\
\hline & $\log \mathrm{FAS} \sim \operatorname{logmass}$ & 0.12 & 37.95 & $<0.01 * *$ & 2 & 273 & -160.46 & 326.91 \\
\hline & $\log F A S \sim$ temp & 0.00 & 0.17 & 0.68 & 2 & 273 & -178.27 & 362.54 \\
\hline & $\log F A S \sim$ mass + temp & 0.11 & 17.10 & $<0.01 * *$ & 3 & 272 & -162.07 & 332.15 \\
\hline & $\log \mathrm{FAS} \sim \operatorname{logmass}+$ temp & 0.12 & 18.97 & $<0.01 * *$ & 3 & 272 & -160.41 & 328.81 \\
\hline & $\log \mathrm{NAS} \sim$ mass & 0.52 & 295.72 & $<0.01 * *$ & 2 & 273 & -332.12 & 670.24 \\
\hline & $\operatorname{logNAS} \sim \operatorname{logmass}$ & 0.73 & 735.48 & $<0.01 * *$ & 2 & 273 & -253.36 & 512.72 \\
\hline & $\log \mathrm{NAS} \sim$ temp & 0.17 & 55.30 & $<0.01 * *$ & 2 & 273 & -407.67 & 821.35 \\
\hline & $\operatorname{logNAS} \sim$ mass + temp & 0.61 & 216.08 & $<0.01 * *$ & 3 & 272 & -302.25 & 612.49 \\
\hline & $\operatorname{logNAS} \sim \operatorname{logmass}+$ temp & 0.82 & 635.45 & $<0.01 * *$ & 3 & 272 & -194.39 & 396.78 \\
\hline
\end{tabular}




\begin{tabular}{|c|c|c|c|c|c|c|c|c|}
\hline Time & Model & Adj. $R^{2}$ & $\mathbf{T}$ & $\mathbf{p}$ & $\mathbf{d F}$ & dF (res) & $\operatorname{logLik}$ & AIC \\
\hline \multirow{20}{*}{ Night } & $\log \mathrm{RMR} \sim$ mass & 0.41 & 179.75 & $<0.01 * *$ & 2 & 261 & -345.86 & 697.71 \\
\hline & $\log \mathrm{RMR} \sim \operatorname{logmass}$ & 0.61 & 410.39 & $<0.01 * *$ & 2 & 261 & -290.51 & 587.03 \\
\hline & $\log \mathrm{RMR} \sim$ temp & 0.38 & 164.21 & $<0.01 * *$ & 2 & 261 & -350.58 & 707.15 \\
\hline & $\log \mathrm{RMR} \sim$ mass + temp & 0.67 & 266.57 & $<0.01 * *$ & 3 & 260 & -268.09 & 544.19 \\
\hline & $\log R M R \sim \operatorname{logmass}+$ temp & 0.87 & 857.75 & $<0.01 * *$ & 3 & 260 & -148.09 & 304.18 \\
\hline & $\log M M R \sim$ mass & 0.49 & 257.56 & $<0.01 * *$ & 2 & 261 & -325.54 & 657.08 \\
\hline & $\log \mathrm{MMR} \sim \log$ mass & 0.67 & 523.58 & $<0.01 * *$ & 2 & 261 & -271.09 & 548.17 \\
\hline & $\log M M R \sim$ temp & 0.33 & 131.55 & $<0.01 * *$ & 2 & 261 & -362.15 & 730.30 \\
\hline & $\log M M R \sim$ mass + temp & 0.70 & 313.81 & $<0.01 * *$ & 3 & 260 & -254.36 & 516.71 \\
\hline & $\log M M R \sim \operatorname{logmass}+$ temp & 0.88 & 932.20 & $<0.01 * *$ & 3 & 260 & -139.60 & 287.19 \\
\hline & $\log \mathrm{FAS} \sim$ mass & 0.03 & 8.70 & $<0.01 * *$ & 2 & 261 & -158.80 & 323.60 \\
\hline & $\log \mathrm{FAS} \sim \operatorname{logmass}$ & 0.01 & 2.63 & 0.11 & 2 & 261 & -161.79 & 329.58 \\
\hline & $\log F A S \sim$ temp & 0.01 & 2.89 & 0.09 & 2 & 261 & -161.66 & 329.33 \\
\hline & $\operatorname{logFAS} \sim$ mass + temp & 0.04 & 7.09 & $<0.01 * *$ & 3 & 260 & -156.13 & 320.25 \\
\hline & $\log \mathrm{FAS} \sim \operatorname{logmass}+$ temp & 0.02 & 3.30 & $0.04 *$ & 3 & 260 & -159.82 & 327.63 \\
\hline & $\log \mathrm{NAS} \sim$ mass & 0.49 & 253.50 & $<0.01 * *$ & 2 & 261 & -331.60 & 669.19 \\
\hline & $\operatorname{logNAS} \sim \operatorname{logmass}$ & 0.65 & 477.50 & $<0.01 * *$ & 2 & 261 & -284.07 & 574.14 \\
\hline & $\log \mathrm{NAS} \sim$ temp & 0.31 & 119.12 & $<0.01 * *$ & 2 & 261 & -371.40 & 748.81 \\
\hline & $\operatorname{logNAS} \sim$ mass + temp & 0.68 & 284.18 & $<0.01 * *$ & 3 & 260 & -268.46 & 544.93 \\
\hline & $\operatorname{logNAS} \sim \operatorname{logmass}+$ temp & 0.84 & 688.93 & $<0.01 * *$ & 3 & 260 & -178.82 & 365.64 \\
\hline
\end{tabular}

Levels of significance: $* \mathrm{p}<0.05 ; * * \mathrm{p}<0.01 ; * * * \mathrm{p}<0.001$. 
Table 4.2. Model fits for each metabolic variable against $\log$ (mass) and temperature for both day and night. The metabolic variables include resting metabolic rate (RMR), maximum metabolic rate (MMR), factorial aerobic scope (FAS), and net aerobic scope.

\begin{tabular}{|c|c|c|c|c|c|c|}
\hline Time & Data & term & coefficient & SE & $\mathbf{T}$ & $\mathbf{p}$ \\
\hline \multirow{12}{*}{ Day } & \multirow{3}{*}{ RMR } & (Intercept) & -5.33 & 0.16 & -32.61 & $<0.01 * *$ \\
\hline & & $\log$ (mass) & 0.73 & 0.02 & 31.67 & $<0.01 * *$ \\
\hline & & temperature & 0.11 & 0.01 & 15.87 & $<0.01 * *$ \\
\hline & \multirow{3}{*}{ MMR } & (Intercept) & -3.56 & 0.17 & -20.33 & $<0.01 * *$ \\
\hline & & $\log$ (mass) & 0.89 & 0.02 & 35.95 & $<0.01 * *$ \\
\hline & & temperature & 0.11 & 0.01 & 14.51 & $<0.01 * *$ \\
\hline & \multirow{3}{*}{ FAS } & (Intercept) & 1.78 & 0.18 & 9.85 & $<0.01 * *$ \\
\hline & & $\log$ (mass) & 0.16 & 0.03 & 6.14 & $<0.01 * *$ \\
\hline & & temperature & 0.00 & 0.01 & -0.32 & 0.75 \\
\hline & \multirow{3}{*}{ NAS } & (Intercept) & -3.71 & 0.20 & -18.16 & $<0.01 * *$ \\
\hline & & $\log$ (mass) & 0.92 & 0.03 & 31.80 & $<0.01 * *$ \\
\hline & & temperature & 0.11 & 0.01 & 12.07 & $<0.01 * *$ \\
\hline \multirow{12}{*}{ Night } & \multirow{3}{*}{ RMR } & (Intercept) & -5.55 & 0.11 & -49.82 & $<0.01 * *$ \\
\hline & & $\log$ (mass) & 0.79 & 0.03 & 30.86 & $<0.01 * *$ \\
\hline & & temperature & 0.14 & 0.01 & 22.54 & $<0.01 * *$ \\
\hline & \multirow{3}{*}{ MMR } & (Intercept) & -3.52 & 0.11 & -32.65 & $<0.01 * *$ \\
\hline & & $\log ($ mass $)$ & 0.84 & 0.02 & 33.95 & $<0.01 * *$ \\
\hline & & temperature & 0.13 & 0.01 & 21.14 & $<0.01 * *$ \\
\hline & \multirow{3}{*}{ FAS } & (Intercept) & 2.03 & 0.12 & 17.41 & $<0.01 * *$ \\
\hline & & $\log ($ mass $)$ & 0.05 & 0.03 & 1.92 & 0.06 \\
\hline & & temperature & -0.01 & 0.01 & -1.98 & $0.05^{*}$ \\
\hline & \multirow{3}{*}{ NAS } & (Intercept) & -3.69 & 0.13 & -29.42 & $<0.01 * *$ \\
\hline & & $\log ($ mass $)$ & 0.84 & 0.03 & 29.40 & $<0.01 * *$ \\
\hline & & temperature & 0.13 & 0.01 & 17.86 & $<0.01 * *$ \\
\hline
\end{tabular}

Levels of significance: $* \mathrm{p}<0.05 ; * * \mathrm{p}<0.01$; *** $\mathrm{p}<0.001$. 
Table 4.3. Phylogenetic signal as measured by Pagel's $\lambda$ and Blomberg's $K$ in the residuals of factorial aerobic scope (rFAS) and net aerobic scope (rNAS).

\begin{tabular}{cccccc}
\hline Time & Data & Pagel's $\lambda$ & $\mathbf{p}$ & Blomberg's $\boldsymbol{~}$ & $\mathbf{p}$ \\
\hline \multirow{2}{*}{ Day } & rFAS & 1.01 & $<0.01^{* *}$ & 1.56 & $<0.01^{* *}$ \\
& rNAS & 1.01 & $<0.01^{* *}$ & 1.69 & $<0.01^{* *}$ \\
\hline \multirow{2}{*}{ Night } & rFAS & 1.01 & $<0.01 * *$ & 1.86 & $<0.01^{* *}$ \\
& rNAS & 1.01 & $<0.01^{* *}$ & 1.67 & $<0.01^{* *}$ \\
\hline Levels of significance: $* \mathrm{p}<0.05 ; * * \mathrm{p}<0.01 ; * * * \mathrm{p}<0.001$. & &
\end{tabular}


Table 4.4. Relative support by Akaike Information Criterion (AIC) and AIC weights (AICw) of evolutionary models applied to the residuals of factorial aerobic scope (rFAS) and net aerobic scope (rNAS). The best-fitting model is in bold for each time and dataset.

\begin{tabular}{|c|c|c|c|c|c|c|}
\hline Time & $\mathbf{A S}$ & Model & $\mathbf{n}$ & logLik & AIC & $\mathrm{AICw}$ \\
\hline \multirow{8}{*}{ Day } & \multirow{4}{*}{ rFAS } & BM & 2 & -98.6477 & 201.2953 & 0.55 \\
\hline & & star & 2 & -106.875 & 217.7503 & 0.00 \\
\hline & & lambda & 3 & -98.4955 & 202.991 & 0.23 \\
\hline & & OU & 3 & -98.5669 & 203.1337 & 0.22 \\
\hline & \multirow{4}{*}{ rNAS } & $\mathrm{BM}$ & 2 & -112.875 & 229.7507 & 0.40 \\
\hline & & star & 2 & -122.975 & 249.9508 & 0.00 \\
\hline & & lambda & 3 & -111.848 & 229.6963 & 0.41 \\
\hline & & $\mathrm{OU}$ & 3 & -112.596 & 231.192 & 0.19 \\
\hline \multirow{8}{*}{ Night } & \multirow{4}{*}{ rFAS } & BM & 2 & -132.166 & 268.3318 & 0.57 \\
\hline & & star & 2 & -137.364 & 278.7275 & 0.00 \\
\hline & & lambda & 3 & -132.122 & 270.2438 & 0.22 \\
\hline & & $\mathrm{OU}$ & 3 & -132.137 & 270.2737 & 0.21 \\
\hline & \multirow{4}{*}{ rNAS } & BM & 2 & -125.001 & 254.0029 & 0.34 \\
\hline & & star & 2 & -131.985 & 267.9702 & 0.00 \\
\hline & & lambda & 3 & -123.721 & 253.4419 & 0.45 \\
\hline & & OU & 3 & -124.529 & 255.0582 & 0.20 \\
\hline
\end{tabular}


Table 4.5. Model fits for linear regressions among the residuals of resting metabolic rate (RMR), maximum metabolic rate (MMR), factorial aerobic scope (FAS), and net aerobic scope (NAS) for day and night.

\begin{tabular}{|c|c|c|c|c|c|c|c|c|}
\hline Time & Formula & Adj. $R^{2}$ & sigma & df & Statistic & $\mathbf{p}$ & coefficient & s.e. \\
\hline \multirow{6}{*}{ Day } & $\mathrm{rMMR} \sim \mathrm{rRMR}$ & 0.184 & 0.380 & 2 & 62.845 & $<0.001 * * *$ & 0.460 & 0.060 \\
\hline & rFAS rRMR & 0.234 & 0.380 & 2 & 84.755 & 0.650 & -0.540 & 0.060 \\
\hline & rNAS rRMR & 0.061 & 0.476 & 2 & 18.716 & $<0.001 * * *$ & 0.320 & 0.070 \\
\hline & $\mathrm{rFAS} \sim \mathrm{rMMR}$ & 0.331 & 0.355 & 2 & 136.280 & 0.090 & 0.600 & 0.050 \\
\hline & rNAS rMMR & 0.957 & 0.102 & 2 & 6060.509 & $<0.001 * * *$ & 1.140 & 0.010 \\
\hline & rFAS $\sim$ rNAS & 0.514 & 0.303 & 2 & 291.055 & 0.750 & 0.630 & 0.040 \\
\hline \multirow{6}{*}{ Night } & $\mathrm{rMMR} \sim \mathrm{rRMR}$ & 0.187 & 0.372 & 2 & 61.240 & $<0.001 * * *$ & 0.420 & 0.050 \\
\hline & $\mathrm{rFAS} \sim \mathrm{rRMR}$ & 0.303 & 0.372 & 2 & 114.803 & $<0.001 * * *$ & -0.580 & 0.050 \\
\hline & $\mathrm{rNAS} \sim \mathrm{rRMR}$ & 0.064 & 0.463 & 2 & 18.929 & 0.690 & 0.290 & 0.070 \\
\hline & $\mathrm{rFAS} \sim \mathrm{rMMR}$ & 0.256 & 0.384 & 2 & 91.298 & $<0.001 * * *$ & 0.550 & 0.060 \\
\hline & rNAS rMMR & 0.957 & 0.099 & 2 & 5846.016 & $<0.001 * * *$ & 1.140 & 0.010 \\
\hline & rFAS $\sim$ rNAS & 0.430 & 0.336 & 2 & 198.537 & 0.860 & 0.610 & 0.040 \\
\hline
\end{tabular}

Levels of significance: $* \mathrm{p}<0.05$; ** $\mathrm{p}<0.01$; *** $\mathrm{p}<0.001$. 
Table 4.6. Results from the analysis of variance (ANOVA) of the residuals of factorial aerobic scope (rFAS) and net aerobic scope (rNAS) among tropical amphibian families for both day and night.

\begin{tabular}{|c|c|c|c|c|c|c|c|}
\hline Time & Group & term & df & SS & MS & $\mathbf{F}$ & $\mathbf{p}$ \\
\hline \multirow{4}{*}{ Day } & \multirow{2}{*}{ rFAS } & Family & 6 & 15.82 & 2.64 & 19.68 & $<0.01 * *$ \\
\hline & & Residuals & 268 & 35.89 & 0.13 & & \\
\hline & \multirow{2}{*}{ rNAS } & Family & 6 & 26.65 & 4.44 & 30.10 & $<0.01 * *$ \\
\hline & & Residuals & 268 & 39.55 & 0.15 & & \\
\hline \multirow{4}{*}{ Night } & \multirow{2}{*}{ rFAS } & Family & 6 & 7.38 & 1.23 & 7.07 & $<0.01 * *$ \\
\hline & & Residuals & 256 & 44.53 & 0.17 & & \\
\hline & \multirow{2}{*}{ rNAS } & Family & 6 & 18.13 & 3.02 & 18.48 & $<0.01 * *$ \\
\hline & & Residuals & 256 & 41.86 & 0.16 & & \\
\hline
\end{tabular}

Levels of significance: $* \mathrm{p}<0.05$; $* * \mathrm{p}<0.01$; *** $\mathrm{p}<0.001$. 
Table 4.7. Results from the analysis of variance (ANOVA) of the residuals of factorial aerobic scope (rFAS) and net aerobic scope (rNAS) among elevational groups for both day and night.

\begin{tabular}{cccccccc}
\hline Time & Group & term & df & SS & MS & F & p \\
\hline \multirow{3}{*}{ Day } & \multirow{2}{*}{ rFAS } & Elevational group & 2 & 1.18 & 0.59 & 3.18 & $0.04^{*}$ \\
\cline { 2 - 7 } & \multirow{2}{*}{ rNAS } & Elevational group & 2 & 3.84 & 1.92 & 8.37 & $<0.01^{* *}$ \\
& \multirow{2}{*}{ rFAS } & Elevational group & 2 & 5.67 & 2.84 & 15.95 & $<0.01^{* *}$ \\
\multirow{3}{*}{ Night } & Residuals & 260 & 46.24 & 0.18 & & \\
\cline { 2 - 8 } & \multirow{2}{*}{ rNAS } & Elevational group & 2 & 1.00 & 0.50 & 2.21 & 0.11 \\
& & Residuals & 260 & 58.99 & 0.23 & & \\
\hline
\end{tabular}

Levels of significance: $* \mathrm{p}<0.05 ; * * \mathrm{p}<0.01$; *** $\mathrm{p}<0.001$. 

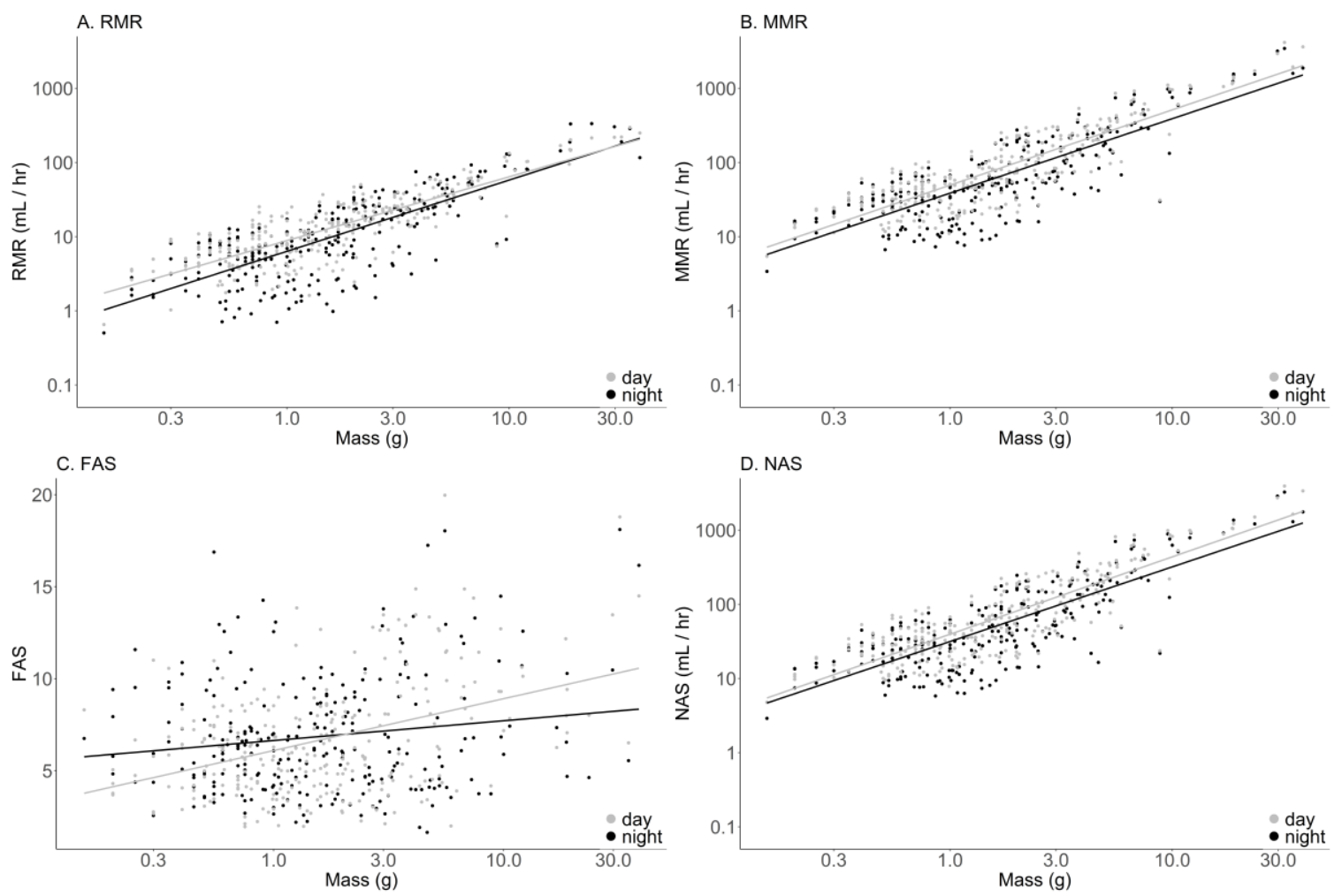

Figure 4.1. Relationship between mass and the metabolic variables resting metabolic rate (RMR), maximum metabolic rate (MMR), factorial aerobic scope (FAS), and net aerobic scope (NAS) for day and night. The metabolic variables and mass were log-transformed prior to analysis. 

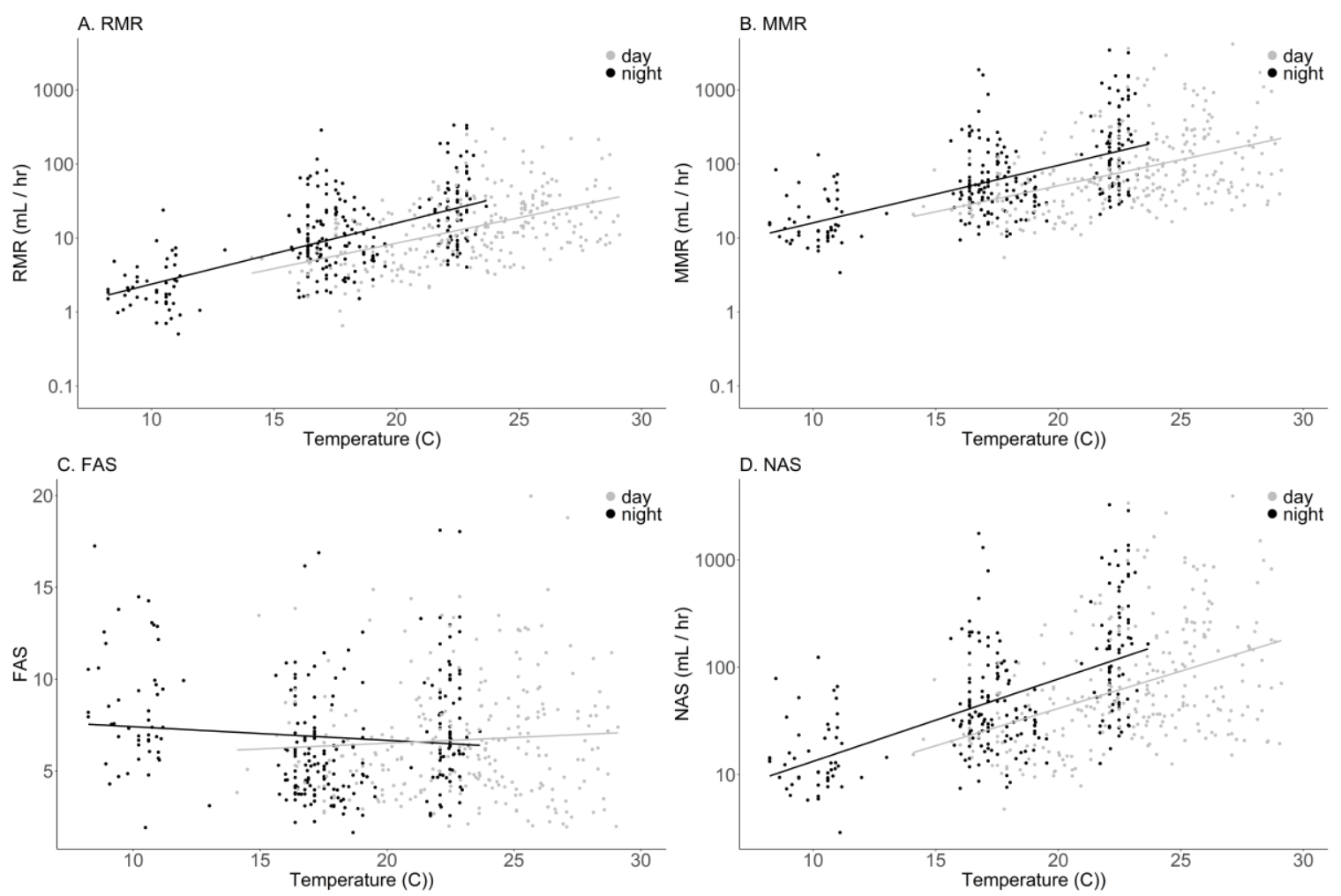

Figure 4.2. Relationship between temperature and the metabolic variables resting metabolic rate (RMR), maximum metabolic rate (MMR), factorial aerobic scope (FAS), and net aerobic scope (NAS) for day and night. The metabolic variables and mass were log-transformed prior to analysis. 

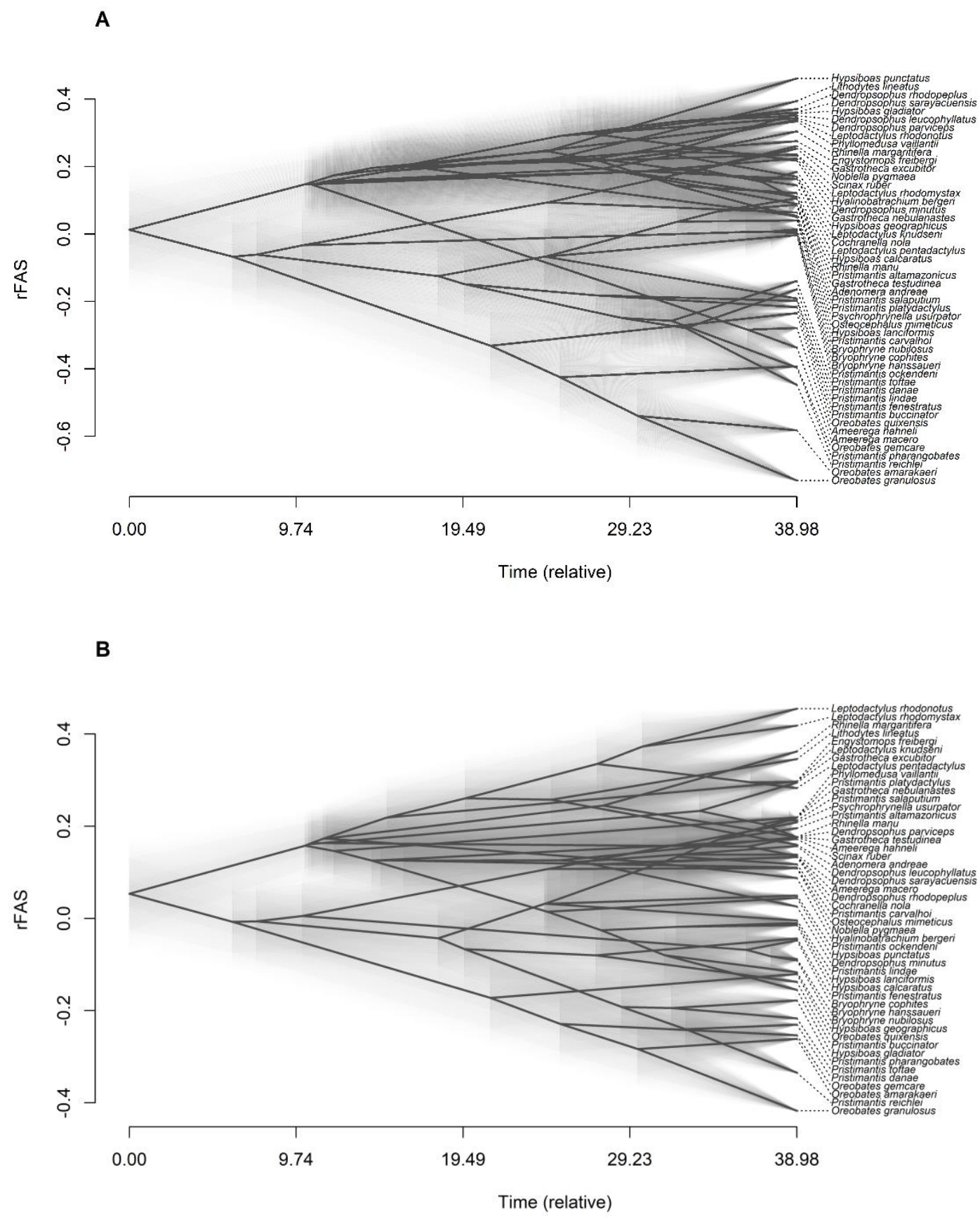

Figure 4.3. Phylogram illustrating how the residuals of factorial aerobic scope (rFAS) may have evolved across the phylogeny for day (A) and night (B). The residuals were calculated through the ordinary least squares regression for the additive model of mass and temperature. The shading shows $95 \%$ confidence intervals throughout the ancestral reconstruction. 


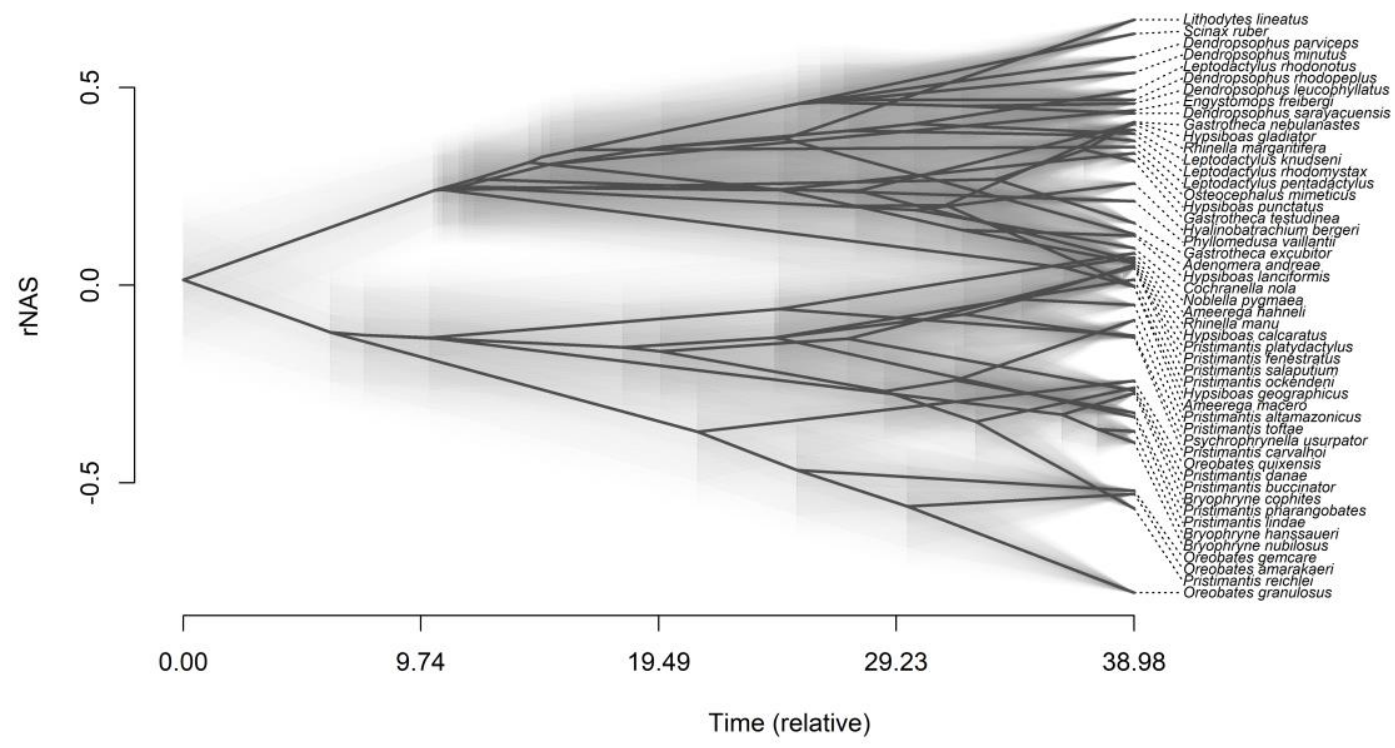

B

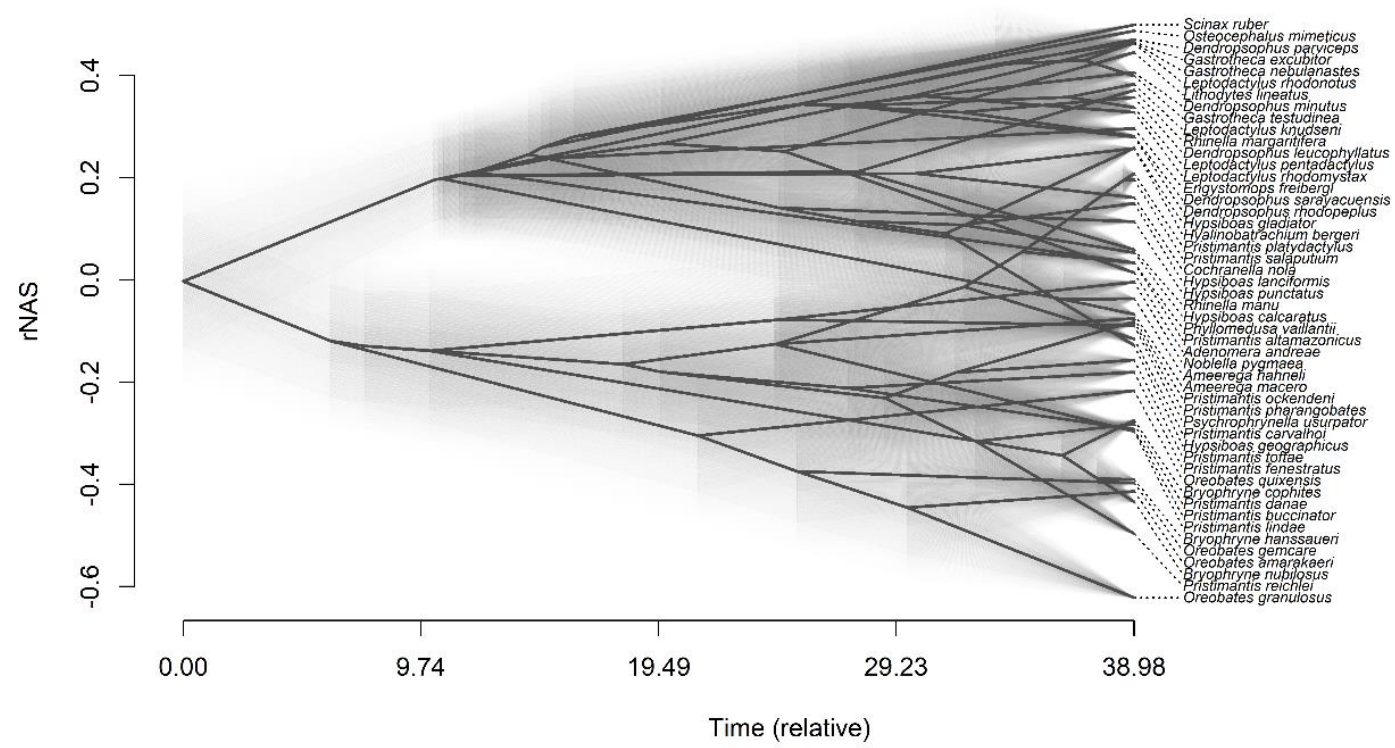

Figure 4.4. Phylogram illustrating how the residuals of net aerobic scope (rNAS) may have evolved across the phylogeny. The residuals were calculated through the ordinary least squares regression for the additive model of mass and temperature. The shading shows $95 \%$ confidence intervals throughout the ancestral reconstruction. 

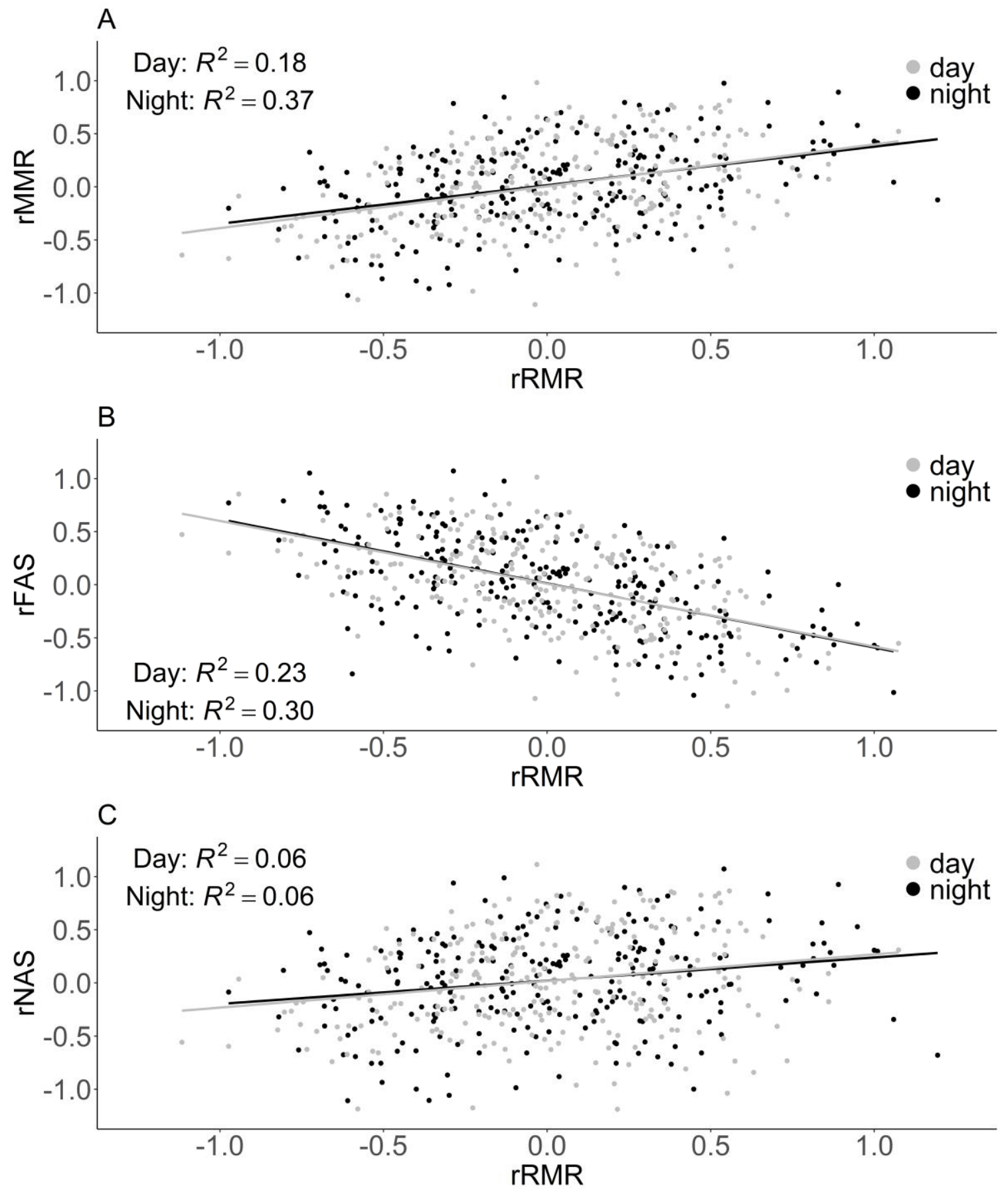

Figure 4.5. Relationship between the residuals of resting metabolic rate (rRMR) and A) maximal aerobic metabolic rate (rMMR), B) factorial aerobic scope (rFAS), and C) net aerobic scope (rNAS) for both day and night after correction for mass and temperature. The residuals were calculated through the ordinary least squares regression for the additive model of mass and temperature. 

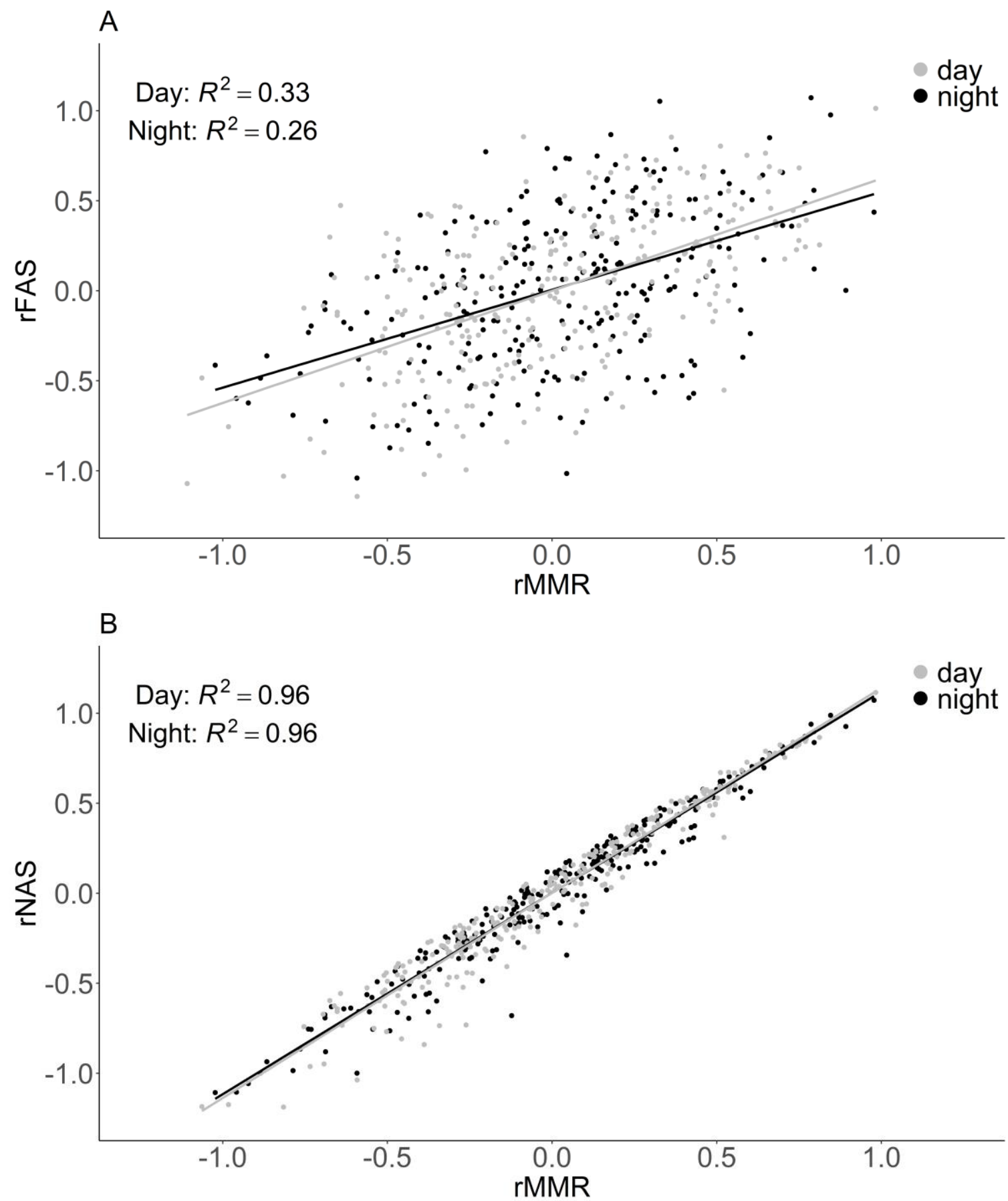

Figure 4.6. Relationship between the residuals of maximum metabolic rate (rMMR) and A) factorial aerobic scope (rFAS) and B) net aerobic scope (rNAS) for both day and night. The residuals were calculated through the ordinary least squares regression for the additive model of mass and temperature. 


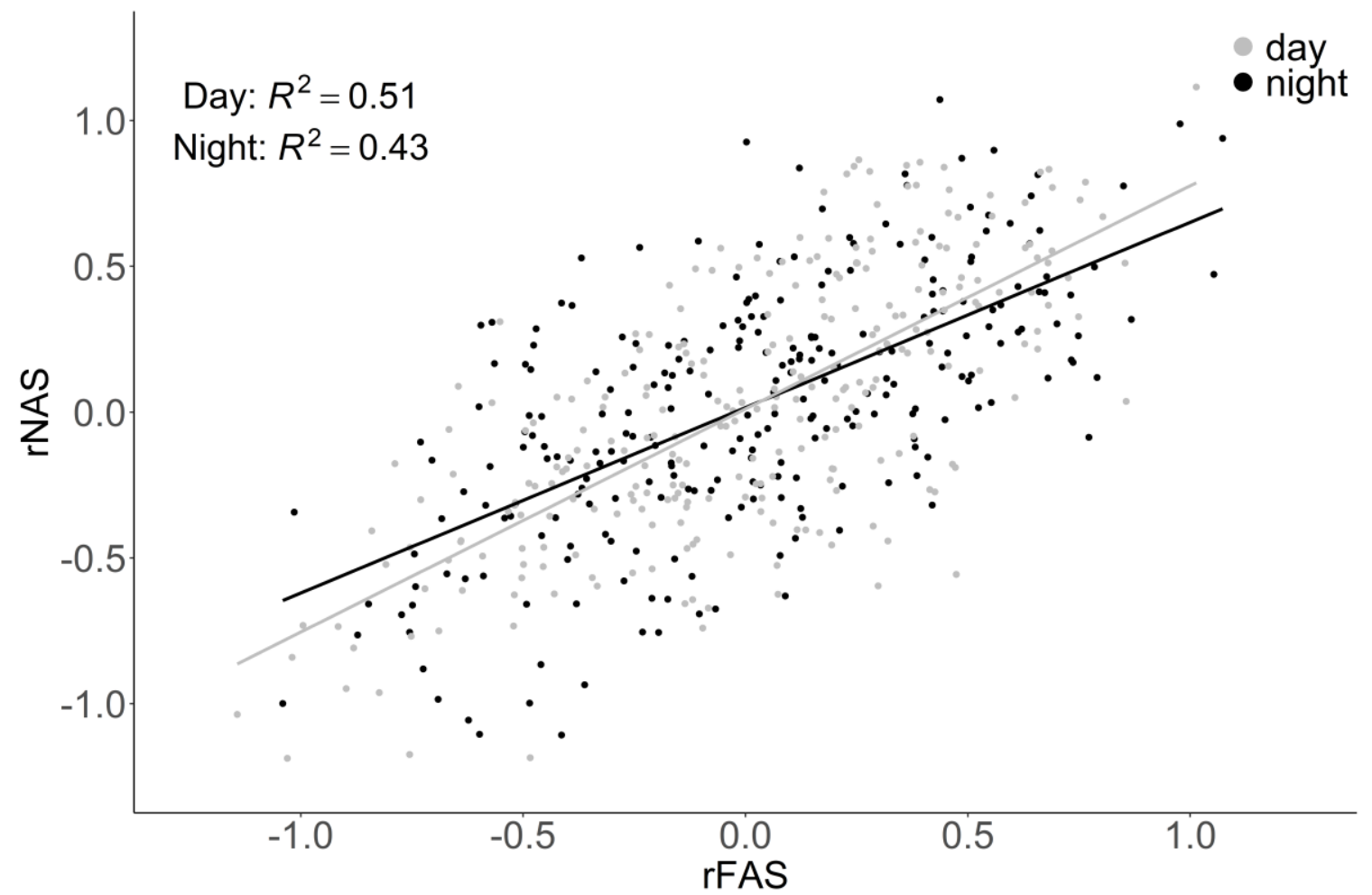

Figure 4.7. Relationship between the residuals of factorial aerobic scope (rFAS) and net aerobic scope (rNAS). The residuals were calculated through the ordinary least squares regression for the additive model of mass and temperature. 

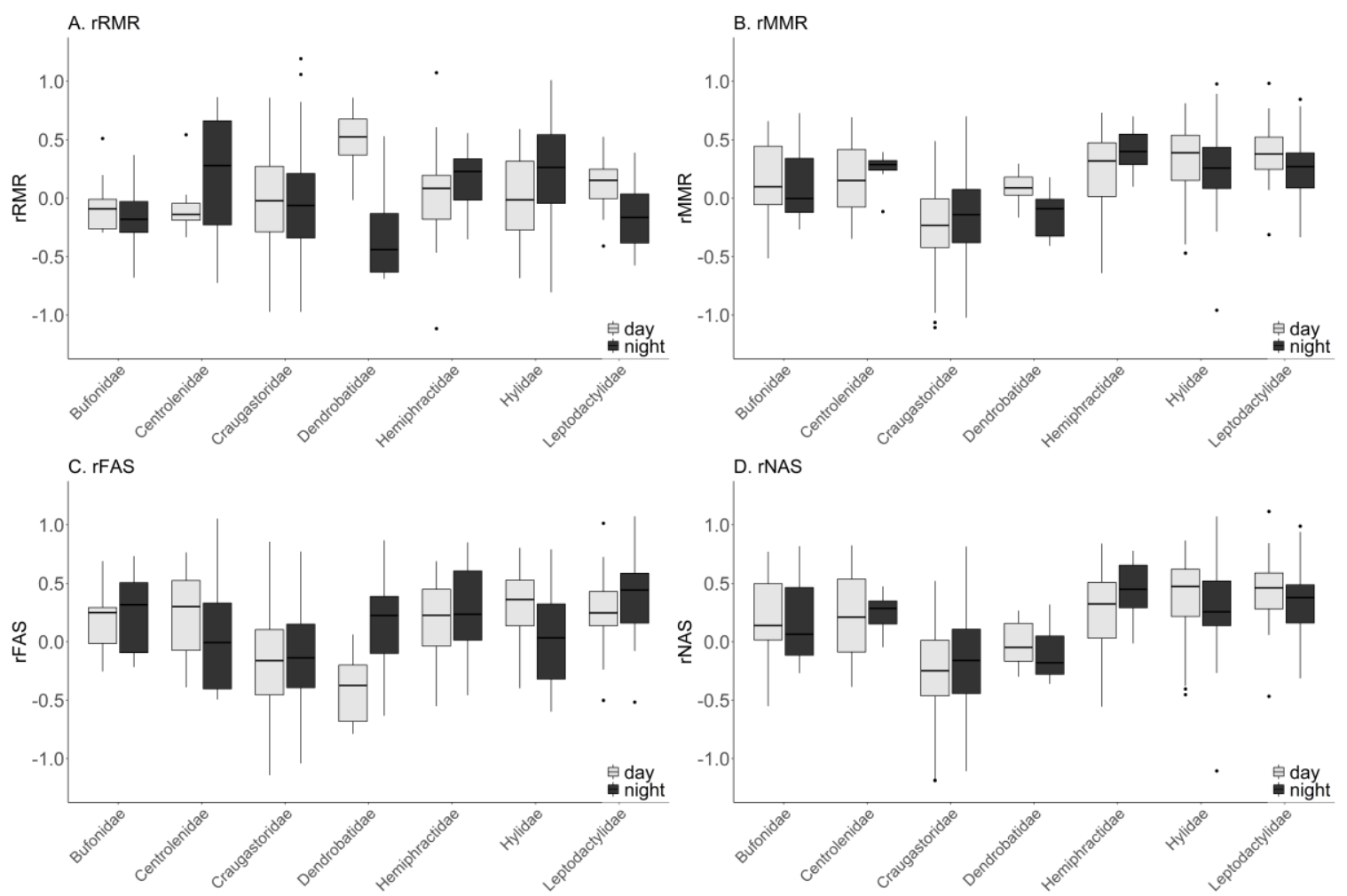

Figure 4.8. Boxplots showing the comparisons of the residuals of resting metabolic rate (rRMR), maximum metabolic rate (rMMR), factorial aerobic scope (rFAS) and net aerobic scope (rNAS) among tropical anuran families for both day and night. The residuals were calculated through the ordinary least squares regression for the additive model of mass and temperature. 

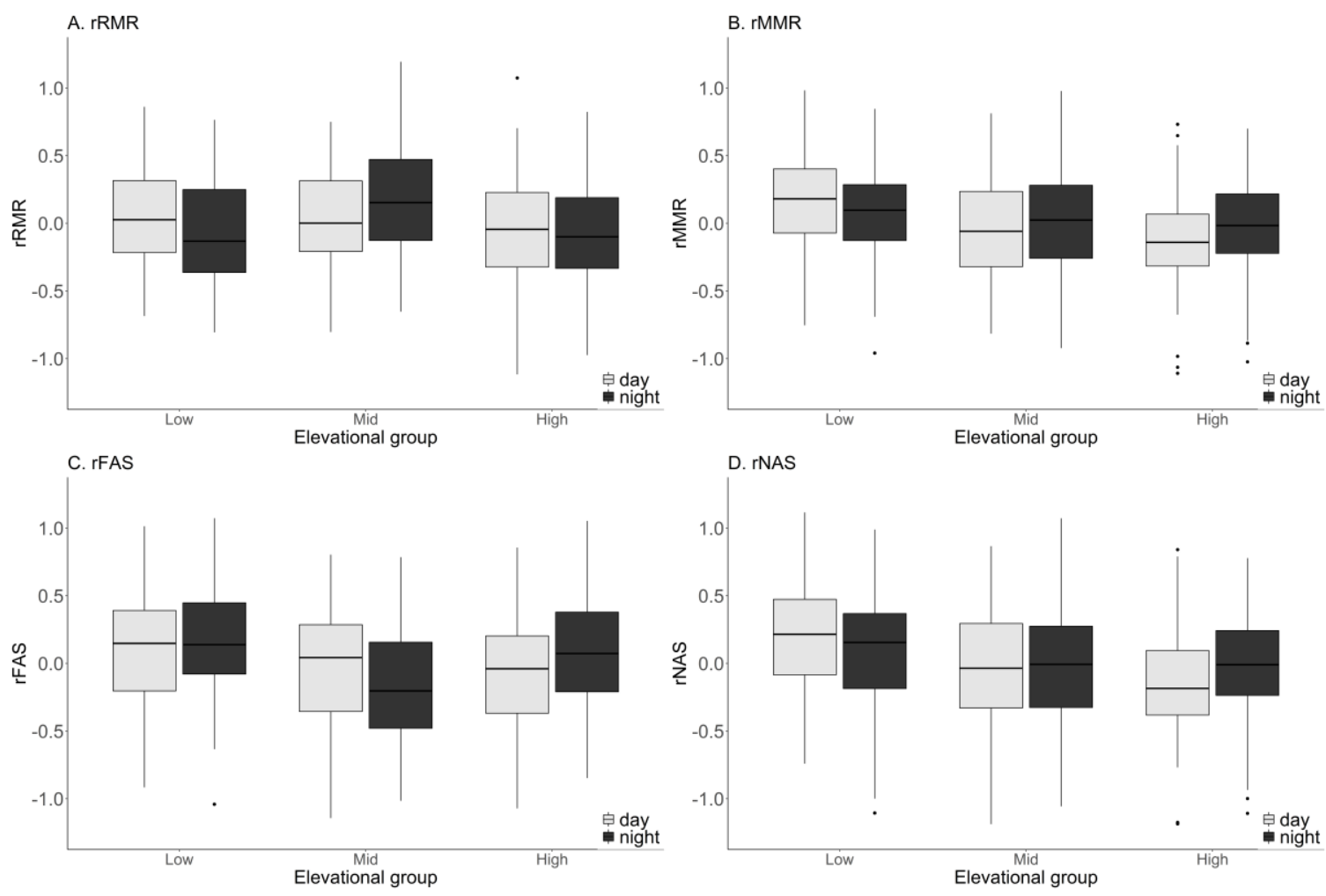

Figure 4.9. Boxplots showing the comparisons of the residuals of resting metabolic rate (rRMR), maximum metabolic rate (rMMR), factorial aerobics scope (rFAS) and net aerobic scope (rNAS) among elevational groups for both day and night. The residuals were calculated through the ordinary least squares regression for the additive model of mass and temperature. Elevational groups were made by binning individuals based on elevation: low (<600 $\mathrm{m}$ asl), mid $(600-2,000 \mathrm{~m}$ asl), and high (> 2,000 $\mathrm{m}$ asl). 


\section{CONCLUSIONS}

Climate change is expected to have extensive impacts on the energy budgets of organisms across the globe (Dillon et al. 2010). Vulnerability to the metabolic impacts of climate change will be governed by the combination of exposure, sensitivity, and potential for response (Foden et al. 2013). My dissertation demonstrates that there is extensive variation in the metabolism of tropical amphibians and illustrates how variation in metabolism relates to ecology, environment, and evolution. Moreover, my dissertation suggests that tropical amphibians have higher thermal sensitivity of metabolism than has been found from studies of temperate taxa. The differences in metabolism among amphibian families and across elevation may translate into differences in sensitivity to the energetic effects of climate change. My dissertation provides an important step to understanding differences in vulnerability to the metabolic impacts of climate change.

In Chapter I, I synthesized the literature on amphibian resting metabolic rate (RMR) while focusing on patterns of variation. I demonstrated that there are important sources of variation in amphibian metabolism that relate to: taxonomic differences across various levels of taxonomy, environmental conditions such as latitude and elevation, life history differences between sexes and across ontogeny, and organismal condition such as time since last feeding and hydration state. Together, the various sources of variation in amphibian metabolism suggest that metabolic rate is adaptive and integrated with a variety of ecological factors.

In Chapter II, I examine the circadian rhythms of RMR of 11 tropical amphibian species across six families. I demonstrate that there are important cycles of RMR that have important implications for methodology and our understanding of amphibian 
biology. The timing of the diel rhythms is significantly different between nocturnal and diurnal species. Moreover, there are differences of the timing of circadian maxima of RMR within nocturnal species. Differences among amphibians in the timing of metabolic maxima could introduce biases in studies that do not account for time of day in analyses, particularly in comparisons between diurnal and nocturnal species. I further demonstrate that there are differences in the average metabolic rate and amplitude of rhythms among families. The differences in the circadian rhythms (average, timing, and amplitude) of amphibian RMR reflects the integration between physiology and ecological strategy.

In Chapter III, I examine the variation in RMR across a large diversity of tropical amphibians across an elevational gradient. I combine a phylogeny and measurements of RMR on 88 tropical amphibian species, both day and night, to investigate patterns and sources of variation. I demonstrate that there are strong phylogenetic signals in RMR, day and night, and that the evolution of RMR may be under stabilizing selection or subject to selective constraints. My results suggest that the thermal sensitivity of metabolism in tropical amphibians is considerably higher than has been assumed in past studies of amphibian metabolism (e.g., Dillon et al. 2010, Gillooly et al. 2001). Moreover, there appears to be important differences in the thermal sensitivity of metabolic rate among tropical anuran families as well as across elevation, highlighting the need to consider the physiological diversity of amphibians. There is an interaction in the metabolic scaling of tropical amphibians between mass and temperature which suggests that small amphibians may have higher thermal sensitivity and be more vulnerable to metabolic impacts from increasing temperatures as a result of climate change than large species. 
In Chapter IV, I examine the relationship between RMR and maximum metabolic rate (MMR) as well as the proxies of the relationship, namely factorial aerobic scope (FAS) and net aerobic scope (NAS). I demonstrate that there is extensive variation in aerobic scope in amphibians in both FAS and NAS that disagrees with the predictions of the aerobic capacity model (Bennett \& Ruben 1979; Nespolo et al. 2017). Both FAS and NAS vary among tropical amphibian families, elevational groups, and with time of day. Moreover, the scaling relationships of RMR and MMR lead to distinct scaling parameters of FAS and NAS. The differences between the patterns of variation in FAS and NAS suggest that each measure of aerobic scope provides important and complementary information on metabolic physiology.

The various metabolic approaches I have employed throughout my dissertation provide complementary views of amphibian metabolism and vulnerability to climate change. For example, in Chapter III, I demonstrated that the family Craugastoridae has high thermal sensitivity $\left(\mathrm{Q}_{10}\right)$ of RMR relative to other families (Figure 3.8). Craugastorids may be further sensitive to the metabolic impacts of climate change as a result of small size (interaction between mass and thermal sensitivity; Chapter III) and potential physiological limitations associated with direct development (Chapter IV). In Chapter II, I showed that the family Craugastoridae exhibit relatively late nocturnal circadian maxima (and likely activity). Late nocturnal activity periods will limit Craugastoridae from shifting activity periods in response to warming or drying conditions (as they likely are already active at the coolest and most humid time periods). Thus, high vulnerability to the metabolic impacts of climate change may be expected for species in 
the family Craugastoridae on account of high thermal sensitivity, small size, late activity periods, and potential metabolic limitations imposed by life history.

The family Bufonidae was also shown to have high thermal sensitivity $\left(\mathrm{Q}_{10}\right)$ in relation to other families (Figure 3.8). In Chapter IV, I found that MMR has a higher thermal sensitivity than RMR (Table 4.2). Most bufonids are active foragers and thus may spend large amounts of time while active (and thermally sensitive) and exposed to changing conditions. Moreover, in Chapter II, the RMR in bufonids was demonstrated to be relatively high with large diel ranges which may be related to active ecological strategies (Figure 2.2). However, the relatively high RMRs of bufonids, particularly at night during active periods, could compound the metabolic impacts of increased temperatures because of expected changes in metabolic rates acting on already high base values (Dillon et al. 2010). Thus, bufonids may be vulnerable to metabolic impacts of climate change as a result of active behaviors, high metabolic rates, and high thermal sensitivity. Some bufonids may be further vulnerable to metabolic impacts of climate change on account of small size or high elevational ranges.

My dissertation demonstrates that there is extensive variation in tropical amphibian metabolism related to ecology, environment, and evolutionary history. The characterization of amphibian metabolism using single metabolic scaling relationships may obscure important biological variation. My dissertation finds that the thermal sensitivity of metabolism in tropical amphibians may be much higher than what has been observed for temperate amphibians. The variation in amphibian metabolic physiology, particularly differences in thermal sensitivity, will translate to differences in vulnerability to the metabolic impacts of climate change. Understanding and incorporating variation in 
metabolic physiology into predictions of climate change impacts is important to guide conservation and management decisions. My dissertation presents a major contribution towards a predictive and integrative understanding of metabolism across amphibians by examining the metabolic physiology of a diverse assemblage of tropical amphibians across a large elevational gradient in the Neotropics.

\section{REFERENCES}

Bennett AF, Ruben JA. 1979. Endothermy and activity in vertebrates. Science. 206:64954

Dillon ME, Wang G, Huey RB. 2010. Global metabolic impacts of recent climate warming. Nature. 467:704-6

Foden WB, Butchart SHM, Stuart SN, Vié JC, Akçakaya HR, et al. 2013. Identifying the world's most climate change vulnerable species: A systematic trait-based assessment of all birds, amphibians and corals. PLOS ONE. 8(6):e65427

Gillooly JF, Brown JH, West GB, Savage VM, Charnov EL. 2001. Effects of size and temperature on metabolic rate. Science. 293:2248-51

Nespolo RF, Solano-Iguaran JJ, Bozinovic F. 2017. Phylogenetic analysis supports the aerobic-capacity model for the evolution of endothermy. American Naturalist. 189(1):13-27 
VITA

MICHAEL R. BRITTON

EDUCATION AND AWARDS

2012

B.S., Biology

Colgate University

Hamilton, New York

2017

M.S., Biological Sciences

Florida International University

Miami, Florida

2020

$\mathrm{PhD}$, Biological Sciences

Florida International University

Miami, Florida

$1^{\text {st }}$ place - Best oral presentation - FIU Biosymposium - February 2020

FIU Dissertation Year Fellowship - Summer and Fall 2019

Frederick H. Stoye Award - Best student oral presentation - JMIH 2019

2nd place - Best oral presentation - FIU Biosymposium - February 2019

FIU Dissertation Evidence Acquisition Fellowship - Fall 2017

American Society of Ichthyologists and Herpetologists Gaige Fund Award - 2014

Tinker Field Research Grant travel award - 2013

\section{PUBLICATIONS AND PRESENTATIONS}

Circadian rhythm of metabolism in tropical amphibians. Oral presentation. Florida International University Biosymposium, Biscayne Bay Campus, North Miami, Florida. February $2020\left(1^{\text {st }}\right.$ place oral presentation $)$.

Tropical elevational gradients: Patterns and importance. Tropical Ecology (PCB 3374).

Department of Biological Sciences, Florida International University. March 2019.

Metabolic ecology of over 100 species of amphibians across a 5,000 meter elevational gradient in the Peruvian Andes. Conference presentation, Joint Meeting of Ichthyologists and Herpetologists, Snowbird, UT, July 2019 (Stoye Award). 
Metabolic ecology of over 100 species of amphibians across a 5,000 meter elevational gradient in the Peruvian Andes. Conference presentation, Florida International University Biosymposium, Miami, FL, February 2019 ( $2^{\text {nd }}$ place oral presentation).

Metabolic ecology of over 100 species of amphibians across a 5,000 meter elevational gradient in the Peruvian Andes. Conference presentation, Ecological Society of America Annual Meeting, New Orleans, LA, August 2018.

Metabolic ecology of over 100 species of amphibians across a 5,000 meter elevational gradient in the Peruvian Andes. Conference presentation, Joint Meeting of Ichthyologists and Herpetologists, Rochester, NY, July 2018.

Plaster models provide insight into the conditions of microhabitats across a 4,000 meter elevational gradient in the Peruvian Andes. Conference presentation, Joint Meeting of Ichthyologists and Herpetologists, Rochester, NY, July 2018.

Workshop on snake sampling, identification, handling, and safety. Oral presentations (2). CREES staff, interns, and volunteers, Manu Learning Centre, 2017 - 2018.

Workshop on methods for tropical biology and conservation. Oral presentation. CREES staff, interns, and volunteers, Manu Learning Centre, March 2017.

Workshop on amphibian sampling, identification, handling, and safety. Oral presentations (3). CREES staff, interns, and volunteers, Manu Learning Centre, $2015-2018$.

Amphibians: Biology, physiology, and conservation. Oral presentations (4). CREES, School for Field Studies, Deakin University, Wildlands Studies. 2015 - 2018.

Conservation in the tropics: Challenges and prospects. Oral presentations (4). CREES, School for Field Studies (2), Deakin University, FIU. 2014 - 2018.

Environmental physiology of amphibians. Oral presentations (5). CREES, School for Field Studies (2), University of Washington Bothell, FIU. 2013 - 2018.

Britton, MR, Watkins, JE, Jr. 2016. The economy of reproduction in dimorphic ferns. Annals of Botany. 118(6): 1139-49.

Extreme Climatic Events Affecting Amphibian Egg and Larval Stages May Impact Future Metapopulation Dynamics Through Latent Effects - Poster presentation, Joint Meeting of Ichthyologists and Herpetologists, Chattanooga, TN, July 2014.

Fertile-sterile leaf dimorphy in ferns: seasonal physiological responses and costs of reproduction. Poster presentation, Botanical Society of America, Providence, RI, July 2010. 